\author{
UNIVERSIDADE DE SÃO PAULO \\ ESCOLA DE ENGENHARIA DE SÃO CARLOS \\ DEPARTAMENTO DE HIDRÁULICA E SANEAMENTO
}

FLÁVIA BOTTINO

Diversidade, Biomassa e Decomposição de Macrófitas Aquáticas no Reservatório Itupararanga - SP.

São Carlos 


\section{Diversidade, Biomassa e Decomposição de Macrófitas Aquáticas no Reservatório Itupararanga - SP.}

Tese apresentada à Escola de Engenharia de São Carlos, Universidade de São Paulo, como parte dos requisitos para obtenção do título de Doutor em Hidráulica e Saneamento

Orientadora: Prof. Tit. Maria do Carmo Calijuri

São Carlos 
"A mente que se abre a uma nova ideia jamais volta ao seu tamanho original." Albert Einstein 
AUTORIZO A REPRODUÇÃO E DIVULGAÇÃO TOTAL OU PARCIAL DESTE TRABALHO, POR QUALQUER MEIO CONVENCIONAL OU ELETRÔNICO, PARA FINS DE ESTUDO E PESQUISA, DESDE QUE CITADA A FONTE.

Ficha catalográfica preparada pela Seção de Tratamento da Informação do Serviço de Biblioteca - EESC/USP

Bottino, Flávia
B751d Diversidade, biomassa e decomposiçăo de macrófitas aquáticas no reservatório Itupararanga - SP / Flávia Bottino ; orientadora Maria do Carmo Calijuri. -- são Carlos, 2011 .

Tese (Doutorado-Programa de Pós-Graduação em Hidráulica e Saneamento) -- Escola de Engenharia de são Carlos da Universidade de são Paulo, 2011.

1. Biomassa. 2. Macrófitas aquáticas. 3. Macrófitas aquáticas - decomposição. 4. Reservatório Itupararanga. I. Título. 
FOLHA DE JULGAMENTO

Candidata: Bacharel FLÁVIA BOTTINO

Titulo da tese: "Diversidade, biomassa e decomposição de macrófitas aquáticas no Reservatório Itupararanga - SP".

Data da defesa: 02/12/2011:

Comissão Julgadora:

Resultado:

Prof $^{\text {a }}$. Titular Maria do Carmo Calijuri (Orientadora)

(Escola de Engenharia de São Carlos/EESC)

Prof. Dr. Irineu Bianchini Junior

(Universidade Federal de São Carlos/UFSCar)

Prof. Dr. Antonio Fernando Monteiro Camargo

sprovisdis. aprovado (Universidade Estadual Paulista "Júlio de Mesquita Filho"/UNESP campus de Rio Claro)

Prof. Dr. Andrê Cordeiro Alves dos Santos

(Universidade Federal de São Carlos/UFSCar - campus de Sorocaba)

Prof $^{a}$. Dr ${ }^{\mathrm{a}}$. Roseli Frederigi Benassi

APRONADO

(Universidade Federal do ABC/UFABC)

Coordenador do Programa de Pós-Graduação em Engenharia Hidráulica c Saneamento:

Prof. Titular Edson Cezar Wendland

Presidente da Comissão de Pós-Graduação:

Prof. Associado Paulo Cesar Lima Segantine 
Dedico este trabalho à minha mãe Sandra, à minha irmã Fernanda e ao Eduardo que sempre acreditaram em $\operatorname{mim}$. 


\section{AGRADECIMENTOS}

Seguir estudando a Biologia sempre foi um objetivo, que começou a se concretizar com a realização da iniciação científica. Não foi fácil chegar até aqui, muito esforço e dedicação foram necessários, desde a época da seleção do mestrado até, finalmente, a conclusão desta pesquisa. Muitas pessoas contribuíram para que tudo isso se tornasse realidade e deixo registrado aqui meus sinceros agradecimentos.

À Prof. Maria do Carmo Calijuri pela oportunidade e confiança a mim concedidos. Pela tranqüilidade que me transmitiu nos momentos mais difíceis, sempre me orientando da forma mais correta e me mostrando os caminhos a seguir. Não posso deixar de agradecer a oportunidade de participar de dois projetos temáticos.

Ao Prof. Kevin Murphy, da University of Glasgow, pessoa simpática, tranqüila e que me recebeu em seu laboratório, me mostrou um pouco dos ambientes temperados e me deu inúmeras explicações sobre ecologia, macrófitas, ciência, vida acadêmica, gastronomia, cerveja e vinho. Muito obrigada pela oportunidade!

Ao Prof. Irineu Bianchini Jr. e à Prof. Marcela B. Cunha Santino que sempre me receberam prontamente e me ajudaram com as minhas infinitas dúvidas.

Ao Prof. André Cordeiro por nos auxiliar nas coletas de campo, nas coletas dos litter bags e pelas boas conversas e conselhos.

À Fundação de Amparo à Pesquisa do Estado de São Paulo - FAPESP - pelo auxílio recebido (08/55636-9) e ao Conselho Nacional de Desenvolvimento Científico e Tecnológico - CNPq - pela bolsa de Doutorado (141074/2009-4 e 202001/2010-5), os quais foram imprescindíveis para a realização desta pesquisa.

Aos técnicos Miro e Betão, profissionais experientes, sem os quais a realização desta pesquisa teria sido muito mais árdua. Ao Sr. Benê, que passou de motorista oficial das viagens a campo para cozinheiro oficial do Biotace. Não posso deixar de agradecer a ajuda com a coleta e lavagem de macrófitas, as conversas, os conselhos e a diversão que vocês proporcionaram.

Aos funcionários do Departamento de Hidráulica e Saneamento, em especial à Flávia, Fernanda, Sá, Pavi, Rose e Valderez.

Aos membros do Biotace, Luci, Adriana, Davi, Simone, Sarah, Paulo, Raquel e Lorena, pela ajuda, incentivo e boas conversas. Um muito obrigado especial à Adriana e ao Davi (Salames!!), 
companheiros de coleta, de análises, de discussões, enfim, passamos muito tempo juntos e pudemos conhecer melhor uns aos outros, trocar boas e más experiências que vou carregar comigo para sempre.

A algumas pessoas que já passaram pelo programa de pós-graduação e até mesmo pelo Biotace, Tatiane Furlaneto, Ignazio Giuntoli, Juliana Moccellin, Thais E. Fontanello e Caroline Cunha. Carol, muito obrigada pelo incentivo e apoio à minha viagem ao exterior. Thais, agradeço muito a sua participação nas coletas e a imensa ajuda com as macrófitas nos dias e dias de moagem.

Ao Sr. José Renato, sempre pronto a nos ajudar, cedendo sua área de lazer para a montagem do nosso laboratório de campo. Sua colaboração foi essencial para que pudéssemos trabalhar no reservatório. Foi muito divertido dormir no seu motor home.

Ao pessoal da ONG SOS Itupararanga, especialmente à Viviane. Ao Julio e à Priscila da Votorantim Energia.

À Julissa Tapia por me receber em Glasgow e me apresentar os bons amigos que fiz por lá. À Lauren Kinninburgh, minha flatmate, pela companhia, por me mostrar um pouco da cidade, da cultura e me aturar no período que estive na Escócia!

A todos os participantes do projeto temático, especialmente ao Frederico Beghelli e à Ana Pavão pela coleta dos litter bags e ao Ricardo pela troca de informações.

Às minhas grandes amigas, Grasi, Pri, Bia, Karina, Cris, Andreza e Carina que me aguentaram todos esses anos, ouviram minhas lamentações e sempre me incentivaram. Obrigada pelos momentos relax às quartas-feiras! Karina, foi muito bom passar um tempo na sua casa, nos divertimos muito!

À toda a minha família que mesmo sem entender muito bem o que eu faço sempre me incentivou e acreditou em mim, especialmente minha mãe e minha irmã. Fer, muito obrigada por me ouvir, tentar me entender, me apoiar, me aconselhar...obrigada por tudo.

E por último, mas não menos importante, ao Eduardo, pela compreensão, companheirismo, paciência, amizade, amor e otimismo. Obrigada por acreditar em mim, por nunca permitir que eu desistisse, por me aconselhar, agüentar meu mau humor, apoiar, muitas vezes sem compreender, minhas decisões, por achar que eu sou a melhor...enfim, não tenho palavras para agradecer e não consigo enumerar tudo aquilo que eu precisaria agradecer. 


\section{SUMÁRIO}

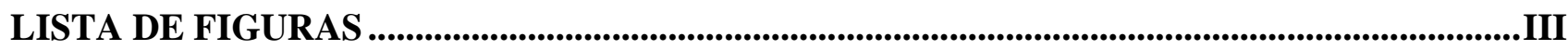

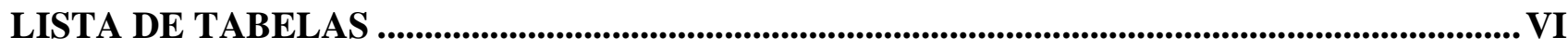

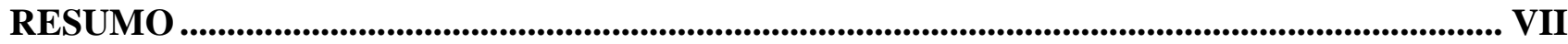

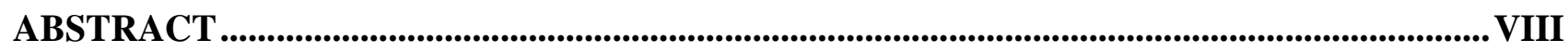

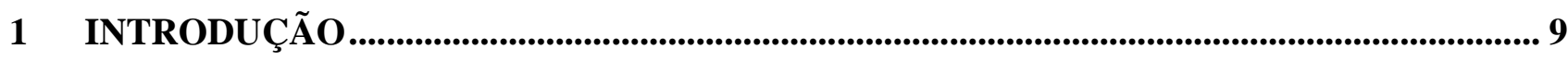

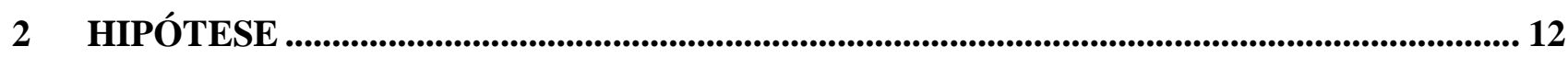

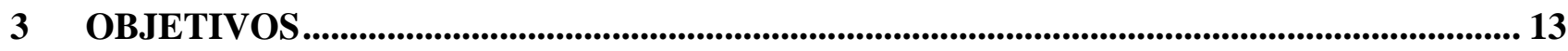

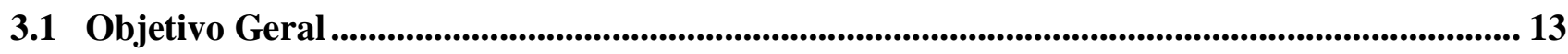

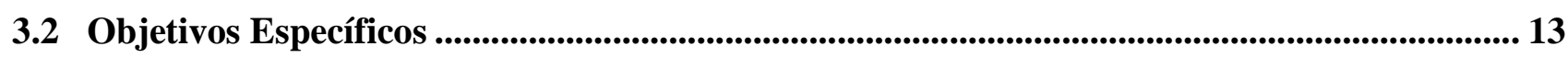

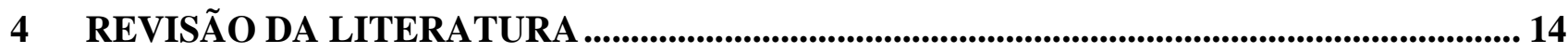

5 CARACTERIZAÇÃO GERAL DA ÁREA DE ESTUDO_................................................... 19

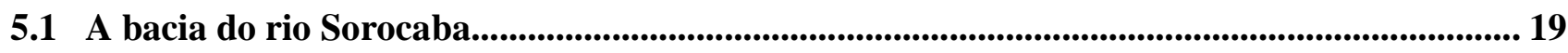

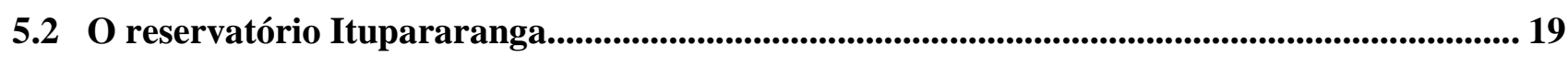

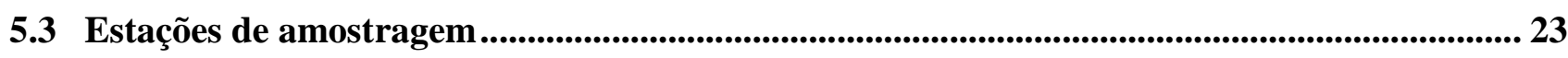

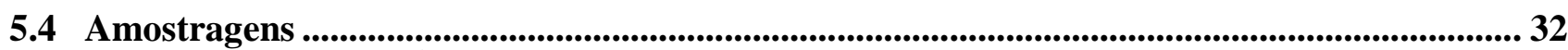

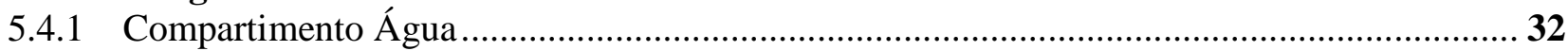

5.4.1.1 Temperatura da água, Oxigênio Dissolvido (OD), Potencial Hidrogeniônico (pH),

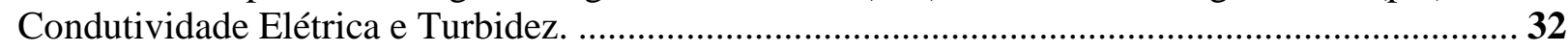

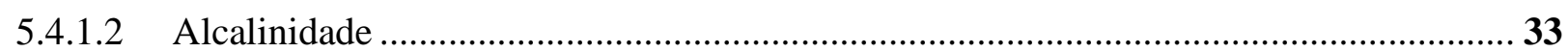

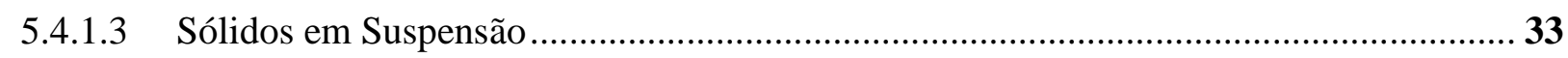

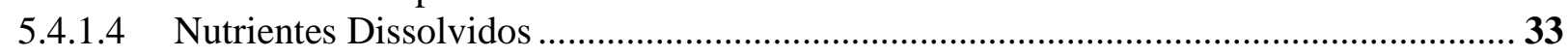

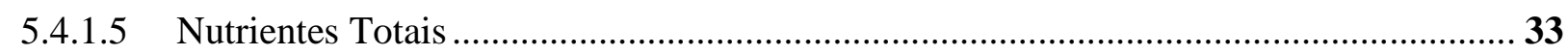

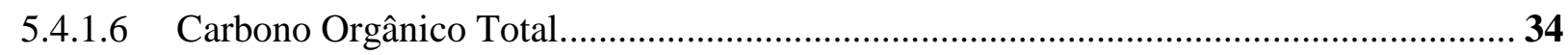

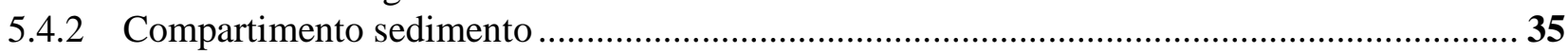

5.4.2.1 Matéria Orgânica, Fósforo Total, Nitrogênio Total e Granulometria............................ 35

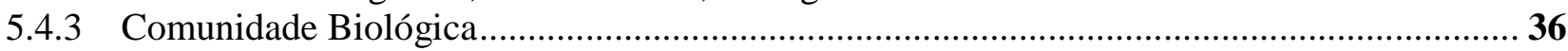

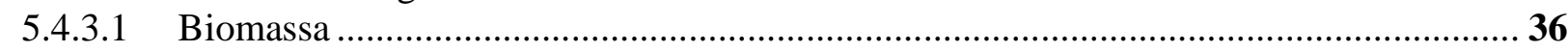

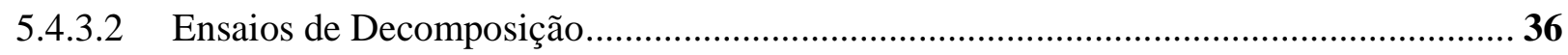

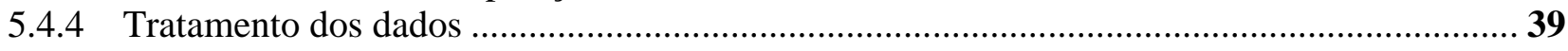




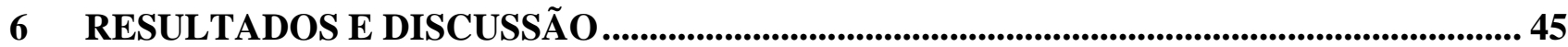

6.1 Características limnológicas e biomassa de macrófitas aquáticas do reservatório

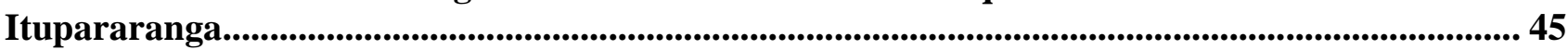

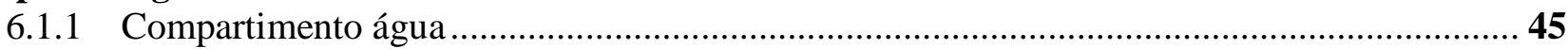

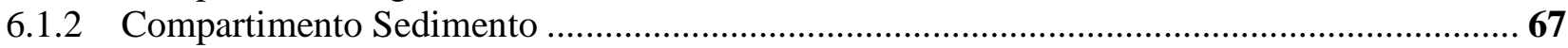

6.1.3 Variáveis Biológicas - Comunidade de Macrófitas Aquáticas........................................... 70

6.2 Decomposição de Macrófitas Aquáticas ........................................................................................... 81

6.2.1 Decomposição de Polygonum lapathifolium ........................................................................ 82

6.2.2 Decomposição de Eichhornia azurea ................................................................................. 92

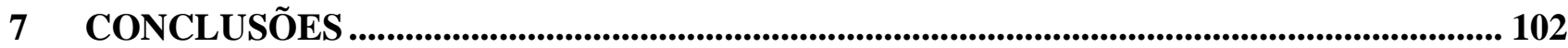

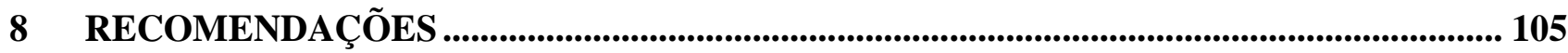

9 REFERÊNCIAS BIBLIOGRÁFICAS ......................................................................................... 106 


\section{LISTA DE FIGURAS}

Figura 1: Localização da Bacia do rio Sorocaba no estado de São Paulo, hidrografia da Bacia do rio Sorocaba com destaque para o reservatório Itupararanga e mapa do reservatório Itupararanga ............ 20

Figura 2: Localização das estações amostrais e de seus principais afluentes no reservatório Itupararanga.

Figura 3: Banco de Eichhornia crassipes uma das principais espécies de macrófitas aquáticas encontradas na estação de coleta $\mathrm{Br}_{1}$ do reservatório Itupararanga.

Figura 4: Banco de Pistia stratiotes uma das principais espécies de macrófitas aquáticas encontradas na estação de coleta $\mathrm{Br}_{1}$ do reservatório Itupararanga.

Figura 5: Banco de Polygonum lapathifolium, principal espécie de macrófita aquática encontrada nas estações de coleta $\mathrm{Br}_{2}$ e $\mathrm{Br}_{3}$ do reservatório Itupararanga.

Figura 6: Banco de Myriophyllum aquaticum, uma das principais espécies de macrófitas aquáticas encontradas na estação de coleta $\mathrm{Br}_{4}$ do reservatório Itupararanga. 30

Figura 7: Banco de Eichhornia azurea, uma das principais espécies de macrófitas aquáticas encontradas na estação de coleta $\mathrm{Br}_{4}$ do reservatório Itupararanga. 31

Figura 8: Incubação dos litter bags (A) e câmaras de decomposição na estufa (B), aeração (C) e filtros com MOP (D) 40

Figura 9: Precipitação pluviométrica mensal $(\mathrm{mm})$ no período de agosto de 2009 a abril de 2010, com destaque para os meses em que ocorreram amostragens.

Figura 10: Precipitação pluviométrica diária $(\mathrm{mm})$ com sete dias de antecedência das amostragens.... 42

Figura 11: Vazão turbinada para geração de energia $\left(\mathrm{m}^{3} . \mathrm{s}^{-1}\right)$ e vazão afluente ao reservatório Itupararanga $\left(\mathrm{m}^{3} \cdot \mathrm{s}^{-1}\right)$ no período de agosto de 2009 a abril de 2010.

Figura 12: Cota média (m) do reservatório Itupararanga no período de agosto de 2009 a abril de 2010.

Figura 13: Perfis de temperatura da água $\left({ }^{\circ} \mathrm{C}\right)$ das estações de amostragem $\mathrm{Br}_{1}, \mathrm{Br}_{2}, \mathrm{Br}_{3}$ e $\mathrm{Br}_{4}$ nos diferentes períodos do ano.

Figura 14: Perfis de oxigênio dissolvido $\left(\mathrm{mg} . \mathrm{L}^{-1}\right)$ das estações de amostragem $\mathrm{Br}_{1}, \mathrm{Br}_{2}, \mathrm{Br}_{3}$ e $\mathrm{Br}_{4}$ nos diferentes períodos do ano. 48

Figura 15: Perfis de Sólidos Suspensos Totais (mg.L-1 $)$ das estações de amostragem $\mathrm{Br}_{1}, \mathrm{Br}_{2}, \mathrm{Br}_{3}$ e $\mathrm{Br}_{4}$ nos diferentes períodos do ano.

Figura 16: Contribuição relativa das frações de Sólidos Suspensos Orgânicos e Sólidos Suspensos Inorgânicos (\%) nas estações de amostragem $\mathrm{Br}_{1}, \mathrm{Br}_{2}, \mathrm{Br}_{3}$ e $\mathrm{Br}_{4}$ nos diferentes períodos do ano.

Figura 17: Perfis de turbidez (UNT) das estações de amostragem $\mathrm{Br}_{1}, \mathrm{Br}_{2}, \mathrm{Br}_{3}$ e $\mathrm{Br}_{4}$ nos diferentes períodos do ano.

Figura 18: Perfis de $\mathrm{pH}$ das estações de amostragem $\mathrm{Br}_{1}, \mathrm{Br}_{2}, \mathrm{Br}_{3}$ e $\mathrm{Br}_{4}$ nos diferentes períodos do ano.

Figura 19: Perfis de alcalinidade (meq. $\mathrm{L}^{-1}$ ) das estações de amostragem $\mathrm{Br}_{1}, \mathrm{Br}_{2}, \mathrm{Br}_{3}$ e $\mathrm{Br}_{4}$ nos diferentes períodos do ano. 
Figura 20: Perfis de nitrato (mg. $\mathrm{L}^{-1}$ ) das estações de amostragem $\mathrm{Br}_{1}, \mathrm{Br}_{2}, \mathrm{Br}_{3}$ e $\mathrm{Br}_{4}$ nos diferentes períodos do ano. 61

Figura 21: Perfis de Fósforo Total $\left(\mu \mathrm{g} . \mathrm{L}^{-1}\right)$ das estações de amostragem $\mathrm{Br}_{1}, \mathrm{Br}_{2}, \mathrm{Br}_{3}$ e $\mathrm{Br}_{4}$ nos diferentes períodos do ano. 62

Figura 22: Perfis de Fosfato Total Dissolvido $\left(\mu \mathrm{g} . \mathrm{L}^{-1}\right.$ ) das estações de amostragem $\mathrm{Br}_{1}, \mathrm{Br}_{2}, \mathrm{Br}_{3}$ e $\mathrm{Br}_{4}$ nos diferentes períodos do ano. 63

Figura 23: Perfis de ortofosfato ( $\mu$ g. $\mathrm{L}^{-1}$ ) das estações de amostragem $\mathrm{Br}_{1}, \mathrm{Br}_{2}, \mathrm{Br}_{3}$ e $\mathrm{Br}_{4}$ nos diferentes períodos do ano. 64

Figura 24: Perfis de Carbono Orgânico Total (COT) (mg.L $\mathrm{L}^{-1}$ ) das estações de amostragem $\mathrm{Br}_{1}, \mathrm{Br}_{2}, \mathrm{Br}_{3}$ e $\mathrm{Br}_{4}$ nos diferentes períodos do ano. 65

Figura 25: Perfis de Carbono Inorgânico (CI) (mg.L $\mathrm{L}^{-1}$ ) das estações de amostragem $\mathrm{Br}_{1}, \mathrm{Br}_{2}, \mathrm{Br}_{3}$ e $\mathrm{Br}_{4}$ nos diferentes períodos do ano. 66

Figura 26: Frações granulométricas (\%) nas estações de amostragem $\mathrm{Br}_{1}, \mathrm{Br}_{2}, \mathrm{Br}_{3}$ e $\mathrm{Br}_{4}$ nos diferentes períodos do ano. 70

Figura 27: Biomassa $\left(\mathrm{gPS} . \mathrm{m}^{-2}\right)$ das diferentes partes de macrófitas aquáticas do reservatório Itupararanga.. 76

Figura 28: Ordenação da CCA 77

Figura 29: Biomassa $\left(\mathrm{gC} . \mathrm{m}^{-2}\right)$ das diferentes partes de macrófitas aquáticas do reservatório Itupararanga. 79

Figura 30: Ajuste dos parâmetros obtidos pelo modelo cinético de decaimento de massa para o experimento com litter bags de P. lapathifoilum .

Figura 31: Ajuste dos parâmetros obtidos pelo modelo cinético de decaimento de massa em condições de laboratório (a $15^{\circ} \mathrm{C}$ e a $25^{\circ} \mathrm{C}$ ) para P. lapathifolium. 84

Figura 32: Peso seco remanescente de Polygonum lapathifolium no experimento de campo. As barras verticais representam \pm desvio padrão 85

Figura 33: Variação da Matéria Orgânica Particulada Lábil Solúvel (MOPLS), Matéria Orgânica Dissolvida (MOD) e Matéria Inorgânica (MI) durante o processo de decomposição de Polygonum lapathifolium à $15^{\circ} \mathrm{C}$ em laboratório. 86

Figura 34: Variação da Matéria Orgânica particulada Lábil Solúvel (MOPLS), Matéria Org6anica Dissolvida (MOD) e Matéria Inorgânica (MI) durante o processo de decomposição Polygonum lapathifolium à $25^{\circ} \mathrm{C}$ em laboratório. 86

Figura 35: Relação entre a MOP remanescente de $P$. lapathifolium nos experimentos de campo e laboratório. 87

Figura 36: Variação temporal do $\mathrm{pH}$ durante a decomposição in vitro de P. lapathifolium 90

Figura 37: Variação temporal da condutividade elétrica durante a decomposição in vitro de $P$. lapathifolium 90

Figura 38: Peso seco remanescente (\%) de Eichhornia azurea no experimento de campo. As barras verticais representam \pm desvio padrão.

Figura 39: Ajuste dos parâmetros obtidos pelo modelo cinético de decaimento de massa para o experimento com litter bags de E. azurea. 
Figura 40: Ajuste dos parâmetros obtidos pelo modelo cinético de decaimento de massa em condições

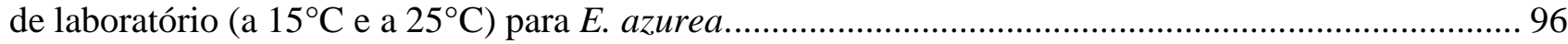

Figura 41: Variação da Matéria Orgânica particulada Lábil Solúvel (MOPLS), Matéria Orgânica Dissolvida (MOD) e Matéria Inorgânica (MI) durante o processo de decomposição de E. azurea à $15^{\circ} \mathrm{C}$ em laboratório. 99

Figura 42: Variação da Matéria Orgânica particulada Lábil Solúvel (MOPLS), Matéria Orgânica Dissolvida (MOD) e Matéria Inorgânica (MI) durante o processo de decomposição de E. azurea à $25^{\circ} \mathrm{C}$ em laboratório. 99

Figura 43: Relação entre a MOP remanescente de E. azurea nos experimentos de campo e laboratório. 100

Figura 44: Variação temporal do pH durante a decomposição in vitro de E. azurea. 101

Figura 45: Variação temporal da condutividade elétrica durante a decomposição in vitro de E.azurea. 


\section{LISTA DE TABELAS}

Tabela 1: Características do reservatório Itupararanga, Bacia do rio Sorocaba, SP ............................. 21

Tabela 2: Uso e ocupação do solo na região da represa de Itupararanga............................................. 22

Tabela 3: Espécies de macrófitas aquáticas encontradas nas estações de coleta do reservatório Itupararanga entre agosto de 2009 e abril de 2010. EM: Emersa; FL: Flutuante Livre........................ 25

Tabela 4: Método de determinação das variáveis temperatura da água, $\mathrm{OD}, \mathrm{pH}$, condutividade elétrica e

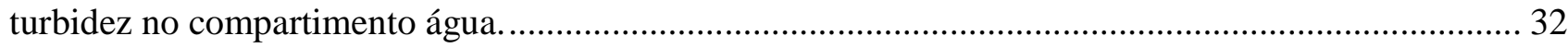

Tabela 5: Métodos de determinação dos nutrientes dissolvidos ......................................................... 33

Tabela 6: Métodos de determinação dos nutrientes totais e nitrogênio amoniacal............................... 34

Tabela 7: Métodos de determinação das variáveis do sedimento ...................................................... 35

Tabela 8: Horário das amostragens (h) e radiação solar fotossinteticamente ativa (RSFA) incidente $\left(\mu \mathrm{E} \cdot \mathrm{m}^{-2} \cdot \mathrm{s}^{-1}\right)$ nas diferentes estações amostrais (EA) do reservatório Itupararanga nos períodos

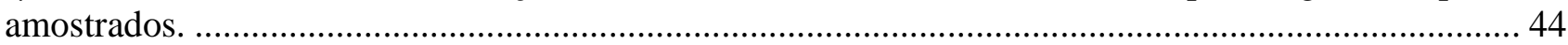

Tabela 9: Condutividade Elétrica $\left(\mu \mathrm{S} . \mathrm{cm}^{-1}\right)$ estações de amostragem $\mathrm{Br}_{1}, \mathrm{Br}_{2}, \mathrm{Br}_{3}$ e $\mathrm{Br}_{4}$ nos diferentes

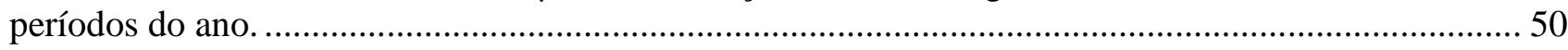

Tabela 10: Concentração de Nitrogênio Total Kjeldhal (mg.L ${ }^{-1}$ ) nas estações de amostragem $\mathrm{Br}_{1}, \mathrm{Br}_{2}$,

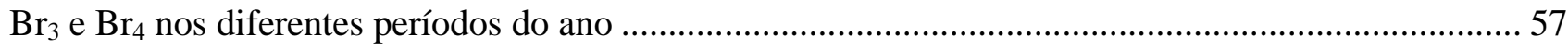

Tabela 11: Concentração de nitrogênio amoniacal $\left(\mathrm{N}_{-} \mathrm{NH}_{3}{ }^{-}\right)\left(\mathrm{mg} \cdot \mathrm{L}^{-1}\right)$ nas estações de amostragem $\mathrm{Br}_{1}$,

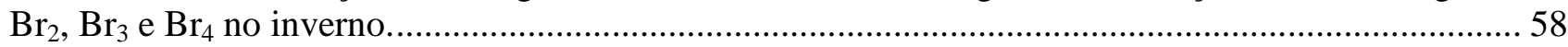

Tabela 12: Concentração de nitrito ( $\mu$ g. $\mathrm{L}^{-1}$ ) nas estações de amostragem $\mathrm{Br}_{1}, \mathrm{Br}_{2}, \mathrm{Br}_{3}$ e $\mathrm{Br}_{4}$ nos

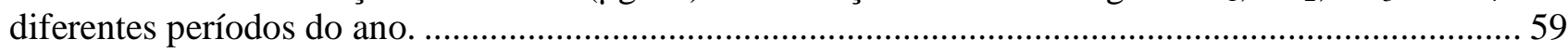

Tabela 13: Matéria Orgânica no Sedimento (MOS) (\%), Fósforo Total no Sedimento (PTS) $\left(\mu \mathrm{g} \cdot \mathrm{g}^{-1}\right)$ e Nitrogênio Total no Sedimento (NTS) ( $\mu \mathrm{g} \cdot \mathrm{g}^{-1}$ ) nas estações de amostragem $\mathrm{Br}_{1}, \mathrm{Br}_{2}, \mathrm{Br}_{3}$ e $\mathrm{Br}_{4}$ nos

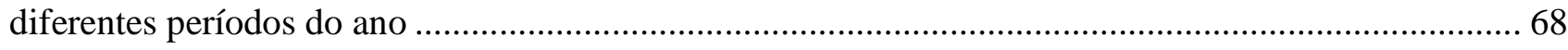

Tabela 14: Condições locais nos dias de amostragem ................................................................. 82

Tabela 15: Variáveis limnológicas monitoradas nos dias de amostragem na estação de coleta $\mathrm{Br}_{3}$...... 82

Tabela 16: Resultados do modelo cinético de decomposição para ambos os tratamentos (campo e

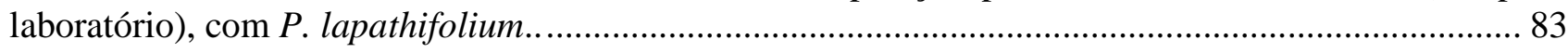

Tabela 17: Resultados do modelo cinético de decomposição para os ensaios de laboratório $\left(15^{\circ} \mathrm{C}\right.$ e

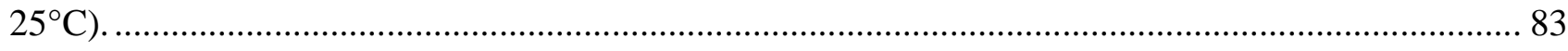

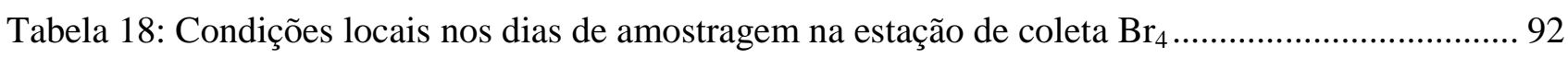

Tabela 19: Resultados do modelo cinético de decomposição para ambos os tratamentos (campo e

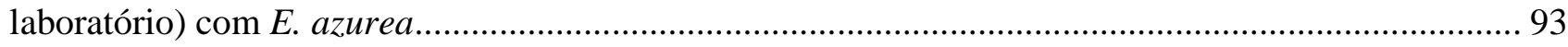

Tabela 20: Resultados do modelo cinético de decomposição para os ensaios de laboratório $\left(15^{\circ} \mathrm{C}\right.$ e $\left.25^{\circ} \mathrm{C}\right)$ com E. azurea.. 


\section{RESUMO}

Bottino, F. (2011). Diversidade, biomassa e decomposição de macrófitas aquáticas no reservatório Itupararanga - SP. Tese de Doutorado. Escola de Engenharia de São Carlos, Universidade de São Paulo, São Carlos.

A presença de macrófitas em reservatórios possui tanto aspectos positivos como negativos para os ecossistemas aquáticos tornando-se, assim, essencial o estudo dessa comunidade para o adequado manejo dos recursos hídricos. O principal objetivo do presente estudo foi verificar a variação sazonal das características limnológicas do reservatório Itupararanga-SP e relacioná-las com a variação da biomassa de macrófitas e com a taxa de decomposição dessas plantas. Sendo assim, selecionaram-se quatro braços no reservatório, com presença relevante de macrófitas. Amostras de água e sedimento foram coletadas sazonalmente e analisadas. Nos mesmos períodos as plantas foram amostradas e a biomassa determinada. Avaliou-se ainda, a decomposição in situ e em laboratório de duas espécies (Polygonum lapathifolium e Eichhornia azurea) com o intuito de comparar as taxas de decomposição sob condições naturais e controladas. Empregou-se um modelo cinético para obtenção dos coeficientes de decaimento de massa. Os resultados obtidos foram analisados estatisticamente através do teste ANOVA e Análise de Correspondência Canônica (CCA). As análises limnológicas revelaram a formação de um gradiente espaço-temporal no reservatório que provavelmente influenciou a distribuição e o desenvolvimento da biomassa nas diferentes estações de amostragem. Verificou-se que Eichhornia crassipes e Pistia stratiotes foram influenciadas pela concentração de nutrientes. A CCA evidenciou a relação entre Polygonum lapathifolium, pH, oxigênio dissolvido, matéria orgânica e nutrientes no sedimento, enquanto Eichhornia azurea e Myriophyllum aquaticum foram influenciados, de forma diferente, por compostos inorgânicos. O processo de decomposição foi mais rápido em condições naturais, tanto para E. azurea como para $P$. lapathifolium, com maior mineralização da matéria orgânica particulada e refratária. Sob condições controladas, o decaimento da matéria orgânica dissolvida foi mais lento em temperaturas mais baixas e o coeficiente $\mathrm{Q}_{10}$ indicou que o incremento da temperatura interferiu no decaimento de massa. Esse fato ficou mais evidente nos resultados obtidos para E. azurea. A decomposição revelou elevada quantidade de matéria orgânica refratária em ambas as espécies, as quais contribuem ao aporte de carbono com, aproximadamente $200 \mathrm{~g}$ de carbono de refratário.

Palavras-chave: macrófitas aquáticas, biomassa, decomposição, reservatório Itupararanga. 


\begin{abstract}
Bottino, F. (2011). Diversity, biomass and decomposition of aquatic macrophytes in Itupararanga Reservoir - São Paulo. PhD Thesis. Engineering School of São Carlos, University of São Paulo, São Carlos.
\end{abstract}

The occurrence of aquatic macrophytes in reservoirs plays positive and negative effects to aquatic ecosystems, therefore the study of macrophyte community is essential to the aquatic resources management. This study aimed to evaluate the seasonal variation of limnological conditions of Itupararanga Reservoir, Sao Paulo State, to associate them with macrophyte biomass and with the decomposition rates of the plants. So four arms in the reservoir, where the presence of macrophytes was relevant, were selected to perform this study. Water and sediment along with macrophytes were sampled in different seasons and analyzed. Decomposition experiments of two macrophyte species (Polygonum lapathifolium and Eichhornia azurea) were carried out in situ and in laboratory conditions in order to compare the decomposition rates in different conditions. A kinetic model was adopted to explain the organic matter decay. The results were statistically analyzed with ANOVA and Canonical Correspondence Analyses (CCA). The limnological results showed a spatial and temporal variation which probably influenced the distribution and development of macrophyte biomass. The nutrient concentration influenced Eichhornia crassipes and Pistia stratiotes. Moreover the CCA showed a relationship among Polygonum lapathifolium, $\mathrm{pH}$, dissolved oxygen, sediment organic matter and sediment nutrients, while Eichhornia azurea and Myriophyllum aquaticum were associated in different way with inorganic compounds. The decomposition process was faster in natural conditions with high mineralization coefficient for both E. azurea and P. lapathifolium. Under laboratory conditions the dissolved organic matter decay was slower for low temperatures and $\mathrm{Q}_{10}$ coefficient showed the temperature interference in the mass breakdown mainly for E. azurea assay. Both species have high refractory contents, which contributes, approximately, with $200 \mathrm{~g}$ of refractory carbon.

Key words: aquatic macrophytes, biomass, decomposition, Itupararanga Reservoir 


\section{INTRODUÇÃO}

O Brasil é um país com grande quantidade de reservatórios artificiais (SOARES et al. 2008), os quais começaram a ser construídos em meados da década de 1950, principalmente na porção sudeste do país, onde a demanda por água era maior. Os reservatórios possuem importância social e econômica, os quais, muitas vezes, vêm acompanhados de problemas ecológicos devido à utilização desses sistemas como receptores de efluentes domésticos, agrícolas e industriais. Esse fato compromete os usos múltiplos dos reservatórios, prejudicando desde o abastecimento público até a geração de energia e navegação.

Alguns estudos tem reportado a degradação da qualidade da água dos reservatórios do Estado de São Paulo (DOS SANTOS e CALIJURI, 2001; MARIANI et al. 2006; SOARES e MOZETO, 2006), principalmente na bacia do rio Tietê, devido ao enriquecimento por nutrientes decorrentes da ação antrópica. Nessa bacia, localiza-se o rio Sorocaba, manancial de uma região economicamente importante, que abriga a reserva da Biosfera do Cinturão Verde de São Paulo (Pedrazzi, 2009). O rio Sorocaba, formado pelos rios Una, Sorocabuçu e Sorocamirim, é o principal curso de água da bacia do Alto Sorocaba. Nessa bacia, com economia fundamentada na produção agrícola, encontra-se o reservatório Itupararanga. Formado pelo represamento do rio Sorocaba, esse reservatório é responsável pelo abastecimento de água de uma população de aproximadamente 1 milhão de pessoas, e é utilizado para irrigação e geração de energia.

O município com maior área percentual de seu território dentro da Área de Proteção Permanente (APA) do reservatório Itupararanga é Vargem Grande Paulista (72\% ou 3010 ha da APA), enquanto Ibiúna apresenta maior área no território da APA (58206 ha) (BEU, MISATO e HAHN, 2011). Ibiúna possui 50 bairros rurais sem tratamento sanitário (SALLES et al. 2008) e a área urbana desse município possui carga potencial de esgoto sanitário de $1347 \mathrm{Kg} \mathrm{DBO}_{5,20} /$ dia, com 55\% de tratamento da mesma. Vargem Grande Paulista apresenta carga potencial de $2319 \mathrm{Kg} \mathrm{DBO}_{5,20} /$ dia lançadas in natura em um afluente do rio Sorocamirim (CETESB 2010). Cerca de $88 \%$ das propriedades rurais de Ibiúna e $82 \%$ de Vargem Grande Paulista utilizam o reservatório Itupararanga para irrigação (SALLES et al. 2008).

Algumas pesquisas realizadas no reservatório Itupararanga (GARCIA, FREITAS E FILHO 1999; PEDRAZZI, 2009; PAVÃO, 2011) tem apontado problemas relacionados à irrigação, exploração da terra e utilização de agrotóxicos. Pedrazzi (2009) concluiu que 90\% das 20 estações de amostragem analisadas em sua pesquisa no reservatório Itupararanga estavam eutrofizadas no período de seca, enquanto no período chuvoso verificou-se elevado grau de trofia, em $60 \%$ dos pontos. Nesse contexto, 
estudos que contemplem o gerenciamento do reservatório Itupararanga são de suma importância, até mesmo os estudos de base assumem grande relevância, tendo em vista a escassez de resultados para esse manancial. Dessa forma, um projeto temático intitulado "Contribuição ao conhecimento do ciclo do carbono no reservatório de Itupararanga como subsídio para a sustentabilidade da bacia hidrográfica do rio Sorocaba (SP)" está sendo realizado com o objetivo de quantificar as formas de carbono na água do reservatório, bem como a contribuição das comunidades aquáticas para a ciclagem deste elemento no ecossistema.

Os reservatórios apresentam importância global no ciclo do carbono, pois tanto a forma orgânica como a inorgânica desse composto estão presentes nos ambientes aquáticos. O carbono inorgânico tem origem nas trocas gasosas entre água e atmosfera, além de ser fixado pelos produtores primários através da fotossíntese, retornando à atmosfera pelo processo de respiração. O carbono orgânico adentra lagos e reservatórios como matéria orgânica alóctone advinda da lixiviação do solo. Além disso, a decomposição tem papel fundamental na liberação de carbono orgânico, particulado ou detrital, nos sistemas aquáticos.

O carbono orgânico alóctone, especialmente o carbono orgânico dissolvido, possui grande importância para o metabolismo dos sistemas aquáticos, sendo que em concentrações elevadas pode causar prejuízos os mesmos. Assim, o estudo do ciclo do carbono em ecossistemas aquáticos permite inferir acerca de seu metabolismo, pois as taxas de produção, respiração e decomposição controlam a entrada e saída do carbono no ambiente. Dessa maneira as comunidades biológicas, principalmente aquelas que são a base da cadeia alimentar (produtores), podem ser consideradas ferramentas para o conhecimento do ciclo do carbono.

A comunidade de macrófitas aquáticas representa importante papel no estudo dos ecossistemas aquáticos e fluxo de energia, pois é composta por organismos macroscópicos e fotossintetizantes, que se desenvolvem, principalmente, nas partes marginais de reservatórios e lagos ou locais de menor velocidade da água em rios, com ocorrência em uma grande amplitude de climas (Chambers et al. 2008). Em relação ao metabolismo do carbono, essas plantas desenvolveram adaptações para sua absorção, principalmente as macrófitas submersas. Elas apresentam metabolismo do tipo C4, metabolismo ácido das crassuláceas (CAM) e absorvem $\mathrm{HCO}_{3}{ }^{-}$como fonte de carbono. A absorção do carbono, juntamente com outros nutrientes da coluna de água, permite o incremento da biomassa e o acúmulo desses compostos nos tecidos das macrófitas. Sabe-se que o carbono é um dos principais componentes da biomassa vegetal e, após a senectude, este é liberado para a cadeia de detritos, contribuindo para a formação de $\mathrm{CO}_{2}$ e biomassa de microrganismos. Sob esse aspecto, Pompêo (1996) 
concluiu que uma área de 67 ha do reservatório Jurumirim - SP, coberta pela macrófita Eichinochloa polystachia, possui elevada produção de matéria orgânica (25 $\mathrm{tPS} \cdot \mathrm{ha}^{-1} \cdot \mathrm{ano}^{-1}$ ) e pode contribuir sobremaneira para a entrada de carbono nesse sistema, caso não haja um equilíbrio entre produção e decomposição.

Sob esse aspecto, avaliar a importância que essa comunidade representa para o metabolismo do reservatório Itupararanga poderá servir como subsídio para o manejo sustentável desse sistema. Embora o estudo desenvolvido por Martins et al. (2008) em 18 reservatórios do estado de São Paulo tenha indicado que os reservatórios da bacia do rio Tietê possuem alto grau de infestação por macrófitas e elevadas concentrações de nutrientes, no reservatório Itupararanga não foi verificada grande incidência por plantas aquáticas (BOTTINO et al. 2011). Entretanto devido aos problemas mencionados e ao aumento do índice de estado trófico do reservatório (CETESB, 2010), poderá haver um incremento da biomassa de macrófitas aquáticas. Esse fato pode representar tanto aspectos positivos (ciclagem de nutrientes, manutenção da linha costeira e da transparência da água, entre outros) como negativos (problemas com recreação, navegação e entupimento de grades da hidrelétrica). Esse fato corrobora o desenvolvimento do presente estudo em um manancial com carência de informações. 


\section{HIPÓTESE}

Este estudo pressupôs que a sazonalidade exerceu influência sobre as características físicas e

químicas da água e do sedimento do reservatório Itupararanga e, consequentemente, sobre o desenvolvimento da biomassa e decomposição de macrófitas aquáticas, influenciando, portanto a liberação de carbono. 


\section{OBJETIVOS}

\subsection{Objetivo Geral}

Avaliar a participação da comunidade de macrófitas aquáticas na dinâmica do carbono no reservatório Itupararanga através da quantificação e composição da biomassa em quatro períodos distintos e do processo de decomposição in situ e in vitro.

\subsection{Objetivos Específicos}

- Determinar as variáveis físicas e químicas da água no compartimento onde a comunidade de macrófitas aquáticas está inserida, através de amostragens sazonais;

- Caracterizar o compartimento sedimento, em amostragens sazonais, através da determinação das formas de nitrogênio, fósforo, matéria orgânica e granulometria;

- Caracterizar a comunidade de macrófitas aquáticas através da diversidade de espécies;

- Determinar a biomassa da comunidade de macrófitas aquáticas em amostragens sazonais;

- Determinar, em dois períodos distintos (verão e inverno), a taxa de decomposição das macrófitas aquáticas. 


\section{REVISÃO DA LITERATURA}

Os reservatórios são ecossistemas reconhecidos pela extensa área que ocupam e por participarem de processos de acumulação e exportação (COLE et al. 2007). Esses sistemas são considerados híbridos, estruturados em padrões verticais e horizontais diferenciados, o fluxo de água é controlado e seu padrão de funcionamento é modificado desde o início de sua construção até sua operação (THORNTON 1990). Sendo assim, é possível caracterizar a formação de gradientes ao longo dos reservatórios, devido às características lóticas à montante e lênticas à jusante. Esse fato influencia as variáveis físicas e químicas da água e do sedimento, consequentemente a ciclagem de compostos, bem como a ocorrência de comunidades biológicas.

Dentre as comunidades afetadas pela dinâmica dos reservatórios, pode-se mencionar a de macrófitas aquáticas, plantas aquáticas visíveis a olho nu, cujas porções fotossinteticamente ativas estão permanentemente, ou por algum período, submersas e flutuantes. As macrófitas podem pertencer ao grupo das angiospermas, pteridófitas ou briófitas, que se tornaram adaptadas à vida, total ou parcialmente, submersa por água (COOK, 1974). Elas podem, ainda, ser classificadas de acordo com o ambiente em que vivem (emersas, submersas, enraizadas e flutuantes) e a colonização dos reservatórios por esses vegetais está relacionada com a heterogeneidade dos habitats que compõem o ecossistema.

Estudos recentes também sugerem que as macrófitas aquáticas mantêm claras as águas de lagos rasos, desempenham importante papel na estrutura e função das zonas litorâneas, fornecem habitat e alimento para animais da coluna de água e podem alterar o ciclo dos nutrientes, principalmente do fósforo, em seu local de ocorrência (CRONIN, LEWIS e SCHIEHSER, 2006). Além disso, Stanley, Johson e Ward (2003) relataram a influência das macrófitas aquáticas na fixação de carbono por bactérias.

Bini et al. (2005) ressaltaram que o crescimento abundante de macrófitas aquáticas em reservatórios tropicais e subtropicais é comum, uma vez que a construção destes acarreta diversas modificações do ambiente, dentre as quais pode-se citar: redução da velocidade da água e de sua transparência, alteração da estabilidade do sedimento, controle do nível da água e aumento do desenvolvimento de linhas costeiras. De acordo com Caffrey, Monahan e Tierney (2006), os fatores que governam a distribuição dessas plantas nos ambientes aquáticos estão associados a fatores ambientais e antropogênicos que agem sinergicamente. Os autores citaram ainda, que baixa profundidade, águas claras com baixa vazão, condições favoráveis do substrato associadas à poluição difusa e/ou pontual favorecem o desenvolvimento da comunidade de macrófitas aquáticas. Sabe-se ainda que a concentração de nutrientes, a radiação solar subaquática, a alcalinidade, o pH, a flutuação 
do nível da água, tempo de detenção hidráulica, precipitação e vento são fatores intimamente relacionados com a riqueza e distribuição de espécies (GLOSSELING e TURNER, 1978; SANDJENSEN, 1989; HENRY-SILVA e CAMARGO, 2005; THOMAZ, 2005; DANIEL et al. 2006; MALTCHICK, ROLON e SCHOTT, 2007 HENRY-SILVA, CAMARGO e PEZZATO, 2008). Em relação à disponibilidade de nutrientes, Henry-Silva, Camargo e Pezzato (2008) concluíram que diferentes concentrações de nitrogênio e fósforo, associadas ou individualmente, limitam o crescimento de macrófitas aquáticas. Thomaz, Souza e Bini (2003) citaram que os fatores determinantes para a riqueza de macrófitas incluem aspectos como área do reservatório, variáveis químicas da água, estado trófico, morfometria do reservatório, grau de exposição ao vento e grau de conectividade com os rios. Quanto a outras variáveis abióticas, os mesmos autores reportaram que a temperatura é um fator limitante para o desenvolvimento desses vegetais. Deve-se mencionar ainda, a influência das interferências antrópicas sobre a ocorrência e desenvolvimento de macrófitas, conforme relatado por Pozo, Fernández-Aláez e Fernández-Aláez (2011).

Nesse contexto, Thomaz (2005), em sua pesquisa realizada nos reservatórios do rio Paranapanema-SP, observou que além da transparência da água, a alcalinidade constituiu-se em um fator relacionado à distribuição de espécies de macrófitas aquáticas, principalmente as submersas. Carvalho, Velini e Martins (2005) citaram que, em represas do rio Tietê-SP, a turbidez favoreceu o desenvolvimento de algumas espécies de plantas, principalmente as emersas e flutuantes. Dellelo (2008), estudando as macrófitas da represa do Lobo-SP, obteve correlação entre a distribuição das mesmas, as características morfométricas e hidrodinâmicas do manancial e o aporte de nutrientes. Martins et al. (2008) concluíram, após estudo em 18 reservatórios do estado de São Paulo, que as concentrações de nutrientes e sólidos estavam correlacionadas com a distribuição de macrófitas, determinando, inclusive, seu tipo ecológico. A influência da temperatura e do fotoperíodo no crescimento de Pistia stratiotes foi citado por Cancian, Camargo e Henry-Silva (2009). Os autores concluíram, em estudo de mesocosmo, que houve maior produção de brotos a $25^{\circ} \mathrm{C}$ com fotoperíodo de 12 horas. Carrilo, Guarín e Guillot (2006) mencionaram ainda, que climas tropicais de elevada altitude influenciam a distribuição e a dinâmica de macrófitas aquáticas.

As macrófitas, além de estarem envolvidas em processos como biomineralização, transpiração, sedimentação, ciclos elementares e liberação de gases, desempenham importante papel na produção primária. Petracco (2006) relatou o aumento da concentração de oxigênio dissolvido durante elevada atividade fotossintética de Egeria najas na Lagoa do Óleo - SP. Biudes e Carmargo (2009) afirmaram a importância da produção primária para o ciclo do carbono e mencionaram que fatores como temperatura, radiação solar fotossinteticamente ativa, velocidade de corrente, variação do nível da 
água, nutrientes e carbono orgânico dissolvido são limitantes à fotossíntese desses vegetais. De fato, Pezzato (2007) avaliou o crescimento de Egeria najas em diferentes condições de temperatura (15, 20, 25 e $30^{\circ} \mathrm{C}$ ) e observou maior produção de biomassa a $25^{\circ}$. A mesma autora, ao avaliar a produção primária de Egeria densa em diferentes concentrações de carbono inorgânico dissolvido, confirmou que esse nutriente é um importante fator limitante à produção primária bruta (Pezzato, 2002)

As macrófitas aquáticas apresentam ainda algumas adaptações para ocupação de áreas com flutuação do nível e da qualidade das águas (BIUDES e CAMARGO, 2008). Santos e Esteves (2004) observaram a relação entre o aumento da biomassa aérea de macrófitas emersas e o aumento do nível da água na Lagoa de Cabuínas - RJ. Thomaz (2005) concluíram que a diminuição no nível da água causou um efeito negativo nas macrófitas submersas do Reservatório de Itaipu - PR. Os autores também comentaram que a flutuação do nível da água pode causar um processo de sucessão entre as macrófitas. Souza, Thomaz e Murphy (2010) reportaram o efeito do regime hidrológico e do nível da água de uma bacia subtropical brasileira sobre o desenvolvimento de espécies de macrófitas potencialmente invasoras. Meyer (1996) também comentou o efeito da hidrologia e da cota hidrométrica sobre o desenvolvimento de Paspalum repens no reservatório de Barra Bonita-SP. Devese ressaltar que muitas macrófitas aquáticas não sobrevivem a períodos de estiagem prolongada, entretanto, ocorre intenso desenvolvimento dessa comunidade no início da estação chuvosa. Esse fato pode estar relacionado com a presença de propágulos no sedimento dos reservatórios, os quais permanecem na forma latente sob condições desfavoráveis. Além disso, os rios podem trazer grande quantidade de nutrientes e sedimento na época chuvosa, fatores que favorecem o desenvolvimento dessas plantas (BINI et al. 2005; THOMAZ, et al. 2006). Matias, Amado e Nunes (2003) relataram que o sedimento de uma lagoa do nordeste do Brasil (Lagoa de Jijoca, Jericoacoara, CE) contém propágulos de macrófitas aquáticas que são resistentes à seca. Dessa forma, essa comunidade pode ser caracterizada como altamente resiliente, respondendo rapidamente às mudanças de ordem climática (PEDRALLI E TEIXEIRA, 2003).

Deve-se mencionar a atuação das plantas aquáticas na remoção de nitrogênio e fósforo em águas superficiais. Lopes-Ferreira (2000) observou, em estudo realizado no reservatório Salto Grande-SP, que as macrófitas reduziram 50\% de nitrito, $63 \%$ de fosfato inorgânico, 32\% de fósforo e $90 \%$ da densidade de coliformes fecais da água desse manancial. Muitos autores (THOMAZ, SOUZA e BINI, 2003; FISHER e ACREMAN, 2004; CRONIN, LEWIS e SCHIESHER, 2006; VERHOVEN et al. 2006) destacaram que devido a alta taxa de produtividade e a crescente eutrofização dos corpos de água, as macrófitas estocam grande quantidade de nutrientes em sua biomassa, a qual pode ser duplicada em um 
curto período de tempo, dependendo da espécie (HU et al. 2007). Pistori (2005), em estudo com efluentes de aquicultura em viveiros com diferentes estados tróficos, concluiu que Salvinia molesta cresceu, aproximadamente, 28 vezes mais rápido em condições hipereutróficas.

Essa alta produtividade faz com que os vegetais aquáticos se tornem importante fonte de detrito autóctone após a senescência. Após a senectude há grande liberação de matéria orgânica particulada (MOP) e matéria orgânica dissolvida (MOD). Essa última adentra, de forma mais rápida, o pool de nutrientes, sendo utilizada na cadeia heterotrófica (ASAEDA, TRUNG e MANATUNGE 2000; BIANCHINI Jr., CUNHA-SANTINO e PERET, 2008). Portanto, a comunidade de macrófitas aquáticas pode ser reconhecida por regular o metabolismo límnico, através da sua participação na cadeia de detritos.

A decomposição dos detritos das macrófitas depende da composição molecular dos mesmos e do metabolismo microbiano. A composição das diferentes frações (MOP, MOD e compostos inorgânicos) faz com que as mesmas sejam processadas em diferentes taxas e constantemente modificadas em função dos fatores bióticos e abióticos (BIANCHINI Jr., CUNHA-SANTINO e PERET, 2008) culminando na perda de massa das plantas.

De acordo com Cunha-Santino e Bianchini Jr. (2000), após a senescência das plantas aquáticas, grandes quantidades de componentes celulares solúveis em água são liberados rapidamente. Entretanto, a velocidade de decomposição é particular de cada espécie, e fatores como temperatura, oxigênio dissolvido e atividade microbiana atuam no decaimento de massa das plantas. A decomposição resulta na mudança de estado de determinado recurso, levando à perda de massa das plantas. Assim, tanto o processo de decomposição aeróbio como o anaeróbio são constituídos por três mecanismos básicos: fragmentação, lixiviação e catabolismo (BIANCHINI Jr., 1999). Segundo Bianchini Jr. (2003), a lixiviação é um processo abiótico, no qual os compostos solúveis dos detritos são removidos por ação mecânica (velocidade da água, por exemplo). Na etapa da fragmentação há a redução do tamanho original do detrito, por meio da atividade dos decompositores, entretanto, esse processo pode ocorrer mecanicamente. Nesse caso, não há mudança na composição química do detrito. No catabolismo, que se dá através de reações específicas, compostos orgânicos complexos são transformados em moléculas pequenas e simples. As diferentes etapas do processo de decomposição, referentes à degradação da matéria orgânica, podem se constituir em importante fonte de carbono. Santos (2004) verificou que Polygonum ferrugineum contribuiu com 1,42 t.ha ${ }^{-1}$ de carbono para lagoa do Carão - PR e com 5,79 t.ha ${ }^{-1}$ de carbono para o rio Baía - PR. O mesmo autor concluiu que a contribuição, em termos de carbono, de Eichhornia azurea foi 10,5 t.ha ${ }^{-1}$ e 8,33 t.ha ${ }^{-1}$ na lagoa do Carão e no rio Baía, 
respectivamente. A intensidade da decomposição e a liberação de recursos é característica para cada espécie.

As taxas de decomposição dos detritos vegetais são, geralmente, expressas por um coeficiente de decaimento $(k)$. A determinação desse coeficiente é feita a partir de modelos matemáticos, os quais possuem diferentes abordagens e consideram o decaimento de massa de diversas formas (modelo linear, exponencial simples, exponencial múltiplo e sigmóide) O estudo realizado por Gimenes, CunhaSantino e Bianchini Jr. (2010) indicou que os valores de k variam de 0,0002 a 0,198 dia ${ }^{-1}$. Os autores comentaram que as macrófitas flutuantes possuem menores taxas de decomposição, seguida pelas emersas e, por último, com decaimento mais rápido, estão as submersas. Entretanto, os autores reportaram que uma mesma espécie pode apresentar diferentes taxas de decaimento, dependo da metodologia empregada e, até mesmo, de fatores intrínsecos e extrínsecos. Dessa forma, a liberação da matéria orgânica e, portanto, do carbono pode variar para uma espécie dentro de um mesmo ecossistema, dependendo das condições do mesmo.

Com base nas considerações apresentadas, pode-se constatar a importância da comunidade de macrófitas aquáticas para o metabolismo dos ecossistemas aquáticos. Estudos que caracterizem os ecossistemas aquáticos, bem como as comunidades e os fatores que influenciam seu desenvolvimento têm grande importância ecológica. Em relação ao reservatório Itupararanga, cabe mencionar sua relevância para uma região economicamente importante do estado de São Paulo (bacia do rio Sorocaba - Médio Tietê). Entretanto, esse reservatório tem recebido pouca atenção e estudos sobre comunidade de macrófitas aquáticas são escassos ou ausentes. Assim, a estimativa da variação sazonal da biomassa e da decomposição das macrófitas, relacionando-as com as características locais nas diferentes estações do ano permitirão compreender melhor as condições ecológicas que regulam o metabolismo desse importante manancial brasileiro. 


\section{CARACTERIZAÇÃO GERAL DA ÁREA DE ESTUDO}

\subsection{A bacia do Sorocaba/Médio Tietê}

A bacia do rio Sorocaba está localizada na Unidade de Gerenciamento dos Recursos Hídricos (UGRHI) número 10 (área $11.827 \mathrm{~km}^{2}$ ), denominada Tietê/Sorocaba (Médio Tietê) e abrange os municípios de Alambari, Alumínio, Anhembi, Araçariguama, Araçoiaba da Serra, Bofete, Boituva, Botucatu, Cabreúva, Capela do Alto, Cerquilho, Cesário Lange, Conchas, Ibiúna, Iperó, Itu, Jumirim, Laranjal Paulista, Mairinque, Pereiras, Piedade, Porangaba, Porto Feliz, Quadra, Salto, Salto de Pirapora, São Roque, Sarapuí, Sorocaba, Tatuí, Tietê, Torre de Pedra, Vargem Grande Paulista e Votorantim (RELATÓRIO DE SITUAÇÃO, 2011). De acordo com a Divisão Geomorfológica do estado de São Paulo, a região de estudo está inserida nas províncias geomorfológicas: Planalto Atlântico, Depressão Periférica e Cuestas Basálticas.

O Médio Tietê Superior compreende o trecho do rio Tietê que vai da barragem de Pirapora até a de Barra Bonita. São oito os reservatórios instalados nessa UGRHI, sendo que os maiores são: Itupararanga, Rasgão, Porto Góes e Barra Bonita. O reservatório mais importante instalado na bacia do rio Sorocaba é o de Itupararanga, utilizado para gerar energia para a Votorantim Energia (SEMA, 2007).

O território desta UGRHI contém áreas urbanas e rurais, sendo que na parte rural predominam pastagens e grandes áreas com cultura temporária de cana de açúcar e silvicultura. As principais atividades desenvolvidas são: indústrias têxteis, alimentícias, química, mecânica, eletroeletrônica e agroindústrias (CETESB, 2010).

\subsection{O reservatório Itupararanga}

O reservatório Itupararanga (Figura 1) tem como formador o rio Sorocaba cujos afluentes são os rios Sorocamirim e Sorocabuçu e Una. A represa está localizada no alto curso do rio Sorocaba (subbacia do Alto Sorocaba - área: 924,5 $\mathrm{km}^{2}$ ), maior afluente do rio Tietê pela margem esquerda. A área da bacia de drenagem do reservatório abrange os municípios de Alumínio, Cotia, Ibiúna, Mairinque, Piedade, São Roque, Vargem Grande Paulista e Votorantim (IPT, 2006), mas apenas Ibiúna e Vargem Grande Paulista possuem sede do município na área denominada como sub-bacia do Alto Sorocaba (população: 114.174 habitantes, CETESB, 2010). 

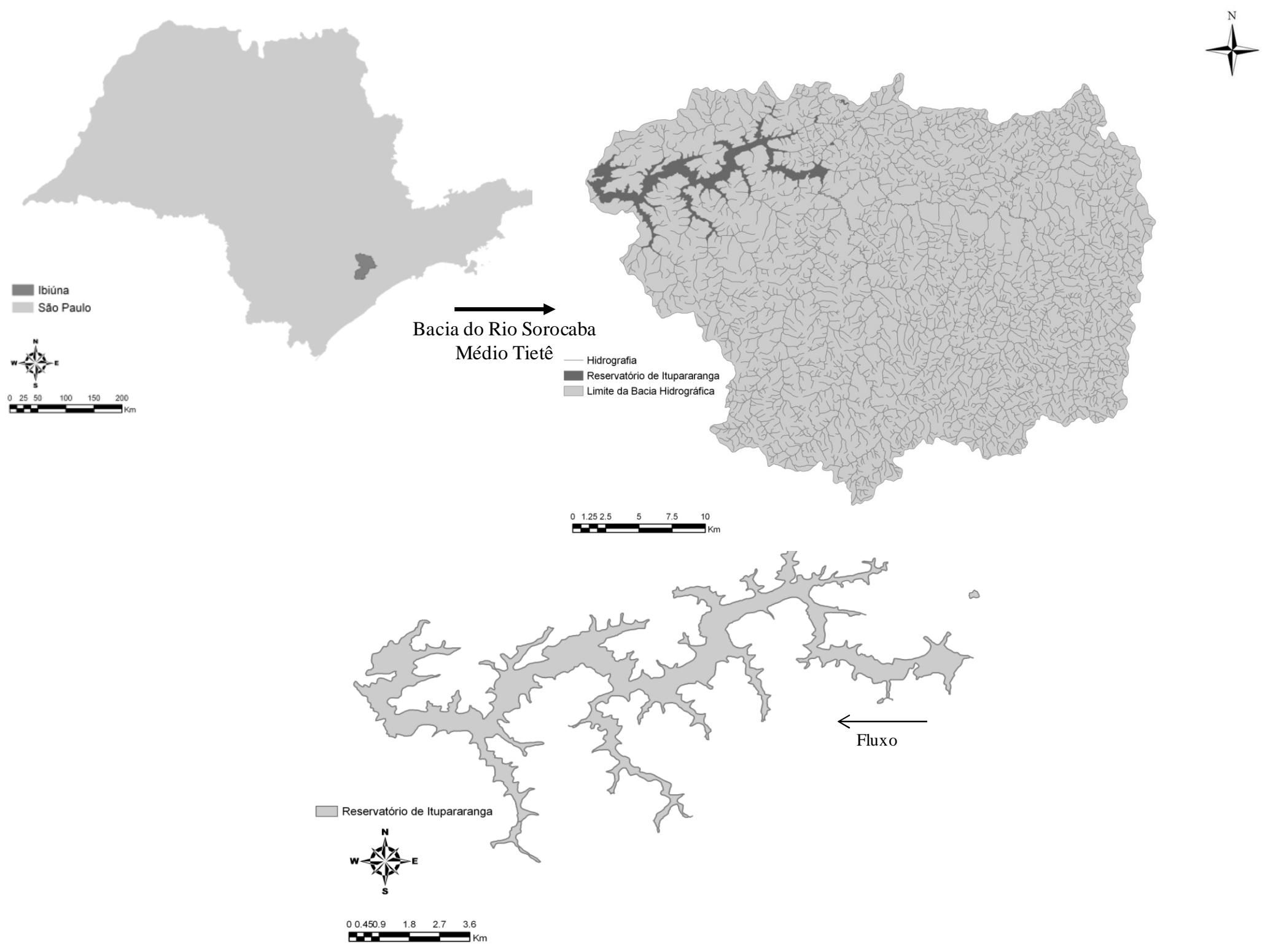

Figura 1: Localização da Bacia do rio Sorocaba no estado de São Paulo, hidrografia da Bacia do rio Sorocaba com destaque para o reservatório Itupararanga e mapa do reservatório Itupararanga. Adaptado de Secchin (em andamento) 
O reservatório foi construído pela empresa Light, entrou em operação em 1912 e é utilizado para abastecimento dos municípios de Votorantim e Sorocaba, com captação realizada pelo Serviço Autônomo de Água e Esgoto de Sorocaba (SAAE), que utiliza $1,51 \mathrm{~m}^{3} \cdot \mathrm{s}^{-1}$ deste manancial. Além disso, possui uma usina hidrelétrica que é operada pela Votorantim Energia. Algumas características deste reservatório podem ser observadas na Tabela 1:

\begin{tabular}{cc} 
Tabela 1: Características do reservatório Itupararanga, Bacia do rio Sorocaba, SP \\
\cline { 1 - 2 } Características & Dados \\
\hline Altitude & $710 \mathrm{~m}$ \\
Profundidade média & $7,8 \mathrm{~m}$ \\
Área & $20,9 \mathrm{~km}^{2}$ \\
Volume total & $286 \times 10^{6} \mathrm{~m}^{3}$ \\
Uso preponderante & Abastecimento \\
Área de drenagem & $936,5 \mathrm{~km}^{2}$ \\
Canal principal & $26 \mathrm{~km}^{3}$ \\
Margem & $192,8 \mathrm{~km}^{3} \mathrm{~m}^{-1}$ \\
Vazão máxima & $39,12 \mathrm{~m}^{3}$ \\
Fonte: Garcia, Freitas e Filho $(1999)$
\end{tabular}

Nas áreas de drenagem dos dois rios formadores do reservatório e do rio Sorocaba concentram-se os maiores problemas ambientais, como uso agrícola intensivo, com pequenas áreas de cultivo de morango, cebola, batata, tomate, entre outros. A sub-bacia do Alto Sorocaba apresenta a maior variedade de agrotóxicos encontrados na água, denotando maior uso e ocupação do solo por plantações de hortaliças (IPT, 2006). De acordo com Garcia, Freitas e Filho (1999), há altos níveis de assoreamento, principalmente na área da cabeceira do reservatório, devido à intensa atividade de mineração de areia na região, além do uso indiscriminado da água para irrigação (demanda por irrigação $2,52 \mathrm{~m}^{3} \cdot \mathrm{s}^{-1}-$ IPT, 2006) e desmatamento de vegetação ciliar.

Em 01 de dezembro de 1998, foi criada a Lei Estadual $n^{\circ} 10.100$ que define uma área ao redor da represa Itupararanga como Área de Proteção Ambiental (APA). Esta área está situada no planalto de Ibiúna/São Roque, na Serra do Taxaquara, entre a Serra do Mar e o Planalto de Jundiaí.

O objetivo dessa APA é a proteção do reservatório, que é responsável por mais da metade do abastecimento público da região, além de gerar energia elétrica, atuar na regularização das vazões na bacia do rio Sorocaba e utilização como área de lazer para as cidades próximas (SEMA, 2007). Em 31 


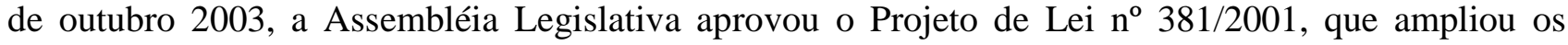
limites da APA, incluindo os municípios de Vargem Grande Paulista, Cotia e Alumínio e estabeleceu a bacia de drenagem da represa como novo perímetro.

Os principais tipos de uso e ocupação de solo na região da bacia do reservatório Itupararanga podem ser observados na Tabela 2, na qual são discriminadas as áreas absoluta e relativa ocupadas por diferentes atividades (SECCHIN, em andamento).

Tabela 2: Uso e ocupação do solo na região da represa de Itupararanga.

\begin{tabular}{ccc}
\hline Tipo de uso & $\begin{array}{c}\text { Área } \\
\left.\mathbf{( k m}^{\mathbf{2}}\right)\end{array}$ & $\begin{array}{c}\text { Porcentagem } \\
\text { da bacia } \mathbf{( \% )}\end{array}$ \\
\hline Água & 22,31 & 2,38 \\
Formações Florestais & 393,61 & 42,03 \\
Várzea & 43,32 & 4,63 \\
Solos Exposto & 28,56 & 3,05 \\
Gramínea & 263,18 & 28,10 \\
Cultura & 158,75 & 16,95 \\
Área Urbana & 26,81 & 2,86 \\
TOTAL & 936,54 & 100 \\
\hline \multicolumn{2}{c}{ Fonte: Secchin (em andamento) }
\end{tabular}

Em análises realizadas pela Cetesb, observou-se que, desde 2006, o reservatório vem sofrendo alterações significativas (aumento da densidade de cianobactérias, deterioração do sedimento e comprometimento da comunidade bentônica). Embora o Índice de Qualidade da Água (IQA) tenha sido classificado como ótimo em 2008 (CETESB, 2008), o Índice de Abastecimento Público (IAP) foi considerado regular, o Índice de Proteção à Vida Aquática (IVA) oscilou entre ruim e regular e o IET foi classificado como mesotrófico na maior parte do ano, chegando a apresentar condições eutróficas em alguns períodos. Quantidades elevadas de células de coliformes fecais e cianobactérias foram encontradas no reservatório (CETESB, 2008). O sedimento do reservatório foi classificado como péssimo devido à alta concentração de metais pesados e pesticidas (CETESB, 2008). Estes dados revelam que a qualidade das águas do reservatório Itupararanga está sofrendo alterações significativas, o que pode vir a interferir nos usos múltiplos desse manancial. 


\subsection{Estações de amostragem}

As amostragens foram realizadas em 10 de agosto e 19 de outubro de 2009 e em 22 de fevereiro e 26 de abril de 2010, em quatro braços com diferentes tipos de uso e ocupação do solo (plantações agrícolas, construção civil, entrada de efluentes advindos de bairros populosos e efluente da estação de tratamento de esgoto) no reservatório Itupararanga. Na Figura 2 é apresentada a localização das estações de amostragem e as principais espécies de macrófitas encontradas em cada braço são mostradas na Tabela 3. A estação de coleta $\mathrm{BR}_{1}\left(23^{\circ} 37^{\prime} 28.3^{\prime \prime} \mathrm{S} 47^{\circ} 13^{\prime} 52.24^{\prime \prime} \mathrm{W}\right)$ localiza-se na cabeceira do reservatório, possui maior vazão e grande influência dos rios formadores do reservatório. Presença de pastagem e urbanização no entorno e pequena faixa de mata na margem direita. A estação de amostragem $\mathrm{BR}_{2}\left(23^{\circ} 39^{\prime} 24.65^{\prime \prime} \mathrm{S} 47^{\circ} 18^{\prime} 36.5^{\prime \prime} \mathrm{W}\right)$ está localizada em um braço que tem como principal afluente o Córrego do Campo Verde, o qual percorre regiões urbanizadas e possui grande quantidade de resíduos sólidos no entorno. Há também plantação de hortaliças na margem esquerda e pequena faixa de mata na margem direita. Em relação à estação $\mathrm{BR}_{3}\left(23^{\circ} 37^{\prime} 42.53^{\prime \prime} \mathrm{S}\right.$ 47017'04.62"W), cujo principal tributário é o Córrego da Ressaca, o qual percorre um dos bairros mais populosos da cidade de Ibiúna e recebe efluentes do mesmo, observou-se presença de chácaras e rodovia, com pouca mata ciliar nas margens. A estação de coleta $\mathrm{BR}_{4}\left(23^{\circ} 40^{\prime} 10.72 " \mathrm{~S} 47^{\circ} 21^{\prime} 21.02^{\prime \prime} \mathrm{W}\right)$ sofre influência do Córrego do Paruru, o qual percorre o bairro mais populoso do município, além de receber efluente da estação de tratamento de esgoto. As margens são ocupadas por casas de veraneio, clubes de pesca e pouca mata ciliar.

Embora diferentes espécies tenham sido encontradas nos quatro bancos amostrados, optou-se por realizar a determinação da variação da biomassa e os experimentos de decomposição com as espécies mais abundantes presentes em bancos considerados homogêneos (Figuras 3 a 7). Nesse caso, na estação de amostragem $\mathrm{BR}_{1}$ amostrou-se Eichhornia crassipes e Pistia stratiotes, nas estações $\mathrm{Br}_{2}$ e $\mathrm{Br}_{3}$ Polygonum lapathifolium, enquanto na estação de coleta $\mathrm{BR}_{4}$, Eichhornia azurea e Myriophyllum aquaticum. Para os experimentos de decomposição realizados tanto in situ, como sob condições controladas, foram utilizadas plantas presentes nas estações de coleta $\mathrm{Br}_{3}$ e $\mathrm{Br}_{4}$, P. lapathifolium e $E$. azurea, respectivamente. Essas estações de amostragem foram escolhidas devido à entrada de tributários que percorrem os bairros mais populosos da cidade de Ibiúna com diferentes tipos de uso e ocupação do solo, o que pode influenciar a composição da comunidade de microrganismos desse local. 


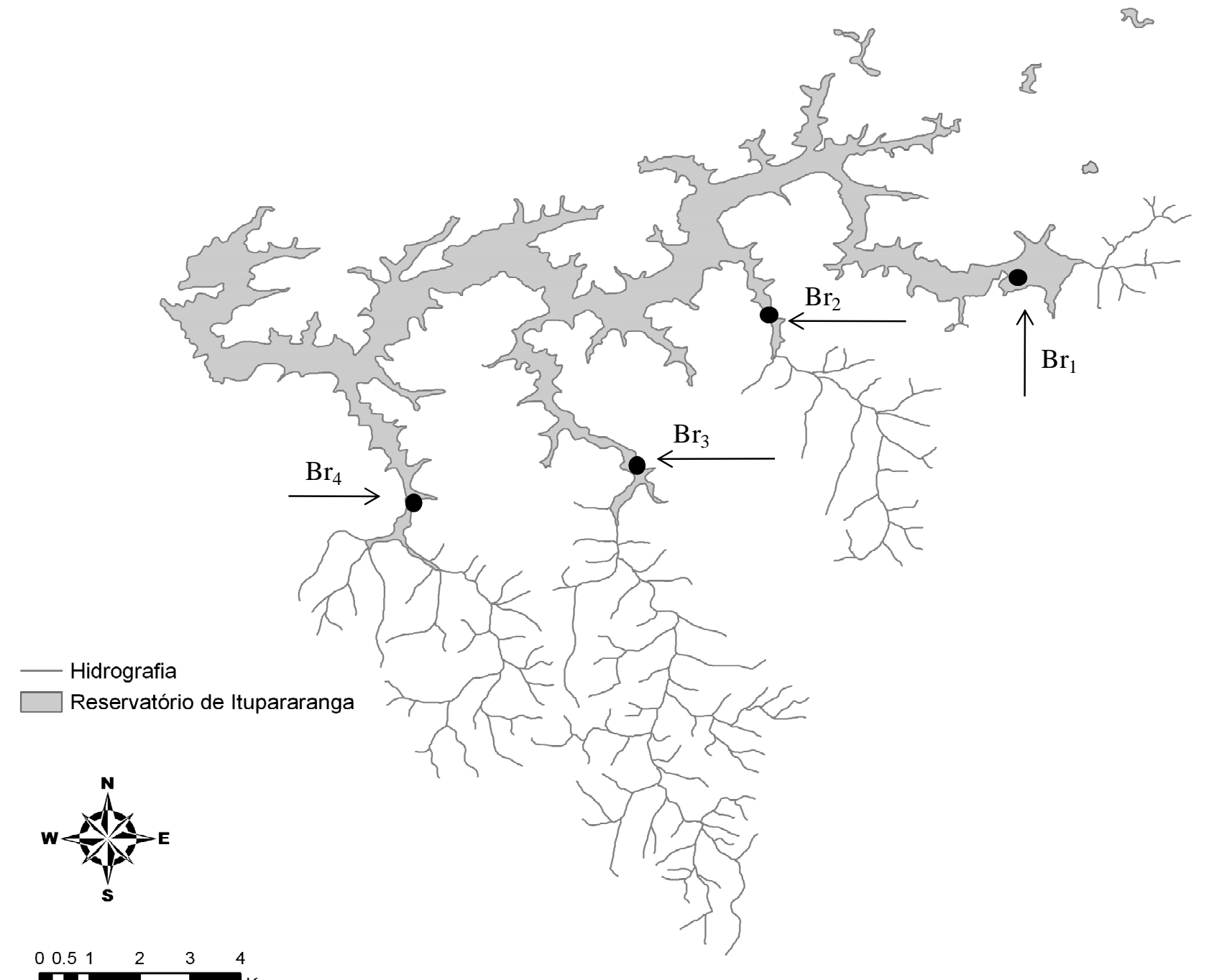

Figura 2: Localização das estações amostrais e de seus principais afluentes no reservatório Itupararanga. Adaptado de Secchin (em andamento). 
Tabela 3: Espécies de macrófitas aquáticas encontradas nas estações de coleta do reservatório Itupararanga entre agosto de 2009 e abril de 2010. EM: Emersa; FL: Flutuante Livre.

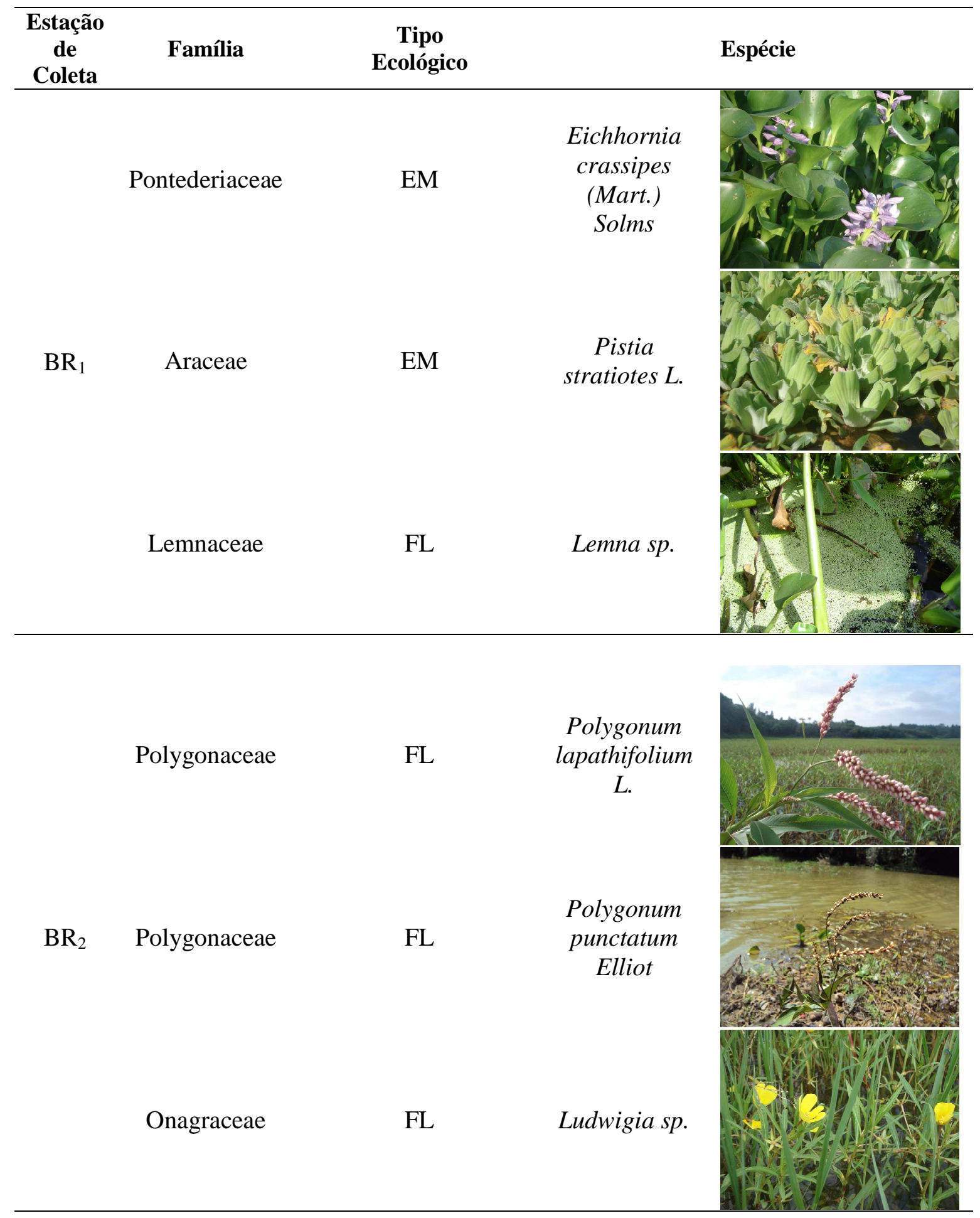


Continuação da Tabela 3: Espécies de macrófitas aquáticas encontradas nas estações de coleta do reservatório Itupararanga entre agosto de 2009 e abril de 2010. EM: Emersa; FL: Flutuante Livre.

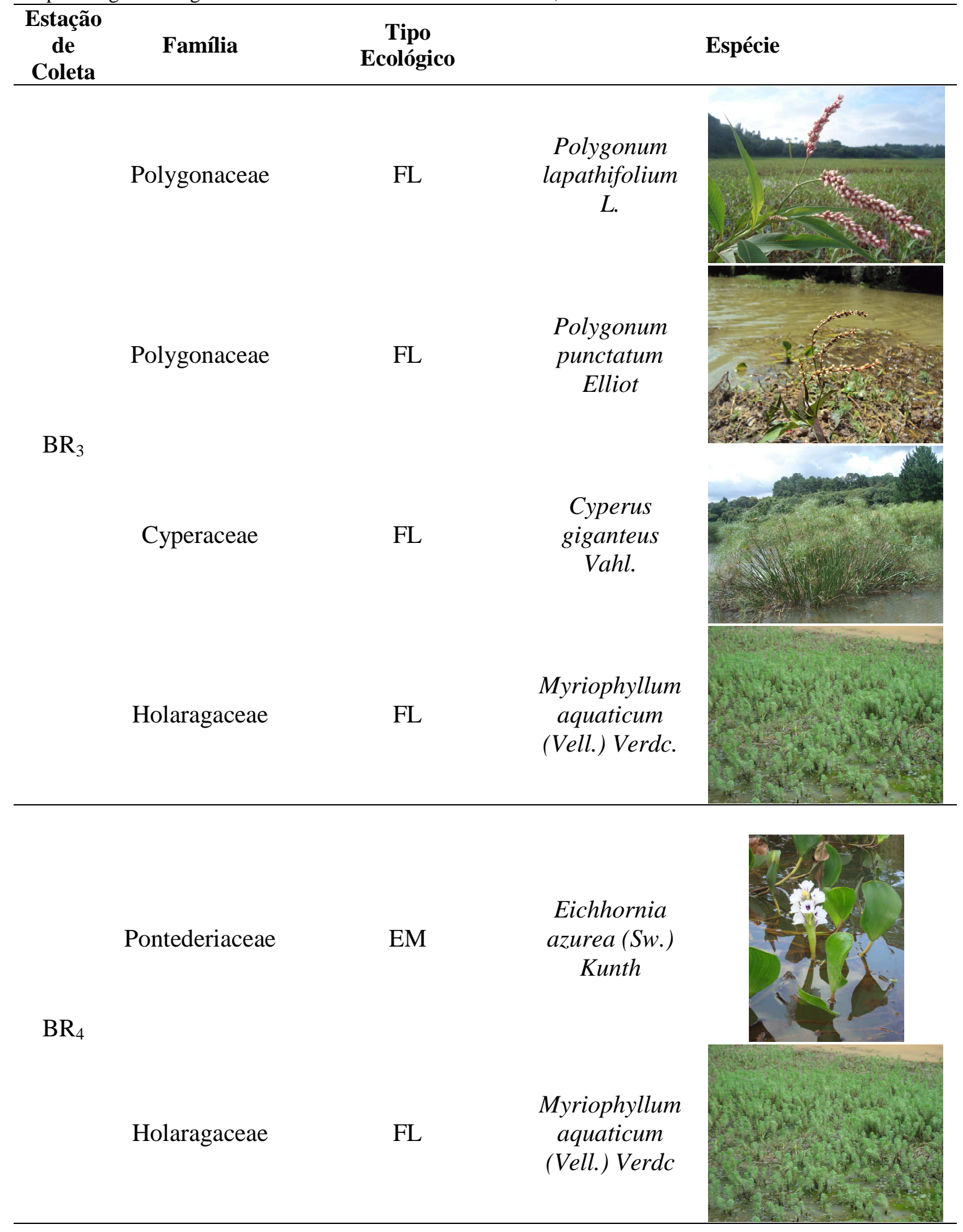




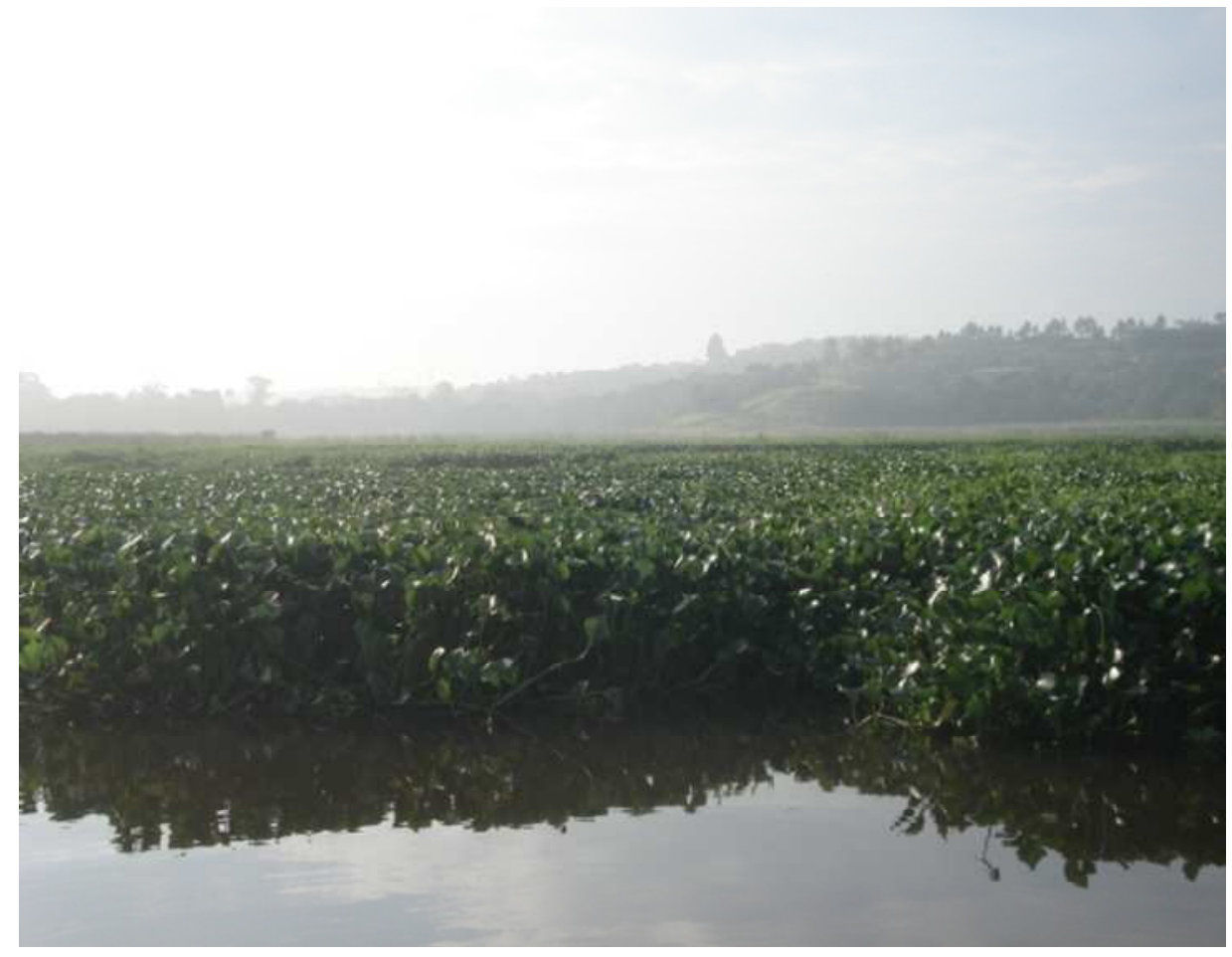

Figura 3: Banco de Eichhornia crassipes uma das principais espécies de macrófitas aquáticas encontradas na estação de coleta $\mathrm{Br}_{1}$ do reservatório Itupararanga.

Eichhornia crassipes (Mart.) Solms, popularmente conhecida como aguapé, pertence à família Pontederiaceae. Erva aquática, livre-flutuante, mas pode ser fixa em águas rasas, estolonífera, com folhas emersas, em rosetas, pecíolos inflados em plantas flutuantes. Inflorescência em espiga multiflora com até $15 \mathrm{~cm}$. Flores bissexuadas, o eixo floral se inverte durante a frutificação liberando a semente na água. A semente pode sobreviver submersa por 15 anos ou ficar em estado latente no sedimento seco, até nova enchente (POTT e POTT, 2000; AMARAL et al. 2008). Segundo Amaral et al. (2008) e Pott e Pott (2000), E. crassipes é uma planta nativa da região amazônica e Pantanal, com ocorrência em todo Brasil. Foi introduzida em áreas tropicais e temperadas de todo o mundo devido à exuberância de suas flores. Utilizada para ornamentação, para despoluição de águas, como ração animal, na produção de biogás e até mesmo na indústria têxtil e de celulose. De acordo com Pott e Pott (2000), essa espécie pode duplicar sua biomassa a cada duas semanas. Seu cultivo se dá em sol pleno e preferencialmente em água rica em nutrientes, pois em águas ácidas ou pobres em nutrientes seu porte fica reduzido e a produção de flor é escassa. 


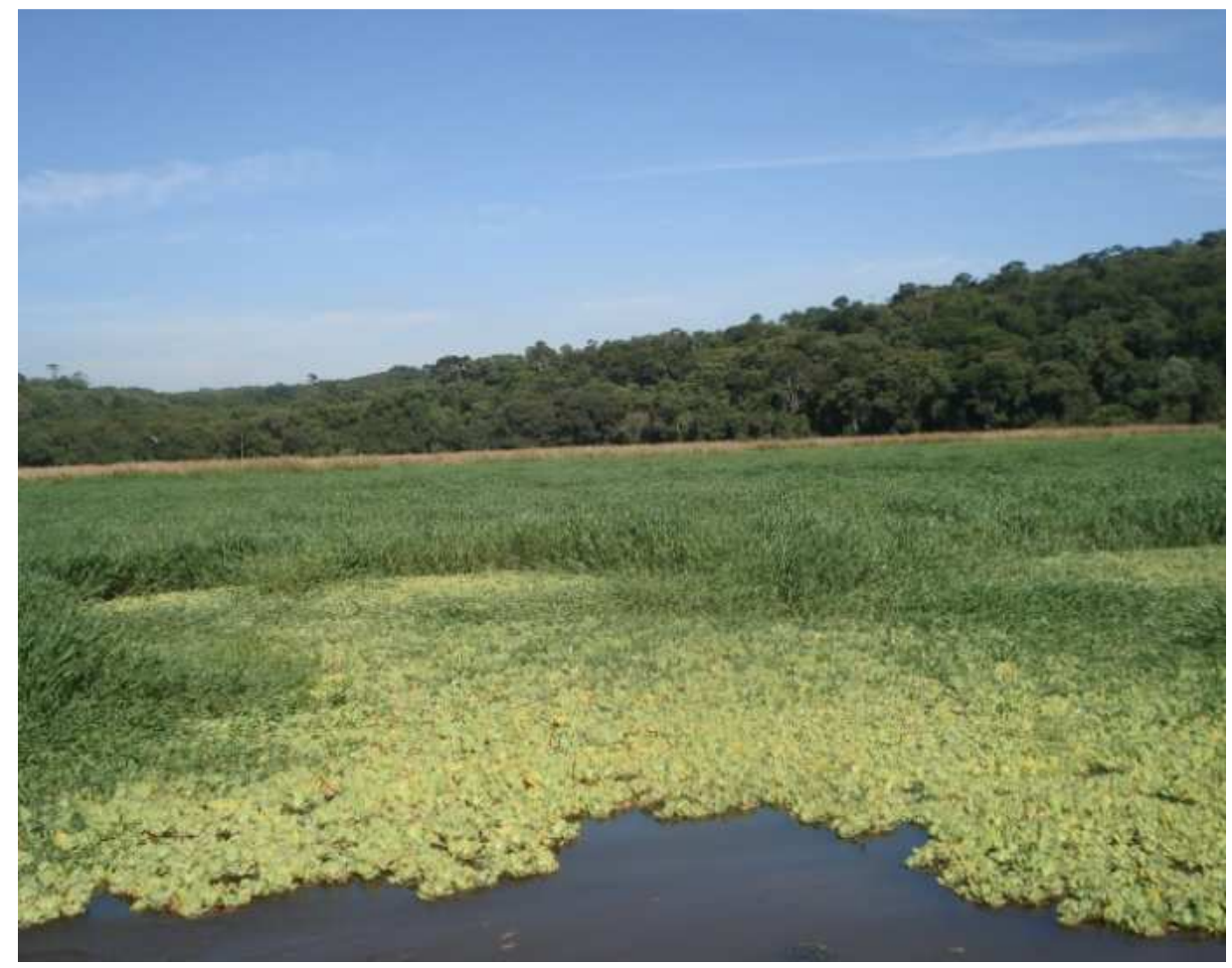

Figura 4: Banco de Pistia stratiotes uma das principais espécies de macrófitas aquáticas encontradas na estação de coleta $\mathrm{Br}_{1}$ do reservatório Itupararanga.

Pista stratiotes L., pertence à família Araceae, é popularmente conhecida como alface d'água ou flor d'água. Planta flutuante, livre ou fixa em águas rasas, alcançam até $25 \mathrm{~cm}$ de diâmetro quando em águas férteis. Possuem estolões para propagação, são esponjosas com muitos pelos e nervuras evidentes. Inflorescência com cerca de $1 \mathrm{~cm}$, portando duas flores unissexuadas, a masculina no ápice e a feminina na base (AMARAL et al. 2008). Espécie pantropical, cosmopolita tropical e subtropical (ocorrendo principalmente do sul dos Estados Unidos à Argentina e em todo Brasil). Ocorrência em margens de rios, lagos e lagoas. Em represas aumenta a transpiração e libera oxalato. Espécie pioneira, indicadora de poluição orgânica, agressiva (avança rapidamente e se adensa, produzindo até 90 t.ha ${ }^{1}$.ano ${ }^{-1}$ de biomassa, não tolera sombra (POTT e POTT 2000). As folhas dessa macrófita são amplamente utilizadas na medicina popular, principalmente na região amazônica e do Pantanal (POTT e POTT, 2000; AMARAL et al. 2008). 


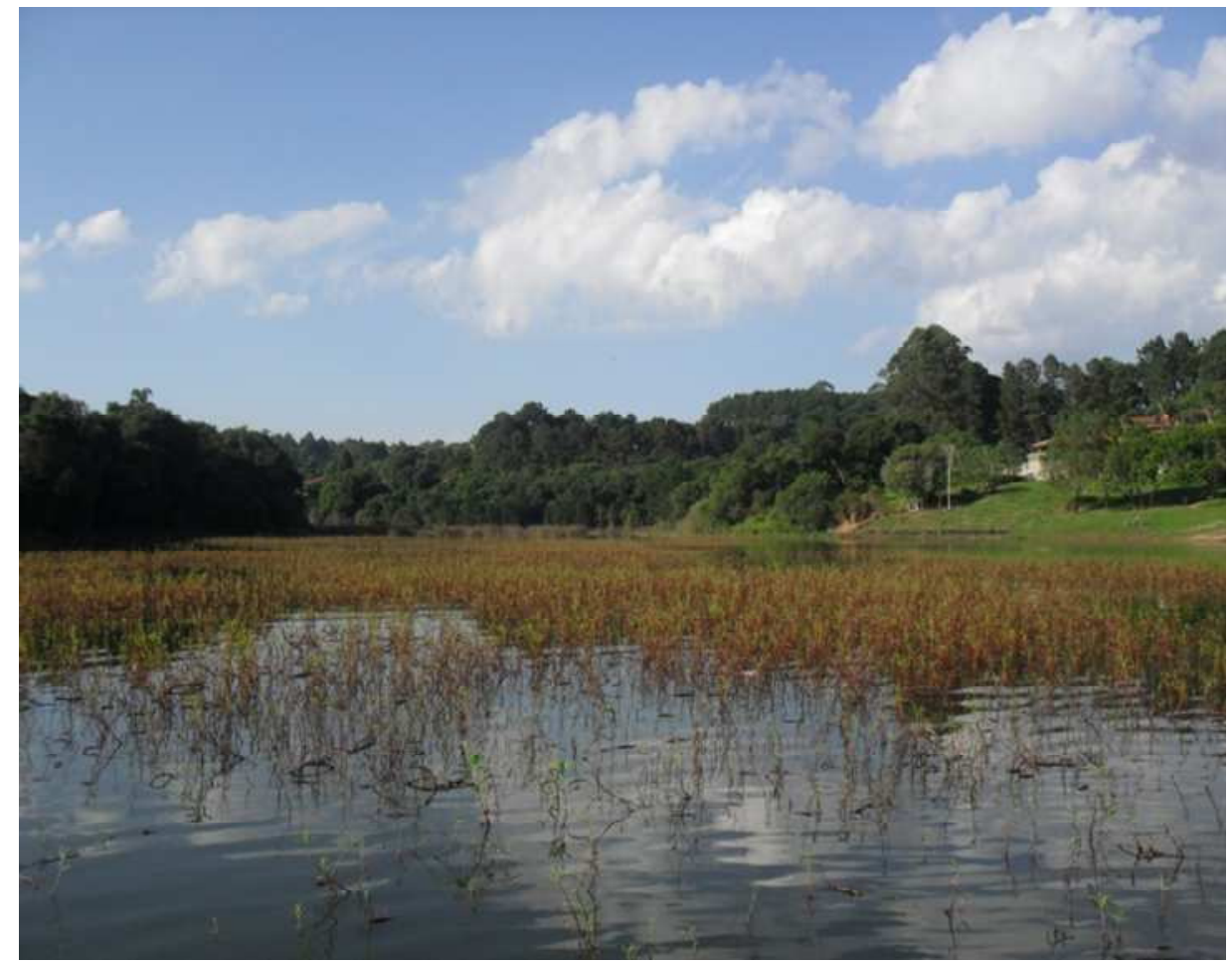

Figura 5: Banco de Polygonum lapathifolium, principal espécie de macrófita aquática encontrada nas estações de coleta $\mathrm{Br}_{2} \mathrm{e} \mathrm{Br}_{3}$ do reservatório Itupararanga.

Polygonum lapathifolium L., pertence à família Polygonaceae e é popularmente conhecida como erva de bicho. De acordo com Pott e Pott (2000) é uma planta de hábito emergente, podendo ser flutuante e até anfíbia, pode alcançar até $2,5 \mathrm{~m}$ de altura. Ramos glabros, raramente com pêlos esparsos, folhas alternas, sésseis, lâmina elíptica, ócrea de até $3 \mathrm{~cm}$. Inflorescência do tipo racemo, pedúnculo glabro, flores bissexuadas. Floresce no verão e no inverno, propaga-se por semente ou por pedaços de caule. Tradicionalmente utilizada na medicina popular (POTT e POTT, 2000; AMARAL et al. 2008). 


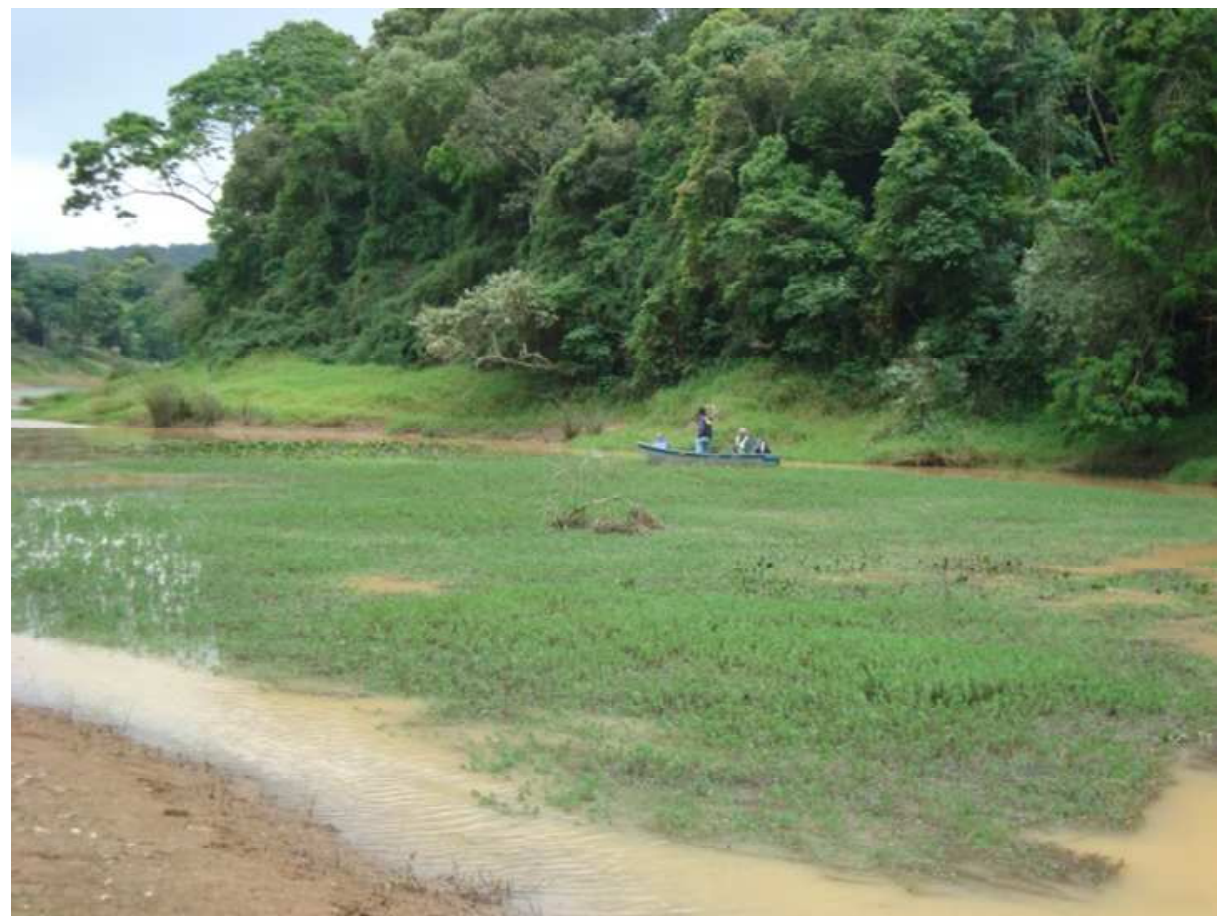

Figura 6: Banco de Myriophyllum aquaticum, uma das principais espécies de macrófitas aquáticas encontradas na estação de coleta $\mathrm{Br}_{4}$ do reservatório Itupararanga.

Myriophyllum aquaticum (Vell.) Verdc. (família Haloragaceae) é popularmente conhecido como pinheirinho d'água. Segundo Amaral et al. (2008) é uma erva aquática rastejante a ascendente, muito ramificada. Flores solitárias, axilares em ramos emergentes, unissexuadas, subsésseis, flor feminina diminuta, fruto globular ou ovóide. Ocorre nas regiões Sul e Sudeste do Brasil, floresce na primavera e no verão. Considerada daninha, vegeta com vigor, formando densas infestações que chegam a impedir o fluxo de água. 


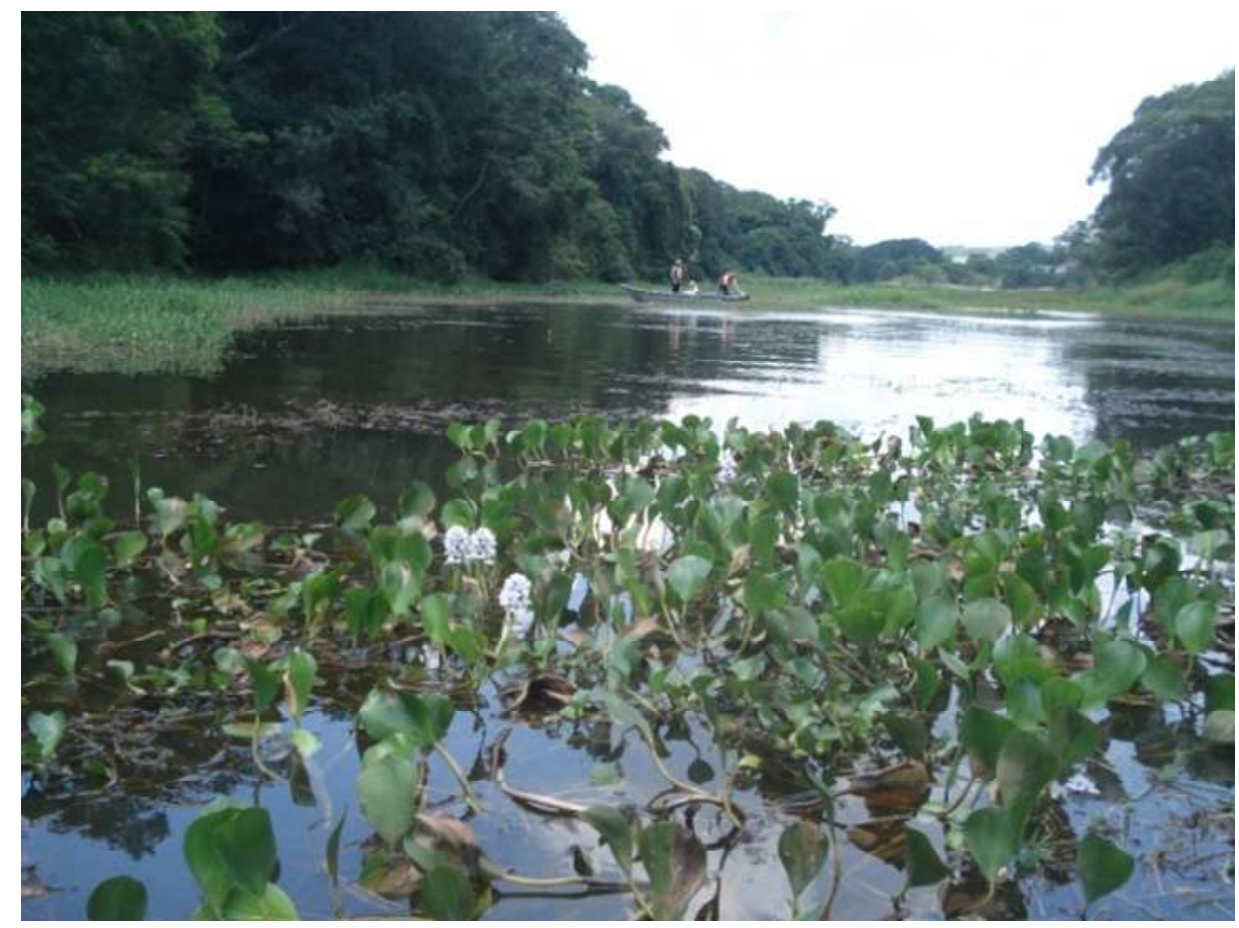

Figura 7: Banco de Eichhornia azurea, uma das principais espécies de macrófitas aquáticas encontradas na estação de coleta $\mathrm{Br}_{4}$ do reservatório Itupararanga.

Eichhornia azurea (Sw.) Kunth (família Pontederiaceae), popularmente conhecida como aguapé ou bico de pato. Erva aquática flutuante, livre ou fixa, estolonífera, folhas submersas ou emersas, com lâminas lineares. As folhas emersas não possuem pecíolo inflado. Flores bissexuadas, zigomorfas, inflorescência do tipo espiga multiflora. As plantas jovens são submersas com folhas lineares. Diferencia-se de E. crassipes principalmente pelas margens das pétalas internas fimbriadas e por nunca apresentarem pecíolos inflados. Reproduz-se tanto de forma vegetativa como sexuadamente e floresce durante o verão e o outono (POTT e POTT, 2000; AMARAL et al. 2008). 


\subsection{Amostragens}

Foram realizadas quatro coletas em diferentes épocas do ano, acompanhando as variações do ciclo hidrológico no reservatório Itupararanga. As amostras de água e sedimento foram coletadas e transportadas ao laboratório de campo em Ibiúna-SP para análise, filtração e preservação até serem levadas ao laboratório Biotace - EESC - USP.

\subsubsection{Compartimento Água}

Com o auxílio de uma garrafa de Van Dorn as amostras de água foram coletadas em diferentes profundidades, as quais foram determinadas a partir da incidência de radiação solar $(100 \%, 75 \%, 50 \%$, 25\%, 10\% e zona afótica) através de um radiômetro Quanta-Meter Li-Cor (LI - 1400). Esse procedimento foi utilizado para as variáveis determinadas em laboratório. Para as variáveis analisadas in situ utilizou-se uma sonda multiparamétrica (Yellow Springer 556 MPS) previamente calibrada e as amostragens foram realizadas a cada $0,1 \mathrm{~m}$ até atingir a profundidade de $1,5 \mathrm{~m}$, em seguida as determinações foram feitas a cada $0,5 \mathrm{~m}$.

5.4.1.1 Temperatura da água, Oxigênio Dissolvido (OD), Potencial Hidrogeniônico (pH), Condutividade Elétrica e Turbidez.

Medidas de temperatura da água, oxigênio dissolvido (OD), potencial hidrogeniônico $(\mathrm{pH})$ e condutividade elétrica foram realizadas in situ com o auxílio de uma sonda multiparamétrica (Yellow Springer 556 MPS) previamente calibrada (Tabela 4).

Tabela 4: Método de determinação das variáveis temperatura da água, $\mathrm{OD}, \mathrm{pH}$ e condutividade elétrica no compartimento água.

\begin{tabular}{ccc}
\hline Variáveis & Unidade & Método \\
\hline Temperatura da água & ${ }^{\circ} \mathrm{C}$ & Potenciométrico \\
Oxigênio Dissolvido & $\mathrm{mg} . \mathrm{L}^{-1}$ & Polarográfico \\
$\mathrm{pH}$ & - & Potenciométrico \\
Condutividade Elétrica & $\mu \mathrm{S} . \mathrm{cm}^{-1}$ & Potenciométrico \\
\hline
\end{tabular}




\subsubsection{Turbidez}

As medidas de turbidez (UNT) foram feitas com o auxílio de um turbidímetro de bancada (Marconi ${ }^{\circledR}$ TB 1000) no laboratório de campo.

\subsubsection{Alcalinidade}

Para a determinação, em réplica, da alcalinidade foi utilizado o método titrimétrico 2320B-4d descrito em APHA (2005), com valores expressos em mEq. $\mathrm{L}^{-1}$.

\subsubsection{Sólidos em Suspensão}

Os sólidos em suspensão (mg. $\left.\mathrm{L}^{-1}\right)$ foram determinados em réplicas. Para isso, as amostras foram filtradas no laboratório de campo, com membrana GF C - AP40 de $47 \mathrm{~mm}$ de diâmetro e 0,8 a $8 \mu \mathrm{m}$ de poro. O método gravimétrico (2540D e E), descrito em APHA (2005), foi utilizado.

\subsubsection{Nutrientes Dissolvidos}

Para determinação dos nutrientes dissolvidos, réplicas das amostras foram filtradas com membrana Wathman - GF C com 47 mm de diâmetro e 1,2 $\mu \mathrm{m}$ de poro. O filtrado foi armazenado em freezer, para posterior determinação de nitrito, nitrato, fosfato total dissolvido (PTD) e ortofosfato no laboratório Biotace - EESC - USP. As unidades e os métodos são apresentados na Tabela 5.

Tabela 5: Métodos de determinação dos nutrientes dissolvidos

\begin{tabular}{cccc}
\hline Variáveis & Unidade & Método & Referência \\
\hline Nitrito & $\mu \mathrm{g} . \mathrm{L}^{-1}$ & $4500_{\mathrm{NO} 2} \mathrm{~B}$ & APHA (2005) \\
Nitrato & $\mathrm{mg} \cdot \mathrm{L}^{-1}$ & $4500_{\mathrm{NO} 3} \mathrm{~B}$ & APHA (2005) \\
PTD & $\mu \mathrm{g} \cdot \mathrm{L}^{-1}$ & $4500 \mathrm{~B}$ & APHA (2005) \\
Ortofosfato & $\mu \mathrm{g} . \mathrm{L}^{-1}$ & $4500 \mathrm{E}$ & APHA (2005) \\
\hline
\end{tabular}

\subsubsection{Nutrientes Totais}

Para a análise de nutrientes totais (fósforo e nitrogênio amoniacal), as amostras, em réplicas, não foram filtradas, apenas congeladas para posterior determinação no laboratório Biotace - EESC - USP. As unidades e os métodos estão representados na Tabela 6. 
Tabela 6: Métodos de determinação dos nutrientes totais e nitrogênio amoniacal.

\begin{tabular}{cccc}
\hline Variáveis & Unidade & Método & Referência \\
\hline Nitrogênio Amoniacal & $\mathrm{mg} . \mathrm{L}^{-1}$ & $4500 \mathrm{NH}_{3} \mathrm{C}$ & APHA (2005) \\
Fósforo Total & $\mu \mathrm{g} . \mathrm{L}^{-1}$ & 4500B (item 5) & APHA (2005)
\end{tabular}

\subsubsection{Nitrogênio Total Kjeldahl}

Para a análise de Nitrogênio Total Kjeldahl $\left(\mathrm{mg} . \mathrm{L}^{-1}\right)$, réplicas das amostras coletadas não foram filtradas, apenas congeladas para posterior determinação no laboratório Biotace - EESC - USP de acordo com o método $4500 \mathrm{~N}_{\text {Org }} \mathrm{C}$, descrito em APHA (2005).

\subsubsection{Carbono Orgânico Total}

Para determinação do carbono orgânico total (COT), as amostras foram resfriadas para posteriormente serem transportadas e analisadas no laboratório Biotace - EESC - USP através de um analisador de carbono TOC Shimadzu SSM 5000 (APHA, 2005 - Método da Combustão - 5310B). 


\subsubsection{Compartimento sedimento}

5.4.2.1 Matéria Orgânica, Fósforo Total, Nitrogênio Total e Granulometria.

No compartimento sedimento foi determinada a porcentagem de matéria orgânica, as concentrações de nutrientes (nitrogênio total Kjeldahl e fósforo total) (Tabela 7) e a fração granulométrica. As amostras foram coletadas com o auxílio de uma draga de Van Veen e acondicionas em potes plásticos de $1 \mathrm{~kg}$ para análise de granulometria, e de $0,5 \mathrm{~kg}$ para análise de matéria orgânica e nutrientes.

Tabela 7: Métodos de determinação das variáveis do sedimento

\begin{tabular}{ccc}
\hline Variáveis & Unidade & Referência \\
\hline Matéria Orgânica & $\%$ & Wetzel e Likens (2001) \\
Nitrogênio Total Kjeldhal & $\mu \mathrm{g} \cdot \mathrm{g}^{-1}$ & APHA (2005) \\
Fósforo Total & $\mu \mathrm{g} \cdot \mathrm{g}^{-1}$ & Andersen (1976) \\
\hline
\end{tabular}

A granulometria foi determinada de acordo com metodologia descrita por Nogueira (2005). A determinação da curva granulométrica foi feita através de dois processos - peneiramento e sedimentação - denominado de granulometria conjunta. $\mathrm{O}$ primeiro peneiramento foi realizado com peneira de 2,00 mm. A partir do material que atravessou essa peneira foram retirados $120 \mathrm{~g}$ (para sedimentos arenosos) ou $70 \mathrm{~g}$ (para sedimentos argilosos) e estes foram levados a estufa a $105^{\circ} \mathrm{C}$ por 12 horas. Em seguida, foi acrescentado às amostras $125 \mathrm{~mL}$ de solução defloculante, deixando-as em repouso por mais 12 horas.

Para o processo de sedimentação, a amostra foi colocada em dispersor durante 10 minutos para armazenamento em proveta de $1 \mathrm{~L}$ (completando a amostra para $1 \mathrm{~L}$ com água destilada). Após agitação de 59 segundos, iniciou-se o registro das densidades nos tempos de 0,$5 ; 1 ; 2 ; 4 ; 8 ; 15 ; 30 ; 60$; 240 minutos e 24 horas.

A etapa seguinte foi realizada com a lavagem do material em peneira de $0,075 \mathrm{~mm}$ acondicionando-o em cadinhos de porcelana, mantidos em estufa a $100^{\circ} \mathrm{C}$ por 12 horas. Após secagem, o material foi submetido à sequiência de peneiras $(2,00 ; 0,600 ; 0,425 ; 0,300 ; 0,125 ; 0,075 \mathrm{~mm})$. Todos os dados foram inseridos em planilha Excel $^{\circledR}$ específica para a metodologia utilizada, a qual forneceu a fração granulométrica de cada amostra. 


\subsubsection{Comunidade Biológica}

\section{Comunidade de Macrófitas Aquáticas}

As amostragens de macrófitas aquáticas foram feitas em braços da represa onde a presença dessa comunidade era relevante. A caracterização da comunidade de macrófitas aquáticas foi realizada por meio da identificação das mesmas, ao menor nível taxonômico, por meio de consulta à literatura (KISSMANN e GOTH, 1997; POTT e POTT, 2000) e à especialistas.

\subsubsection{Biomassa}

A metodologia utilizada na coleta macrófitas aquáticas foi sugerida por Westlake (1965), sendo que para cada coleta das amostras foram escolhidos os bancos mais homogêneos, ou seja, aqueles com indivíduos de mesma espécie e aspecto fenológico semelhante.

Após a escolha dos bancos, foi utilizado como amostrador um quadrado de $0,25 \mathrm{~m}^{2}$ de área. Foram feitas três amostragens por banco, coletando-se todos os indivíduos que estavam dentro do quadrado. Em seguida, os organismos foram lavados com água do próprio local e acondicionados em sacos plásticos.

No laboratório de campo foi feita a limpeza das plantas para retirada do material aderido. Posteriormente, as plantas foram secas ao sol e depois em estufa a uma temperatura máxima de $60^{\circ} \mathrm{C}$, até atingir peso constante. Em seguida, o material foi pesado, determinando-se, assim, o seu peso seco. Para a obtenção da biomassa em peso seco por metro quadrado (gPS.m ${ }^{-2}$ ) foi calculada a média dos pesos obtidos, o qual foi multiplicado por quatro. A biomassa de peso seco foi transformada em biomassa de carbono conforme descrito em Wetzel e Likens (2001), onde se considera que 0,47 do peso seco remanescente livre de cinzas são carbono.

\subsubsection{Ensaios de Decomposição}

Foram realizados ensaios de decomposição in situ e em escala de laboratório para comparação das taxas de decomposição das macrófitas aquáticas em seu ambiente natural e sob condições controladas (Figura 8). O modelo cinético de decaimento de massa, proposto por Bianchini Jr. e CunhaSantino (2011), foi utilizado para analisar os resultados. De acordo com os autores, o modelo de duplo 
decaimento considera o detrito como um recurso heterogêneo e a decomposição da biomassa se dá pela soma de diferentes funções exponenciais. Primeiramente, o modelo pressupõe que os compostos lábeis são oxidados rapidamente. Em seguida, considera-se que os processos de lixiviação e catabolismo ocorram simultaneamente na produção e mineralização da matéria orgânica dissolvida (MOD). Finalmente, a terceira rota admite a oxidação da fração refratária, que é responsável pela perda de massa. As equações de 1 a 4 descrevem o processo (BIANCHINI Jr. e CUNHA-SANTINO, 2011).

Perda de massa da fração particulada:

$\frac{\mathbf{d C}_{\mathrm{MOP}}}{\mathbf{d t}}=-\mathbf{k}_{\mathrm{T}} \mathbf{C}_{\mathrm{MOPLS}}-\mathbf{k}_{\mathbf{4}} \mathbf{C}_{\mathrm{MOR}} \quad$ Equação 1

em que:

MOP: Matéria Orgânica Particulada (\%);

$\mathrm{C}_{\text {MOPLs: }}$ Mudança, por unidade de tempo, da quantidade de MOP (fração lábil-solúvel);

$\mathrm{C}_{\mathrm{MOR}}$ : Mudança, por unidade de tempo, da quantidade de MOR (fração refratária);

$\mathrm{k}_{\mathrm{T}}$ : coeficiente de perda global de massa ( dia $^{-1}$ ) (lixiviação e oxidação da $\mathrm{C}_{\mathrm{MOPLS}}$ );

$\mathrm{k}_{4}$ : coeficiente de mineralização da matéria refratária $\left(\mathrm{dia}^{-1}\right)$.

Mineralização da MOD:

$\frac{\mathbf{d C}_{\text {MOD }}}{\mathbf{d t}}=\frac{\mathbf{k}_{\mathbf{1}}}{\mathrm{kT}} \mathrm{C}_{\text {MOPLS }}-\mathbf{k}_{\mathbf{3}} \mathrm{C}_{\text {MOD }} \quad$ Equação 2

em que:

$\mathrm{C}_{\mathrm{MOD}}$ : Mudança, por unidade de tempo, da concentração de MOD;

$\mathrm{k}_{1}$ : coeficiente de lixiviação $\left(\operatorname{dia}^{-1}\right)$;

$\mathrm{k}_{1} / \mathrm{k}_{\mathrm{T}}$ : coeficiente que define o rendimento da lixiviação frente à perda de massa de $\mathrm{C}_{\mathrm{MOPLS}}$;

$\mathrm{k}_{3}$ : coeficiente de mineralização da $\operatorname{MOD}\left(\operatorname{dia}^{-1}\right)$.

Meia vida do detrito (correspondendo a diferentes coeficientes do processo):

$\boldsymbol{t}_{\mathbf{1} / \mathbf{2}}=\frac{\ln \mathbf{0 , 5}}{-\boldsymbol{k}} \quad$ Equação 3

$\mathrm{O}$ coeficiente $\mathrm{Q}_{10}$, que indica a mudança da taxa metabólica com o incremento de $10^{\circ} \mathrm{C}$, é calculado segundo a Equação 4: 
$\mathbf{Q}_{\mathbf{1 0}}=\frac{\mathbf{k}_{\mathbf{t} 1}}{\mathbf{k}_{\mathbf{t} 2}} \quad$ Equação 4

em que:

$\mathrm{k}_{\mathrm{t} 1}$ : coeficiente de decaimento na temperatura $1\left(\mathrm{t}+10^{\circ} \mathrm{C}\right)$;

$\mathrm{k}_{\mathrm{t} 2}$ : coeficiente de decaimento na temperatura 2.

\section{Ensaios de Decomposição in situ.}

Foi realizada a amostragem da espécie de macrófita aquática predominante nos braços $\mathrm{Br}_{3}$ e $\mathrm{Br}_{4}$, (Polygonum lapathifolium e Eichhornia azurea, respectivamente) em agosto de 2009, e a metodologia de decomposição in situ nesses locais seguiu a proposta de Campos Jr. (1998). As plantas coletadas foram lavadas e colocadas em litter bags de nylon (tamanho de malha $=0,4 \mathrm{~mm}$ ), os quais foram fixados na sub-superfície da água (aproximadamente $10 \mathrm{~cm}$ ) através de um lastro ligado a uma corda. Em cada litter bag foram colocadas $15 \mathrm{~g}$ de plantas previamente secas $\left(60^{\circ} \mathrm{C}\right.$ até peso constante) e cortadas manualmente em porções de aproximadamente $1 \mathrm{~cm}$.

As amostragens dos litter bags foram feitas com 1, 3, 5, 10, 15, 30, 60, 90 e 120 dias de incubação (período de 9 de agosto a 7 de dezembro de 2009), sendo que para cada dia de amostragem foram retirados da água 3 litter bags. Os litter bags foram cuidadosamente lavados com água da torneira para remoção do material aderido e o conteúdo remanescente foi primeiramente seco ao sol e, em seguida, em estufa até peso constante $\left(60^{\circ} \mathrm{C}\right)$. O peso final foi comparado com o valor inicial da massa de planta colocada para decompor.

Paralelamente, em cada dia de amostragem, foram realizadas medidas de temperatura da água, condutividade elétrica, oxigênio dissolvido, transparência do disco de Secchi e profundidade do reservatório no compartimento de macrófitas.

\section{Ensaios de Decomposição em laboratório - Experimento de Decomposição Aeróbia}

Os ensaios de decomposição consistiram em analisar o decaimento de massa (decomposição aeróbia) de $P$. lapathifolium e $E$. azurea, em diferentes temperaturas $\left(15^{\circ} \mathrm{C}\right.$ - simulação de inverno e $25^{\circ} \mathrm{C}$ - simulação de verão). Para isso, foram montadas câmaras de mineralização $(n=33)$ contendo 0,5 gPS da planta moída em $50 \mathrm{~mL}$ de água do reservatório. A água foi coletada com o auxílio de uma garrafa de Van Dorn em 3 profundidades (superfície, meio e fundo) com o intuito de selecionar a comunidade bacteriana de toda a coluna de água. Posteriormente, a água foi filtrada em membrana de éster de celulose $(0,45 \mu \mathrm{m})$ para em seguida montarem-se as câmaras. 
Para cada dia amostral $(0,1,3,5,10,15,20,30,60,90$ e 120) houve o fracionamento da Matéria Orgânica Particulada (MOP) e da Matéria Orgânica Dissolvida (MOD) através da filtragem do conteúdo das câmaras (tréplicas) em membrana AP20 $\left(\right.$ Boeco $\left.^{\circledR}\right)$ previamente calcinadas e pesadas. O filtro contendo a MOP foi seco em estufa a $40^{\circ} \mathrm{C}$ por 24 horas e pesado. O conteúdo de matéria orgânica e inorgânica foi determinado por meio da incineração dos filtros secos com a $\mathrm{MOP}\left(550^{\circ} \mathrm{C}-\right.$ 2h). Diariamente, monitorou-se o pH das câmaras, bem como a condutividade elétrica e o oxigênio dissolvido. As câmaras de mineralização tiveram borbulhamento de ar comprimido quando a concentração de oxigênio estava inferior a $2 \mathrm{mg} \cdot \mathrm{L}^{-1}$.

\subsubsection{Tratamento dos dados}

Para verificar a variação sazonal e espacial das varáveis físicas e químicas da água e do sedimento, a variação sazonal da biomassa de macrófitas aquáticas e a diferença entre os tratamentos aplicados ao processo de decomposição, utilizou-se o teste MANOVA através do software STATISTICA $10^{\circledR}$. Foi aplicado um teste de correlação de Spearman (STATISTICA 10 ${ }^{\circledR}$ ) para verificar a relação entre as variáveis limnológicas, biológicas e hidrológicas. A relação entre as variáveis da água e do sedimento com a biomassa de macrófitas foi obtida através de uma análise de CCA realizada com o software CANOCO $4.5^{\circledR}$. 

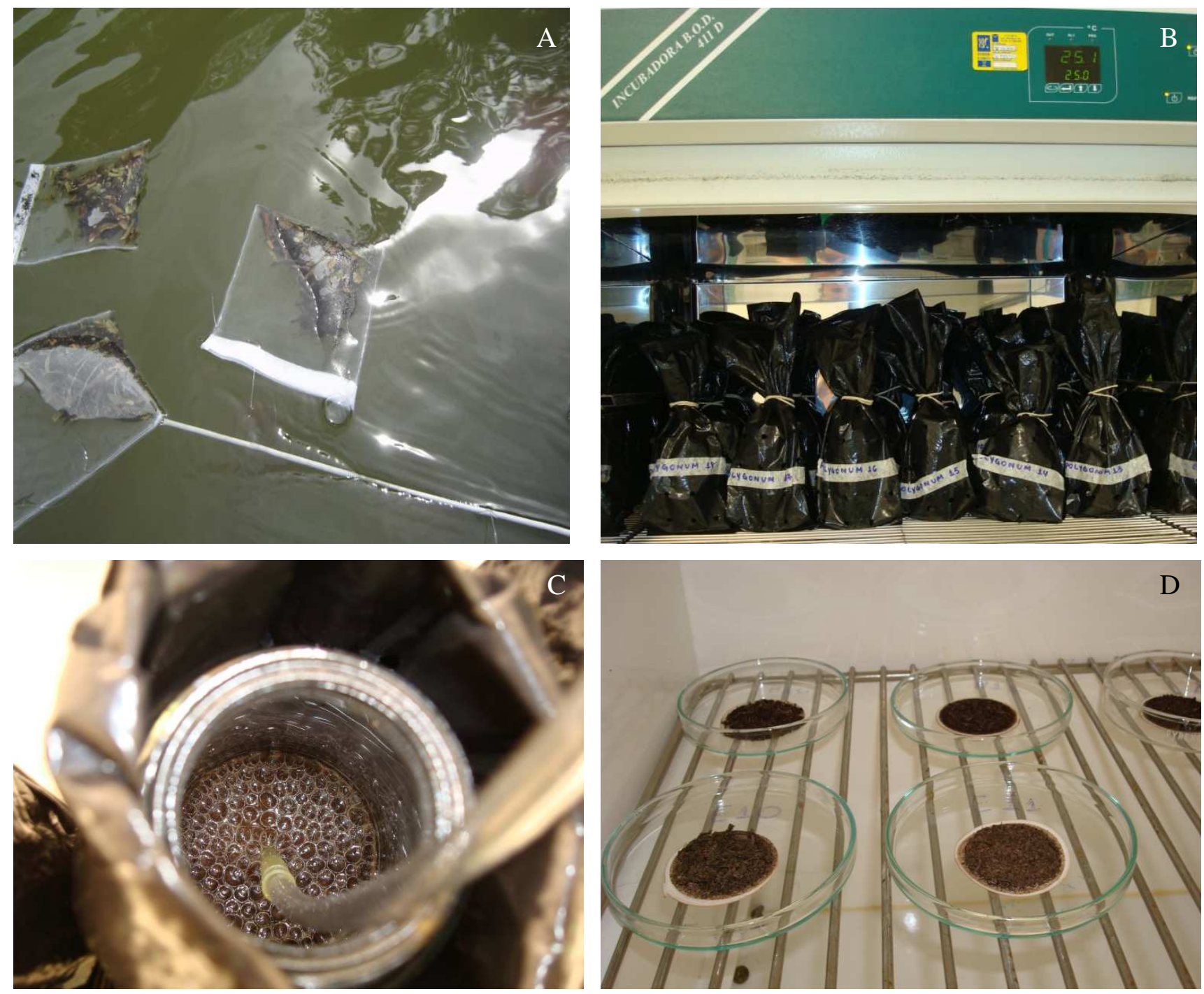

Figura 8: Incubação dos litter bags (A) e câmaras de decomposição na incubadora (B), aeração (C) e filtros com MOP (D).

\subsection{Dados hidrológicos}

Os dados hidrológicos foram obtidos com a operadora da barragem (Votorantim Energia). Na Figura 9 encontram-se os dados de precipitação pluviométrica mensal do período de agosto de 2009 a abril de 2010. O período de novembro/2009 a janeiro/2010, que compreende o verão, foi o mais chuvoso, com máxima de $504 \mathrm{~mm}$ em janeiro. Dentre os períodos amostrados, a menor precipitação ocorreu em agosto/2009 (57 mm), seguido por abril/2010 (79 mm). A maior precipitação ocorreu em outubro/2009 (135 mm).

São apresentados, na Figura 10, os dados diários de precipitação pluviométrica $(\mathrm{mm})$ com sete dias de antecedência ao dia de cada amostragem. Foi possível verificar que no inverno não houve 
registro de chuva nos dias que antecederam a coleta, porém, na primavera, observou-se aproximadamente $39 \mathrm{~mm}$ de precipitação dois dias antes da amostragem, $6 \mathrm{~mm}$ no dia anterior e 7,5 $\mathrm{mm}$ no dia da coleta. No verão houve aproximadamente $17 \mathrm{~mm}$ de chuva quatro dias antes da data amostral e no outono $15 \mathrm{~mm}$ com três dias de antecedência.

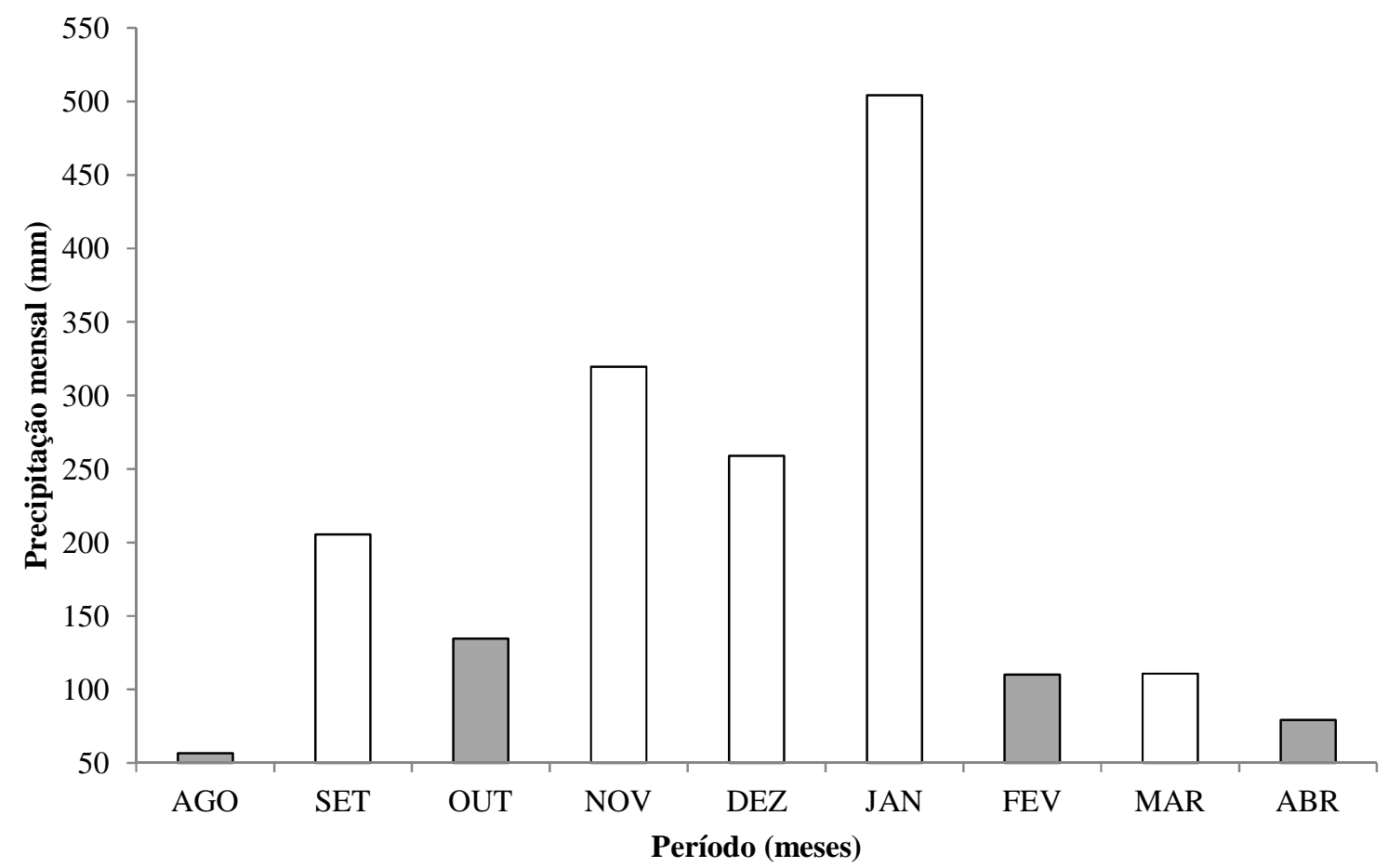

Figura 9: Precipitação pluviométrica mensal (mm) no período de agosto de 2009 a abril de 2010, com destaque para os meses em que ocorreram amostragens. 


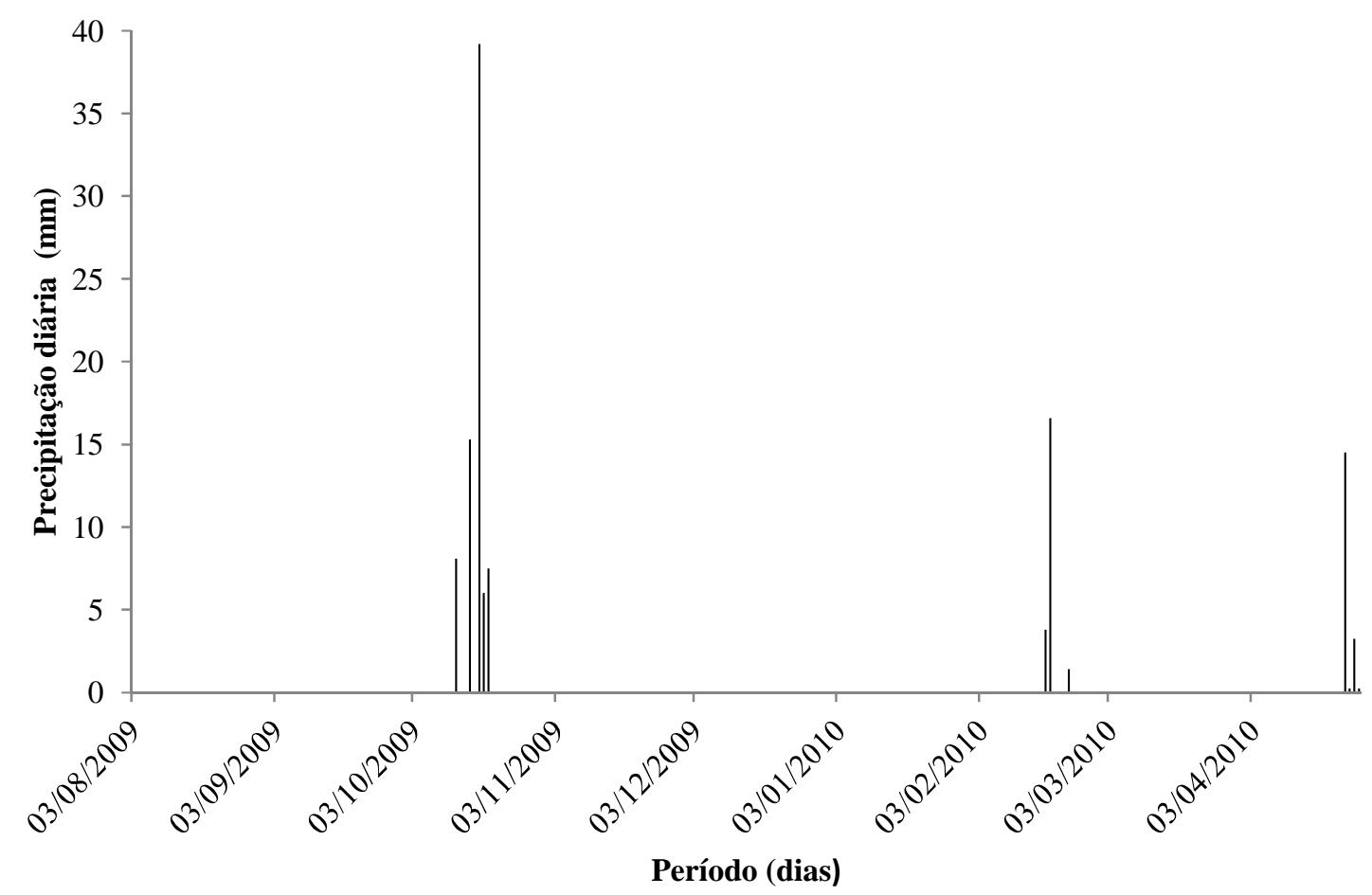

Figura 10: Precipitação pluviométrica diária $(\mathrm{mm})$ com sete dias de antecedência das amostragens.

A vazão turbinada e a vazão afluente ao reservatório Itupararanga estão apresentadas na Figura 11. Pode-se dizer que a média da vazão turbinada, no período de amostragem, variou entre 14 e 16 $\mathrm{m}^{3} . \mathrm{s}^{-1}$, porém foi possível observar picos de até $30 \mathrm{~m}^{3} . \mathrm{s}^{-1}$ em períodos de elevada cota média do reservatório (Figura 12). Entretanto, sete dias antes dos dias de amostragem, a vazão turbinada não foi elevada, mantendo média de aproximadamente $16 \mathrm{~m}^{3} . \mathrm{s}^{-1}$.Como era de se esperar, a vazão afluente seguiu o padrão da precipitação, com picos de novembro/2009 a janeiro/2010. Nos dias antecedentes à coleta não foram registrados valores extremos.

Em relação à cota média, observaram-se maiores valores no período de janeiro até meados de abril/2010 (valor máximo de 825,4 m). Nos sete dias que antecederam as amostragens obteve-se menor média em outubro/2009 (aproximadamente 822,5 m), enquanto que o maior valor médio foi registrado em fevereiro/2010 (825 m). A partir dos dados de vazão e volume útil do reservatório foi possível calcular o tempo de detenção hidráulica nas épocas de amostragem: 190, 168, 101 e 123 dias em agosto, outubro, fevereiro e abril, respectivamente. 


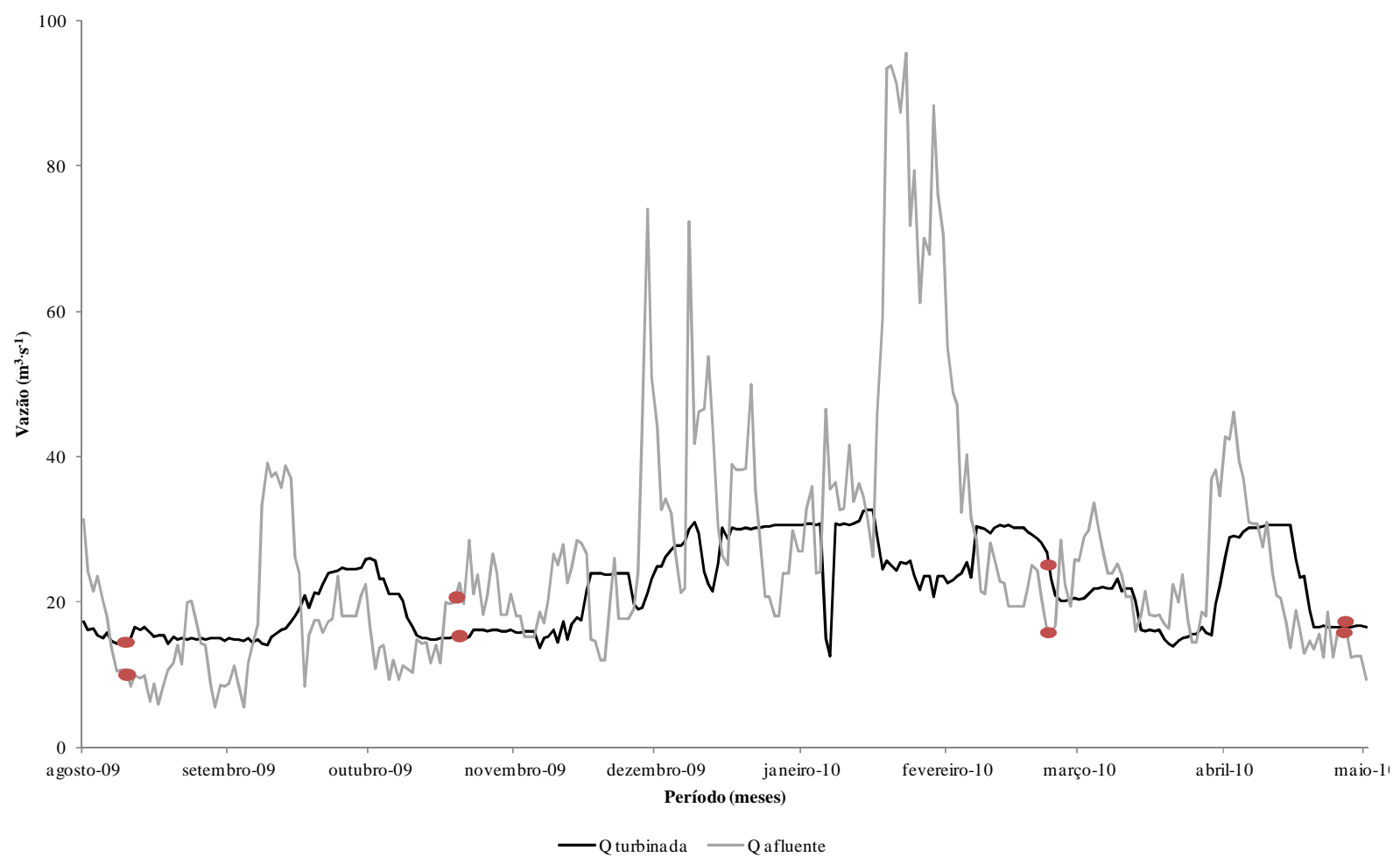

Figura 11: Vazão turbinada para geração de energia $\left(\mathrm{m}^{3} \cdot \mathrm{s}^{-1}\right)$ e vazão afluente ao reservatório Itupararanga $\left(\mathrm{m}^{3} \cdot \mathrm{s}^{-1}\right)$ no período de agosto de 2009 a abril de 2010, com indicação para as datas de amostragem.

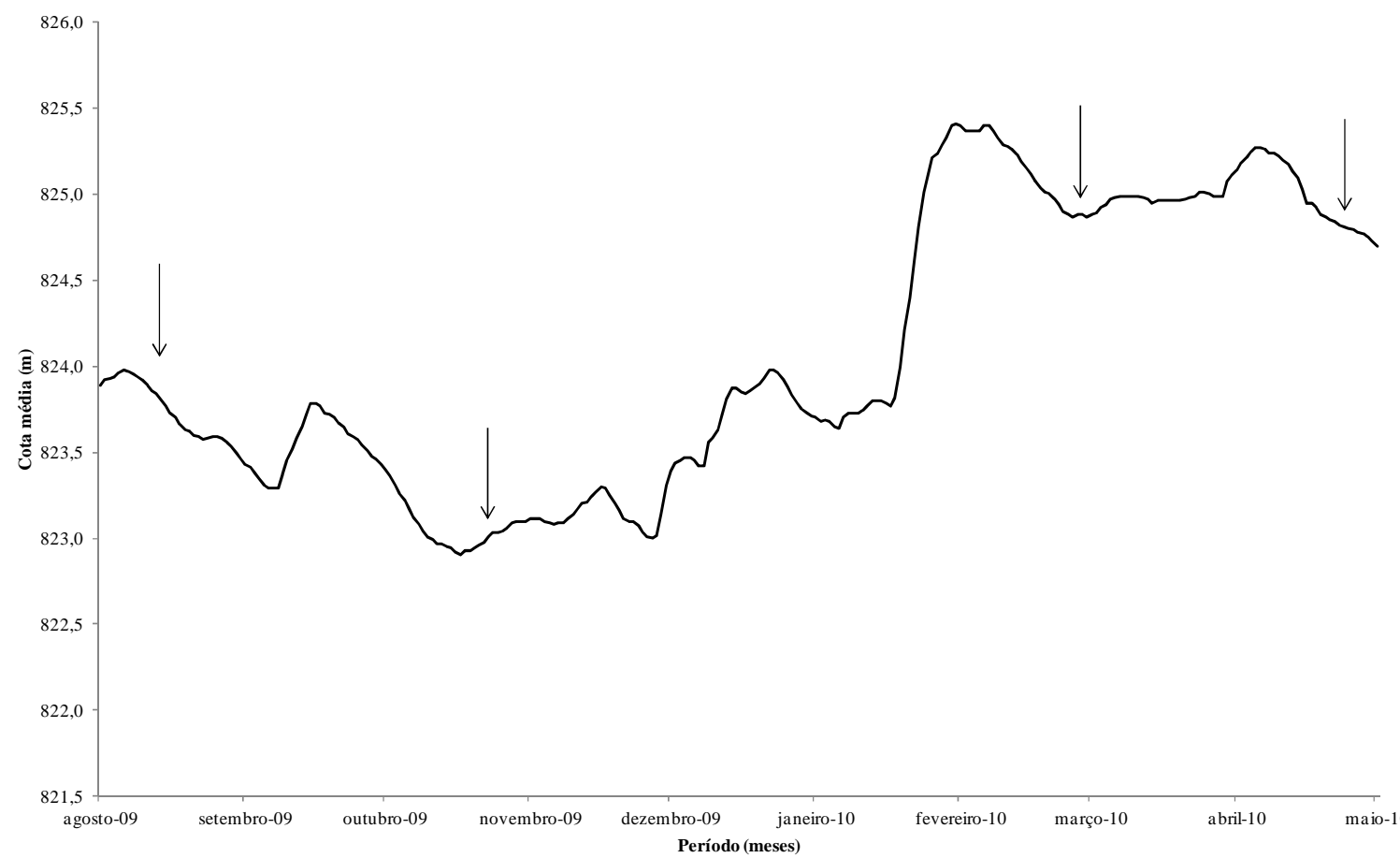

Figura 12: Cota média (m) do reservatório Itupararanga no período de agosto de 2009 a abril de 2010. As setas indicam as datas em que as amostragens foram realizadas. 
Na Tabela 8 são apresentados os valores de radiação solar fotossinteticamente ativa (RFSA) incidente nas diferentes estações de amostragem. Os resultados demonstraram que os maiores valores de RSFA incidente ocorreram no outono para todas as estações de amostragem, exceto para $\mathrm{Br}_{3}$. Esse fato pode estar relacionado com o horário da amostragem feita na referida estação de coleta nesse período. Os menores valores foram registrados na primavera em todas as estações de coleta devido às condições climáticas no dia da amostragem (dia nublado e com pancadas de chuva).

Tabela 8: Horário das amostragens (h) e radiação solar fotossinteticamente ativa (RSFA) incidente $\left(\mu \mathrm{E} \cdot \mathrm{m}^{-2} . \mathrm{s}^{-1}\right)$ nas diferentes estações amostrais (EA) do reservatório Itupararanga nos períodos amostrados.

\begin{tabular}{ccccccccc}
\hline Período & \multicolumn{2}{c}{ agosto/09 } & \multicolumn{2}{c}{ outubro/09 } & \multicolumn{2}{c}{ fevereiro/10 } & \multicolumn{2}{c}{ abril/10 } \\
\hline EA & Horário & RSFA & Horário & RSFA & Horário & RSFA & Horário & RSFA \\
$\mathrm{Br}_{1}$ & $13: 15$ & 246 & $9: 40$ & 95 & $9: 40$ & 1.945 & $10: 40$ & 2.703 \\
$\mathrm{Br}_{2}$ & $14: 45$ & 160 & $10: 40$ & 45 & $10: 30$ & 2.388 & $12: 00$ & 3.577 \\
$\mathrm{Br}_{3}$ & $9: 00$ & 245 & $13: 15$ & 202 & $11: 40$ & 2.244 & $7: 30$ & 1.754 \\
$\mathrm{Br}_{4}$ & $10: 20$ & 162 & $12: 00$ & 50 & $13: 00$ & 1.720 & $8: 50$ & 2.171 \\
\hline
\end{tabular}




\section{RESULTADOS E DISCUSSÃO}

\subsection{Características limnológicas e biomassa de macrófitas aquáticas do reservatório Itupararanga}

\subsubsection{Compartimento água}

Um reservatório pode ser caracterizado como um lago dinâmico, no qual significante parte de seu volume assemelha-se a um rio, inclusive no que diz respeito às funções biológicas (THORNTON, 1990). A zona litorânea desses ecossistemas é intensamente afetada pelos processos que ocorrem tanto na zona pelágica como na área de entorno e, portanto, pode ser considerada como ecótono. Essas áreas possuem grande importância nos estudos sobre caracterização limnológica, bem como sobre comunidades biológicas. Sabe-se ainda, que a região litorânea apresenta alta produtividade e, por possuir baixa profundidade, está mais susceptível às variações climáticas diárias. Sendo assim, a temperatura da água, por exemplo, pode variar em toda a coluna de água em apenas algumas horas, fato que interfere na dissolução dos gases, como oxigênio dissolvido e, consequentemente, na dinâmica de nutrientes.

Os perfis de temperatura da água das quatro estações de amostragem no reservatório Itupararanga estão apresentados na Figura 13. A temperatura da água foi mais elevada no verão em todas as estações de amostragem (média: $27,0^{\circ} \mathrm{C} \pm 1,0$ na estação $\mathrm{Br}_{1} ; 28,3^{\circ} \mathrm{C} \pm 1,0$ na estação $\mathrm{Br}_{2} ; 29,0^{\circ} \mathrm{C} \pm 1,0$ na estação $\mathrm{Br}_{3} ; 28,0^{\circ} \mathrm{C} \pm 1,0$ na estação $\left.\mathrm{Br}_{4}\right)$. No inverno verificaram-se as menores médias em todas as estações de coleta $\left(\mathrm{Br}_{1}: 19,0^{\circ} \mathrm{C} \pm 0,4 ; \mathrm{Br}_{2}: 20,0^{\circ} \mathrm{C} \pm 0,3 ; \mathrm{Br}_{3}: 20,0^{\circ} \mathrm{C} \pm 0,1 ; \mathrm{Br}_{4} ; 19,0^{\circ} \mathrm{C} \pm 0,1\right)$. Valores similares foram obtidos por Pedrazzi (2009) em seu estudo realizado no reservatório Itupararanga, caracterizando uma dinâmica temporal. No inverno e na primavera, os perfis de temperatura estavam praticamente homogêneos em todos os braços, exceto na estação de coleta $\mathrm{Br}_{4}$, que apresentou micro estratificação no fundo. Elçi (2008) verificou o mesmo padrão no reservatório Tahtali, na Turquia, com perfil homogêneo de temperatura em meses mais frios, influenciando a solubilidade do oxigênio e, consequentemente, a distribuição das comunidades biológicas.

Nas estações de amostragem $\mathrm{Br}_{3}$ e $\mathrm{Br}_{4}$ ocorreu estratificação térmica no verão. Embora, ambientes mais rasos, como braços de reservatórios, estejam menos propensos a sofrer estratificações térmicas, pequenas variações na temperatura em determinados períodos do dia podem causar alterações no perfil de temperatura nesses compartimentos (GIKAS et al. 2009). Além disso, Henry (1995) mecionou que o clima quente e úmido do Brasil favorece a estratificação térmica de ecossistemas aquáticos. Sob esse aspecto, Soares et al. (2008), relataram a ocorrência de estratificação térmica nos 
meses mais quentes nos reservatórios do Funil e Lajes, ambos localizados no Rio de Janeiro. De modo contrário, Mariani et al. (2006) e Padovesi-Fonseca, Philomeno e Andreoni-Batista (2009) mencionaram a ocorrência de coluna de água homogênea nos reservatórios Riacho Grande - SP e Paranoá (Brasília), respectivamente. Os autores atribuíram esse resultado à perda de calor da água devido à intensidade dos ventos na região. Não há dados de velocidade do vento disponíveis para a área do reservatório Itupararanga, entretanto, pode-se dizer que esses não foram fortes o suficiente para promover a mistura da coluna de água em um ambiente raso, como no caso dos braços.
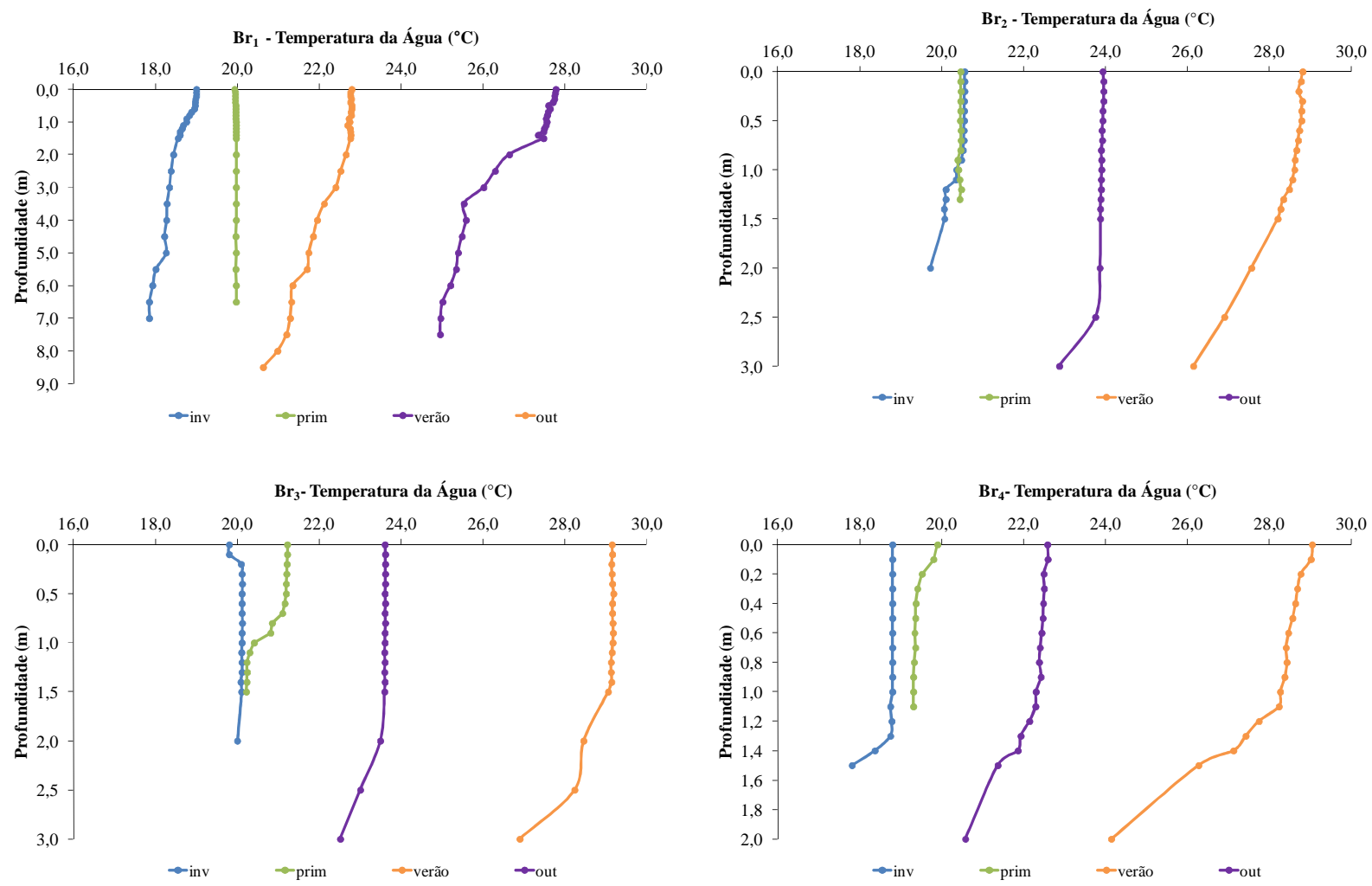

Figura 13: Perfis de temperatura da água $\left({ }^{\circ} \mathrm{C}\right)$ das estações de amostragem $\mathrm{Br}_{1}, \mathrm{Br}_{2}, \mathrm{Br}_{3}$ e $\mathrm{Br}_{4}$ nos diferentes períodos do ano.

A variação da concentração de oxigênio dissolvido é um reflexo dos processos físicos, químicos e biológicos que ocorrem num corpo de água e, portanto, pode ser considerada uma das variáveis limnológicas que melhor reflete as alterações em um ecossistema aquático (MARIANI et al. 2006).

As concentrações de OD foram, de modo geral, elevadas em todas as estações de amostragem (Figura 14) e houve uma tendência de diminuição destas ao longo da coluna de água. Altas concentrações de OD também foram encontradas por Pedrazzi (2009) no reservatório Itupararanga. De 
acordo com Soares et al. (2008) altos terores de OD em toda a coluna de água pode estar relacionada com a vazão de diversos afluentes que adentram o reservatório.

$\mathrm{Na}$ estação de amostragem $\mathrm{Br}_{1}$, as menores concentrações ocorreram na primavera, oscilando entre 2,15 mg. $\mathrm{L}^{-1}$ e 1,6 mg. $\mathrm{L}^{-1}$. Esse resultado pode estar relacionado à entrada de esgoto através dos rios formadores do reservatório, pois no momento da amostragem foi constatado fortes odores, característicos de efluentes domésticos. Micro-estratificações químicas foram observadas no inverno e no verão na estação $\mathrm{Br}_{1}$. Em relação à estação de coleta $\mathrm{Br}_{2}$, verificou-se que a média máxima ocorreu no inverno $\left(8,0 \pm 1,0 \mathrm{mg} . \mathrm{L}^{-1}\right)$, enquanto que a menor foi registrada na primavera $\left(6,3 \pm 0,25 \mathrm{mg} . \mathrm{L}^{-1}\right)$. No córrego afluente à estação $\mathrm{Br}_{2}$, concentrações de até $6,7 \mathrm{mg} . \mathrm{L}^{-1}$ foram registradas por Salles et al. (2008), no período chuvoso. Micro-estratificações químicas foram observadas no verão e no outono. O perfil de OD permaneceu praticamente homogêneo na estação de coleta $\mathrm{Br}_{3}$ no inverno, com concentrações elevadas da superfície ao fundo (de 9,65 a $8,5 \mathrm{mg} \cdot \mathrm{L}^{-1}$ ). No outono, as concentrações decaíram a partir de $1,0 \mathrm{~m}$ e a média foi $6,5 \mathrm{mg} . \mathrm{L}^{-1} \pm 1,0$. No verão, o teor de OD estava elevado $(7,7$ $\mathrm{mg} . \mathrm{L}^{-1}$ a $\left.2,5 \mathrm{~m}\right)$, enquanto, no outono, houve um pequeno decréscimo dessas concentrações. Ainda em relação à estação $\mathrm{Br}_{3}$, verificou-se que as maiores concentrações ocorreram nesse local e foram registradas no inverno com média máxima de $9,0 \mathrm{mg} \cdot \mathrm{L}^{-1} \pm 0,35$. Salles et al. (2008) observaram elevada concentração de OD (7,8 mg. $\left.\mathrm{L}^{-1}\right)$ no Córrego da Ressaca, afluente da estação de coleta $\mathrm{Br}_{3}$.

As menores concentrações de OD foram obtidas na estação amostral $\mathrm{Br}_{4}$, fato que pode ter sido favorecido pela baixa profundidade (profundidade máxima de $2 \mathrm{~m}$ ) e pela entrada de efluente da estação de tratamento de esgoto. No Córrego do Paruru, afluente da estação $\mathrm{Br}_{4}$, também foram encontrados baixos teores de OD (4,0 mg.L $\left.\mathrm{L}^{-1}\right)$ (SALLES et al. 2008). A menor concentração média foi observada na primavera $\left(3,5 \pm 0,35 \mathrm{mg} . \mathrm{L}^{-1}\right)$ e a máxima no verão $\left(6,0 \mathrm{mg} . \mathrm{L}^{-1} \pm 1,5\right)$. Microestratificações químicas ocorreram no outono e no inverno.

Verificou-se que a concentração de OD foi menor na primavera em todas as estações amostrais. A precipitação pluviométrica do mês de outubro pode estar relacionada a esse resultado, uma vez que a matéria orgânica, oriunda do escoamento superficial, intensifica os processos biológicos e pode aumentar o consumo de oxigênio. O resultado da análise de correlação indicou a influência da precipitação pluviométrica sobre as baixas concentrações de OD $(\rho=-0,7 ; \rho=-0,94 ; \rho=-0,94$ para $\mathrm{Br}_{1}, \mathrm{Br}_{2}$ e $\mathrm{Br}_{3}$, respectivamente). De acordo com Soares et al. (2008), em ecossistemas aquáticos, localizados em latitudes tropicais e subtropicais, variações temporais das características limnológicas são induzidas pelo padrão sazonal de precipitação. Pode-se inferir ainda, que os córregos afluentes aos braços selecionados influenciaram a concentração de OD nesses compartimentos. Salles et al. (2008) verificaram a ocorrência de despejos de esgoto doméstico e deposição de resíduos sólidos no leito ou 
nas margens dos rios em bairros com alta densidade populacional, os quais cresceram desordenadamente e sem serviços municipais adequados. Segundo os autores, os impactos verificados nesses rios podem ser classificados de moderado a alto, o que pode comprometer a qualidade da água do reservatório Itupararanga, de um modo geral e causar a depleção do oxigênio dissolvido em determinados períodos do ano.
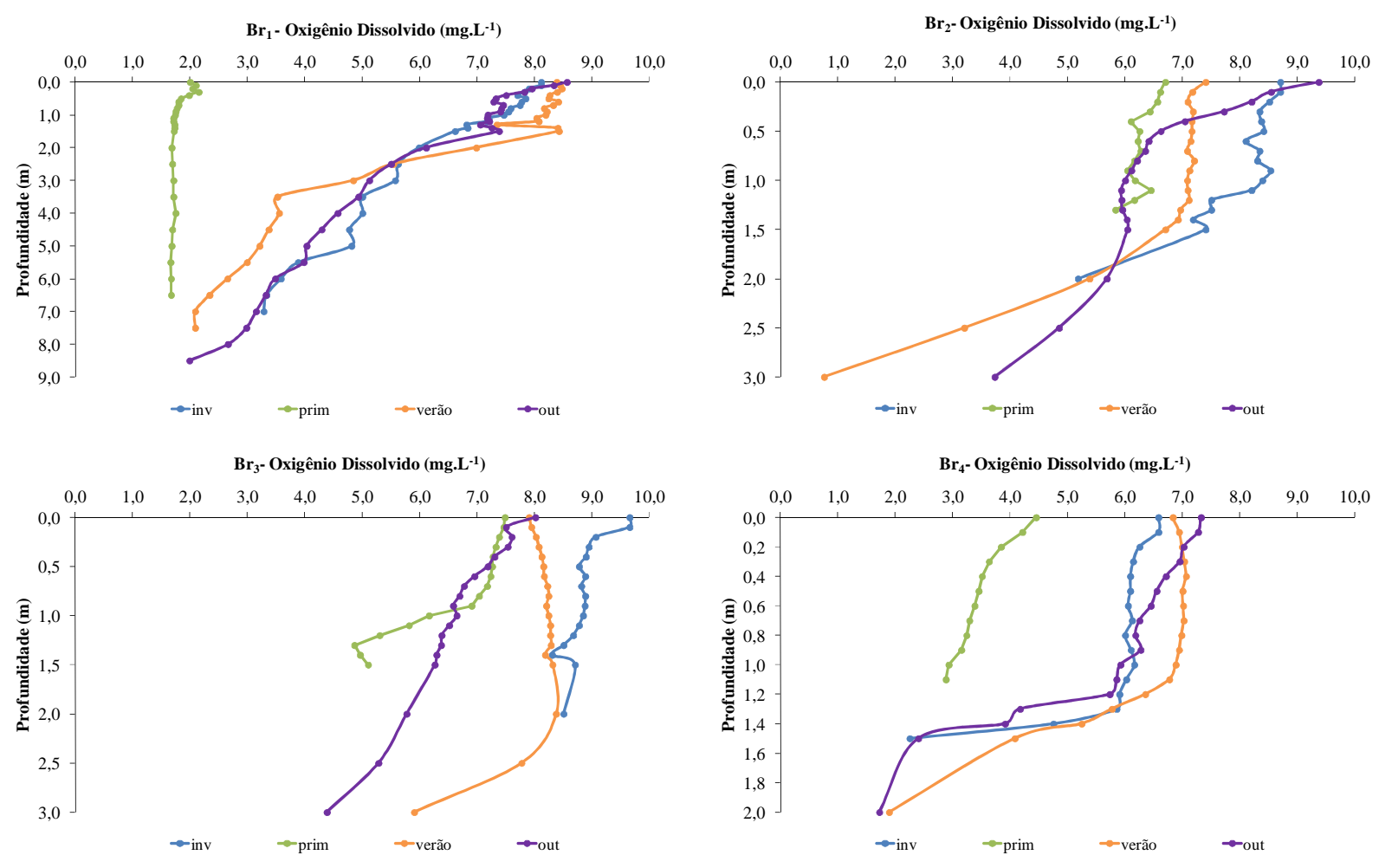

Figura 14: Perfis de oxigênio dissolvido $\left(\mathrm{mg} . \mathrm{L}^{-1}\right.$ ) das estações de amostragem $\mathrm{Br}_{1}, \mathrm{Br}_{2}, \mathrm{Br}_{3}$ e $\mathrm{Br}_{4}$ nos diferentes períodos do ano.

Houve grande variação vertical da condutividade elétrica em todas as estações de amostragem e em todos os períodos estudados (Tabela 9). Apenas no outono observou-se coluna de água mais homogênea para essa variável. Nesse período foram encontradas, ainda, os menores valores médios de condutividades na estação de amostragem $\mathrm{Br}_{1}\left(56 \mu \mathrm{S} . \mathrm{cm}^{-1}\right)$, sendo que os maiores valores ocorreram no verão $\left(81 \mu \mathrm{S} . \mathrm{cm}^{-1}\right)$. Ainda na estação amostral $\mathrm{Br}_{1}$ foi possível verificar um pico de $220 \mu \mathrm{S} . \mathrm{cm}^{-1}$ a 0,8 m. Obteve-se, na estação de coleta $\mathrm{Br}_{2}$, maior condutividade média na primavera $\left(68 \pm 28 \mu \mathrm{S} . \mathrm{cm}^{-1}\right)$ e a menor no outono $\left(53 \pm 0,75 \mu \mathrm{S} . \mathrm{cm}^{-1}\right)$. Um pico de $150 \mu \mathrm{S} . \mathrm{cm}^{-1}$ foi registrado na superfície de $\mathrm{Br}_{2}$ na primavera. $\mathrm{Na}$ estação $\mathrm{Br}_{3}$, valores médios semelhantes foram obtidos no inverno e no outono (56 \pm $\left.0,70 \mu \mathrm{S} . \mathrm{cm}^{-1}\right)$ e a máxima condutividade média ocorreu na primavera $\left(62 \pm 9,0 \mu \mathrm{S} . \mathrm{cm}^{-1}\right)$. O perfil 
vertical de condutividade elétrica apresentou-se homogêneo no verão e no outono na estação de coleta

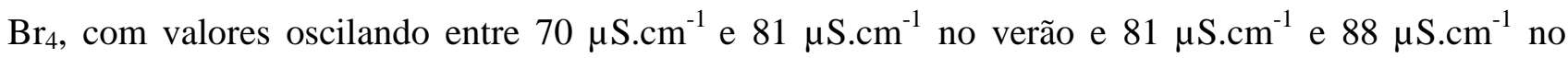
outono. A média mínima ocorreu no verão $\left(76 \pm 3,3 \mu \mathrm{S} . \mathrm{cm}^{-1}\right)$ e a máxima no outono $\left(82 \pm 2,0 \mu \mathrm{S} . \mathrm{cm}^{-1}\right)$.

No outono, período caracterizado por baixas pluviosidade e vazão, pode ter havido menor mistura da coluna de água e, portanto, menor oscilação vertical da condutividade. Entretanto, a alta precipitação registrada, tanto na primavera (nos dias de amostragem - outubro de 2009) como no verão (janeiro de 2010), pode ter aportado compostos químicos para o reservatório e revolvido o sedimento, contribuindo para o aumento da condutividade elétrica. Pedrazzi (2009) não observou diferença entre os valores de condutividade obtidos nas estações seca e chuvosa no reservatório Itupararanga, os quais variaram entre 60 e $70 \mu \mathrm{S} . \mathrm{cm}^{-1}$. Entretanto, o presente estudo confirmou, através da análise de correlação, a influência da precipitação pluviométrica sobre a condutividade nas estações de amostragem $\mathrm{Br}_{1}, \mathrm{Br}_{3}$ e $\mathrm{Br}_{4}(\rho=0,8 ; \rho=0,8 ; \rho=0,7$, respectivamente).

Nos rios, afluentes às estações de amostragem, os valores obtidos por Pedrazzi (2009), foram semelhantes aos obtidos nas estações de coleta do presente estudo, exceto para o Córrego do Paruru,

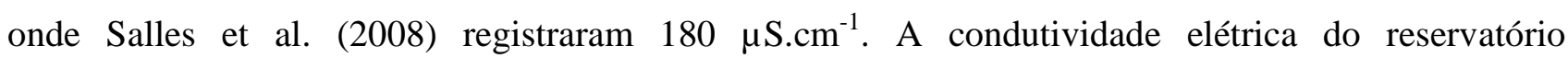
Itupararanga foi inferior aos valores registrados por Calijuri et al. (1999) no reservatório Salto Grande $\left(159 \mu \mathrm{S} . \mathrm{cm}^{-1}\right)$, por Bicudo et al. (2002) no reservatório das Garças-SP $\left(172 \mu \mathrm{S} . \mathrm{cm}^{-1}\right)$, por Mariani et al. (2006) no reservatório Riacho Grande-SP $\left(181,5 \mu \mathrm{S} . \mathrm{cm}^{-1}\right)$, e aos encontrados por Padovesi-Fonseca,

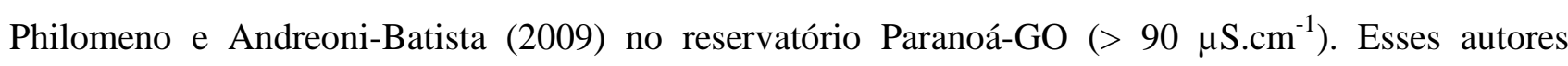
citaram que a alta condutividade observada estava diretamente relacionada ao processo de eutrofização dos respectivos corpos de água.. 
Tabela 9: Condutividade Elétrica $\left(\mu \mathrm{S} . \mathrm{cm}^{-1}\right.$ ) estações de amostragem $\mathrm{Br}_{1}, \mathrm{Br}_{2}, \mathrm{Br}_{3}$ e $\mathrm{Br}_{4}$ nos diferentes períodos do ano.

I: Inverno; P: Primavera; V: Verão; O; Outono.

\begin{tabular}{|c|c|c|c|c|c|c|c|c|c|c|c|c|c|c|c|c|}
\hline \multirow{2}{*}{$\begin{array}{c}\text { Prof. } \\
\text { (m) }\end{array}$} & \multicolumn{4}{|c|}{$\mathbf{B r}_{1}$} & \multicolumn{4}{|c|}{$\mathrm{Br}_{2}$} & \multicolumn{4}{|c|}{$\mathrm{Br}_{3}$} & \multicolumn{4}{|c|}{$\mathrm{Br}_{4}$} \\
\hline & I & $\mathrm{P}$ & $\mathrm{V}$ & $\mathrm{O}$ & I & $\mathrm{P}$ & $\mathrm{V}$ & $\mathrm{O}$ & I & $\mathrm{P}$ & $\mathrm{V}$ & $\mathrm{O}$ & I & $\mathrm{P}$ & $\mathrm{V}$ & $\mathrm{O}$ \\
\hline 0,0 & 57 & 80 & 64 & 54 & 67 & 150 & 50 & 52 & 47 & 56 & 52 & 56 & 69 & 77 & 70 & 81 \\
\hline 0,1 & 57 & 74 & 57 & 54 & 67 & 80 & 74 & 52 & 47 & 57 & 56 & 56 & 69 & 76 & 73 & 81 \\
\hline 0,2 & 54 & 71 & 61 & 54 & 45 & 86 & 76 & 53 & 74 & 57 & 59 & 56 & 78 & 81 & 72 & 81 \\
\hline 0,3 & 54 & 73 & 48 & 54 & 75 & 65 & 73 & 53 & 48 & 59 & 86 & 56 & 74 & 93 & 74 & 81 \\
\hline 0,4 & 57 & 48 & 68 & 54 & 53 & 60 & 60 & 53 & 59 & 60 & 38 & 56 & 59 & 86 & 76 & 81 \\
\hline 0,5 & 57 & 31 & 120 & 54 & 47 & 62 & 51 & 53 & 58 & 59 & 61 & 56 & 65 & 82 & 74 & 81 \\
\hline 0,6 & 56 & 49 & 134 & 54 & 54 & 57 & 52 & 53 & 55 & 48 & 52 & 56 & 73 & 83 & 71 & 81 \\
\hline 0,7 & 56 & 68 & 151 & 54 & 57 & 44 & 50 & 53 & 55 & 66 & 59 & 56 & 77 & 77 & 75 & 81 \\
\hline 0,8 & 63 & 37 & 220 & 54 & 50 & 59 & 51 & 53 & 53 & 81 & 55 & 56 & 80 & 64 & 75 & 81 \\
\hline 0,9 & 62 & 64 & 85 & 55 & 57 & 46 & 50 & 53 & 56 & 77 & 33 & 56 & 85 & 180 & 75 & 81 \\
\hline 1,0 & 57 & 58 & 77 & 54 & 55 & 50 & 50 & 53 & 58 & 62 & 36 & 56 & 83 & 89 & 77 & 82 \\
\hline 1,1 & 65 & 57 & 72 & 55 & 58 & 95 & 50 & 53 & 57 & 69 & 80 & 56 & 90 & 94 & 77 & 82 \\
\hline 1,2 & 26 & 55 & 63 & 55 & 54 & 44 & 52 & 53 & 56 & 65 & 32 & 56 & 85 & & 79 & 83 \\
\hline 1,3 & 61 & 55 & 68 & 55 & 54 & 57 & 50 & 53 & 55 & 70 & 62 & 56 & 89 & & 78 & 83 \\
\hline 1,4 & 68 & 57 & 74 & 55 & 52 & & 52 & 53 & 58 & 48 & 54 & 56 & 85 & & 81 & 84 \\
\hline 1,5 & 57 & 59 & 80 & 55 & 54 & & 50 & 53 & 58 & 57 & 64 & 56 & 67 & & 80 & 85 \\
\hline 2,0 & 56 & 58 & 50 & 55 & 54 & & 52 & 53 & 56 & & 67 & 56 & & & 81 & 88 \\
\hline 2,5 & 61 & 61 & 66 & 55 & & & 38 & 52 & & & 122 & 56 & & & & \\
\hline 3,0 & 53 & 58 & 68 & 56 & & & 47 & 50 & & & 71 & 59 & & & & \\
\hline 3,5 & 68 & 58 & 70 & 57 & & & & & & & & & & & & \\
\hline 4,0 & 67 & 140 & 58 & 57 & & & & & & & & & & & & \\
\hline 4,5 & 68 & 66 & 81 & 58 & & & & & & & & & & & & \\
\hline 5,0 & 66 & 23 & 68 & 59 & & & & & & & & & & & & \\
\hline 5,5 & 66 & 70 & 91 & 59 & & & & & & & & & & & & \\
\hline 6,0 & 62 & 137 & 74 & 60 & & & & & & & & & & & & \\
\hline 6,5 & 66 & 204 & 40 & 60 & & & & & & & & & & & & \\
\hline 7,0 & 65 & & 85 & 60 & & & & & & & & & & & & \\
\hline 7,5 & & & 73 & 60 & & & & & & & & & & & & \\
\hline 8,0 & & & & 61 & & & & & & & & & & & & \\
\hline 8,5 & & & & 61 & & & & & & & & & & & & \\
\hline
\end{tabular}

Foi possível verificar, em todas as estações amostrais, uma variação sazonal de sólidos suspensos totais (SST), com valores mais elevados na primavera e menores no verão (Figura 15). Novamente, a precipitação referente ao mês de outubro de 2010 (primavera) pode ter favorecido esse aumento, devido ao escoamento superficial e à lixiviação do solo da bacia de drenagem. Esse fato tornou-se mais evidente ao se analisar os resultados na estação $\mathrm{Br}$ 4, que apresentou alta correlação entre precipitação pluviométrica e SST $(\rho=0,8)$.

De modo geral, em todas as estações de amostragem, observou-se aumento vertical dos teores de SST. Este aumento pode estar relacionado ao processo de sedimentação, principalmente nos períodos menos chuvosos, como no inverno e no outono. Na estação de coleta $\mathrm{Br}_{2}$ a maior concentração média foi registrada na primavera $\left(10,0 \pm 1,50 \mathrm{mg} \cdot \mathrm{L}^{-1}\right)$, enquanto a menor ocorreu no 
verão $\left(6,0 \pm 0,40 \mathrm{mg} \cdot \mathrm{L}^{-1}\right)$. Na estação $\mathrm{Br}_{3}$, as concentrações de SST foram elevadas na primavera (pico de $18 \mathrm{mg} . \mathrm{L}^{-1}$ na superfície), assim como em $\mathrm{Br}_{4}$, cuja média foi $57 \pm 11,0 \mathrm{mg} . \mathrm{L}^{-1}$. Xu et al. (2009) também relataram um aumento de SST na estação chuvosa no reservatório Three-Gorges, na China. Os autores citaram ainda que a elevada concentração de sólidos após eventos de precipitação indicam a dominância de processos alóctones no controle da quantidade de sólidos, da sua composição no sistema (orgânico ou inorgânico) e dos compostos adsorvidos à eles.
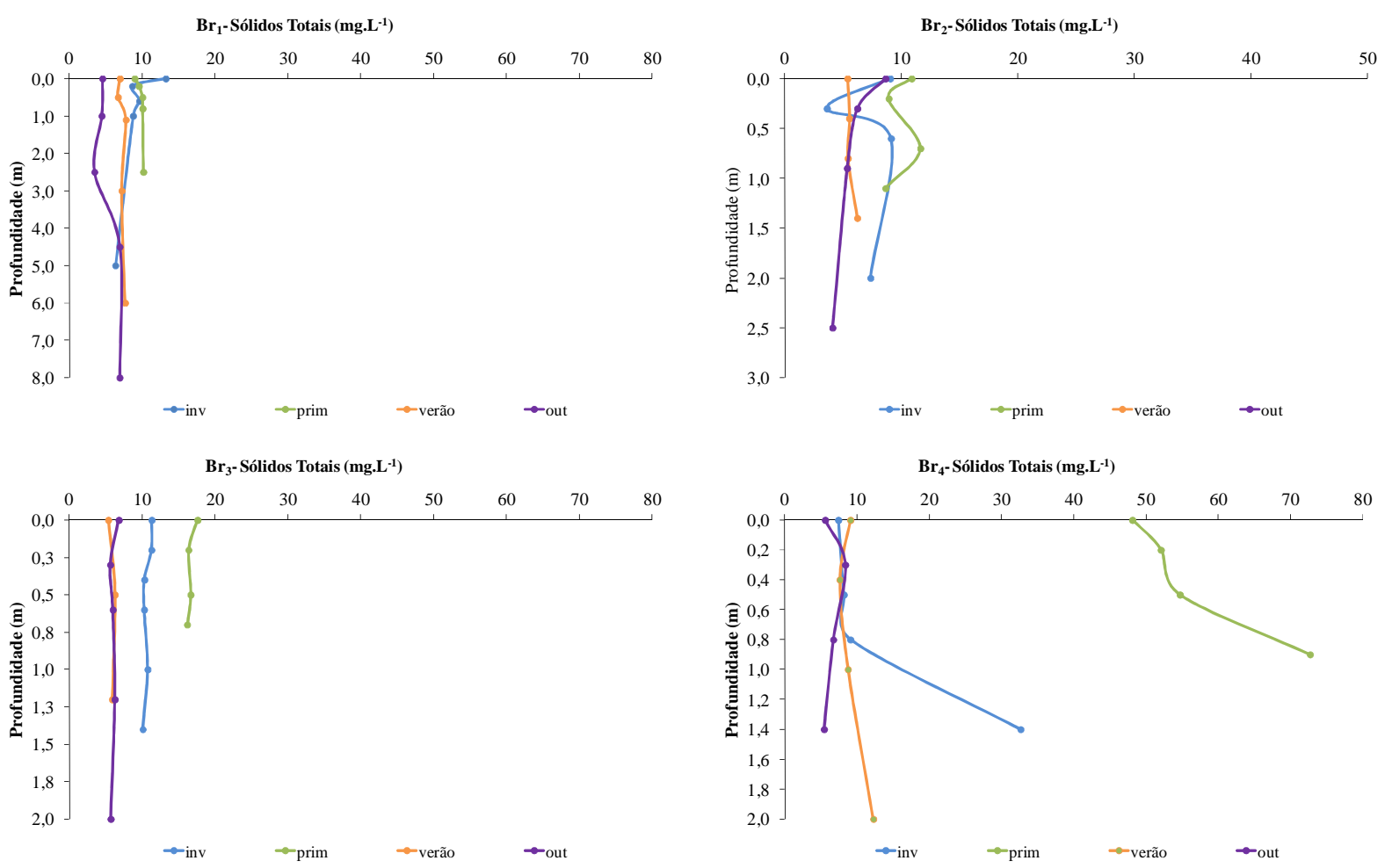

Figura 15: Perfis de Sólidos Suspensos Totais $\left(\mathrm{mg} . \mathrm{L}^{-1}\right)$ das estações de amostragem $\mathrm{Br}_{1}, \mathrm{Br}_{2}, \mathrm{Br}_{3}$ e $\mathrm{Br}_{4}$ nos diferentes períodos do ano.

A análise da participação relativa dos Sólidos Supensos Orgânicos (SSO) Sólidos Supensos Inorgânicos (SSI) (Figura 16) permitiu verificar maior contribuição de SSO em todo período amostrado na estação $\mathrm{Br}_{1}$. A concentração de SSO pode estar relacionada com a presença de organismos das comunidades fitoplanctônica e zooplanctônica (XU et al. 2009). $\mathrm{Em} \mathrm{Br}_{2}, \mathrm{Br}_{3}$ e $\mathrm{Br}_{4}$, a maior participação de SSI ocorreu na primavera, após fortes chuvas. Cabe mencionar que, na primavera, a precipitação nos dias precedentes à coleta foi, aproximadamente, $39 \mathrm{~mm}$, o que pode ter interferido nos resultados mencionados. Esse fato foi corroborado pela análise de correlação, que indicou uma relação inversa entre precipitação e SSO, principalmente em $\mathrm{Br}_{1}, \mathrm{Br}_{3}$ e $\mathrm{Br}_{4}(\rho=-0,8 ; \rho=-0,8 ; \rho=-0,9$, respectivamente). Similarmente, $\mathrm{Xu}$ et al. (2009) encontraram predomínio de SSI no reservatório 
Three-Gorges (China) no período chuvoso, bem como Padovesi-Fonseca, Philomeno e AndreoniBatista (2009) no reservatório Paranoá-GO.
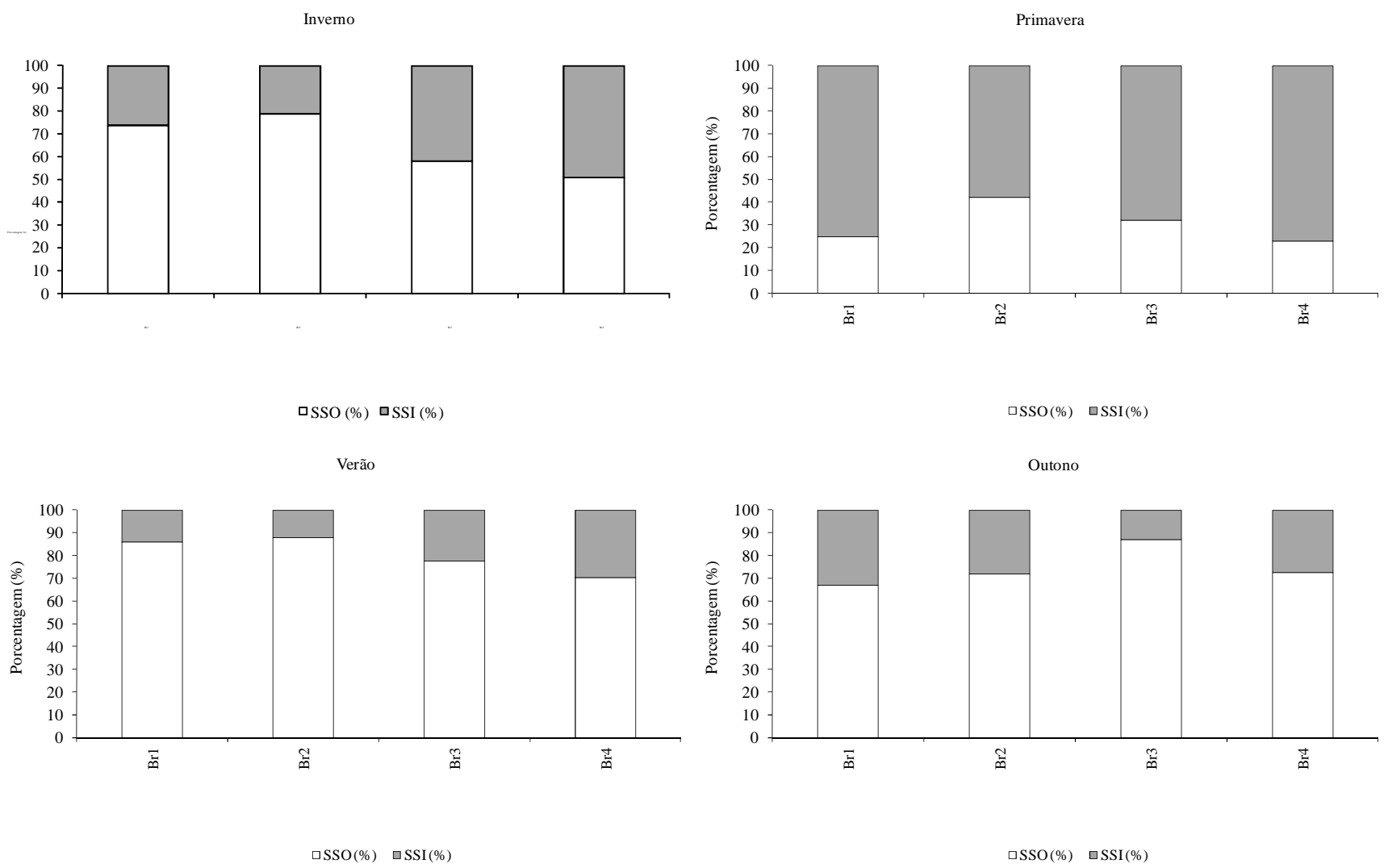

Figura 16: Contribuição relativa das frações de Sólidos Suspensos Orgânicos e Sólidos Suspensos Inorgânicos (\%) nas estações de amostragem $\mathrm{Br}_{1}, \mathrm{Br}_{2}, \mathrm{Br}_{3}$ e $\mathrm{Br}_{4}$ nos diferentes períodos do ano.

Em relação à turbidez (Figura 17), em nenhuma estação de amostragem foi observada intensa variação vertical durante o período de estudo. $\mathrm{Na}$ estação de coleta $\mathrm{Br}_{1}$, a maior média de turbidez foi registrada na primavera $(21,5 \pm 0,50 \mathrm{UNT})$, devido, provavelmente, às chuvas que antecederam a amostragem. Deve-se destacar ainda, que os valores de turbidez foram mais elevados na estação de amostragem $\mathrm{Br}_{4}$, com pico de 145,0 UNT a 0,5 m. É importante comentar que os maiores valores de turbidez coincidiram com a maior concentração média de SSI em todas as estações de coleta.

A turbidez é uma variável tipicamente sazonal, pois há um aumento da mesma devido ao aumento de materiais advindos da bacia de drenagem, principalmente, em períodos chuvosos (FIGUEIREDO e BIANCHINI Jr., 2008). Os mesmos autores relataram que o tempo de detenção hidráulico (TDH) pode melhorar as condições de transparência da água, devido ao processo de sedimentação das partículas. O TDH do reservatório Itupararanga foi maior no inverno (190 dias), 
quando os valores de turbidez estavam relativamente baixos. Entretanto, o regime pluviométrico parece ter maior influência sobre a turbidez no sistema em estudo, uma vez que na primavera o TDH foi alto, mas a ocorrência de precipitação pluviométrica no período de amostragem pode ter tanto ressuspendido partículas já sedimentadas, como favorecido o aporte dessas via bacia de drenagem. No verão, quando a precipitação pluviométrica antecedente foi menor, os valores de turbidez decaíram, como exemplo, pode-se citar a estação de coleta $\mathrm{Br}_{4}$, onde a turbidez era 126,0 UNT na primavera e passou a 10,0 UNT no verão.
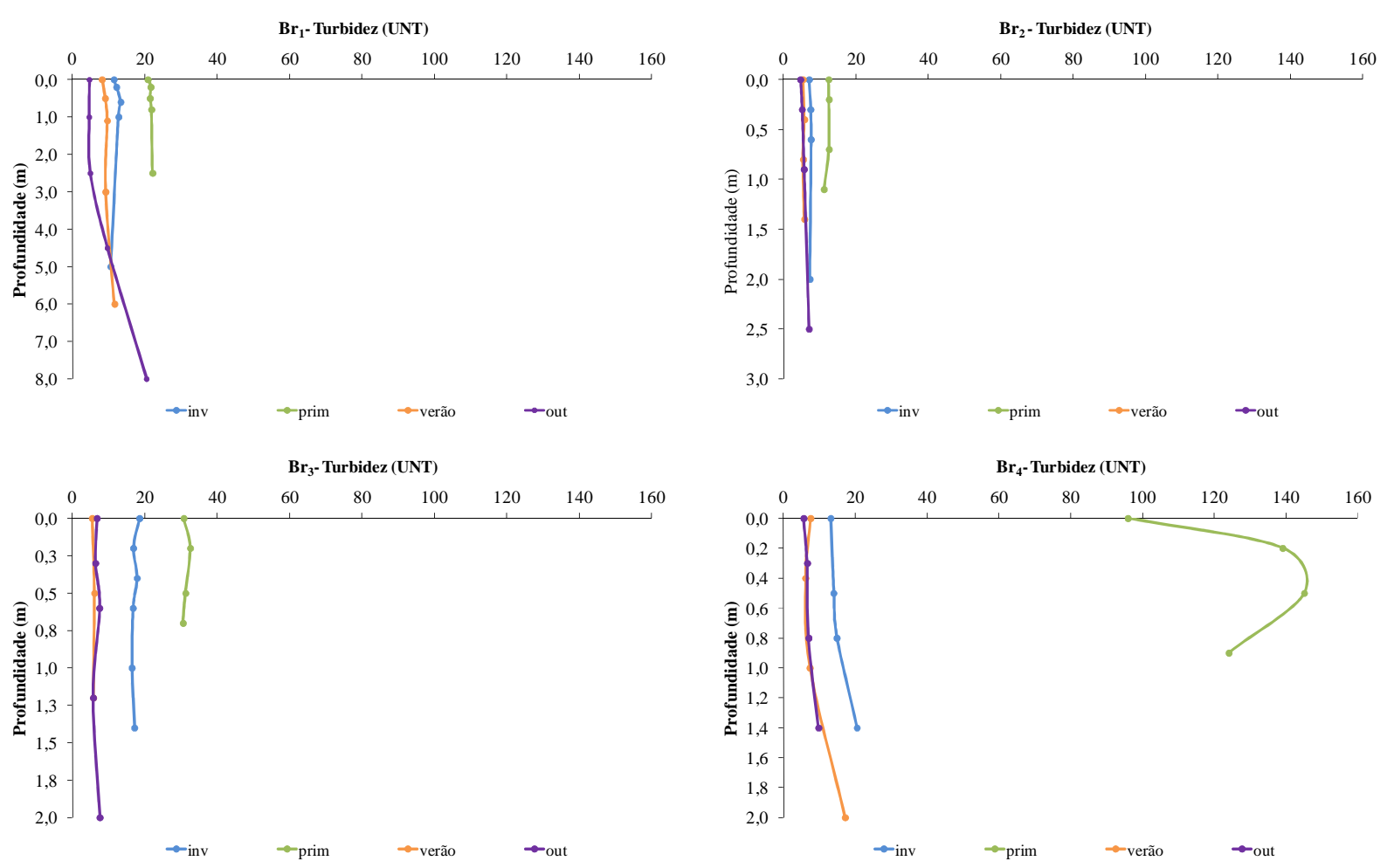

Figura 17: Perfis de turbidez (UNT) das estações de amostragem $\mathrm{Br}_{1}, \mathrm{Br}_{2}, \mathrm{Br}_{3}$ e $\mathrm{Br}_{4}$ nos diferentes períodos do ano.

A variação vertical do $\mathrm{pH}$ pode ser visualizada na Figura $18 . \mathrm{O} \mathrm{pH}$, de modo geral, diminuiu verticalmente em todas as estações de amostragem. Os valores de $\mathrm{pH}$ podem ter diminuído devido ao incremento de $\mathrm{CO}_{2}$ liberado no processo de decomposição da matéria orgânica, o qual se dissolve nas camadas de água mais profundas, formando carbonato. Em conseqüência, há um aumento da concentração desse íon, que diminui a capacidade tampão do meio. Deve-se mencionar ainda que, no fundo da coluna de água, o processo de fotossíntese é menos intenso, ocasionando uma diferença entre o pH da superfície e do fundo. Mariani et al. (2006) também encontraram o mesmo padrão de variação do $\mathrm{pH}$ no reservatório Riacho Grande-SP. 
Um padrão diferenciado foi verificado na primavera em $\mathrm{Br}_{4}$, onde os valores aumentaram verticalmente. $\mathrm{O}$ mesmo ocorreu em $\mathrm{Br}_{3}$ no inverno e no verão. $\mathrm{Na}$ estação amostral $\mathrm{Br}_{1}$ obtiveram-se os menores valores de $\mathrm{pH}$ com média variando entre $6,12 \pm 0,2$ no inverno e $8,05 \pm 0,6$ no verão. Provavelmente esses valores mais baixos são decorrentes da entrada de esgoto através dos rios formadores do reservatório. É importante mencionar que no verão foram obtidos os maiores valores de pH para todas as estações de amostragem, destacando-se $\mathrm{Br}_{3}$ com pico de 10,3 a 1,5m. No verão, a maior penetração de luz, baixa concentração de sólidos e turbidez permitem uma atividade fotossintética mais intensa, que eleva os valores de pH. Pedrazzi (2009) também encontrou valores de $\mathrm{pH}$ acima de 7,0 em todas as estações de amostragem estudadas no reservatório Itupararanga. Salles et al. (2008) reportaram valores de $\mathrm{pH}$ em torno de 7,0 nos rios afluentes às estações de amostragem do presente estudo. Ressalta-se ainda a ocorrência de estratificação química nas estações de coleta $\mathrm{Br}_{1}$ (no verão) e $\mathrm{Br}_{3}$ (no verão e no outono). $\mathrm{O}$ mesmo padrão de estratificação foi observado para o $\mathrm{OD}$, fato que assume relevância ao se comparar ambos os perfis, os quais foram, provavelmente, influenciados pela fotossíntese e apresentaram decréscimo vertical das concentrações.
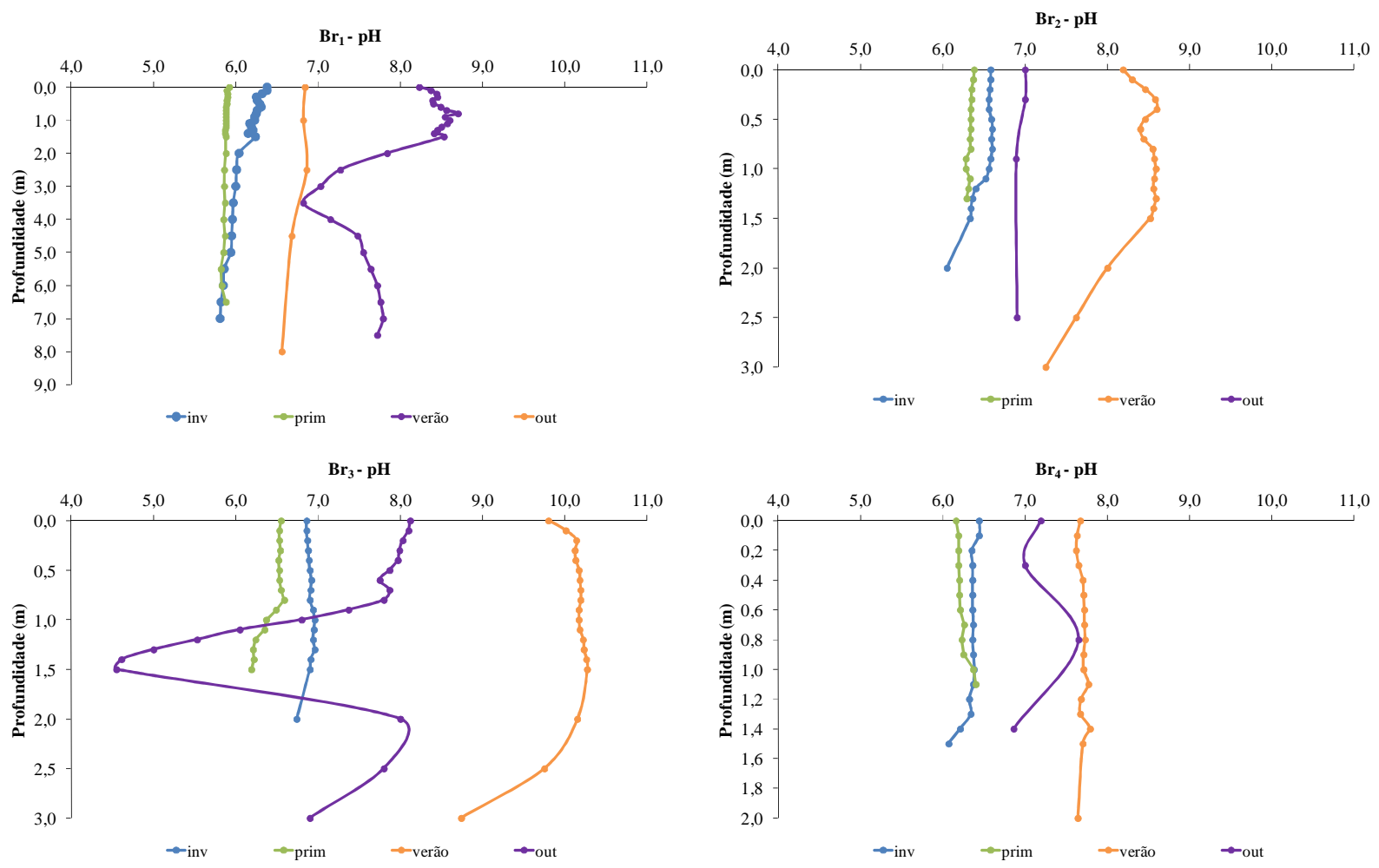

Figura 18: Perfis de $\mathrm{pH}$ das estações de amostragem $\mathrm{Br}_{1}, \mathrm{Br}_{2}, \mathrm{Br}_{3}$ e $\mathrm{Br}_{4}$ nos diferentes períodos do ano. 
De maneira geral, não foi observada grande variação vertical da alcalinidade nas estações de amostragem (Figura 19). Os valores dessa variável foram menores no outono em todas as estações de coleta. Nas estações $\mathrm{Br}_{1}$ e $\mathrm{Br}_{4}$, os valores médios de alcalinidade foram maiores no verão $(0,83 \pm 0,04 \mathrm{e}$ $\left.1,25 \pm 0,02 \mathrm{mEq} \cdot \mathrm{L}^{-1}\right)$. Na estação $\mathrm{Br}_{2}$ as concentrações mais elevadas foram encontradas na primavera e no verão (média de $0,54 \mathrm{mEq} \cdot \mathrm{L}^{-1}$ em ambos os períodos). $\mathrm{Na}$ estação de coleta $\mathrm{Br}_{3}$, a alcalinidade foi maior no inverno, com máxima de $0,8 \mathrm{mEq} . \mathrm{L}^{-1}$ na superfície. Dentre os braços selecionados, verificouse, em todas as estações do ano, principalmente no verão (pico de $1,3 \mathrm{mEq} \cdot \mathrm{L}^{-1}$ a $1,4 \mathrm{~m}$ ) elevada alcalinidade em $\mathrm{Br}_{4}$. Fonseca e Bicudo (2008) obtiveram alcalinidade variando entre 0,6 e $0,9 \mathrm{mEq} . \mathrm{L}^{-1}$ na Lagoa das Garças-SP. Médias semelhantes foram encontradas no reservatório Itupararanga.

De acordo com Merino-Ibarra et al. (2008), os valores de alcalinidade registrados em um reservatório tropical do México (reservatório Valle Bravo) foram baixos (1,4 mEq. $\left.\mathrm{L}^{-1}\right)$ e, portanto, a capacidade tampão do meio foi considerada baixa, fato que permite fortes variações verticais do $\mathrm{pH}$. Sendo assim, pode-se dizer que a capacidade tampão do reservatório Itupararanga é baixa, o que ocasionou variação vertical do $\mathrm{pH}$.
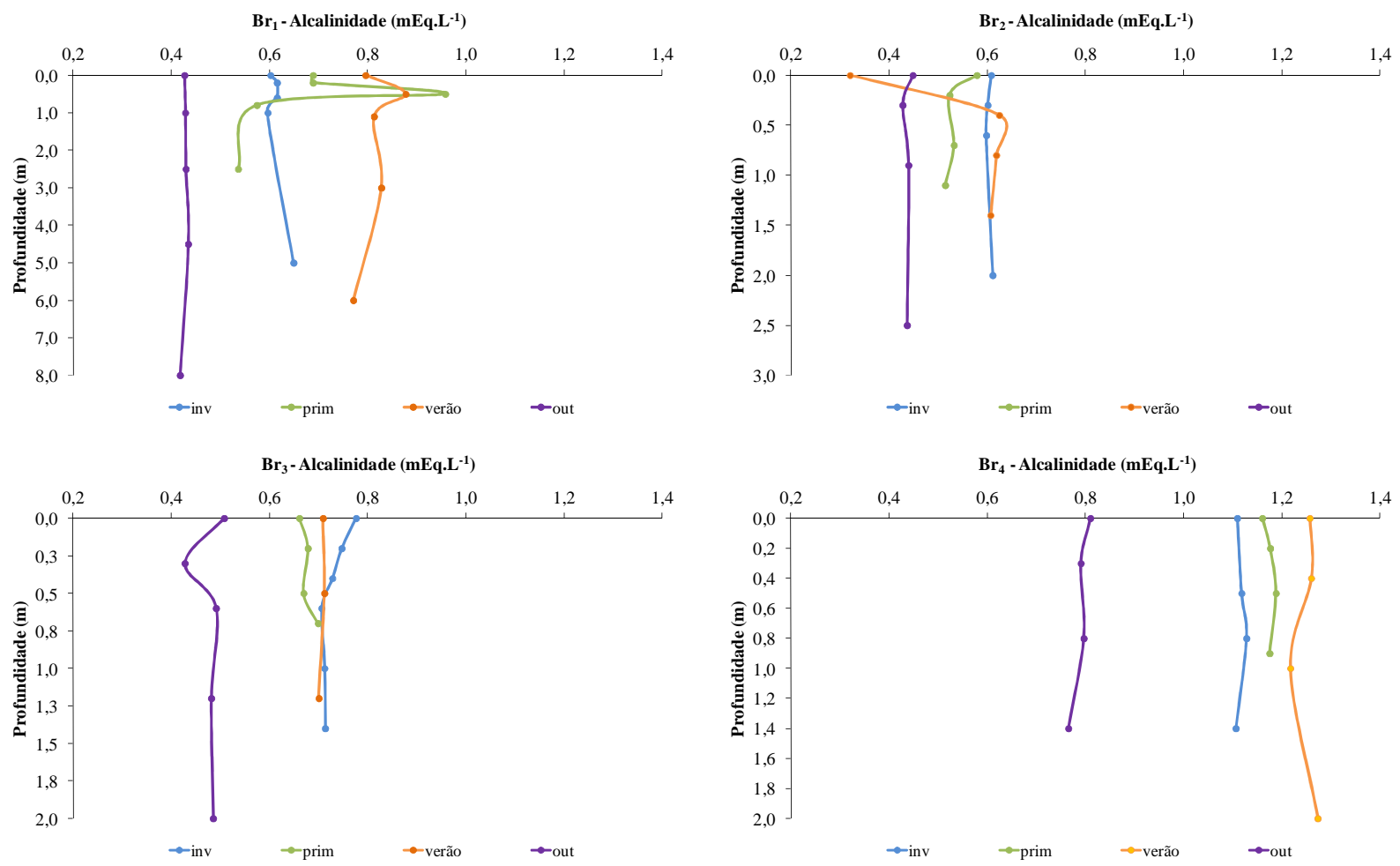

Figura 19: Perfis de alcalinidade (meq. $\mathrm{L}^{-1}$ ) das estações de amostragem $\mathrm{Br}_{1}, \mathrm{Br}_{2}, \mathrm{Br}_{3}$ e $\mathrm{Br}_{4}$ nos diferentes períodos do ano.

Não foram observados padrões de variação vertical e sazonal definidos para as concentrações de nitrogênio Total Kjeldhal (NTK), as quais apresentaram grande amplitude espacial (Tabela 10). Gikas et al. (2009) observaram o mesmo resultado no reservatório Polyphytos, na Grécia. Entretanto, 
González et al. (2004) encontraram padrão sazonal definido, com maiores valores de NTK no período chuvoso e menores na seca, em reservatório tropical da Venezuela.

Deve-se destacar que em alguns pontos das estações de amostragem (superfície e fundo da estação $\mathrm{Br}_{1}$ no inverno; no outono, superfície e fundo da estação $\mathrm{Br}_{2}$, superfície de $\mathrm{Br}_{3}$ e fundo da estação $\left.\mathrm{Br}_{4}\right)$, a concentração de NTK estava abaixo do limite de detecção do método $\left(0,01 \mathrm{mg} \cdot \mathrm{L}^{-1}\right)$. Na estação de coleta $\mathrm{Br}_{1}$, a concentração média mais elevada ocorreu no outono (com pico de 1,3 mg.L $\mathrm{L}^{-1}$ ), enquanto na estação $\mathrm{Br}_{2}$ e $\mathrm{Br}_{3}$, a média máxima foi obtida no verão. Esse resultado pode estar associado à ocorrência das comunidades fitoplanctônica e bacterioplanctônica, que contribuem para o incremento da fração orgânica do nitrogênio. Na estação $\mathrm{Br}_{4}$ registrou-se concentração média mais elevada no inverno $\left(0,42 \pm 0,04 \mathrm{mg} \cdot \mathrm{L}^{-1}\right)$. Comparando-se com outros reservatórios tropicais, as concentrações de NTK foram baixas no reservatório Itupararanga, pois, no reservatório de Rosana-SP, as concentrações variaram entre 0,52 e $0,74 \mathrm{mg} . \mathrm{L}^{-1}$ (BORGES et al. 2010), enquanto no reservatório Paranoá-GO, a maior concentração média foi $0,83 \mathrm{mg}^{-1}{ }^{-1}$ (PADOVESI-FONSECA, PHILOMENO, ANDREONI-BATISTA, 2009) e no reservatório Pao-Cachinche (Venezuela), as concentrações e NTK oscilaram entre 1,07 e 4,3 mg.L $\mathrm{L}^{-1}$ (GONZÁLEZ et al. 2004). 
Tabela 10: Concentração de Nitrogênio Total Kjeldhal (mg.L $\left.\mathrm{L}^{-1}\right)$ nas estações de amostragem $\mathrm{Br}_{1}, \mathrm{Br}_{2}, \mathrm{Br}_{3}$ e $\mathrm{Br}_{4}$ nos diferentes períodos do ano

\begin{tabular}{|c|c|c|c|c|c|c|c|}
\hline \multicolumn{8}{|c|}{ Inverno } \\
\hline \multicolumn{2}{|c|}{$\mathbf{B r}_{1}$} & \multicolumn{2}{|c|}{$\mathbf{B r}_{2}$} & \multicolumn{2}{|c|}{$\mathbf{B r}_{3}$} & \multicolumn{2}{|c|}{$\mathbf{B r}_{4}$} \\
\hline $\begin{array}{l}\text { Prof } \\
\text { (m) }\end{array}$ & $\begin{array}{c}\text { NTK } \\
\left(\mathrm{mg.L}^{-1}\right)\end{array}$ & $\begin{array}{l}\text { Prof } \\
\text { (m) }\end{array}$ & $\begin{array}{c}\text { NTK } \\
\left(\mathrm{mg}^{-L^{-1}}\right)\end{array}$ & $\begin{array}{l}\text { Prof } \\
\text { (m) }\end{array}$ & $\begin{array}{c}\text { NTK } \\
\left(\mathrm{mg} . \mathrm{L}^{-1}\right)\end{array}$ & $\begin{array}{l}\text { Prof } \\
\text { (m) }\end{array}$ & $\begin{array}{c}\mathrm{NTK} \\
\left(\mathrm{mg} . \mathrm{L}^{-1}\right)\end{array}$ \\
\hline 0,0 & 0,05 & 0,0 & 0,04 & 0,0 & 0,04 & 0,0 & 0,05 \\
\hline 0,2 & 0,02 & 0,3 & 0,19 & 0,2 & 0,15 & 0,5 & 1,02 \\
\hline 0,6 & 0,16 & 0,6 & 0,20 & 0,4 & 0,28 & 0,8 & 0,31 \\
\hline 1,0 & 0,22 & 2,0 & 0,01 & 0,6 & 0,04 & 1,4 & 0,33 \\
\hline 5,0 & 0,04 & & & 1,0 & 0,04 & & \\
\hline & & & & 1,4 & 0,09 & & \\
\hline \multicolumn{8}{|c|}{ Primavera } \\
\hline \multicolumn{2}{|r|}{$\mathbf{B r}_{1}$} & \multicolumn{2}{|r|}{$\mathbf{B r}_{2}$} & \multicolumn{2}{|r|}{$\mathbf{B r}_{3}$} & \multicolumn{2}{|r|}{$\mathrm{Br}_{4}$} \\
\hline $\begin{array}{l}\text { Prof } \\
\text { (m) }\end{array}$ & $\begin{array}{c}\mathrm{NTK} \\
\left(\mathrm{mg}^{-L^{-1}}\right)\end{array}$ & $\begin{array}{l}\text { Prof } \\
\text { (m) }\end{array}$ & $\begin{array}{c}\text { NTK } \\
\left(\mathrm{mg} . \mathrm{L}^{-1}\right)\end{array}$ & $\begin{array}{l}\text { Prof } \\
\text { (m) }\end{array}$ & $\begin{array}{c}\text { NTK } \\
\left(\mathrm{mg} \cdot \mathrm{L}^{-1}\right)\end{array}$ & $\begin{array}{l}\text { Prof } \\
\text { (m) }\end{array}$ & $\begin{array}{c}\mathrm{NTK} \\
\left(\mathrm{mg.L}^{-1}\right)\end{array}$ \\
\hline 0,0 & $*$ & 0,0 & $*$ & 0,0 & $*$ & 0,0 & 0,03 \\
\hline 0,2 & 0,04 & 0,2 & $*$ & 0,2 & 0,02 & 0,2 & 0,01 \\
\hline 0,5 & 0,05 & 0,7 & 0,06 & 0,5 & 0,02 & 0,5 & 0,09 \\
\hline 0,8 & 0,13 & 1,1 & 0,09 & 0,7 & 0,03 & 0,9 & 0,03 \\
\hline 2,5 & $*$ & & & & & & \\
\hline \multicolumn{8}{|c|}{ Verão } \\
\hline \multicolumn{2}{|r|}{$\mathbf{B r}_{1}$} & \multicolumn{2}{|c|}{$\mathbf{B r}_{2}$} & \multicolumn{2}{|r|}{$\mathbf{B r}_{3}$} & \multicolumn{2}{|r|}{$\mathrm{Br}_{4}$} \\
\hline $\begin{array}{l}\text { Prof } \\
\text { (m) }\end{array}$ & $\begin{array}{c}\text { NTK } \\
\left(\mathrm{mg}^{-L^{-1}}\right)\end{array}$ & $\begin{array}{l}\text { Prof } \\
\text { (m) }\end{array}$ & $\begin{array}{c}\text { NTK } \\
\left(\mathrm{mg} . \mathrm{L}^{-1}\right)\end{array}$ & $\begin{array}{l}\text { Prof } \\
\text { (m) }\end{array}$ & $\begin{array}{c}\text { NTK } \\
\left(\mathrm{mg} . \mathrm{L}^{-1}\right)\end{array}$ & $\begin{array}{l}\text { Prof } \\
\text { (m) }\end{array}$ & $\begin{array}{c}\text { NTK } \\
\left(\mathrm{mg.L}^{-1}\right)\end{array}$ \\
\hline 0,0 & 0,16 & 0,0 & 0,43 & 0,0 & 0,48 & 0,0 & 0,37 \\
\hline 0,5 & 0,15 & 0,4 & 0,33 & 0,5 & 0,20 & 0,4 & 0,35 \\
\hline 1,1 & 0,01 & 0,8 & 0,38 & 1,2 & 0,48 & 1,0 & 0,34 \\
\hline 3,0 & 0,30 & 1,4 & 0,33 & & & 2,0 & 0,35 \\
\hline 6,0 & 0,11 & & & & & & \\
\hline \multicolumn{8}{|c|}{ Outono } \\
\hline \multicolumn{2}{|r|}{$\mathbf{B r}_{1}$} & \multicolumn{2}{|r|}{$\mathbf{B r}_{2}$} & \multicolumn{2}{|r|}{$\mathbf{B r}_{3}$} & \multicolumn{2}{|c|}{$\mathrm{Br}_{4}$} \\
\hline $\begin{array}{l}\text { Prof } \\
\text { (m) }\end{array}$ & $\begin{array}{c}\text { NTK } \\
\left(\mathrm{mg.L}^{-1}\right)\end{array}$ & $\begin{array}{l}\text { Prof } \\
\text { (m) }\end{array}$ & $\begin{array}{c}\text { NTK } \\
\left(\mathrm{mg} \cdot \mathrm{L}^{-1}\right)\end{array}$ & $\begin{array}{l}\text { Prof } \\
\text { (m) }\end{array}$ & $\begin{array}{c}\text { NTK } \\
\left(\mathrm{mg} \cdot \mathrm{L}^{-1}\right)\end{array}$ & $\begin{array}{l}\text { Prof } \\
\text { (m) }\end{array}$ & $\begin{array}{c}\text { NTK } \\
\left(\mathrm{mg.L}^{-1}\right)\end{array}$ \\
\hline 0,0 & $*$ & 0,0 & 0,12 & 0,0 & 0,17 & 0,0 & $*$ \\
\hline 1,0 & 0,07 & 0,3 & 0,08 & 0,3 & 0,09 & 0,3 & 0,13 \\
\hline 2,5 & 1,34 & 0,9 & $*$ & 0,6 & $*$ & 0,8 & 0,16 \\
\hline 4,5 & $*$ & 2,5 & 0,09 & 1,2 & 0,18 & 1,4 & 0,11 \\
\hline 8,0 & $*$ & & & 2 & 0,20 & & \\
\hline
\end{tabular}

As concentrações de nitrogênio amoniacal (Tabela 11) ficaram abaixo do limite de detecção do método $\left(0,01 \mathrm{mg} . \mathrm{L}^{-1}\right)$, sendo apenas registradas no inverno, provavelmente devido à menor precipitação e, consequentemente, baixa diluição. Padovesi-Fonseca, Philomeno e Andreoni-Batista (2009) comentaram que a variação das características limnológicas tende a exibir um padrão temporal relacionado ao regime hidrológico. Portanto, meses chuvosos são associados a elevadas concentrações de nutrientes inorgânicos, advindos de fontes alóctones. Dessa forma, os mesmos autores verificaram 
que o nitrogênio amoniacal foi a forma predominante de nitrogênio após um flushing no reservatório Paranoá-GO, resultados antagônicos aos obtidos no reservatório Itupararanga. Ainda no inverno, observou-se tendência de aumento da superfície ao fundo em $\mathrm{Br}_{1}$ e $\mathrm{Br}_{4}$. A máxima concentração registrada foi $0,13 \mathrm{mg} . \mathrm{L}^{-1}$ a 1,4 $\mathrm{m}$ em $\mathrm{Br}_{3}$. Esses resultados permitem supor que, embora haja despejos de esgoto doméstico nos tributários do reservatório, a poluição, no reservatório, não é recente e o processo de nitrificação é favorecido pelas altas concentrações de oxigênio, tanto dos rios afluentes como dos braços.

\begin{tabular}{|c|c|c|c|c|c|c|c|}
\hline \multicolumn{8}{|c|}{ Inverno } \\
\hline \multicolumn{2}{|c|}{$\mathrm{Br}_{1}$} & \multicolumn{2}{|r|}{$\mathrm{Br}_{2}$} & \multicolumn{2}{|c|}{$\mathrm{Br}_{3}$} & \multicolumn{2}{|r|}{$\mathrm{Br}_{4}$} \\
\hline $\begin{array}{l}\text { Prof } \\
\text { (m) }\end{array}$ & $\begin{array}{c}\mathrm{N}-\mathrm{NH}_{3} \\
\left(\mathrm{mg} \cdot \mathrm{L}^{-1}\right)\end{array}$ & $\begin{array}{l}\text { Prof } \\
(\mathrm{m})\end{array}$ & $\begin{array}{l}\mathrm{N}-\mathrm{NH}_{3} \\
\left(\mathrm{mg} \cdot \mathrm{L}^{-1}\right)\end{array}$ & $\begin{array}{l}\text { Prof } \\
\text { (m) }\end{array}$ & $\begin{array}{l}\mathrm{N}-\mathrm{NH}_{3} \\
\left(\mathrm{mg} \cdot \mathrm{L}^{-1}\right)\end{array}$ & $\begin{array}{l}\text { Prof } \\
\text { (m) }\end{array}$ & $\begin{array}{c}\mathrm{N}-\mathrm{NH}_{3} \\
\left(\mathrm{mg} \cdot \mathrm{L}^{-1}\right)\end{array}$ \\
\hline 0,0 & 0,01 & 0,0 & 0,01 & 0,0 & 0,01 & 0,0 & 0,01 \\
\hline 0,2 & 0,02 & 0,3 & 0,01 & 0,2 & 0,05 & 0,5 & 0,02 \\
\hline 0,6 & 0,04 & 0,6 & 0,1 & 0,4 & 0,03 & 0,8 & 0,01 \\
\hline 1,0 & 0,04 & 2,0 & 0,01 & 0,6 & 0,04 & 1,4 & 0,04 \\
\hline \multirow[t]{2}{*}{5,0} & 0,02 & & & 1,0 & 0,11 & & \\
\hline & & & & 1,4 & 0,13 & & \\
\hline
\end{tabular}

As concentrações de nitrito $\left(\mathrm{NO}_{2}{ }^{-}\right)$(Tabela 12) estavam, na maioria das estações de coleta e períodos, abaixo do limite de detecção do método $\left(0,25 \mu \mathrm{g} \cdot \mathrm{L}^{-1}\right)$. Na estação $\mathrm{Br}_{1}$ foram obtidas concentrações acima do limite de detecção no inverno e parcialmente no outono, enquanto na estação $\mathrm{Br}_{4}$ registraram-se concentrações abaixo do limite apenas no verão, exceto a 2,0 m $\left(1,6 \mu \mathrm{g} . \mathrm{L}^{-1}\right)$. Nessas estações de amostragem verificou-se ainda, maior amplitude vertical das concentrações de nitrito em relação aos outros braços. $\mathrm{Na}$ estação $\mathrm{Br}_{2}$, concentrações abaixo do limite de detecção foram encontradas em todos os períodos. A estação de coleta $\mathrm{Br}_{3}$, também apresentou concentrações abaixo do limite detectável na maioria das estações do ano, exceto na primavera. As maiores concentrações de nitrito foram observadas na estação $\mathrm{Br}_{4}$, principalmente na primavera, atingindo $1,25 \mu \mathrm{g} \cdot \mathrm{L}^{-1}$ a $0,5 \mathrm{~m}$. Em outros reservatórios tropicais, as concentrações de $\mathrm{NO}_{2}$ foram mais elevadas que no reservatório Itupararanga, conforme reportado por González et al. (2004) no reservatório Pao-Cachinche, na Venezuela, (até $300 \mu \mathrm{g} . \mathrm{L}^{-1}$ em uma estação de amostragem), por Granado e Henry (2008) em três lagos marginais do rio Paranapanema-SP (concentrações variando entre 11 e $17 \mu \mathrm{g} . \mathrm{L}^{-1}$ ) e por Friese et al. (2010) na lagoa da Pampulha (máximo de $33 \mu \mathrm{g} . \mathrm{L}^{-1}$ ). As menores concentrações foram registradas no 
verão em todas as estações amostrais. Esses resultados são decorrentes da elevada instabilidade do nitrito, composto que é rapidamente oxidado a nitrato.

Tabela 12: Concentração de nitrito $\left(\mu \mathrm{g} . \mathrm{L}^{-1}\right.$ ) nas estações de amostragem $\mathrm{Br}_{1}, \mathrm{Br}_{2}, \mathrm{Br}_{3}$ e $\mathrm{Br}_{4}$ nos diferentes períodos do ano.

\begin{tabular}{|c|c|c|c|c|c|c|c|}
\hline \multicolumn{8}{|c|}{ Inverno } \\
\hline \multicolumn{2}{|c|}{$\mathbf{B r}_{1}$} & \multicolumn{2}{|c|}{$\mathrm{Br}_{2}$} & \multicolumn{2}{|c|}{$\mathbf{B r}_{3}$} & \multicolumn{2}{|c|}{$\mathrm{Br}_{4}$} \\
\hline $\begin{array}{r}\text { Prof } \\
(\mathrm{m})\end{array}$ & $\begin{array}{c}\mathrm{NO}_{2}^{-} \\
\left(\mu \mathrm{g} . \mathrm{L}^{-1}\right)\end{array}$ & $\begin{array}{l}\text { Prof } \\
(\mathrm{m})\end{array}$ & $\begin{array}{c}\mathrm{NO}_{2}^{-} \\
\left(\mu \mathrm{g} . \mathrm{L}^{-1}\right)\end{array}$ & $\begin{array}{r}\text { Prof } \\
(\mathrm{m})\end{array}$ & $\begin{array}{c}\mathrm{NO}_{2}^{-} \\
\left(\mu \mathrm{g} . \mathrm{L}^{-1}\right)\end{array}$ & $\begin{array}{r}\text { Prof } \\
\text { (m) }\end{array}$ & $\begin{array}{c}\mathrm{NO}_{2}^{-} \\
\left(\mu \mathrm{g} . \mathrm{L}^{-1}\right)\end{array}$ \\
\hline 0,0 & 0,30 & 0,00 & 0,15 & 0,00 & 0,21 & 0,00 & 0,52 \\
\hline 0,2 & 0,30 & 0,30 & 0,15 & 0,20 & 0,24 & 0,50 & 0,50 \\
\hline 0,6 & 0,32 & 0,60 & 0,14 & 0,40 & 0,24 & 0,80 & 0,48 \\
\hline 1,0 & 0,33 & 2,00 & 0,17 & 0,60 & 0,45 & 1,40 & 0,43 \\
\hline \multirow[t]{2}{*}{5,0} & 0,36 & & & 1,00 & 0,22 & & \\
\hline & & & & 1,40 & 0,22 & & \\
\hline \multicolumn{8}{|c|}{ Primavera } \\
\hline \multicolumn{2}{|c|}{$\mathbf{B r}_{1}$} & \multicolumn{2}{|c|}{$\mathrm{Br}_{2}$} & \multicolumn{2}{|c|}{$\mathrm{Br}_{3}$} & \multicolumn{2}{|c|}{$\mathrm{Br}_{4}$} \\
\hline $\begin{array}{l}\text { Prof } \\
\text { (m) }\end{array}$ & $\begin{array}{c}\mathrm{NO}_{2}^{-} \\
\left(\mu \mathrm{g} . \mathrm{L}^{-1}\right)\end{array}$ & $\begin{array}{l}\text { Prof } \\
(\mathrm{m})\end{array}$ & $\begin{array}{c}\mathrm{NO}_{2}^{-} \\
\left(\mu \mathrm{g} . \mathrm{L}^{-1}\right)\end{array}$ & $\begin{array}{r}\text { Prof } \\
\text { (m) }\end{array}$ & $\begin{array}{c}\mathrm{NO}_{2}^{-} \\
\left(\mu \mathrm{g} . \mathrm{L}^{-1}\right)\end{array}$ & $\begin{array}{r}\text { Prof } \\
\text { (m) }\end{array}$ & $\begin{array}{c}\mathrm{NO}_{2}^{-} \\
\left(\mu \mathrm{g} . \mathrm{L}^{-1}\right)\end{array}$ \\
\hline 0,0 & 0,23 & 0,00 & 0,09 & 0,00 & 0,29 & 0,00 & 1,22 \\
\hline 0,2 & 0,23 & 0,20 & 0,11 & 0,20 & 0,27 & 0,20 & 1,20 \\
\hline 0,5 & 0,24 & 0,70 & 0,15 & 0,50 & 0,29 & 0,50 & 1,25 \\
\hline 0,8 & 0,20 & 1,10 & 0,11 & 0,70 & 0,32 & 0,90 & 1,17 \\
\hline 2,5 & 0,23 & & & & & & \\
\hline \multicolumn{8}{|c|}{ Verão } \\
\hline \multicolumn{2}{|c|}{$\mathbf{B r}_{1}$} & \multicolumn{2}{|c|}{$\mathbf{B r}_{2}$} & \multicolumn{2}{|c|}{$\mathbf{B r}_{3}$} & \multicolumn{2}{|c|}{$\mathrm{Br}_{4}$} \\
\hline $\begin{array}{l}\text { Prof } \\
\text { (m) }\end{array}$ & $\begin{array}{c}\mathrm{NO}_{2}^{-} \\
\left(\mu \mathrm{g} . \mathrm{L}^{-1}\right)\end{array}$ & $\begin{array}{l}\text { Prof } \\
(\mathrm{m})\end{array}$ & $\begin{array}{c}\mathrm{NO}_{2}^{-} \\
\left(\mu \mathrm{g} . \mathrm{L}^{-1}\right)\end{array}$ & $\begin{array}{r}\text { Prof } \\
(\mathrm{m})\end{array}$ & $\begin{array}{c}\mathrm{NO}_{2}^{-} \\
\left(\mu \mathrm{g} . \mathrm{L}^{-1}\right)\end{array}$ & $\begin{array}{r}\text { Prof } \\
\text { (m) }\end{array}$ & $\begin{array}{c}\mathrm{NO}_{2}^{-} \\
\left(\mu \mathrm{g} . \mathrm{L}^{-1}\right)\end{array}$ \\
\hline 0,0 & 0,04 & 0,00 & 0,04 & 0,00 & 0,01 & 0,00 & 0,04 \\
\hline 0,5 & 0,03 & 0,40 & 0,07 & 0,50 & 0,05 & 0,40 & 0,06 \\
\hline 1,1 & 0,11 & 0,80 & 0,08 & 1,20 & 0,02 & 1,00 & 0,03 \\
\hline 3,0 & 0,23 & 1,40 & 0,03 & & & 2,00 & 1,58 \\
\hline 6,0 & 0,45 & & & & & & \\
\hline \multicolumn{8}{|c|}{ Outono } \\
\hline \multicolumn{2}{|c|}{$\mathbf{B r}_{1}$} & \multicolumn{2}{|c|}{$\mathrm{Br}_{2}$} & \multicolumn{2}{|c|}{$\mathrm{Br}_{3}$} & \multicolumn{2}{|c|}{$\mathrm{Br}_{4}$} \\
\hline $\begin{array}{l}\text { Prof } \\
\text { (m) }\end{array}$ & $\begin{array}{c}\mathrm{NO}_{2}^{-} \\
\left(\mu \mathrm{g} . \mathrm{L}^{-1}\right)\end{array}$ & $\begin{array}{l}\text { Prof } \\
(\mathrm{m})\end{array}$ & $\begin{array}{c}\mathrm{NO}_{2}^{-} \\
\left(\mu \mathrm{g} . \mathrm{L}^{-1}\right)\end{array}$ & $\begin{array}{r}\text { Prof } \\
\text { (m) }\end{array}$ & $\begin{array}{c}\mathrm{NO}_{2}^{-} \\
\left(\mu \mathrm{g} . \mathrm{L}^{-1}\right)\end{array}$ & $\begin{array}{r}\text { Prof } \\
\text { (m) }\end{array}$ & $\begin{array}{c}\mathrm{NO}_{2}^{-} \\
\left(\mu \mathrm{g} . \mathrm{L}^{-1}\right)\end{array}$ \\
\hline 0,0 & 0,13 & 0,00 & 0,06 & 0,00 & 0,03 & 0,00 & 0,42 \\
\hline 1,0 & 0,13 & 0,30 & 0,05 & 0,30 & 0,05 & 0,30 & 0,60 \\
\hline 2,5 & 0,17 & 0,90 & 0,05 & 0,60 & 0,04 & 0,80 & 0,44 \\
\hline 4,5 & 0,40 & 2,50 & 0,12 & 1,20 & 0,04 & 1,40 & 0,85 \\
\hline 8,0 & 0,51 & & & 2,00 & 0,15 & & \\
\hline
\end{tabular}

No que diz respeito ao nitrato $\left(\mathrm{NO}_{3}{ }^{-}\right)$, pode-se dizer que essa foi a forma nitrogenada predominante no reservatório (Figura 20), pois as concentrações desse composto foram mais elevadas que as de $\mathrm{NTK}, \mathrm{N}^{-\mathrm{NH}_{3}}{ }^{-}$e $\mathrm{NO}_{2}{ }^{-}$. Da mesma forma, Soares et al. (2008) concluíram que o $\mathrm{NO}_{3}$ foi a forma mais importante no reservatório do Funil-RJ. Os autores associaram as altas concentrações de 
nutrientes nesse reservatório à influência do principal tributário, rio Paraíba do Sul, o qual tem papel fundamental sobre a dinâmica do reservatório do Funil.

Os resultados indicaram baixa variação vertical das concentrações de nitrato, com ocorrência de maiores valores na primavera e menores no outono em todas as estações de coleta. Esses resultados parecem corroborar a influência do escoamento superficial e, consequentemente, do tipo de uso e ocupação do solo ao aporte de nutrientes ao reservatório Itupararanga. A análise de correlação evidenciou forte relação entre precipitação e $\mathrm{NO}_{3}{ }^{-}$, principalmente em $\mathrm{Br}_{2}$ e $\mathrm{Br}_{3}(\rho=0,8 ; \rho=0,7$, respectivamente) Não menos importante parece ser a contribuição dos tributários para o incremento de $\mathrm{NO}_{3}{ }^{-}$, conforme constatado por Gikas et al. (2009) em um reservatório da Grécia.

É possível verificar ainda, através da Figura 20, que no inverno houve semelhança das concentrações de $\mathrm{NO}_{3}$ em praticamente todas as estações amostrais, com valores médios de 0,84 $\pm 0,08$ $\mathrm{mg} \cdot \mathrm{L}^{-1}, 0,52 \pm 0,05 \mathrm{mg} \cdot \mathrm{L}^{-1}, 0,6 \pm 0,05 \mathrm{mg} \cdot \mathrm{L}^{-1}$ e $0,5 \pm 0,06 \mathrm{mg} \cdot \mathrm{L}^{-1}$ em $\mathrm{Br}_{1}, \mathrm{Br}_{2}, \mathrm{Br}_{3}$ e $\mathrm{Br}_{4}$, respectivamente. As concentrações de $\mathrm{NO}_{3}$ obtidas por Mariani et al. (2006) no reservatório Riacho Grande-SP foram até 11 vezes menores do que as observadas no reservatório Itupararanga; 10 vezes menores que as encontradas no reservatório Paranoá-GO por Padovesi-Fonseca, Philomeno e Andreoni-Batista (2009); e até 4 vezes maior que as registradas no reservatório Rosana por Borges et al. (2010). O reservatório Itupararanga está de acordo com legislação pertinente (CONAMA 357, BRASIL, 2005) para corpos de água classe II (10 mg. $\left.\mathrm{L}^{-1}\right)$.

A distribuição vertical do $\mathrm{NO}_{3}{ }^{-}$na coluna de água esteve, provavelmente, ligada à do $\mathrm{OD}(\rho=$ 0,8 em $\mathrm{Br}_{1} ; \rho=0,8$ em $\mathrm{Br}_{3} ; \rho=0,9$ em $\mathrm{Br}_{4}$ ), uma vez que a elevada atividade fotossintética faz com que maiores teores de oxigênio estejam dissolvidos na água e, consequentemente, diminui o processo de amonificação, favorecendo a formação de nitrato. Sendo assim, pode-se dizer, novamente, que o processo de nitrificação é predominante no reservatório Itupararanga, devido às elevadas concentrações de $\mathrm{OD} \mathrm{e} \mathrm{NO}_{3}^{-}$. 

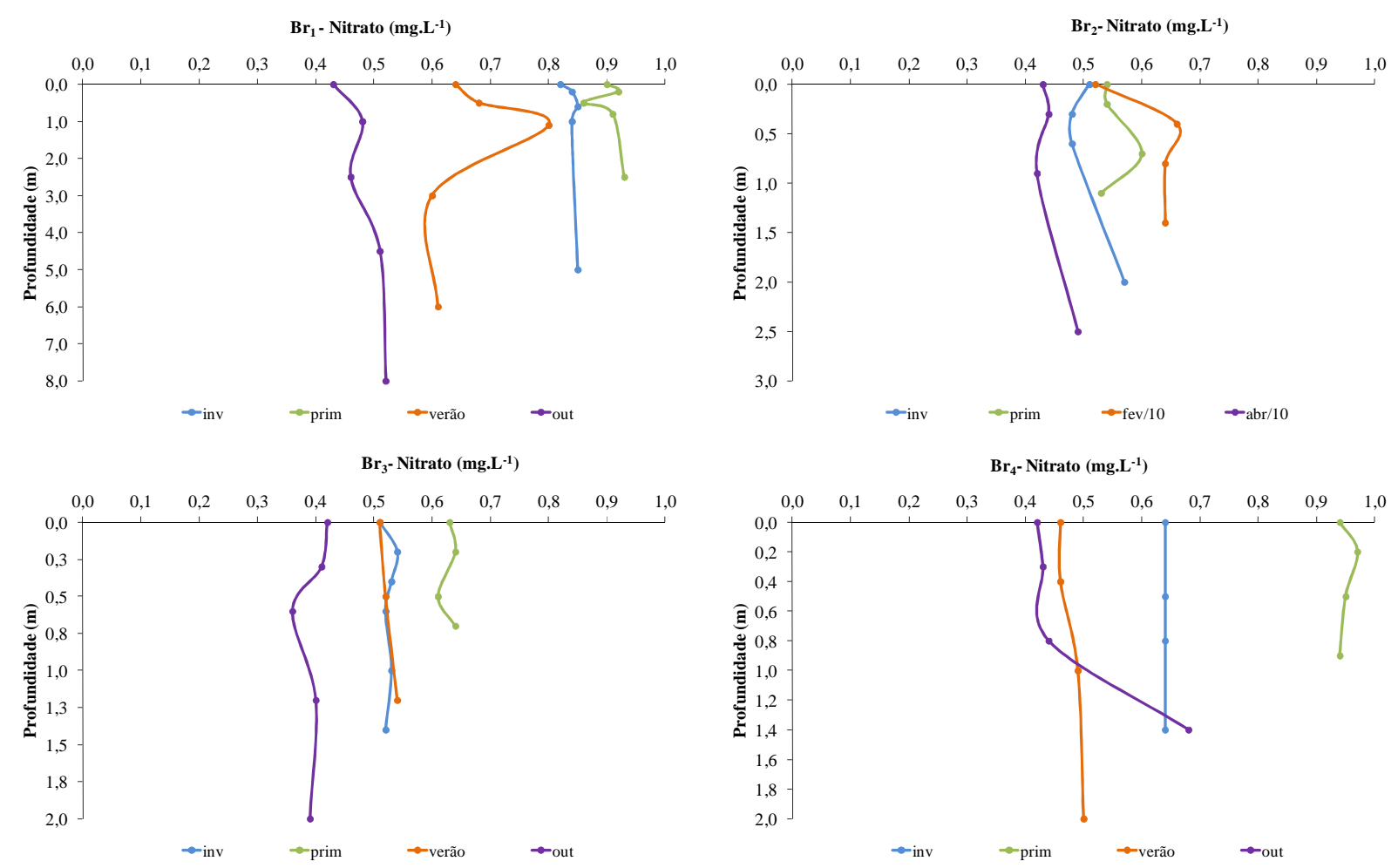

Figura 20: Perfis de nitrato (mg. $\mathrm{L}^{-1}$ ) das estações de amostragem $\mathrm{Br}_{1}, \mathrm{Br}_{2}, \mathrm{Br}_{3}$ e $\mathrm{Br}_{4}$ nos diferentes períodos do ano.

Em relação ao fósforo total (PT), verificou-se que as concentrações desse nutriente tiveram grande variação tanto vertical como sazonal (Figura 21). As maiores concentrações ocorreram na estação de coleta $\mathrm{Br}_{1}$, destacando-se o verão, quando se registrou $126 \mu \mathrm{g} . \mathrm{L}^{-1}$ na superfície da coluna de água. Pedrazzi (2009) também reportou elevadas concentrações de PT na cabeceira do reservatório Itupararanga durante a estação chuvosa, com valores, aproximadamente, três vezes maior do que o obtido no presente estudo. Verificou-se correlação significativa entre PT e precipitação pluviomética ( $\rho$ $=0,7$ em $\mathrm{Br}_{1}, \mathrm{Br}_{2}$ e $\mathrm{Br}_{4}$ ). Por outro lado, Padovesi-Fonseca, Philomeno e Andreoni-Batista (2009), verificaram que as maiores concentrações de PT no reservatório Paranoá-GO ocorreram na estação seca, devido à baixa capacidade de diluição nesse período.

Em todas as estações de amostragem foram obtidas concentrações baixas no outono, exceto na estação $\mathrm{Br}_{3}$, em que a menor média foi registrada no verão. $\mathrm{O}$ mesmo padrão foi observado por Pedrazzi (2009) no reservatório Itupararanga e por González et al. (2004) em um reservatório da Venezuela, os quais atribuíram esses resultados à baixa capacidade de diluição do sistema em períodos de baixas vazões. As maiores concentrações médias foram obtidas na primavera, exceto para $\mathrm{Br}_{3}$, que apresentou elevados valores no inverno. $\mathrm{Na}$ estação de coleta $\mathrm{Br}_{4}$, a $1,4 \mathrm{~m}$, verificou-se a máxima concentração registrada dentre todas as estações de coleta e períodos $\left(144,0 \mu . L^{-1}\right)$. As concentrações médias de PT encontradas no reservatório Itupararanga variaram entre $23 \pm 4,3$ e $87 \pm 13,3 \mu . L^{-1}$, 
valores superiores aos observados por Borges et al. (2010) no reservatório de Rosana-SP (de 11,5 $\mu . \mathrm{L}^{-1}$ a 18,6 $\left.\mu . L^{-1}\right)$. Entretanto, no reservatório Salto Grande, Lopes-Ferreira (2000) encontrou concentrações três vezes superiores $\left(260 \mu . \mathrm{L}^{-1}\right)$. A concentração desse nutriente no reservatório Itupararanga ficou acima do limite preconizado pela resolução CONAMA 357 (BRASIL, 2005) para corpos de água classe II (0,05 mg.L $\left.\mathrm{L}^{-1}\right)$ na maioria das estações de amostragem e períodos estudados.
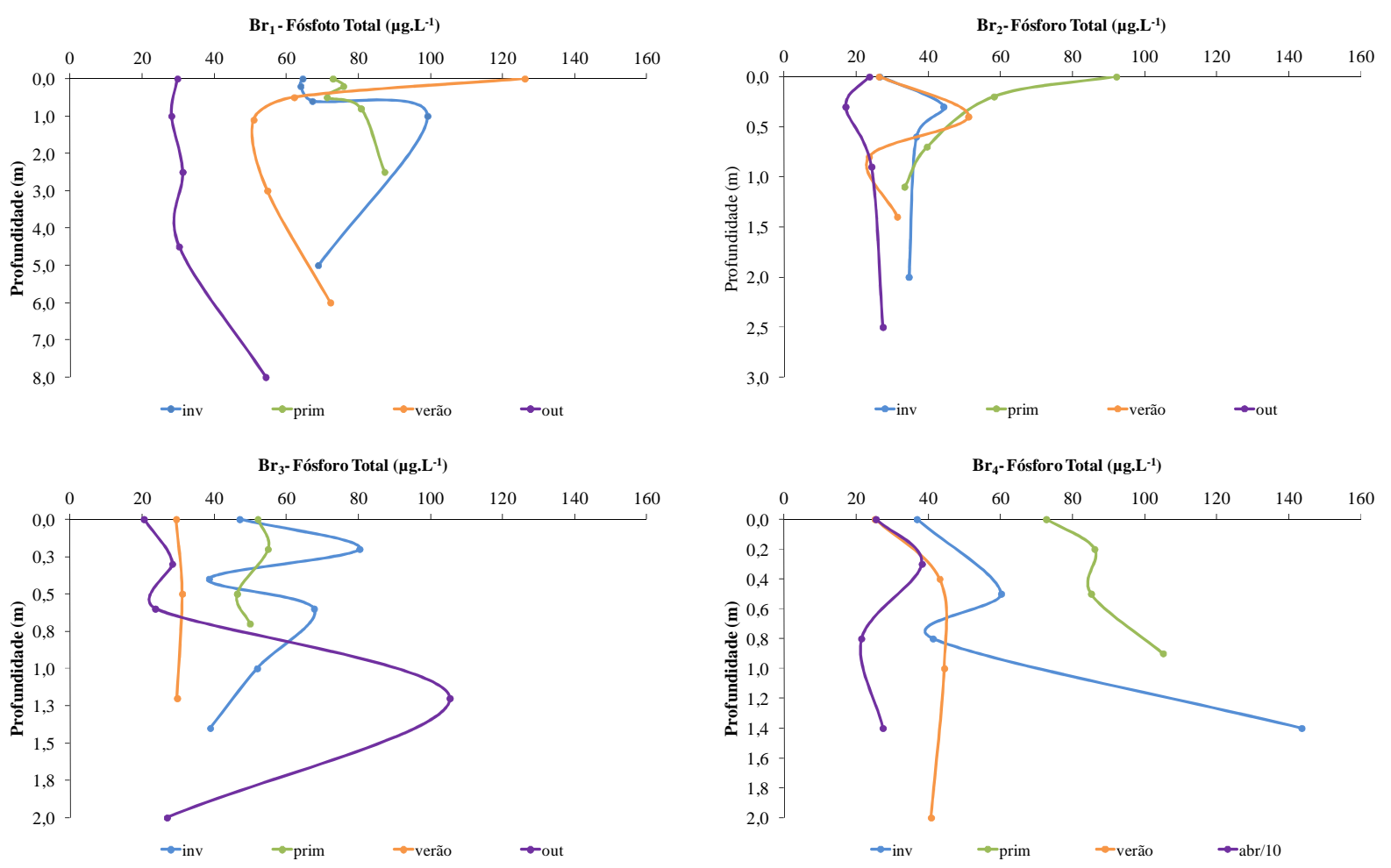

Figura 21: Perfis de Fósforo Total ( $\mu \mathrm{g} . \mathrm{L}^{-1}$ ) das estações de amostragem $\mathrm{Br}_{1}, \mathrm{Br}_{2}, \mathrm{Br}_{3}$ e $\mathrm{Br}_{4}$ nos diferentes períodos do ano.

Na Figura 22 são apresentadas as concentrações de fosfato total dissolvido (PTD) do reservatório Itupararanga. Houve grande variação dessa variável (picos de $87 \mu \mathrm{g} . \mathrm{L}^{-1}$ na estação $\mathrm{Br}_{1} ; 92 \mu \mathrm{g} . \mathrm{L}^{-1}$ na estação $\mathrm{Br}_{2}$ e $83 \mu \mathrm{g} \cdot \mathrm{L}^{-1}$ na estação $\mathrm{Br}_{4}$ ). Além disso, observou-se heterogeneidade temporal das concentrações mínimas e máximas, as quais ocorreram na primavera e no outono, respectivamente. Gentil, Tucci e Sant'Anna (2008) também registraram maiores concentrações de PTD no período de maior intensidade chuvosa na lagoa das Garças-SP. A análise de correlação confirmou a influ6encia da precipitação sobre as concentrações de $\operatorname{PTD}$ em $\operatorname{Br}_{1}, \mathrm{Br}_{2}$ e $\mathrm{Br}_{4}(\rho=0,7 ; \rho=0,8 ; \rho=0,7$, respectivamente)

As maiores concentrações de PTD ocorreram na estação de coleta $\mathrm{Br}_{1}$, enquanto as menores foram observadas, de modo geral, na estação $\mathrm{Br}_{3}$. Os resultados obtidos em $\mathrm{Br}_{1}$ podem estar relacionados com a entrada de esgoto através dos córregos afluentes ou com o escoamento superficial. 
Ainda na estação $\mathrm{Br}_{3}$, pode-se dizer que a coluna de água estava mais homogênea, quando comparada com as demais estações de amostragem.
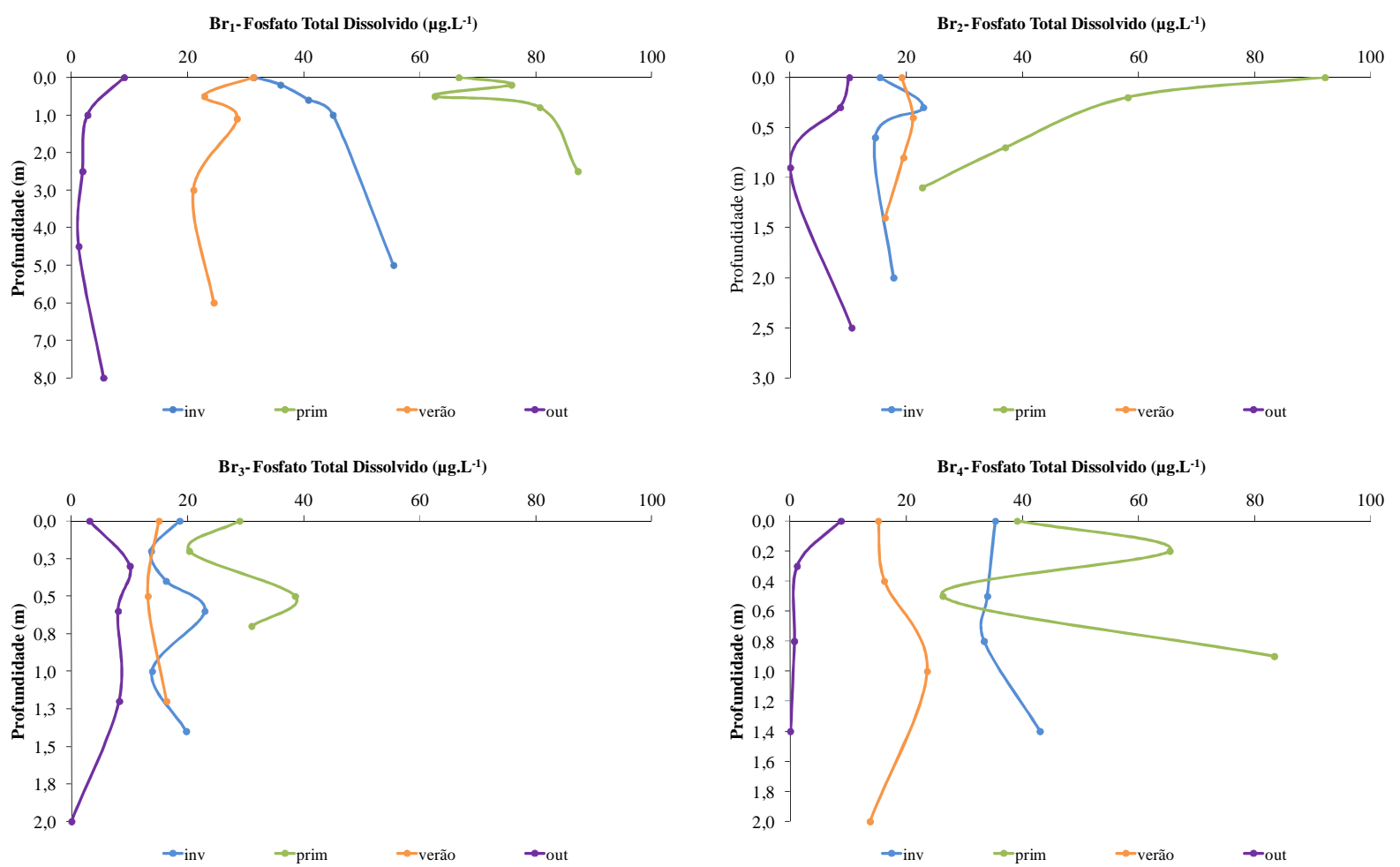

Figura 22: Perfis de Fosfato Total Dissolvido $\left(\mu \mathrm{g} . \mathrm{L}^{-1}\right.$ ) das estações de amostragem $\mathrm{Br}_{1}, \mathrm{Br}_{2}, \mathrm{Br}_{3}$ e $\mathrm{Br}_{4}$ nos diferentes períodos do ano.

O limite de detecção do método de determinação do ortofosfato é $10 \mu \mathrm{g} . \mathrm{L}^{-1}$. Sendo assim, podese verificar, através da Figura 23, que em todas as estações de coleta, exceto em $\mathrm{Br}_{1}$ no inverno, a $5 \mathrm{~m}$ de profundidade, registrou-se concentração abaixo desse valor. Mariani et al. (2006), Gikas et al. (2009) e Friesi et al. (2010) também encontraram concentrações de ortofosfato abaixo do limite de detecção do método. Mariani et al. (2006) comentaram ainda, que essa forma fosfatada pode estar abaixo do mínimo detectável em muitos reservatórios tropicais, pois as altas temperaturas aceleram a utilização do ortofosfato. Provavelmente, no reservatório Itupararanga, o ortofosfato encontrava-se, no momento da amostragem, como componente da biomassa de organismos vivos, que absorvem principalmente essa forma de fósforo como fonte de nutriente.

Apenas na primavera, os valores foram mais elevados na estação amostral $\mathrm{Br}_{1}$, os quais variaram entre 12 e $16 \mu \mathrm{g} . \mathrm{L}^{-1}$. Concentrações de até $9 \mu \mathrm{g} \cdot \mathrm{L}^{-1}$ foram obtidas no reservatório Rosana-SP por Borges et al. (2010), de $140 \mu \mathrm{g} . \mathrm{L}^{-1}$ no reservatório Pao-Cachinche (Venezuela) (GONZÁLEZ et al. 2004) e de até $119 \mu \mathrm{g} . \mathrm{L}^{-1}$ no reservatório Valle Bravo (México) (MERINO-IBARRA et al. 2008). Esse 
fato indica que as concentrações de ortofosfato podem apresentar grande variação ao longo de um gradiente de latitude ou até mesmo dependendo das condições locais no momento da amostragem.
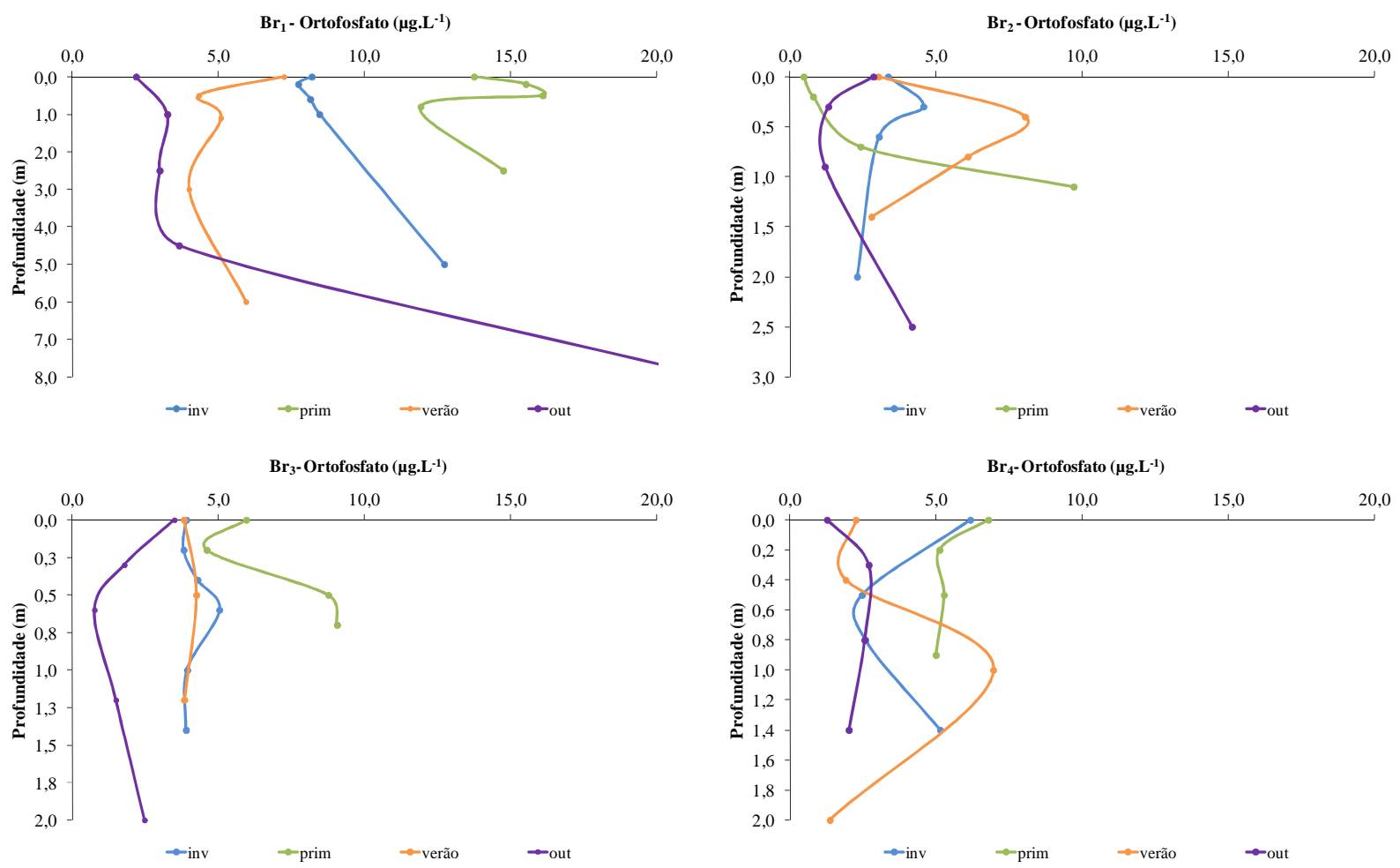

Figura 23: Perfis de ortofosfato ( $\left.\mu \mathrm{g} . \mathrm{L}^{-1}\right)$ das estações de amostragem $\mathrm{Br}_{1}, \mathrm{Br}_{2}, \mathrm{Br}_{3}$ e $\mathrm{Br}_{4}$ nos diferentes períodos do ano.

A coluna de água estava praticamente homogênea em relação às concentrações de carbono orgânico total (COT), com exceção da estação $\mathrm{Br}_{3}$ no inverno (Figura 24). Na estação de amostragem $\mathrm{Br}_{1}$ ocorreu maior variação das concentrações entre os períodos amostrados, entre 3,0 e 5,0 mg. $\mathrm{L}^{-1}$. No inverno verificou-se um pico a $0,6 \mathrm{~m}\left(8,16 \mathrm{mg} . \mathrm{L}^{-1}\right)$, sendo que na superfície a concentração foi de 5,04 mg. $\mathrm{L}^{-1}$. Esses resultados, provavelmente, refletem a entrada de carga orgânica pelos rios formadores do reservatório, conforme constatado por Hobson et al. (2010) nos reservatórios de Myponga e Little Para, na Austrália.

Em todas as estações de amostragem, as maiores concentrações foram obtidas no verão, exceto em $\mathrm{Br}_{1}$, onde se observou concentrações mais elevadas no inverno. As menores concentrações de COT foram registradas no outono nas quatro estações de amostragem. É interessante notar que quando a contribuição relativa dos SSO foi maior, a concentração de COT aumentou. 

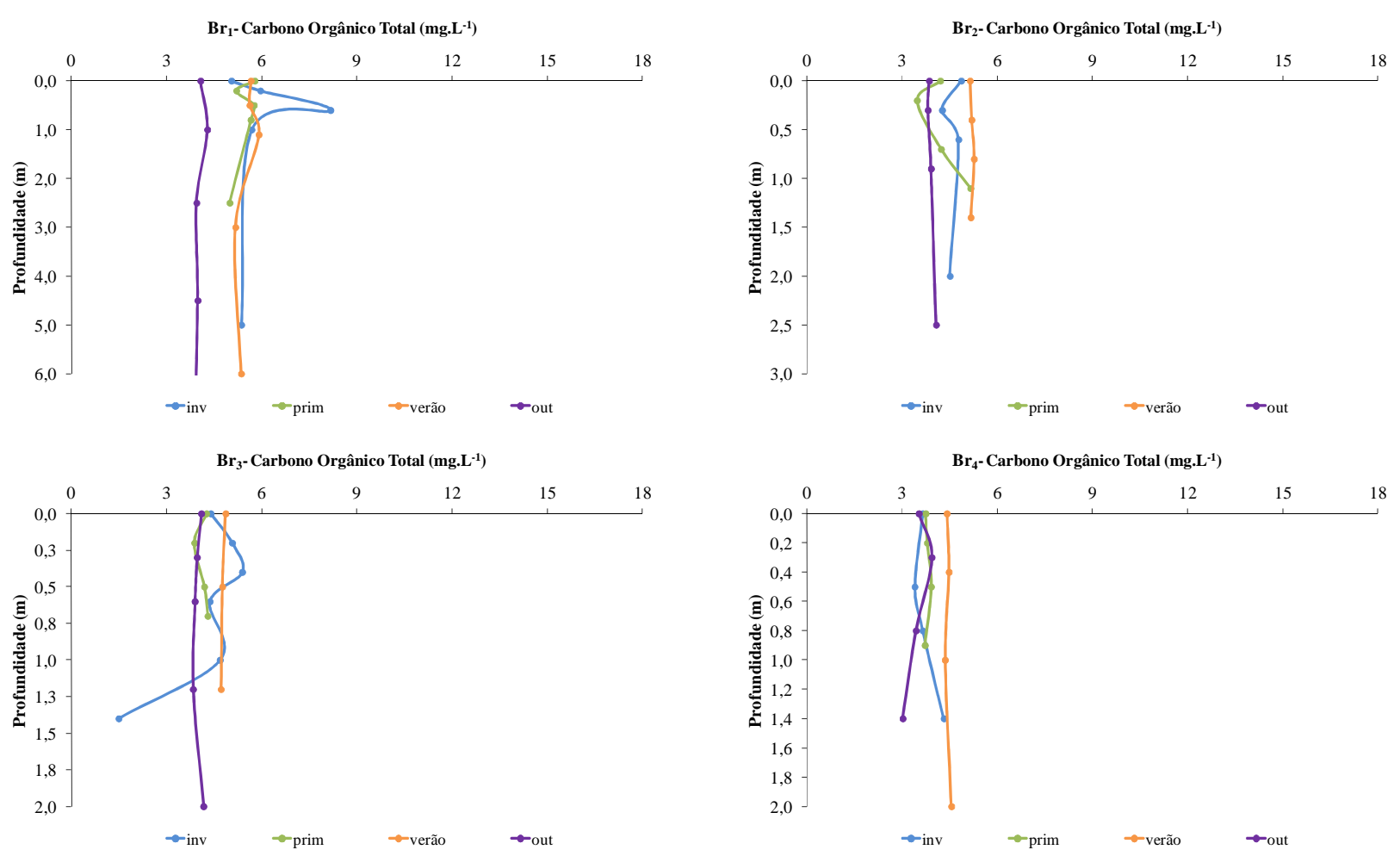

Figura 24: Perfis de Carbono Orgânico Total (COT) (mg.L $\mathrm{L}^{-1}$ ) das estações de amostragem $\mathrm{Br}_{1}, \mathrm{Br}_{2}, \mathrm{Br}_{3}$ e $\mathrm{Br}_{4}$ nos diferentes períodos do ano.

A coluna de água apresentou-se mais homogênea para as concentrações de carbono inorgânico (CI) (Figura 25) nas estações de coleta $\mathrm{Br}_{3}$ e $\mathrm{Br}_{4}$, exceto na primavera. Verificou-se uma tendência de aumento das concentrações da superfície ao fundo, evidenciando a formação de $\mathrm{CO}_{2}$ no fundo da coluna de água, corroborando os resultados obtidos para o pH. Em algumas estações de amostragem (a 2,5 m na estação $\mathrm{Br}_{1}$ na primavera e à 2,0 m e $1,0 \mathrm{~m}$ na estação $\mathrm{Br}_{2}$ no inverno e na primavera, respectivamente) obtiveram-se concentrações muito baixas $\left(<0,01 \mathrm{mg} . \mathrm{L}^{-1}\right)$. Dentre as estações de amostragem, $\mathrm{Br}_{4}$ foi a que apresentou as concentrações de $\mathrm{CI}$ mais elevadas, com pico de $29,0 \mathrm{mg} . \mathrm{L}^{-1}$ na superfície da coluna de água na primavera. As menores concentrações ocorreram no outono em todas as estações de coleta, enquanto as maiores foram registradas na primavera, coincidindo com os picos de condutividade elétrica e SSI. Nas estações $\mathrm{Br}_{1}$ e $\mathrm{Br}_{4}$ foram obtidas fortes correlações entre CI e precipitação pluviométrica ( $\rho=0,7$ para ambas as estações de amostragem) 

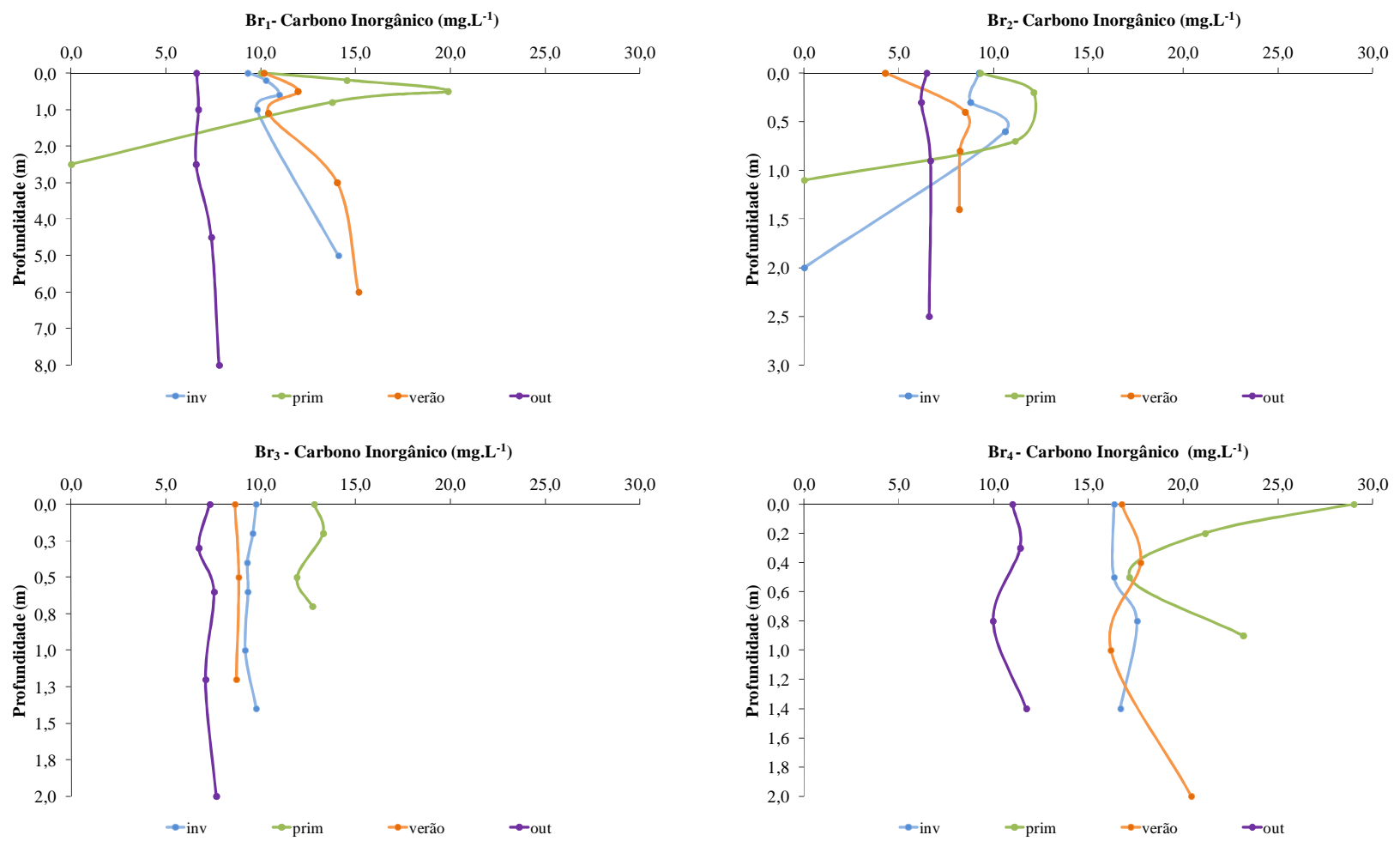

Figura 25: Perfis de Carbono Inorgânico (CI) (mg.L $\mathrm{L}^{-1}$ ) das estações de amostragem $\mathrm{Br}_{1}, \mathrm{Br}_{2}, \mathrm{Br}_{3}$ e $\mathrm{Br}_{4}$ nos diferentes períodos do ano.

O resultado do teste MANOVA sugeriu diferença significativa, tanto entre as estações de amostragem, como entre os períodos estudados ( $\mathrm{p}<0,01$ para ambos os casos). Dessa forma, realizouse um segundo teste para cada estação de amostragem, com o intuito de verificar a ocorrência de diferença significativa entre as variáveis limnológicas amostradas nas diferentes profundidades. A análise dos dados indicou diferença significativa entre as profundidades amostradas $(\mathrm{p}<0,01$ para todos os casos).

A variação vertical das variáveis físicas e químicas da água indicou que os braços do reservatório Itupararanga apresentam heterogeneidade espaço-temporal, onde ocorreram estratificações químicas e térmicas. Esse fato pode influenciar a distribuição das comunidades biológicas, bem como o manejo desse manancial, devido à dinâmica de nutrientes e gases dissolvidos na coluna de água. Verificou-se, ainda, que a área de entorno do reservatório pode exercer importante papel sobre a qualidade das águas, devido à lixiviação da bacia de drenagem em períodos chuvosos. Esse fato pode ser confirmado através dos resultados de condutividade elétrica, SST, SSI, PT e CI, maiores em períodos de precipitação pluviométrica elevada. Deve-se mencionar também, a contribuição dos tributários ao aporte de substâncias ao reservatório, principalmente na cabeceira do mesmo. 


\subsubsection{Compartimento Sedimento}

Em todas as estações amostrais, as concentrações de fósforo total no sedimento foram semelhantes sazonalmente (Tabela 13). As menores concentrações, na maioria das estações de coleta, foram registradas no inverno (entre 0,2 e $0,3 \mu \mathrm{g} \cdot \mathrm{g}^{-1}$ ). Em $\mathrm{Br}_{1}$ verificou-se maior concentração de fósforo total na primavera $\left(2,0 \mu \mathrm{g} \cdot \mathrm{g}^{-1}\right)$, enquanto em $\mathrm{Br}_{2} \mathrm{o}$ máximo foi obtido no verão $\left(2,2 \mu \mathrm{g} \cdot \mathrm{g}^{-1}\right)$, assim como na estação $\mathrm{Br}_{3}\left(3,0 \mu \mathrm{g} \cdot \mathrm{g}^{-1}\right)$. As menores concentrações de fósforo total no sedimento ocorreram na estação de amostragem $\mathrm{Br}_{4}$, sendo que a mais alta $\left(2,0 \mu \mathrm{g} \cdot \mathrm{g}^{-1}\right)$ ocorreu no outono. Os resultados de fósforo no sedimento do reservatório Itupararanga foram extremamente baixos quando comparados com os obtidos por Friesi et al. (2010) na Lagoa da Pampulha-MG, que apresentou concentrações de até $12 \mu \mathrm{g} \cdot \mathrm{g}^{-1}$.

Comparativamente ao fósforo, o nitrogênio total apresentou concentrações elevadas no sedimento (Tabela 13), e grande variação temporal. Entretanto, não é possível afirmar que tal variação tenha sido sazonal. Observou-se considerável oscilação temporal da concentração de nitrogênio total na estação $\mathrm{Br}_{1}$ (valores entre 1465 e $280 \mu \mathrm{g} \cdot \mathrm{g}^{-1}$ ). Essa variação foi menor na estação $\mathrm{Br}_{3}$, que apresentou maior concentração na primavera $\left(2445 \mu \mathrm{g} \cdot \mathrm{g}^{-1}\right)$, após eventos de precipitação, e menor no outono (1484 $\left.\mu \mathrm{g} \cdot \mathrm{g}^{-1}\right)$. Na estação de amostragem $\mathrm{Br}_{2}$ foram encontradas as concentrações mais elevadas, com máxima registrada no verão $\left(4648 \mu \mathrm{g} \cdot \mathrm{g}^{-1}\right)$ e mínima no inverno $\left(2277 \mu \mathrm{g} \cdot \mathrm{g}^{-1}\right)$. Em contrapartida, as menores concentrações de nitrogênio total foram obtidas em $\mathrm{Br}_{4}$, com valor mínimo de $270 \mu \mathrm{g}^{-1} \mathrm{~g}^{-1}$, no inverno, e máximo de $952 \mu \mathrm{g} \cdot \mathrm{g}^{-1}$, no outono. Dessa maneira, é possível notar que mesmo a menor concentração registrada na estação $\mathrm{Br}_{2}$ foi elevada, mais de 8 vezes maior, que a concentração mínima observada em $\mathrm{Br}_{4}$.

Cavenaghi et al. (2003) também encontrou resultados elevados de nitrogênio total no sedimento em cinco reservatórios da bacia do rio Tietê-SP, destacando-se os reservatórios de Barra Bonita (até $1270 \mu \mathrm{g} \cdot \mathrm{g}^{-1}$ ) e Ibitinga (até $2323 \mu \mathrm{g} \cdot \mathrm{g}^{-1}$ ). O autor atribuiu esses resultados ao uso agrícola da bacia. Sabe-se que o entorno do reservatório Itupararanga é principalmente ocupado por plantações de hortaliças (IPT, 2006), as quais necessitam de grande quantidade de fertilizantes e agrotóxicos. Esse fato pode acarretar o incremento de nitrogênio no sedimento, além disso, a presença de macrófitas aquáticas pode contribuir com as elevadas concentrações de nitrogênio, devido à decomposição das mesmas.

Na Tabela 13 é possível visualizar os resultados de porcentagem de matéria orgânica no sedimento. Para a estação de amostragem $\mathrm{Br}_{1}$, pode-se dizer que houve um comportamento sazonal do 
teor de matéria orgânica no sedimento, pois as porcentagens obtidas foram maiores no inverno e menores nos demais períodos, com mínimo valor registrado no verão $(2,0 \%)$. Para as demais estações de amostragem, não se observou esse comportamento, provavelmente porque $\mathrm{Br}_{1}$ é influenciada diretamente pelos rios formadores do reservatório. Nas estações $\mathrm{Br}_{2}$ e $\mathrm{Br}_{3}$ verificou-se que os teores de matéria orgânica foram mais elevados no verão ( $26 \%$ e $20 \%$, respectivamente), os quais decresceram no outono (19\% em $\mathrm{Br}_{2}$ e 12,4\% em $\mathrm{Br}_{3}$ ). Novamente na estação de coleta $\mathrm{Br}_{4}$ foram observados os menores conteúdos de matéria orgânica no sedimento, sendo que o menor ocorreu na primavera (4\%) e o maior no outono $(14 \%)$.

Tabela 13: Matéria Orgânica no Sedimento (MOS) (\%), Fósforo Total no Sedimento (PTS) ( $\left.\mu \mathrm{g} \cdot \mathrm{g}^{-1}\right)$ e Nitrogênio Total no Sedimento (NTS) $\left(\mu \mathrm{g} \cdot \mathrm{g}^{-1}\right)$ nas estações de amostragem $\mathrm{Br}_{1}, \mathrm{Br}_{2}, \mathrm{Br}_{3}$ e $\mathrm{Br}_{4}$ nos diferentes períodos do ano

\begin{tabular}{|c|c|c|c|c|}
\hline Variável & Local & MOS & PTS & NTS \\
\hline \multicolumn{5}{|l|}{ Estação do ano } \\
\hline \multirow{4}{*}{ INVERNO } & $\mathrm{Br}_{1}$ & 16,4 & 1,3 & 1465 \\
\hline & $\mathrm{Br}_{2}$ & 19,0 & 0,24 & 2277 \\
\hline & $\mathrm{Br}_{3}$ & 19,0 & 0,3 & 1773 \\
\hline & $\mathrm{Br}_{4}$ & 8,0 & 0,2 & 270 \\
\hline \multirow{4}{*}{ PRIMAVERA } & $\mathrm{Br}_{1}$ & 6,4 & 2,0 & 952 \\
\hline & $\mathrm{Br}_{2}$ & 14,0 & 1,75 & 2510 \\
\hline & $\mathrm{Br}_{3}$ & 18,5 & 3,0 & 2445 \\
\hline & $\mathrm{Br}_{4}$ & 4,0 & 0,2 & 298 \\
\hline \multirow{4}{*}{ VERÃO } & $\mathrm{Br}_{1}$ & 2,0 & 0,2 & 336 \\
\hline & $\mathrm{Br}_{2}$ & 26,0 & 2,2 & 4648 \\
\hline & $\mathrm{Br}_{3}$ & 20,0 & 2,15 & 2193 \\
\hline & $\mathrm{Br}_{4}$ & 5,0 & 0,4 & 438 \\
\hline \multirow{4}{*}{ OUTONO } & $\mathrm{Br}_{1}$ & 3,4 & 0,15 & 280 \\
\hline & $\mathrm{Br}_{2}$ & 18,5 & 1,3 & 2333 \\
\hline & $\mathrm{Br}_{3}$ & 12,4 & 1,4 & 1484 \\
\hline & $\mathrm{Br}_{4}$ & 14,0 & 2,0 & 952 \\
\hline
\end{tabular}

Os resultados da análise de granulometria (Figura 26) indicaram que, na estação de amostragem $\mathrm{Br}_{1}$, a fração silte (diâmetro dos grãos de aproximadamente $0,1 \mathrm{~mm}$ ) foi mais abundante no inverno. Além disso, encontrou-se frações como areia fina e areia média em menor quantidade. Na primavera, 
essas mesmas frações foram obtidas na estação $\mathrm{Br}_{1}$, porém em quantidades superiores. Os resultados observados no verão mostraram que a fração silte estava presente em elevada quantidade (aproximadamente 87\%), enquanto que a areia foi menor (aproximadamente 20\%). No outono, novamente, a fração silte estava presente em alta quantidade e registrou-se menor média para a areia nessa estação de coleta $(18 \%)$.

$\mathrm{Na}$ estação de coleta $\mathrm{Br}_{2}$, na amostragem realizada no inverno, entre $20 \%$ e $25 \%$ eram silte. Também se verificou a presença de areia fina e areia média (7\% e 4\%, respectivamente). Na primavera observou-se o mesmo padrão de distribuição dos grãos, entretanto a fração silte foi ligeiramente maior, enquanto a areia fina menor (aproximadamente $2 \%$ ). Obteve-se maior quantidade de silte no verão (31\%). Ainda nesse período, observou-se $1,7 \%$ de areia fina. Valores entre $21 \%$ e $29 \%$ foram encontrados no outono para a fração silte em $\mathrm{Br}_{2}$. A quantidade de areia fina foi aproximadamente $4,5 \%$ e areia média de $2 \%$.

$\mathrm{Na}$ estação de coleta $\mathrm{Br}_{3}$, no inverno, verificou-se que a fração silte estava presente em baixa quantidade (entre 13\% e 16\%). Ainda nesse local, observou-se a presença de areia fina e média (3\% e 1,5\%, respectivamente). Em comparação ao inverno, na primavera, encontrou-se porcentagem inferior da fração silte (entre $8 \%$ e 15,5\%), bem como a fração areia fina (entre 0,5\% e 1\%). No verão observou-se que a fração silte foi mais elevada (entre 45\% e 69\%). As frações areia fina e areia média atingiram $13 \%$ e $2 \%$, respectivamente. No outono também se verificou grande quantidade de silte, porém menor quando comparada com o verão (entre $19 \%$ e $29 \%$ ). As porcentagens de areia fina e média foram de $6 \%$ e $0,8 \%$, respectivamente.

$\mathrm{Na}$ estação $\mathrm{Br}_{4}$, obtiveram-se valores entre $55 \%$ e $63 \%$ da fração silte no inverno. Tais porcentagens foram altas quando comparadas com as obtidas em outras estações de amostragem no mesmo período. Foram encontradas ainda porcentagens entre $10 \%$ e $30 \%$ de areia fina e $2 \%$ de areia média. Encontrou-se elevados valores da fração silte (entre 73\% e 75\%) na primavera. Deve-se mencionar ainda, que a fração areia estava presente em grande quantidade (entre $65,3 \%$ e 57,3\% de areia fina e entre $23,4 \%$ e $51 \%$ de areia média). No verão, entre $30,7 \%$ e $36,4 \%$ pertenciam à fração silte. Em relação às frações de areia, entre $2 \%$ e $11 \%$ eram de areia fina e $0,5 \%$ de areia média. Novamente, no outono, registrou-se elevada quantidade de silte (entre $51 \%$ e 61\%), de areia fina (entre $17 \%$ e $35 \%)$ e de areia média $(4,2 \%)$.

Os resultados da análise das frações granulométricas revelaram a prevalência de silte no sedimento, porém em períodos chuvosos (principalmente na primavera) houve um aumento da ocorrência de areia fina e média. Esse resultado pode estar relacionado com a drenagem dos tributários e da bacia como um todo na época de fortes chuvas que carreia materiais mais pesados. O silte, 
entretanto, por ser um material de baixa resistência, pode ser trazido pelos rios até mesmo nos períodos de menor vazão.
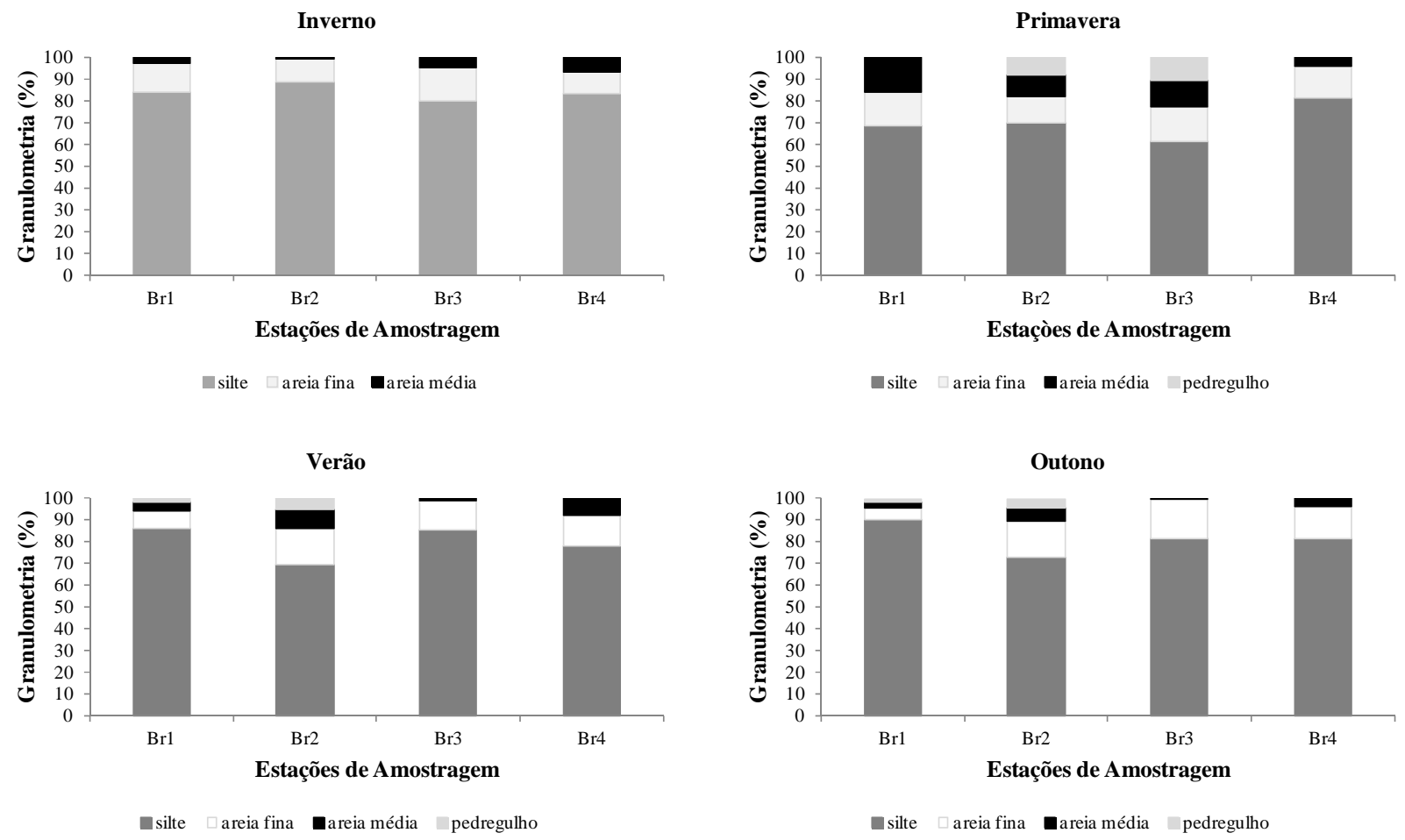

Figura 26: Frações granulométricas (\%) nas estações de amostragem $\mathrm{Br}_{1}, \mathrm{Br}_{2}, \mathrm{Br}_{3}$ e $\mathrm{Br}_{4}$ nos diferentes períodos do ano.

\subsubsection{Variáveis Biológicas - Comunidade de Macrófitas Aquáticas}

De acordo com Dos Santos e Calijuri (2001), a maioria dos ecossistemas aquáticos lênticos do estado de São Paulo é eutrófico. Em conseqüência, vários autores (TANAKA et al. 2002; CARVALHO et al. 2003; CARVALHO, VELINI e MARTINS 2005; CAVENAGHI et al. 2005) tem reportado um aumento da biomassa de macrófitas, principalmente de espécies livre flutuantes. Embora os benefícios das macrófitas para os ecossistemas aquáticos sejam reconhecidos (MARION e PAILLISSON, 2003; THOMAZ, SOUZA e BINI, 2003; CRONIN, LEWIS e SCHIEHSER, 2006; NAHLIK e MITSCH, 2006; VERHOEVEN et al. 2006; REJMÁNKOVÁ e SIROVÁ, 2007; KOUKI et al. 2009; HASSAN et al. 2010; VYMAZAL, 2011), o crescimento exacerbado das mesmas interfere na utilização dos recursos hídricos (PIETERSE e MURPHY, 1993), através do bloqueio do fluxo de água, depleção do oxigênio dissolvido e problemas na geração de energia e navegação. Devido a esses fatores (ambos, problemas e benefícios), o estudo da comunidade de macrófitas aquáticas é de suma importância, 
principalmente, em ecossistemas com escassez de informações e com potencial para a infestação de plantas, como no caso do reservatório Itupararanga-SP.

Na Figura 27 pode-se visualizar a variação da biomassa das diferentes partes das espécies de macrófitas aquáticas predominantes nos quatro braços amostrados. $\mathrm{Na}$ estação de coleta $\mathrm{Br}_{1}$, onde Eichhornia crassipes foi uma das espécies dominantes, maior biomassa da parte aérea da planta foi obtida no outono $\left(648,0\right.$ gPS.m $\left.{ }^{-2}\right)$. A biomassa determinada nas raízes sofreu baixa oscilação entre os períodos amostrados e o maior valor foi registrado na primavera $\left(301,3 \mathrm{gPS} . \mathrm{m}^{-2}\right)$. Para essa mesma espécie, a menor biomassa da parte aérea foi obtida no inverno (163,2 gPS.m ${ }^{-2}$ ), período em que a contribuição de biomassa foi maior na parte das raízes. A menor biomassa das raízes foi observada no verão $\left(217,3\right.$ gPS.m $\left.{ }^{-2}\right)$. Esses resultados sugerem que E. crassipes aloca maior biomassa na parte aérea em períodos de temperatura mais elevada, favorecendo, dessa forma, o crescimento da planta. A contribuição das raízes é maior em períodos de menor temperatura fotoperíodo, aumentando a taxa de respiração. Os resultados obtidos no verão podem ter sido influenciados pela intensa precipitação que ocorreu entre janeiro e fevereiro de 2010 e que fez com que frações dos bancos se deslocassem do braço para o eixo central do reservatório.

Ainda na estação $\mathrm{Br}_{1}$, encontrou-se Pistia stratiotes. Essa espécie estava em baixa quantidade na amostragem realizada na primavera e por isso não foi amostrada. Assim como para E. crassipes, a maior biomassa da parte aérea de $P$. stratiotes foi registrada no outono $\left(451,3 \mathrm{gPS} . \mathrm{m}^{-2}\right)$ e a menor no inverno (148,3 gPS.m $\left.{ }^{-2}\right)$. Os valores de biomassa das raízes tiveram maior variação, com máxima de 202 gPS.m ${ }^{-2}$ no verão e mínima de 71,1 gPS.m ${ }^{-2}$ no inverno. O máximo valor de biomassa de $P$. stratiotes coincidiu com a maior concentração de NTK e o crescimento dessa espécie tem sido reportado como dependente da concentração de nitrogênio (HENRY-SILVA, CAMARGO e PEZZATO, 2008). Além disso, foi possível verificar correlação positiva entre NTK e a biomassa de P. stratiotes $(\rho=0,9)$, tanto parte aérea como submersa.

Em estudo realizado com P. stratiotes, Cancian, Camargo e Henry-Silva (2009) concluíram que, a $25^{\circ} \mathrm{C}$, o ganho de biomassa dessa macrófita é maior do que a $15^{\circ} \mathrm{C}$ e $30^{\circ} \mathrm{C}$. Esse fato pode estar relacionado com os resultados obtidos, pois se observou elevada biomassa no outono, período posterior ao verão, com temperaturas da água mais elevadas, em torno de $25^{\circ} \mathrm{C}$. No inverno e primavera registraram-se baixos valores de biomassa devido, provavelmente, às menores temperaturas. Além disso, no verão verificou-se recuperação da biomassa de $P$. stratiotes, com valores elevados tanto da parte aérea como da submersa, demonstrando a capacidade de recuperação dessa espécie.

Lacoul e Freedman (2006) mencionaram que a presença de E. crassipes e P. stratiotes está associada à concentração de nutrientes. Similarmente, Bini et al. (1999) afirmaram que a concentração 
de fósforo total foi um importante preditor para a presença dessas espécies no reservatório de ItaipuPR. Além disso, sabe-se que essas espécies são abundantes em ecossistemas eutróficos (HENRYSILVA, CAMARGO e PEZZATO, 2008). De acordo com a análise de CCA (Figura 28), E. crassipes e P. stratiotes parecem ter sido influenciadas tanto por PT como por COT no reservatório Itupararanga.

Em relação à senescência de $P$. stratiotes observada na primavera, pode-se associar esse fato está ao processo de competição com E. crassipes, pois esta tem vantagem competitiva sobre $P$. stratiotes (MILNE, LANG e MURPHY, 2007). P. stratiotes esteve senescente quando a biomassa de $E$. crassipes aumentou aproximadamente $56 \%$ e essa última normalmente tem vantagens competitivas devido ao seu intenso crescimento, eficiente uso da energia solar e alta capacidade de absorver nutrientes quando esses são abundantes (AGAMI e REDDY, 1990; HENRY-SILVA, CAMARGO e PEZZATO, 2008). Além disso, Sajna et al. (2007) concluíram que baixas temperaturas são desfavoráveis para $P$. stratiotes (a temperatura da água variou entre $18,9^{\circ} \mathrm{C}$ e $19,9^{\circ} \mathrm{C}$ no período de senescência da $P$. stratiotes no reservatório Itupararanga).

Nas estações de amostragem $\mathrm{Br}_{2}$ e $\mathrm{Br}_{3}$, a espécie dominante foi Polygonum lapathifolium. Em $\mathrm{Br}_{2}$ verificou-se que, no inverno, a biomassa de $P$. lapathifoilum estava elevada $\left(966,27 \mathrm{gPS} . \mathrm{m}^{-2}\right)$, a qual decaiu na primavera (391,1 gPS.m ${ }^{-2}$ ). Pitelli et al. (2009) estudaram o comportamento de colonização de macrófitas aquáticas no reservatório de Santana - RJ e concluíram que a população de $P$. lapathifolium possui grande plasticidade fenotípica, mantendo alta sua taxa de colonização que ocorre a partir de agosto. Em $\mathrm{Br}_{3}$ a maior biomassa ocorreu no outono (541,5 gPS.m ${ }^{-2}$ ), e a menor no verão (410 gPS. $\left.\mathrm{m}^{-2}\right)$. Esse resultado pode estar relacionado com a alta pluviosidade de janeiro e fevereiro de 2010, que fez com que os bancos se desprendessem do seu local original, formando ilhas no eixo central do reservatório. Essas ilhas continuam produtivas e ao atingirem novamente a margem, por ação dos ventos, podem voltar a se desenvolver intensamente (PITELLI et al. 2009). O incremento da biomassa do verão para o outono em $\mathrm{Br}_{3}$ indica a capacidade dessa espécie de se recuperar após um distúrbio, conforme reportado por Willis e Mitsh (1995).

A análise de CCA (Figura 28) revelou uma relação positiva de P. lapathifolium (tanto em $\mathrm{Br}_{2}$ como em $\mathrm{Br}_{3}$ ) com pH e OD. Os coeficientes de correlação foram elevados para a relação entre $\mathrm{P}$. lapathifolium, $\mathrm{pH}$ e OD ( $\rho=0,7$ e $\rho=0,94$, respectivamente). Elevados valores de $\mathrm{pH}$ foram registrados nas estações de amostragem com presença de $P$. lapathifolium, assim como reportado por Takamura et al. (2003) para Polygonaceae em lagos rasos do Japão. Além disso, os resultados sugerem que PT estava inversamente correlacionado com a referida espécie e que o sedimento parece ter sido um importante fator para o desenvolvimento de P. lapathifolium, influenciando a distribuição dessa 
planta no reservatório. Willis e Mitsh (1995) concluíram que o desenvolvimento de biomassa dessa espécie é limitado por nitrogênio no sedimento, uma vez que em meios enriquecidos com esse nutriente houve maior acúmulo de massa de P. lapathifolium. As concentrações de nitrogênio no sedimento do reservatório Itupararanga foram altas, principalmente nas estações $\mathrm{Br}_{2}$ e $\mathrm{Br}_{3}$, favorecendo o desenvolvimento da espécie nesses locais. A análise de correlação permitiu evidenciar a relação entre fósforo no sedimento, nitrogênio no sedimento e P. lapathifolum ( $\rho=0,8$ e $\rho=0,7$, respectivamente)

De acordo com Takamura et al. (2003), Polygonaceae é importante para restringir a liberação de $\mathrm{P}$ do sedimento devido às altas concentrações de OD nos bancos dessas plantas, mesmo no fundo, assim como observado no reservatório Itupararanga (de 6,5 a 8,94 mg. $\mathrm{L}^{-1}$ ). Sob esse aspecto, pode-se assumir que o banco de $P$. lapathifolium no reservatório Itupararanga estava em fase de desenvolvimento, uma vez que essa espécie possui altos teores de celulose e hemicelulose (ANDERSON e SMITH, 2002) e sua decomposição poderia acarretar condições de anoxia, contribuindo para o processo de eutrofização. Em ambas as estações de amostragem com a presença de P. lapathifolium $\left(\mathrm{Br}_{2}\right.$ e $\left.\mathrm{Br}_{3}\right)$ foram verificadas elevadas concentrações de PTS quando a biomassa dessa espécie foi maior. Sendo assim, os resultados obtidos corroboram as afirmações de Takamura et al. (2003).

Observou-se comportamento bastante diverso na estação de coleta $\mathrm{Br}_{4}$, com predomínio de Eichhornia azurea no inverno, Myriophyllum aquaticum na primavera e quantidades insignificantes de ambas as espécies no verão e outono. Em relação à E. azuera, a contribuição das raízes foi maior (510 gPS.m ${ }^{-2}$ ) quando comparada com a contribuição da parte aérea $\left(107\right.$ gPS.m ${ }^{-2}$ ). As variações de biomassa entre as partes de uma planta podem ocorrer devido às diferentes funções da estrutura do vegetal (BIUDES e CAMARGO, 2008). A biomassa de M. aquaticum foi 317,1 gPS.m ${ }^{-2}$ e essa planta correlacionou-se com sólidos totais e inorgânicos e $\mathrm{NO}_{2}$ (Figura 28). Lacoul e Freedman (2006) citaram a importância de compostos inorgânicos e condutividade elétrica como preditores da presença de M. aquaticum. E. azurea foi influenciada pelas concentrações de COT e essa espécie estava ausente quando o pH e a concentração de SST foram elevadas, assim como mencionado por Bini et al. (1999) no reservatório de Itaipu.

Quanto à diversidade de espécies, os resultados desse estudo indicaram um baixo número de taxa (9 taxa) de macrófitas aquáticas quando comparado com outras pesquisas realizadas em reservatórios brasileiros (THOMAZ et al. 1999; TANAKA et al. 2002; CARVALHO et al. 2003, CAVENAGHI et al. 2003; BINI et al. 2005 e MARTINS et al. 2008), entretanto apenas quatro braços do reservatório Itupararanga foram estudados. Na pesquisa realizada por Pavão (2011), em nove braços do reservatório Itupararanga, a autora registrou 16 taxa, revelando a dominância de espécies emergentes. Em cinco 
outros reservatórios da bacia do rio Tietê, Cavenaghi et al. (2003) também verificaram predomínio de espécies emergentes.

De acordo com Jeffries (2008), os padrões de cobertura de macrófitas aquáticas são dependentes da heterogeneidade espacial e temporal dos ecossistemas aquáticos. Essa afirmação corrobora com os resultados obtidos no reservatório Itupararanga, os quais sugeriram variação temporal e espacial das variáveis limnológicas e podem ter influenciado a cobertura de macrófitas aquáticas.

Cheruvelil e Soranno (2008) destacaram as atividades antropogênicas como fatores responsáveis pela presença de macrófitas aquáticas. Esses autores observaram uma ligação entre agricultura e a presença de macrófitas emergentes, bem como da densidade de estradas e a cobertura de macrófitas flutuantes. Similarmente Pozo, Fernández-Aláez e Fernández-Alaéz (2011) concluíram que a ocorrência de macrófitas emergentes e flutuantes pode ser melhor explicada a partir de variáveis de uso e ocupação do solo. Essas conclusões corroboram os resultados obtidos no reservatório Itupararanga, pois $E$. crassipes e $P$. stratiotes foram encontradas na cabeceira do reservatório, próxima à cidade e à estradas, enquanto $P$. lapathifolium esteve presente em estações de amostragem com predomínio de atividades de agricultura no entorno. Muitas espécies de Polygonaceae são conhecidas como ruderais, R-estrategistas, com estabelecimento imediato após um distúrbio, além de serem tolerantes à poluição, como por exemplo, compostos derivados da drenagem de áreas de agricultura (Lacoul e Freedman, 2006).

Devido à proximidade dos tributários com os bancos de macrófitas, pode-se propor que a dinâmica fluvial desempenhou um importante papel no desenvolvimento da biomassa e pode estar relacionada com a dispersão de espécies na bacia. Esse fato torna-se mais evidente quando se compara os resultados obtidos pela presente pesquisa com o estudo de Cavenaghi et al. (2003) em diferentes reservatórios da mesma bacia hidrográfica. AMORIM et al. (2009) concluíram que a presença de macrófitas foi significativamente correlacionada com a entrada de tributários em lagos da várzea do rio Curuaí, na Amazônia.

Em relação à granulometria, foi possível inferir que a fração silte provavelmente favoreceu a adsorção de alguns compostos químicos que contribuem para o aumento da biomassa, conforme constatado por AMORIM et al. (2009). Esses mesmos autores mencionaram que a presença de plantas aquáticas foi positivamente correlacionada com a quantidade de matéria orgânica, nitrogênio e fósforo no sedimento.

Em síntese, os resultados evidenciaram variação espacial e temporal das variáveis limnológicas, algumas delas como $\mathrm{pH}$, OD, COT, CI, $\mathrm{NO}_{2}$, SST, SSI, PTS, NTS e MOS foram importantes para 
predizer a ocorrência de macrófitas. Elevados valores de pH e OD foram registrados, principalmente nos braços com presença de $P$. lapathifolium. Ressalta-se, também, que essa espécie correlacionou-se com as variáveis do sedimento (matéria orgânica, nitrogênio e fósforo total). E. crassipes e P. stratiotes estiveram relacionadas com PT e COT, já E. azurea e $M$. aquaticum foram observadas apenas em dois períodos e, provavelmente, estiveram associadas à substâncias inorgânicas. Dessa forma, assumiu-se que $P$. lapathifolium gerou diferentes condições na coluna de água, com elevada concentração de OD e pH. E. crassipes foi considerada como indicadora de concentrações elevadas de nutrientes, enquanto $E$. azurea e M. aquaticum foram indicativas da presença de compostos inorgânicos na água, provavelmente, provenientes da bacia de drenagem.

Além disso, a presença de $P$. lapathifolium, E. crassipes e $P$. stratiotes foi associada à diferentes tipos de uso e ocupação do solo na bacia hidrográfica. Embora dados de uso e ocupação do solo não estejam disponíveis nesse estudo (apenas reconhecimento visual da área), assumiu-se que esses tem grande relevância no desenvolvimento e distribuição das espécies. A heterogeneidade espaço-temporal das variáveis físicas e químicas foi importante para o desenvolvimento da biomassa de macrófitas. Dessa forma, pressupõe-se que variáveis limnológicas juntamente com dados de uso e ocupação do solo e características do reservatório (morfometria, por exemplo) são importantes para predizer a ocorrência de macrófitas em pequena escala (reservatórios), enquanto características da bacia (grande escala - caracterização dos tributários, dominância de espécies na bacia) fornecem evidências da dispersão e manutenção dessas plantas. 
$\mathrm{Br}_{1}-$ Eichhornia crassipes

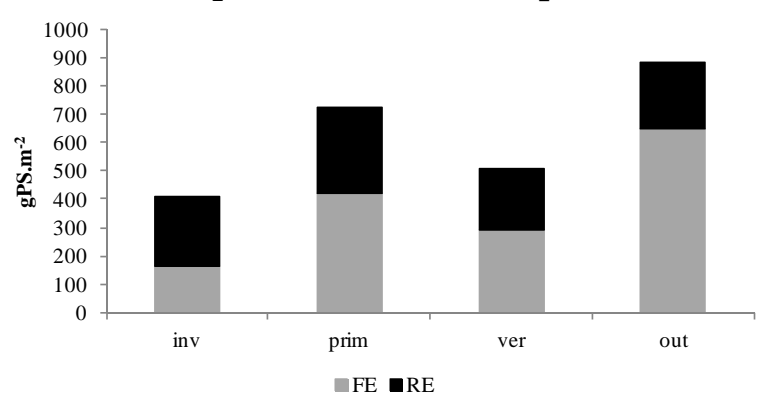

$\mathrm{Br}_{2}$ - Polygonum lapathifolium

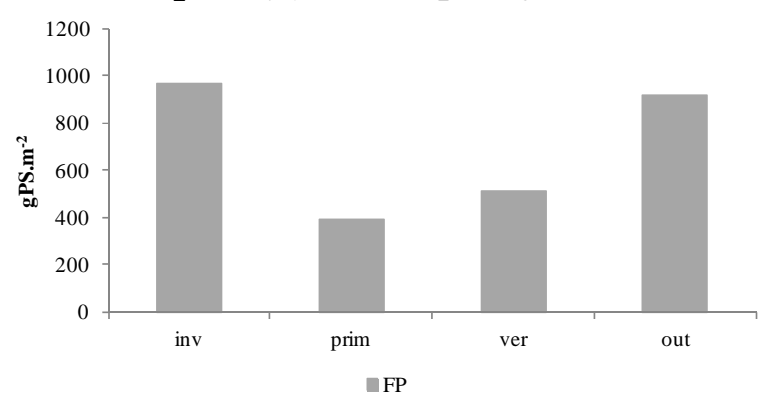

$\mathrm{Br}_{4}$ - Eichhornia azurea e Myriophyllum aquaticum

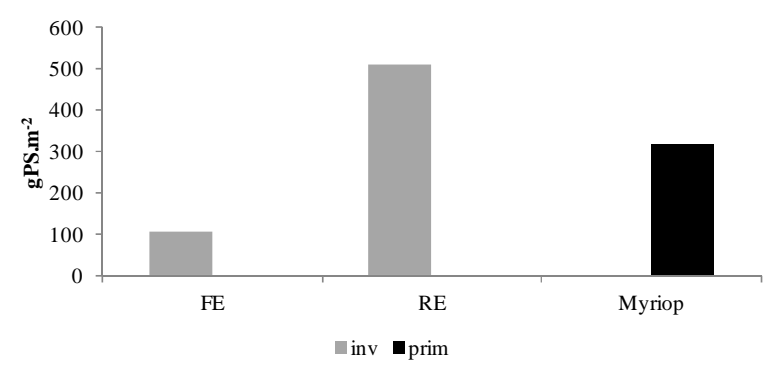

$\mathrm{Br}_{1}-$ Pistia stratiotes

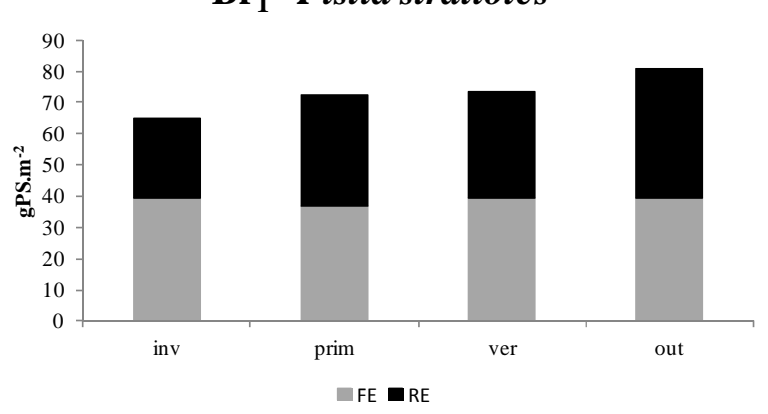

$\mathrm{Br}_{3}-$ Polygonum lapathifolium

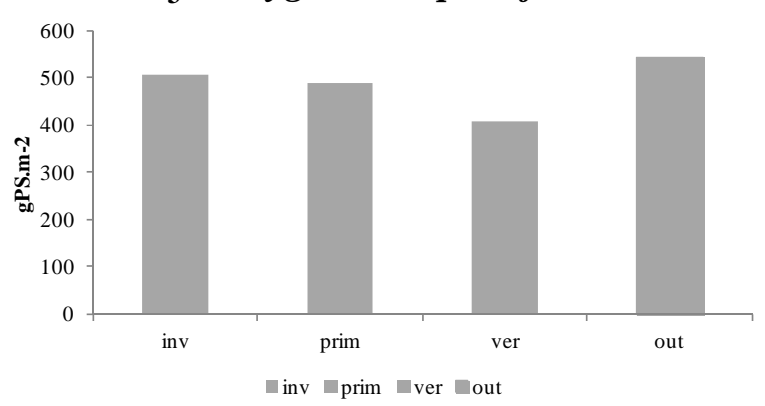

Figura 27: Biomassa (gPS.m $\left.{ }^{-2}\right)$ das diferentes partes de macrófitas aquáticas do reservatório Itupararanga. $\mathrm{Br}_{1}$-FE: Folha de Eichhornia crassipes em $\mathrm{Br}_{1} ; \mathrm{Br}_{1}$-RE: Raíz de Eichhornia crassipes em $\mathrm{Br}_{1} ; \mathrm{Br}_{1}$-FP: Folha de Pistia stratiotes em $\mathrm{Br}_{1} ; \mathrm{Br}_{1}-\mathrm{RP}$ : Raiz de Pistia stratiotes em $\mathrm{Br}_{1} ; \mathrm{BR}_{2}-\mathrm{P}$ : Polygonum lapathifolium em $\mathrm{Br}_{2} ; \mathrm{Br}_{3}-\mathrm{P}$ : Polygonum lapathifolium em $\mathrm{Br}_{3} ; \mathrm{Br}_{4}-\mathrm{FE}$ : Folha de Eichhornia azurea $\mathrm{em}$ $\mathrm{Br}_{4} ; \mathrm{Br}_{4}-\mathrm{RE}$ : Raíz de Eichhornia azurea em $\mathrm{Br}_{4} ; \mathrm{Br}_{4}-\mathrm{M}$ : Myriophyllum aquaticum em $\mathrm{Br} 4$. 


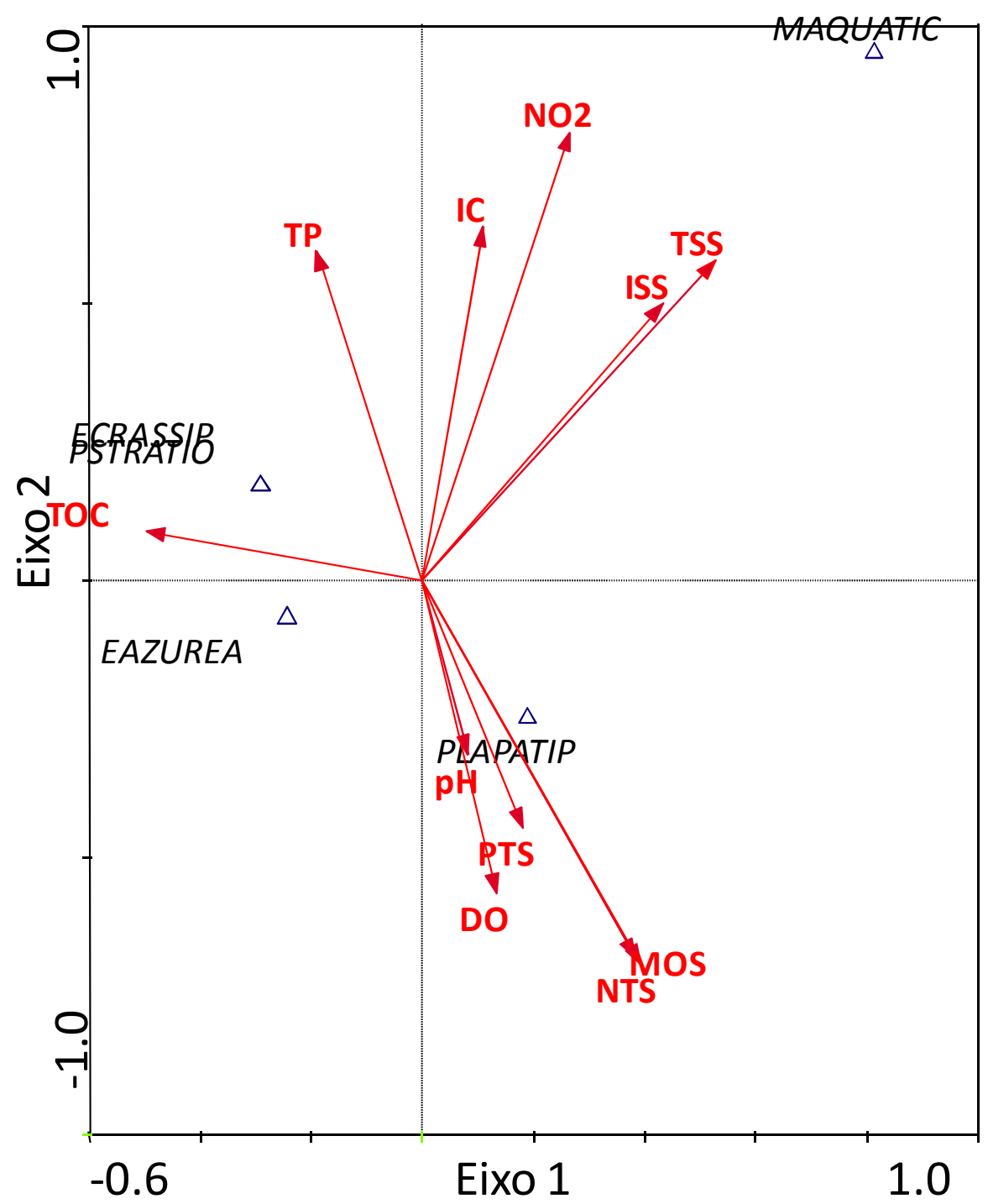

Figura 28: Ordenação da CCA no eixo 1 (horizontal) e no eixo 2 (vertical) de 5 espécies de macrófitas aquáticas e 11 variáveis ambientais. Códigos das espécies: EAZUREA: Eichhornia azurea; ECRASSIP: Eichhornia crassipes; PSTRATIO: Pistia stratiotes; MAQUATIC: Myriophyllum aqaticum; PLAPATIP: Polygonum lapathifolium. Códigos das variávies ambientais: COT: Carbono Orgâncio Total (mg.L $\left.\mathrm{L}^{-1}\right)$; PT: Fóforo Total (mg.L $\left.\mathrm{L}^{-1}\right)$; CI: Carbono Inorgânico (mg.L $\left.{ }^{-1}\right)$; $\mathrm{NO}_{2}$ : Nitrito $\left(\mu \mathrm{g} . \mathrm{L}^{-1}\right)$; SST: Sólidos Supensos Totais $\left(\mathrm{mg} . \mathrm{L}^{-1}\right)$; SSI: Sólidos Supensos Inorgânicos (mg.L $\left.{ }^{-1}\right)$; OD: Oxigênio Dissolvido (mg.L $\left.\mathrm{L}^{-1}\right)$; PTS: Fósforo Total no Sedimento $\left(\mu \mathrm{g} . \mathrm{g}^{-1}\right)$; NTS: Nitrogênio Total no Sedimento $\left(\mu \mathrm{g} . \mathrm{g}^{-1}\right)$; MOS: Matéria Orgânica no Sedimento (\%). Ordenação estatística: Teste de Monte Carlo: Eixo1: valor de F: 2.329, P=0.03; todos os eixo canônios: valor de F: 4.037, P=0.006; Eigenvalues: Eixo 1 (horizontal): 0.993; Eixo 2 (vertical): 0.967; Variação cumulativa dos dados de espécies (no Eixo $1-4$ ) = 86.6\%; relação espécies-ambiente $=96.2 \%$; (iv) Correlação espécieambiente $($ Eixo $1-4)=0.918,(v)$ variação do fator de inflexão para cada variável: $1.9462-24.1951$. 
A biomassa de carbono pode ser visualizada na Figura 29, na qual é possível notar que o conteúdo de carbono foi semelhante tanto na parte aérea como na submersa das macrófitas. Além disso, a variação sazonal foi mínima, sugerindo que o conteúdo de carbono de um vegetal aquático não tem muita variação independentemente do peso da planta, desde que esta esteja num estágio de vida adulto e suas partes estejam íntegras.

Essa afirmação fica mais evidente ao se analisar os resultados obtidos na estação $\mathrm{Br}_{1}$, pois embora no inverno tenha-se obtido mínima biomassa $\left(\mathrm{gPS} . \mathrm{m}^{-2}\right)$ da parte aérea, o teor de carbono $\left(\mathrm{gC} . \mathrm{m}^{-2}\right)$ foi o mesmo para o período em que se registrou o maior peso seco (outono), ou seja 39,5 gC.m ${ }^{-2}$, em ambos os períodos. O mesmo padrão foi verificado para P. lapathifolium nas estações $\mathrm{Br}_{2} \mathrm{e}$ $\mathrm{Br}_{3}$. Nessas estações de amostragem, os valores de biomassa não variaram mais que $1 \mathrm{gC} . \mathrm{m}^{-2}$ e 2 gC.m ${ }^{2}$, respectivamente. Para $P$. stratiotes, os menores valores de biomassa também coincidiram $\left(36 \mathrm{gC} . \mathrm{m}^{-2}\right.$ na parte aérea e $33 \mathrm{gC} . \mathrm{m}^{-2}$ na parte submersa, ambos no inverno). Entretanto, registrou-se elevados valores de carbono nas folhas dessa espécie no verão (39 gC. $\left.\mathrm{m}^{-2}\right)$, enquanto nas raízes obteve-se 38,2 gC.m $\mathrm{m}^{-2}$ no outono. 
$\mathrm{Br}_{1}-$ Eichhornia crassipes

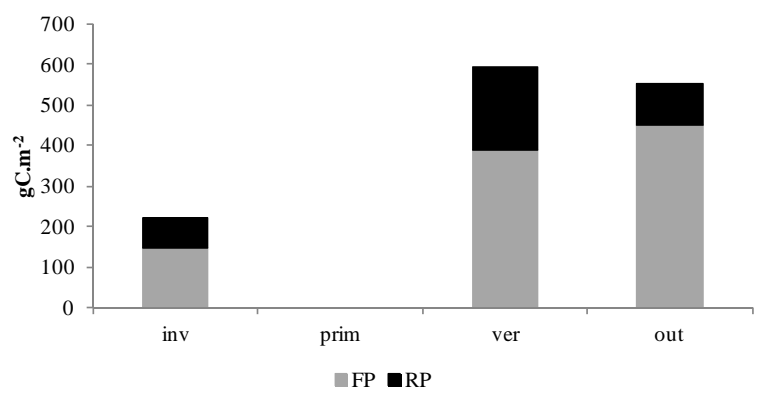

$\mathrm{Br}_{2}-$ Polygonum lapathifolium

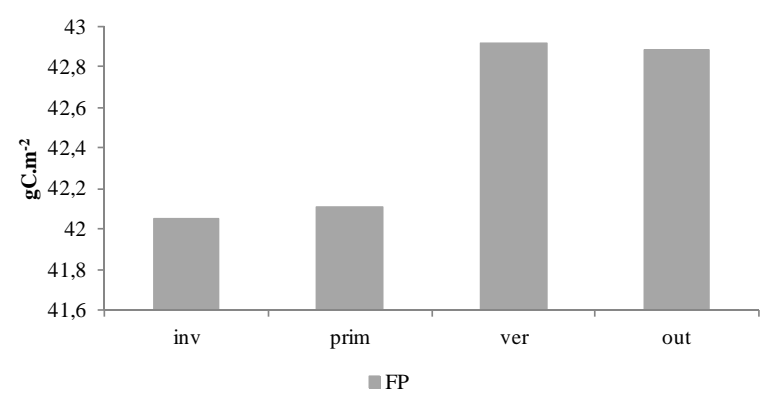

Br4 - Eicchornia azurea e Myriophyllum aquaticum

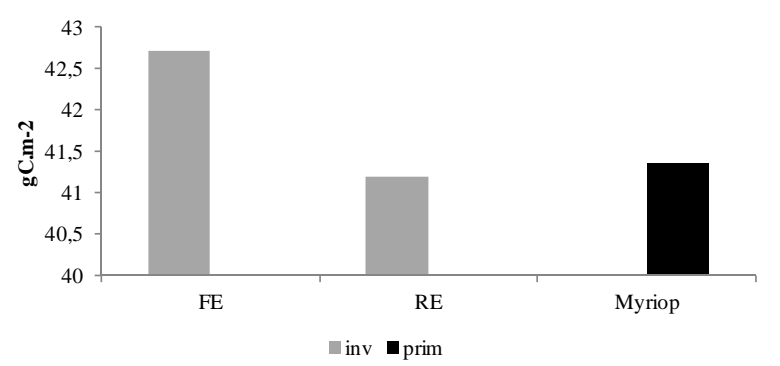

$\mathrm{Br}_{1}$ - Pistia stratiotes

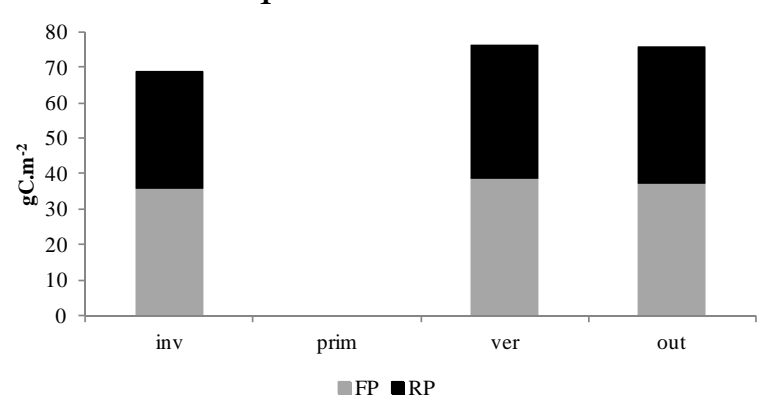

$\mathrm{Br}_{3}-$ Polygonum lapathifolium

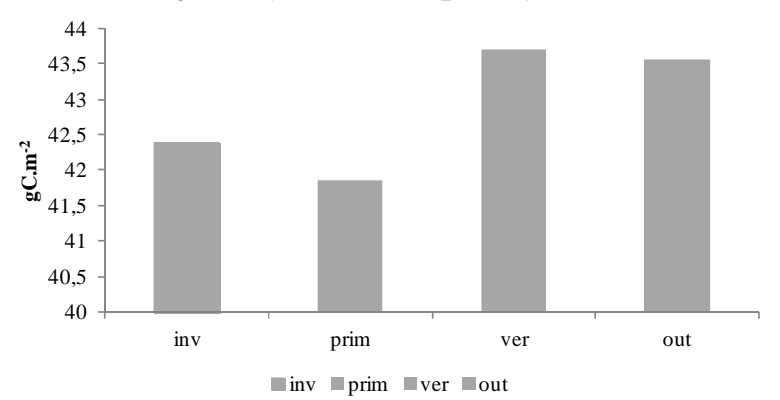

Figura 29: Biomassa $\left(\mathrm{gC} . \mathrm{m}^{-2}\right)$ das diferentes partes de macrófitas aquáticas do reservatório Itupararanga. $\mathrm{Br}_{1}$-FE: Folha de Eichhornia crassipes em $\mathrm{Br}_{1} ; \mathrm{Br}_{1}$-RE: Raíz de Eichhornia crassipes em $\mathrm{Br}_{1} ; \mathrm{Br}_{1}$-FP: Folha de Pistia stratiotes em $\mathrm{Br}_{1} ; \mathrm{Br}_{1}-\mathrm{RP}$ : Raiz de Pistia stratiotes em $\mathrm{Br}_{1} ; \mathrm{BR}_{2}-\mathrm{P}$ : Polygonum lapathifolium em $\mathrm{Br}_{2} ; \mathrm{Br}_{3}-\mathrm{P}$ : Polygonum lapathifolium em $\mathrm{Br}_{3} ; \mathrm{Br}_{4}-\mathrm{FE}$ : Folha de Eichhornia azurea em $\mathrm{Br}_{4} ; \mathrm{Br}_{4}-\mathrm{RE}$ : Raíz de Eichhornia azurea em $\mathrm{Br}_{4} ; \mathrm{Br}_{4}-\mathrm{M}$ : Myriophyllum aquaticum em $\mathrm{Br} 4$. 
A partir dos resultados obtidos pode-se inferir que, em longo prazo, o reservatório Itupararanga poderá apresentar problemas mais críticos em relação aos seus aspectos qualitativos, visto que alguns princípios da gestão e da sustentabilidade dos recursos hídricos estão sendo negligenciados (princípio da equidade, por exemplo).

O estabelecimento de indicadores de sustentabilidade para a gestão dos recursos hídricos pode se constituir numa alternativa para a identificação de problemas ambientais prioritários e, a partir de então, delinear-se um plano de monitoramento. No caso do reservatório Itupararanga, os resultados do presente estudo indicaram que o fósforo pode se constituir em um problema, ao longo dos anos e até mesmo o nitrato poderá vir a comprometer a qualidade das águas desse manancial. Além disso, o sedimento revelou-se uma fonte de nutrientes e as macrófitas aquáticas, se não controladas, poderão ocasionar prejuízos aos usos múltiplos do reservatório. Sob esse aspecto, considerar a bacia hidrográfica como unidade de estudo assume grande importância. De acordo com Calijuri et al. (2000), uma bacia hidrográfica apresenta características que interagem entre si, formando uma rede interligada, de relações mútuas, permitindo, assim, uma análise integrada do potencial ecológico de acordo com a influência antrópica no sistema. Dessa maneira, os sistemas fluviais, principalmente os afluentes do reservatório Itupararanga, devem ser caracterizados a fim de se garantir a sustentabilidade dos mesmos (estudos limnológicos e propostas de manejo). Projetos que contemplem a educação ambiental da população devem ser colocados em prática com o intuito de se evitar a disposição inadequada de resíduos sólidos e o lançamento clandestino de efluentes. É necessário ainda controlar a demanda de água (devido à irrigação), a ocupação do solo, a qual deve obedecer à legislação para manutenção da mata ciliar, bem como o despejo de efluentes (políticas públicas). Outro ponto a ser destacado é o papel das macrófitas aquáticas no reservatório. Elas podem estar atuando de modo a impedir o aumento das cargas poluidoras, e utilizar essas plantas, de maneira controlada, para o tratamento da poluição, traria benefícios ao reservatório Itupararanga.

Sabe-se, no entanto, que essas medidas estão intimamente relacionadas às dimensões política, social e econômica, o que pode acarretar divergências na busca por soluções quantitativas e qualitativas da gestão dos recursos hídricos. O uso e a gestão integrada, por meio de uma visão sistêmica e considerando os usos múltiplos é essencial para que conflitos sejam evitados e/ou minimizados e finalmente os planos de sustentabilidade sejam atendidos. 


\subsection{Decomposição de Macrófitas Aquáticas}

A elevada produtividade da zona litorânea de lagos e reservatórios está, frequentemente, relacionada com a biomassa de macrófitas aquáticas. Essas plantas são responsável por grande porção de matéria orgânica presente nos ambientes aquáticos (GESSNER, 2000), e apenas pequena fração desse material é consumida pelos herbívoros (JIN-HO et al. 2007).

Durante o período de crescimento, as macrófitas aquáticas absorvem nutrientes do sedimento ou da coluna de água, sendo consideradas estocadoras desses compostos. $\mathrm{O}$ acúmulo de biomassa torna esses vegetais, após a morte, uma importante fonte de detritos. Dessa forma, o processo de decomposição é importante para o fluxo de carbono e ciclagem de nutrientes dentro dos ecossistemas aquáticos (REJMÁNKOVÁ e SIROVÁ, 2007).

Estudos envolvendo a decomposição de macrófitas aquáticas são comumente realizados sob condições controladas (BEST et al. 1990; CUNHA-SANTINO e BIANCHINI Jr., 2007; SANTOS, CUNHA-SANTINO e BIANCHINI Jr., 2009), enquanto incubações em campo tem sido negligenciadas, devido à dificuldade de se predizer mudanças ambientais em curto período de tempo. Entretanto, experimentos in situ permitem a avaliação das interferências naturais e antropogênica no processo de decomposição (controle no nível da água, por exemplo), contribuindo, assim, para um maior entendimento da dinâmica dos detritos em ecossistemas aquáticos.

Durante o período de incubação dos litter bags no reservatório Itupararanga (de 9 de agosto de 2009 à 7 de dezembro de 2009), a companhia que opera a barragem forneceu dados referentes ao reservatório, os quais são apresentados na Tabela 14. Em agosto, a precipitação média mensal foi 57 $\mathrm{mm}$, ocorrendo entre os dias $18^{\circ}$ e $23^{\circ}$ de incubação. Em setembro, foram registrados $205 \mathrm{~mm}$, mas apenas $43 \mathrm{~mm}$ incidiram sobre o reservatório no dia anterior à amostragem. Em outubro, observaram-se $135 \mathrm{~mm}$ de precipitação média mensal, entretanto nenhum valor foi registrado no dia precedente à coleta. O maior valor de precipitação média ocorreu em novembro $(319 \mathrm{~mm})$, sendo que no $5^{\circ}$ dia deste mês (um dia antes do $90^{\circ}$ dia de amostragem), verificaram-se $52 \mathrm{~mm}$. No último mês do experimento, a precipitação média mensal foi $259 \mathrm{~mm}$ e no dia de amostragem mediu-se, aproximadamente, $55 \mathrm{~mm}$. Durante dezembro as vazões médias aumentaram (vazão defluente: $31 \mathrm{~m}^{3} . \mathrm{s}^{-1}$; vazão afluente: $34 \mathrm{~m}^{3} . \mathrm{s}^{-}$ ${ }^{1}$ ), porém o nível da água foi similar em todos os dias de amostragem. 
Tabela 14: Condições locais nos dias de amostragem

Dados

\begin{tabular}{|c|c|c|c|c|c|c|c|c|c|c|}
\hline \multirow{2}{*}{ Dados } & \\
\hline & 1 & 3 & 5 & 10 & 15 & 20 & 30 & 60 & 90 & 120 \\
\hline Precipitação (mm) & 0 & 0 & 0 & 8,6 & 5,7 & 0 & 0 & 0 & 18,8 & 55 \\
\hline Nível Hidrométrico (m) & 823,9 & 823,9 & 823,8 & 823,6 & 823,6 & 823,6 & 823,3 & 823,1 & 823,1 & 823,4 \\
\hline Vazão afluente $\left(\mathrm{m}^{3} \cdot \mathrm{s}^{-1}\right)$ & 10,7 & 8,3 & 9,5 & 9 & 20 & 8,5 & 17 & 9,3 & 19 & 22 \\
\hline Vazão defluente $\left(\mathrm{m}^{3} \cdot \mathrm{s}^{-1}\right)$ & 14,4 & 15 & 16,2 & 15 & 15 & 15 & 15 & 21,2 & 14 & 28,3 \\
\hline
\end{tabular}

\subsubsection{Decomposição de Polygonum lapathifolium}

As condições em que o processo de decomposição in situ ocorreu, em $\mathrm{Br}_{3}$, são apresentadas na Tabela 15. De modo geral, a profundidade, na estação $\mathrm{Br}_{3}$, variou pouco, apresentando picos de $3,2 \mathrm{~m}$ nos dias 20 e 120. A profundidade do Disco de Secchi foi menor no $120^{\circ}$ dia, quando houve maior precipitação pluviométrica. Em relação à temperatura da água, observou-se pico de $24,2^{\circ} \mathrm{C}$ (dia 120 ) e mínima de $17^{\circ} \mathrm{C}$ no $15^{\circ}$ dia de experimento. A condutividade elétrica aumentou gradativamente, enquanto que para o OD verificou-se diminuição das concentrações a partir do $30^{\circ}$ dia.

Tabela 15: Variáveis limnológicas monitoradas nos dias de amostragem na estação de coleta $\mathrm{Br}_{3}$

\begin{tabular}{ccccccccccc}
\hline & \multicolumn{10}{c}{ Dias amostrais } \\
\cline { 2 - 11 } & $\mathbf{1}$ & $\mathbf{3}$ & $\mathbf{5}$ & $\mathbf{1 0}$ & $\mathbf{1 5}$ & $\mathbf{2 0}$ & $\mathbf{3 0}$ & $\mathbf{6 0}$ & $\mathbf{9 0}$ & $\mathbf{1 2 0}$ \\
Profundidade $(\mathrm{m})$ & 2,7 & 2,8 & 2,7 & 2,7 & 2,5 & 3,2 & 2,8 & 1,9 & 2,5 & 3,2 \\
Secchi $(\mathrm{m})$ & 0,7 & 0,7 & 0,9 & 0,8 & 0,6 & 1,5 & 0,6 & 0,7 & 1,0 & 0,5 \\
Temperatura $\left({ }^{\circ} \mathrm{C}\right)$ & 18,5 & 18,0 & 17,0 & 19,06 & 17,05 & 19,1 & 18,0 & 18,0 & 22,5 & 24,2 \\
pH & 6,7 & 6,63 & 6,94 & 7,07 & 7,3 & 7,0 & 7,5 & 7,7 & 8,0 & 8,0 \\
Conductividade & 68 & 65 & 69 & 72 & 72 & 70 & 77 & 77 & 80 & 85 \\
$\left(\mu \mathrm{S} . \mathrm{cm}^{-1}\right)$ & 6 & & & & & & & & & \\
OD $\left(\mathrm{mg}_{\mathrm{L}} \mathrm{L}^{-1}\right)$ & 5,8 & 6,54 & 6,58 & 6,4 & 6,5 & 5,5 & 4,89 & 4,2 & 4,45 & 6,98 \\
\hline
\end{tabular}

Na Tabela 16 são mostrados os valores de matéria Orgânica Particulada Lábil-Solúvel (MOPLS), Matéria Orgânica Refratária (MOR), constante global de decaimento de massa $\left(\mathrm{k}_{\mathrm{T}}\right)$ e constante de mineralização $\left(\mathrm{k}_{4}\right)$ tanto para o experimento em campo como em laboratório. Valores de MOD e $\mathrm{k}_{3}$ (constante de mineralização da MOD) para ensaios de laboratório são apresentados na Tabela 17.

O modelo cinético adotado ajustou todos os dados experimentais com alto valor de coeficiente de correlação de $\mathrm{MOP}\left(\mathrm{r}^{2}=0,88,0,91\right.$ e 0,96 do ajuste dos dados provenientes do experimento a $15^{\circ} \mathrm{C}$, $25^{\circ} \mathrm{C}$ e litter bags, respectivamente) e $\operatorname{MOD}\left(\mathrm{r}^{2}=0,70\right.$, a $15^{\circ} \mathrm{C}$ e 0,70 a $\left.25^{\circ} \mathrm{C}\right)$. O ajuste dos parâmetros é mostrado nas Figuras 30 e 31. 
Tabela 16: Resultados do modelo cinético de decomposição para ambos os tratamentos (campo e laboratório), com $P$. lapathifolium. MOPLS: Matéria orgânica lábil solúvel; MOR: Matéria orgânica refratária; MI: Matéria inorgânica; $\mathrm{k}_{\mathrm{T}}$ : constante de perda total de massa; $\mathrm{k}_{4}$ : constante de decaimento do material refratário; $\mathrm{r}^{2}$ : coeficiente de ajuste dos dados; E: Erro.

\begin{tabular}{ccccccccccc}
\hline Tratamento & $\begin{array}{c}\text { MOPLS } \\
(\boldsymbol{\%})\end{array}$ & $\mathbf{E}$ & $\mathbf{k}_{\mathbf{T}}$ & $\mathbf{E}$ & $\begin{array}{c}\text { MOR } \\
(\boldsymbol{\%})\end{array}$ & $\mathbf{E}$ & $\mathbf{k}_{\mathbf{4}}$ & $\mathbf{E}$ & $\mathbf{r}^{\mathbf{2}}$ & $\begin{array}{c}\mathbf{M I} \\
(\boldsymbol{\%})\end{array}$ \\
\hline $15^{\circ} \mathrm{C}$ & 15,6 & 4,9 & 1 & - & 83,2 & 2,1 & 0,00289 & 0,0005 & 0,88 & 37 \\
$25^{\circ} \mathrm{C}$ & 20,2 & 4,4 & 1 & - & 77,0 & 1,92 & 0,00299 & 0,0005 & 0,91 & 42,5 \\
Litter Bags & 30,8 & 4,0 & 0,35 & 0,11 & 67,0 & 2,6 & 0,0035 & 0,007 & 0,96 & 71,4 \\
\hline
\end{tabular}

Tabela 17: Resultados do modelo cinético de decomposição para os ensaios de laboratório $\left(15^{\circ} \mathrm{C}\right.$ e $\left.25^{\circ} \mathrm{C}\right)$, MOD: Matéria Orgânica Dissolvida; $\mathrm{k}_{3}$ : Constante de mineralização de MOD; $\mathrm{r}^{2}$ : coeficiente de ajuste dos dados; E: erro.

\begin{tabular}{cccccc}
\hline Tratamento & $\begin{array}{c}\text { MOD } \\
(\boldsymbol{\%})\end{array}$ & $\mathbf{E}$ & $\mathbf{k}_{\mathbf{3}}$ & $\mathbf{E}$ & $\mathbf{r}^{\mathbf{2}}$ \\
\hline $15^{\circ} \mathrm{C}$ & 7,5 & 1,6 & 0,018 & 0,01 & 0,5 \\
$25^{\circ} \mathrm{C}$ & 15,2 & 4,1 & 0,031 & 0,003 & 0,5 \\
\hline
\end{tabular}

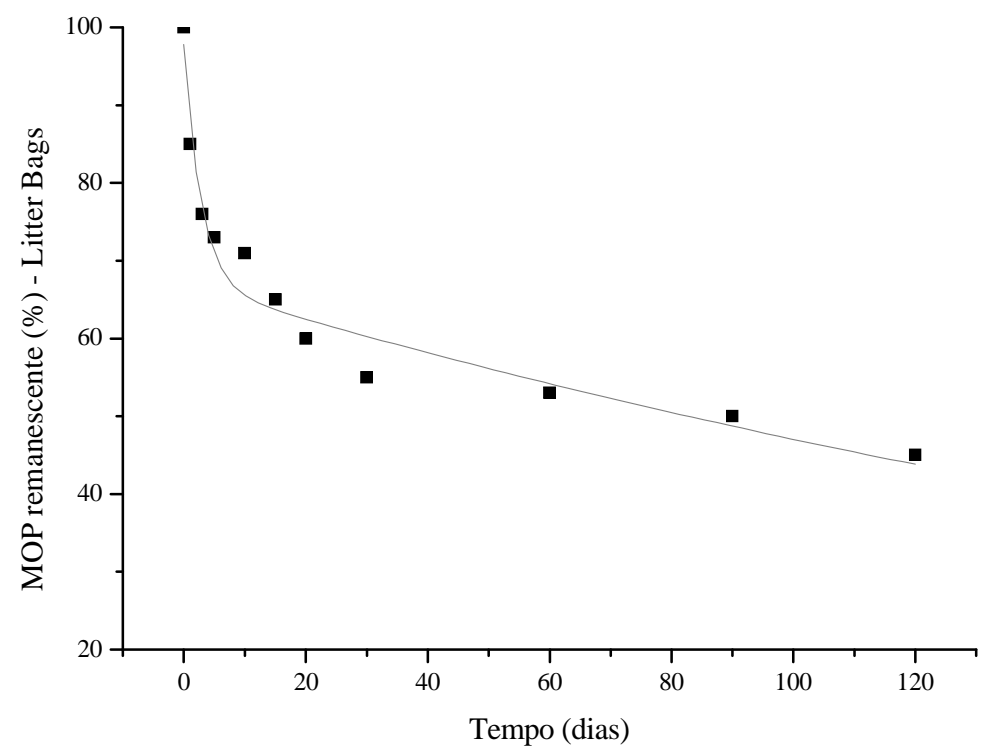

Figura 30: Ajuste dos parâmetros obtidos pelo modelo cinético de decaimento de massa para o experimento com litter bags de $P$. lapathifoilum 

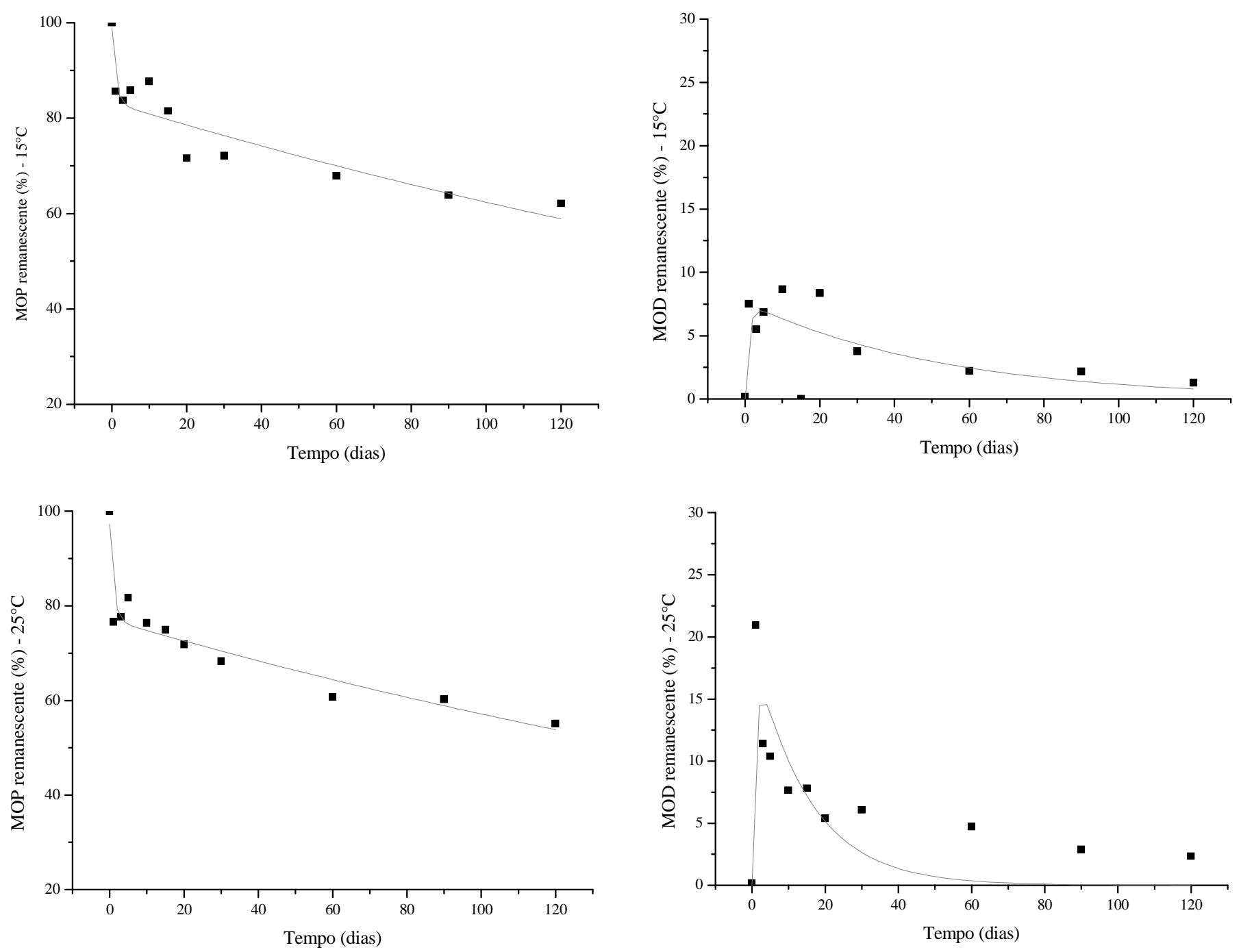

Figura 31: Ajuste dos parâmetros obtidos pelo modelo cinético de decaimento de massa em condições de laboratório (a $15^{\circ} \mathrm{C}$ e a $25^{\circ} \mathrm{C}$ ) para P. lapathifolium.

Durante o processo de decomposição observou-se elevada perda de MOP em apenas 24 horas para os litter bags (15\%) (Figura 32). Sob condições controladas $\left(15^{\circ} \mathrm{C}\right)$, a dissolução da MOP foi menor (14\% em 24 horas) e, tanto a MOD $(8,4 \%)$, como a MI aumentaram até o $15^{\circ}$ dia (Figura 33). A $25^{\circ} \mathrm{C}$ a perda de massa em 24 horas foi mais intensa $(23,4 \%)$, contribuindo para o incremento da MOD até o $5^{\circ}$ dia de experimento (Figura 34). A partir dos dados apresentados na Tabela 16, aparentemente o conteúdo MOPLS foi maior no experimento dos litter bags (30,8\%), bem como o decaimento da MOR (0,0035 $\mathrm{d}^{-1}$ - meia-vida: 198 dias). Além disso, elevada quantidade de MOPLS foi lixiviada no experimento de campo, devido possivelmente à exposição dos litter bags à abrasão, fotodegradação, mineralização microbiana, sedimentação e ação de macroinvertebrados, fatores que contribuem para a perda de massa (SILVA et al. 2011). 
A lixiviação de P. lapathifolium foi responsável pela perda de massa no início do processo de decomposição (em média 3 dias para todos os tratamentos), com substancial perda de massa nas primeiras 24 horas em ambos os tratamentos e condições de temperatura. O processo de lixiviação prevalece nas primeiras fases da decomposição de macrófitas aquáticas (BEST et al. 1990; ASAEDA, TRUNG e MANATUNGE, 2000; CUNHA-SANTINO, BIANCHINI Jr. e OKAWA, 2010), e está relacionada com a liberação de frações do citoplasma e compostos estruturais hidrossolúveis, podendo durar de 24 horas a 15 dias (SILVA et al. 2011).

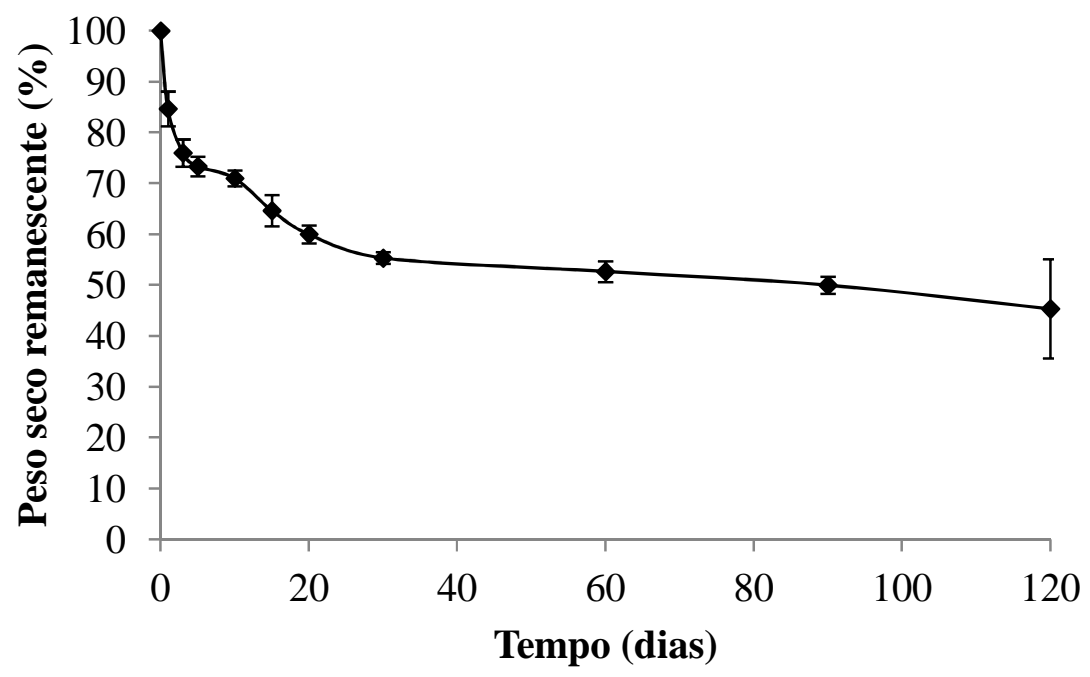

Figura 32: Peso seco remanescente de Polygonum lapathifolium no experimento de campo. As barras verticais representam \pm desvio padrão 


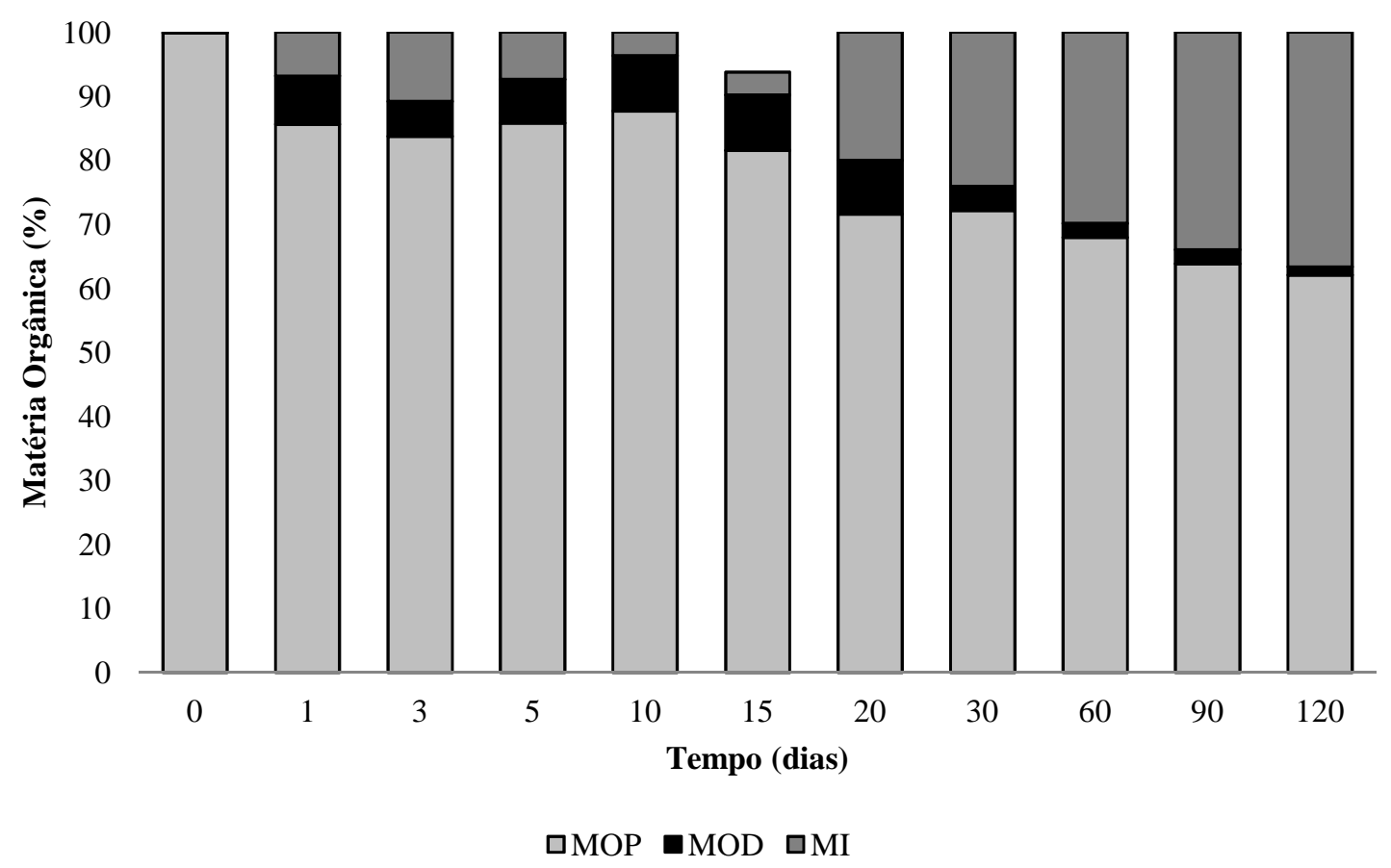

Figura 33: Variação da Matéria Orgânica Particulada (MOP), Matéria Orgânica Dissolvida (MOD) e Matéria Inorgânica (MI) durante o processo de decomposição de Polygonum lapathifolium à $15^{\circ} \mathrm{C}$ em laboratório.

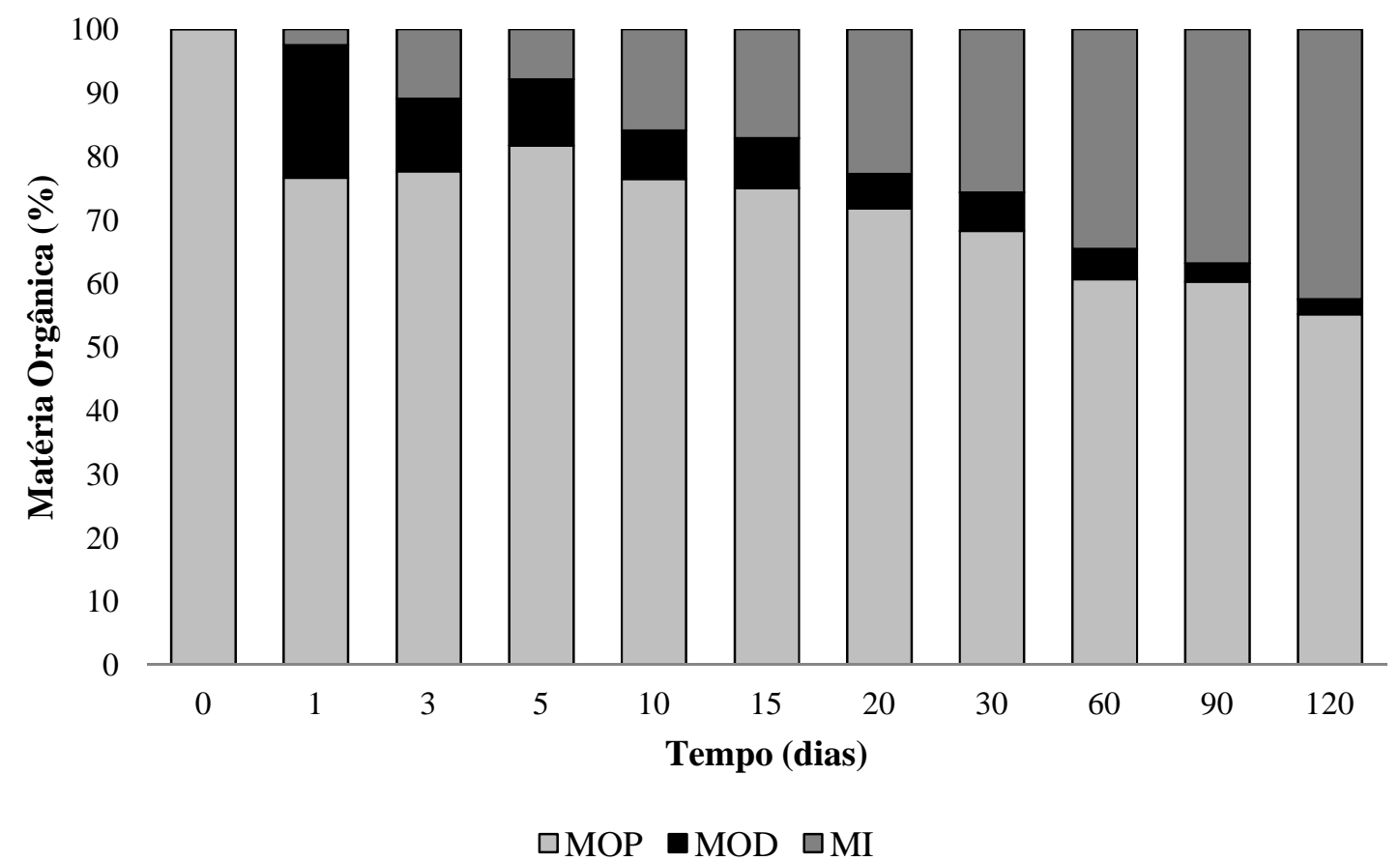

Figura 34: Variação da Matéria Orgânica Particulada (MOP), Matéria Orgânica Dissolvida (MOD) e Matéria Inorgânica (MI) durante o processo de decomposição Polygonum lapathifolium à $25^{\circ} \mathrm{C}$ em laboratório. 
A comparação da liberação da MOP entre os testes de temperatura revelou maior perda de massa a $25^{\circ} \mathrm{C}$ do que a $15^{\circ} \mathrm{C}$, com valores estatisticamente diferentes $(\mathrm{p}=0,05)$. O experimento de campo foi estatisticamente semelhante ao bioensaio realizado a $15^{\circ} \mathrm{C}(\mathrm{p}>0,05)$ e significativamente diferente dos dados obtidos em laboratório a $25^{\circ} \mathrm{C}(\mathrm{p}<0,01)$. Esses resultados provavelmente estão associados à similaridade da temperatura da água do experimento que representou o inverno $\left(15^{\circ} \mathrm{C}\right)$ e das condições da coluna de água quando os litter bags foram incubados $\left(18,5^{\circ} \mathrm{C}\right.$ no primeiro dia após a incubação). $\mathrm{Na}$ Figura 35 pode-se visualizar a relação entre os experimentos realizados em laboratório e em campo, evidenciando-se alto coeficiente de ajuste entre o ensaio de campo e o realizado a $15^{\circ} \mathrm{C}$.
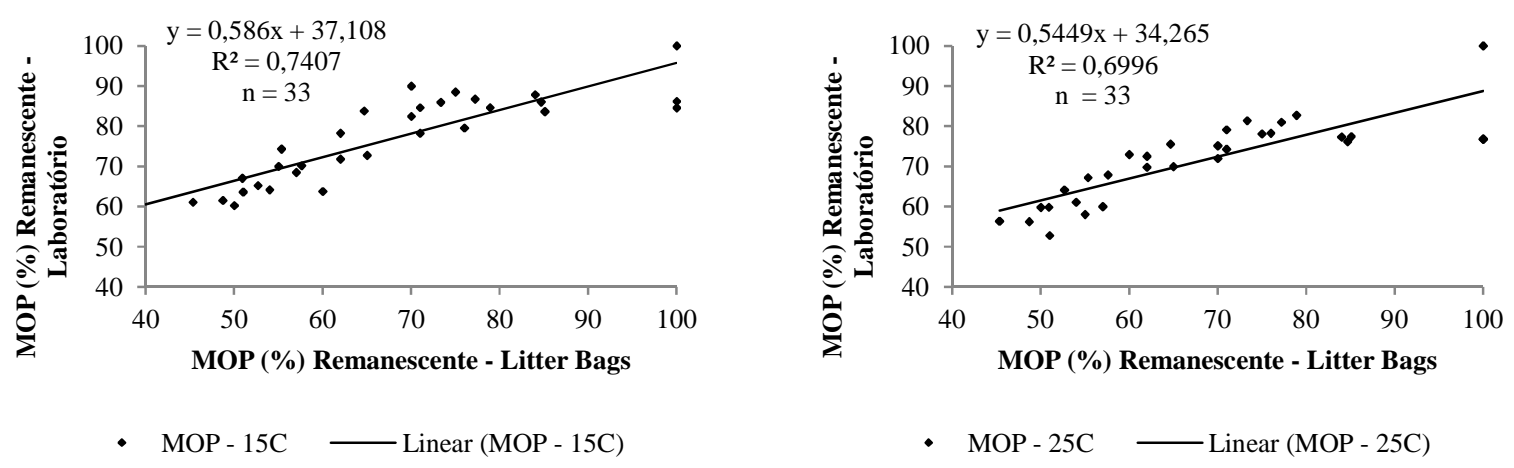

Figura 35: Relação entre a MOP remanescente de $P$. lapathifolium nos experimentos de campo e laboratório.

Em relação à formação de MOD (Tabela 17), o valor de $\mathrm{k}_{3}$ foi 0,031 a $25^{\circ} \mathrm{C}$ e, portanto, 1,72 vezes maior que o valor de $\mathrm{k}_{3}$ a $15^{\circ} \mathrm{C}$. Os resultados evidenciaram diferentes quantidades de compostos lábeis e solúveis em $P$. lapathifolium nas diferentes temperaturas. No experimento a $15^{\circ} \mathrm{C}, P$. lapathifolium apresentou 15,6\% de compostos lábeis-solúveis, dos quais 7,5\% constituíram a fração lábil e $8,1 \%$ a fração solúvel. A $25^{\circ} \mathrm{C}, 20,2 \%$ de P. lapathifolium eram compostos lábeis solúveis, sendo que $15,2 \%$ pertenciam à fração lábil e $5 \%$ à solúvel.

Os picos de MOD nos primeiros dias de experimento a $25^{\circ} \mathrm{C}$ (Figura 34) podem estar relacionados à maior solubilização das frações lábeis durante a etapa de lixiviação. Após a diminuição da concentração de compostos lábeis, a MOD passou a ser solubilizada mais lentamente em virtude da mineralização da MOR. A contribuição de $P$. lapathifolium com MOD foi baixa em ambas as temperaturas (Tabela 17). Esse fato pode estar relacionado com o uso do fragmento íntegro no experimento, pois a quantidade de material refratário presente no caule de $P$. lapathifolium pode ter influenciado os resultados. A dissolução da MOP leva à formação da MOD e à oxidação de frações lábeis e refratárias, entretanto isso depende da composição química do citoplasma. O conteúdo de MOD, por sua vez, acarreta a formação de substâncias húmicas dissolvidas o que mantém o elo 
microbiano, mas, por outro lado, pode gerar um desequilíbrio na quantidade de oxigênio dissolvido (Bianchini Jr. e Cunha-Santino, 2011).

A comparação entre as temperaturas revelou diferentes valores da constante de mineralização da MOR $\left(\mathrm{k}_{4}\right)$ e menor quantidade de compostos refratários no experimento in situ $(67 \%)$. Os valores de $\mathrm{k}_{4}$ indicaram que as meias-vidas de $P$. lapathifolium foram 232 dias e 240 dias para $15^{\circ} \mathrm{C}$ e $25^{\circ} \mathrm{C}$, respectivamente.

Os resultados obtidos sugeriram que os detritos de $P$. lapathifolium continham principalmente compostos refratários e a mineralização dos mesmos (determinadas por $\mathrm{k}_{4}$ ) foi lenta. Em condições naturais o coeficiente de decomposição da MOR foi maior que em laboratório, sendo que as vias que determinam a mineralização dos compostos refratários foram responsáveis por mais de 30\% da decomposição em campo. Embora a MOR seja uma fração de difícil degradação, populações microbianas especializadas são capazes de hidrolizá-la enzimaticamente (SILVA et al. 2011). Porém quantidade de compostos refratários nos detritos pode influenciar a taxa de decomposição De acordo com Anderson e Smith (2002), plantas da família Polygonaceae possuem altos teores de celulose e hemicelulose no caule, levando a uma decomposição relativamente lenta. Os autores relataram, ainda, que os níveis de celulose e hemicelulose de $P$. pennsylvanicum aumentaram após 56 dias de incubação, indicando que a maior parte do material prontamente disponível para a decomposição desaparece num curto período de tempo.

Bianchini Jr. (2003) reuniu resultados de vários experimentos de decomposição de diferentes plantas (em condições de campo e laboratório) e concluiu que o valor de MOPLS é, em média, 29,6\%, enquanto para MOR é 70,4\%. As constantes de lixiviação e mineralização apresentaram valores médios de 0,81 e $0,078 \mathrm{~d}^{-1}$, respectivamente. Portanto, os dados obtidos no presente trabalho estão de acordo com as citações da literatura e, então, foi possível estimar a contribuição de $P$. lapathifolium para liberação de carbono no reservatório Itupararanga nas diferentes condições estudadas (in situ, in vitro e temperatura). Sendo assim, determinou-se o peso médio dessa espécie obtido nas quatro campanhas $\left(485,6\right.$ gPS.m $\left.{ }^{-2}\right)$ e verificou-se que a $15^{\circ} \mathrm{C}$ P. lapathifolium contribuiu com $36 \mathrm{~g}$ de carbono lábil solúvel e $190 \mathrm{~g}$ de carbono refratário. A $25^{\circ} \mathrm{C}$ obteve-se $46 \mathrm{~g}$ de carbono lábil solúvel e $176 \mathrm{~g}$ de carbono refratário, enquanto o experimento em campo contribuiu com $70 \mathrm{~g}$ de carbono lábil solúvel e $153 \mathrm{~g}$ de carbono refratário. Dados sobre o tamanho total do stand de P. lapathifolium não estão disponíveis, portanto não foi possível fazer a extrapolação da contribuição de carbono para a área total ocupada por essa espécie. 
Em relação às constantes de decaimento de massa, Gimenes, Cunha-Santino e Bianchini Jr., (2010) compilaram dados experimentais para várias famílias de macrófitas, incluindo Polygonaceae. Os autores verificaram que os coeficientes dessa família variam entre 0,0016 e 0,017 $\mathrm{d}^{-1} \mathrm{em}$ ecossistemas aquáticos tropicais. Capps et al. (2011) encontraram, para a mesma família, valores entre 0,00105 e 0,0084 $\mathrm{d}^{-1}$ na bacia amazônica, enquanto Esteves e Barbieri (1983) registraram taxas de 0,13 e $0,15 \mathrm{~d}^{-1}$ para folhas e caules de Polygonum ferrugineum, respectivamente. Os coeficientes de decomposição de Polygonum pennsylvanicum foram 0,0084 e $0,004 \mathrm{~d}^{-1}$ no verão e no inverno, respectivamente (MIDDLETON, 1994). Em relação à MOR a constante de mineralização para $P$. ferrugineum foi $0,0027 \mathrm{~d}^{-1}$ pra folhas e $0,0028 \mathrm{~d}^{-1}$ para caules (ESTEVES e BARBIERI 1983).

Dentre muitos fatores, a elevada temperatura de ecossistemas aquáticos tropicais e subtropicais é responsável pela rápida perda de massa de macrófitas aquáticas (ESTEVES e BARBIERI 1983). Nesse sentido, Howard-Williams e Davies (1979) mostraram que um aumento de $10^{\circ} \mathrm{C}$ pode causar um incremento de duas ou três vezes na atividade microbiana, afetando o processo de decomposição. A mineralização da fração refratária de $P$. lapathifolium revelou um valor de $\mathrm{Q}_{10}$ de aproximadamente 1. De acordo com Cunha-Santino e Bianchini Jr. (2010), Q10 é um coeficiente que expressa o aumento da atividade metabólica microbiana devido a um incremento na temperatura a cada $10^{\circ} \mathrm{C}$. Os mesmos autores comentaram que valores de $\mathrm{Q}_{10}$ próximo de 2 são comumente encontrados na literatura e, portanto, frequentemente utilizados em simulações de ciclagem de nutrientes. Contudo, quando se considera um substrato simples, o valor desse coeficiente pode variar significativamente, indicando que uma temperatura ótima age de maneiras diferentes em organismos de uma mesma comunidade (CunhaSantino e Bianchini Jr., 2010).

Durante o processo de decomposição em laboratório, verificou-se que o $\mathrm{pH}$ aumentou do inicio ao fim da incubação, apenas a $15^{\circ} \mathrm{C}$ observou-se declínio no $15^{\circ}$ dia ( de 7,3 a 6,7) (Figura 36). A $25^{\circ} \mathrm{C}$, o maior valor de $\mathrm{pH}$ foi 8,4 e ocorreu no final do experimento. A condutividade elétrica (Figura 37) foi

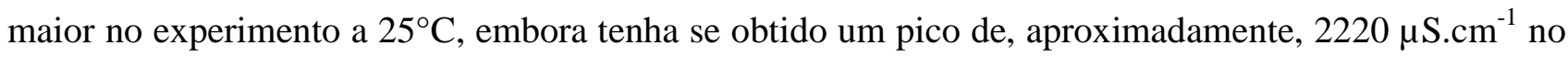
$20^{\circ}$ dia a $15^{\circ} \mathrm{C}$, provavelmente devido à menor atividade microbiana que metaboliza menos material dissolvido em baixas temperaturas. No decorrer dos experimentos, a condutividade elétrica apresentou um padrão de variação menos homogêneo que o do pH, com tendência de aumento ao longo do tempo. Cunha-Santino, Bianchini e Okawa (2010) também reportaram o aumento do $\mathrm{pH}$ durante a decomposição de macrófitas aquáticas. Os autores atribuíram esse resultado à liberação de ânions e hidratação da amônia. Da mesma maneira, a condutividade elétrica aumenta devido ao consumo da matéria orgânica e colonização de diferentes comunidades biológicas. 


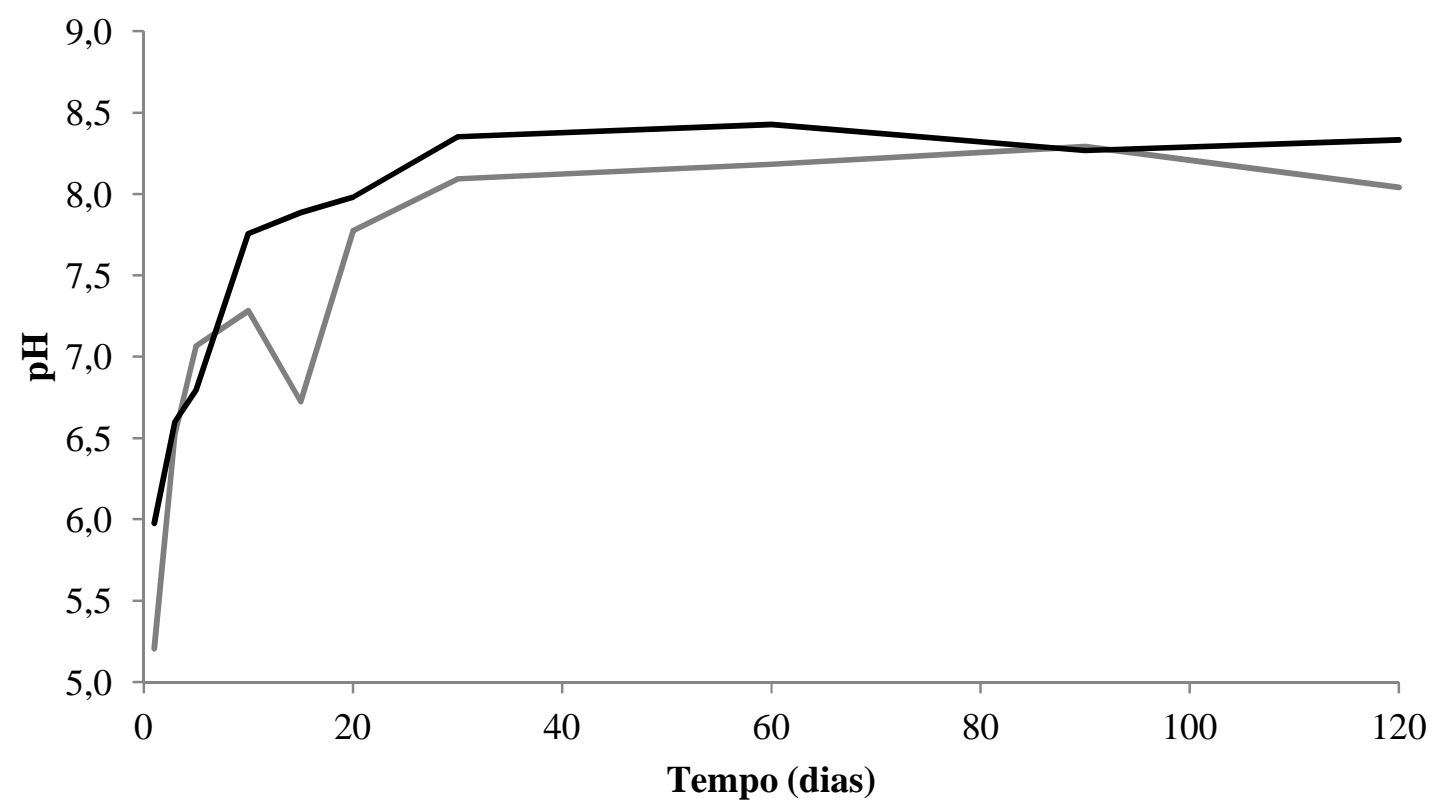

$-15 \mathrm{C}-25 \mathrm{C}$

Figura 36: Variação temporal do $\mathrm{pH}$ durante a decomposição in vitro de $P$. lapathifolium

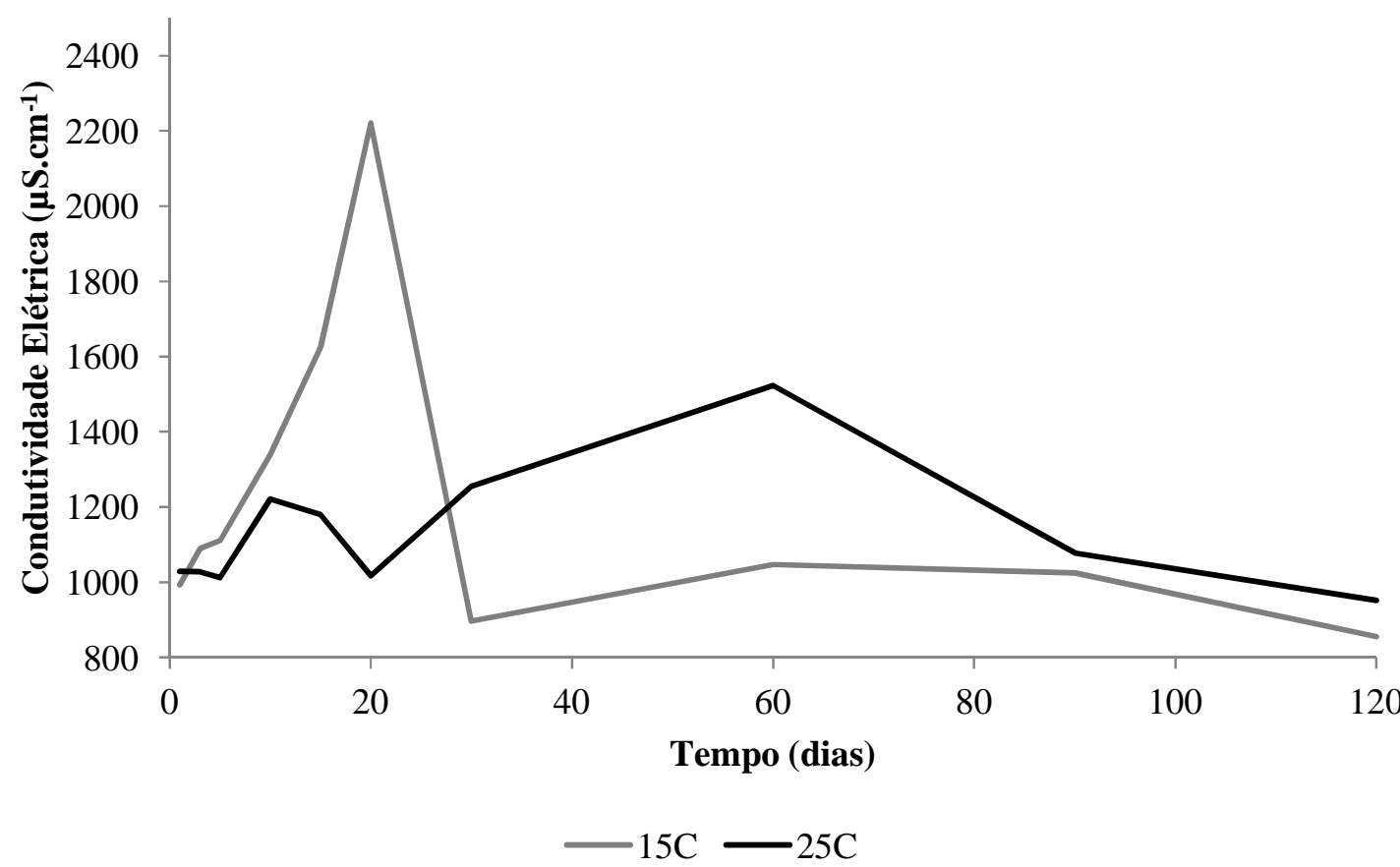

Figura 37: Variação temporal da condutividade elétrica durante a decomposição in vitro de $P$. lapathifolium 
No que diz respeito aos métodos empregados no estudo de decomposição, ambos os experimentos, in situ e in vitro, possuem restrições, porém são amplamente aplicados (PAGIORO e THOMAZ, 1998; VILLAR et al, 2001; CARVALHO, THOMAZ e BINI, 2005; PADIAL e THOMAZ, 2006; CHRISTENSEN, CRUMPTON, VAN der VALK, 2009). A metodologia dos litter bags tem sido criticada devido à redução da atividade microbiana, redução de invertebrados, intensidade luminosa e correnteza (SCHNITZER e NEELY 2000). Por outro lado, experimentos de laboratório não são capazes de reproduzir exatamente as condições do campo (naturais), embora eles permitam o controle de fatores importantes para o processo de decomposição.

O maior desafio em ciências aquáticas é integrar observações em campo e em laboratório (VIGNATI, FERRARI e DOMINIK, 2007). Portanto a decisão sobre qual método experimental é mais apropriado depende do objetivo do estudo, uma vez que qualquer procedimento pode apresentar problemas e restrições. Silva et al. (2011) sugeriram uma equivalência, do ponto de vista cinético, entre dados obtidos em campo e em laboratório, mas um coeficiente $(1,32)$ deve ser usado para garantir a similaridade de experimentos in situ e in vitro.

Em relação aos resultados obtidos, pode-se dizer que ambos os procedimentos adotados forneceram informações importantes do ponto de vista da dinâmica de detritos, como influência das condições locais no processo de perda de massa, no caso do experimento em campo, e, no caso do experimento em laboratório, pode-se verificar os efeitos da mortandade em massa, principalmente, sobre as características químicas e biológicas do reservatório. Sob condições controladas, evidenciouse que temperaturas mais elevadas favoreceram a mineralização da MOD, contribuindo de forma mais rápida com a cadeia de detritos. Entretanto, o baixo valor de $\mathrm{Q}_{10}$ indicou que a temperatura não se constituiu em fator inibidor ou estimulante dos processos de degradação.

O predomínio da fração refratária no detrito de P. lapathifolium indica que o processo de mineralização pode ser dominante no reservatório Itupararanga, caso o stand dessa espécie aumente e haja mortalidade em massa. Esse fato pode se constituir em objeto de preocupação, visto que $P$. lapathifolium foi predominante em dois dos quatro bancos analisados, com elevada biomassa em todos os períodos de estudo. 


\subsubsection{Decomposição de Eichhornia azurea}

As condições locais durante o experimento de campo, realizado na estação de amostragem $\mathrm{Br}_{4}$, são apresentadas na Tabela 18. Observou-se, de maneira geral, pequena variação da profundidade. A profundidade do Disco de Secchi foi baixa no $30^{\circ}$ dia amostral, provavelmente devido à precipitação de $43 \mathrm{~mm}$ registrada no dia anterior à coleta. No $120^{\circ}$ dia de amostragem ocorreram $55 \mathrm{~mm}$ de precipitação, o que também pode ter influenciado os resultados obtidos para o disco de Secchi. A temperatura variou de $19^{\circ} \mathrm{C}$ a, aproximadamente, $24^{\circ} \mathrm{C}$ e o menor valor foi observado no $5^{\circ}$ dia de experimento. $\mathrm{O}$ pH do meio manteve-se próximo à neutralidade e a condutividade elétrica aumentou até o $20^{\circ}$ dia, decaindo a partir do $30^{\circ}$ dia. Em relação ao OD, apenas entre os dias 30 e 90 do experimento, houve queda considerável das concentrações.

Tabela 18: Condições locais nos dias de amostragem na estação de coleta $\mathrm{Br}_{4}$

\begin{tabular}{|c|c|c|c|c|c|c|c|c|c|c|}
\hline \multirow{2}{*}{ Variáveis } & \multicolumn{10}{|c|}{ Dias amostrais } \\
\hline & 1 & 3 & 5 & 10 & 15 & 20 & 30 & 60 & 90 & 120 \\
\hline Profundidade $(\mathrm{m})$ & 1,50 & 1,60 & 1,60 & 1,60 & 1,5 & 1,8 & 1,6 & 0,9 & 1,2 & 1,8 \\
\hline Secchi (m) & 0,8 & 0,9 & 1,0 & 0,9 & 0,55 & 1,3 & 0,2 & 0,9 & 1,1 & 0,6 \\
\hline Temperatura $\left({ }^{\circ} \mathrm{C}\right)$ & 19 & 17,04 & 16,4 & 19,0 & 17 & 19,0 & 18,0 & 18,0 & 22,0 & 24,0 \\
\hline $\mathrm{pH}$ & 6,44 & 6,45 & 6,33 & 6,87 & 7,32 & 6,89 & 7,45 & 7,2 & 6,87 & 6,73 \\
\hline $\begin{array}{l}\text { Condutividade } \\
\left(u S . \mathrm{cm}^{-1}\right)\end{array}$ & 69 & 66,0 & 41 & 70 & 93 & 102 & 87 & 100 & 79 & 84 \\
\hline $\mathrm{OD}\left(\mathrm{mg} . \mathrm{L}^{-1}\right)$ & 6,58 & 6,67 & 5,11 & 8,8 & 7,53 & 5,40 & 4,2 & 4,45 & 3,9 & 7,49 \\
\hline
\end{tabular}

As variáveis limnológicas monitoradas são extremamente importantes para a oxidação dos detritos em um curso de água, pois como reportou Bianchini Jr. (2003), o pH e a condutividade são fatores dos quais a velocidade do processo de decomposição é dependente. $\mathrm{O}$ autor afirmou ainda, que essas variáveis condicionam a ocorrência de comunidades biológicas e interferem nas velocidades das reações mediadas por enzimas. Além disso, o teor de oxigênio dissolvido na água é essencial para a oxidação eficaz da matéria orgânica.

Na Tabela 19 são mostrados os valores de Matéria Orgânica Lábil Solúvel (MOPLS), Matéria Orgânica Refratária (MOR) e das constantes de decaimento de ambas as frações ( $\mathrm{k}_{\mathrm{T}} \mathrm{e} \mathrm{k}_{4}$, respectivamente) obtidos para o estudo com litter bags e para os experimentos mantidos sob condições controladas $\left(15^{\circ} \mathrm{C}\right.$ e $\left.25^{\circ} \mathrm{C}\right)$. 
Tabela 19: Resultados do modelo cinético de decomposição para ambos os tratamentos (campo e laboratório) com $E$. azurea. MOPLS: Matéria orgânica lábil solúvel; MOR: Matéria orgânica refratária; MI: Matéria inorgânica; $\mathrm{k}_{\mathrm{T}}$ : constante de perda total de massa; $\mathrm{k}_{4}$ : constante de decaimento do material refratário; $\mathrm{r}^{2}$ : coeficiente de ajuste dos dados; E: Erro.

\begin{tabular}{ccccccccccc}
\hline Tratamento & $\begin{array}{c}\text { MOPLS } \\
(\boldsymbol{\%})\end{array}$ & $\mathbf{E}$ & $\mathbf{k}_{\mathbf{T}}$ & $\mathbf{E}$ & $\begin{array}{c}\text { MOR } \\
(\boldsymbol{\%})\end{array}$ & $\mathbf{E}$ & $\mathbf{k}_{\mathbf{4}}$ & $\mathbf{E}$ & $\mathbf{r}^{2}$ & $\begin{array}{c}\mathbf{M I} \\
(\boldsymbol{\%})\end{array}$ \\
\hline $15^{\circ} \mathrm{C}$ & 15,33 & 3,1 & 1 & - & 84,1 & 1,3 & 0,0026 & 0,0003 & 0,94 & 36,0 \\
$25^{\circ} \mathrm{C}$ & 19,72 & 5,0 & 1 & - & 76,8 & 2,2 & 0,0023 & 0,0006 & 0,87 & 42,5 \\
Litter Bags & 27,82 & 6,4 & 0,6 & 0,3 & 73,93 & 3,7 & 0,0051 & 0,002 & 0,93 & 38,0 \\
\hline
\end{tabular}

Nas primeiras 24 horas do processo de decomposição evidenciou-se baixa perda de MOP no experimento in situ (7\%) (Figura 38), enquanto, em laboratório, a perda foi de $12,4 \%$ a $15^{\circ} \mathrm{C}$ e $26 \%$ a $25^{\circ} \mathrm{C}$. Sabe-se que o processo de lixiviação ocorre nas primeiras horas do processo de decomposição, através da liberação de frações citoplasmáticas do detrito culminando na perda inicial de massa. No caso do experimento de campo, provavelmente as condições locais (temperatura relativamente baixa e baixa profundidade do disco de Secchi) e o local de incubação dos litter bags (sub-superfície) interferiram na lixiviação. Cunha-Santino, Bianchini Jr. e Okawa (2010) citaram que vários fatores podem afetar a fase de lixiviação, incluindo procedimentos experimentais, tais como secagem do fragmento e tamanho da abertura de malha dos litter bags. Crhistensen, Crumpton e Van der Valk (2009) comentaram que litter bags colocados na superfície da água podem apresentar decaimento de massa diferente daqueles colocados no meio ou no fundo da coluna de água. Staripari e Henry (2002) sugeriram que o detrito de E. azurea se torna mais palatável aos colonizadores invertebrados após alguns dias de decomposição, devido à perda de compostos fenólicos, fato que pode favorecer a elevada perda de massa da planta apenas após alguns dias de incubação.

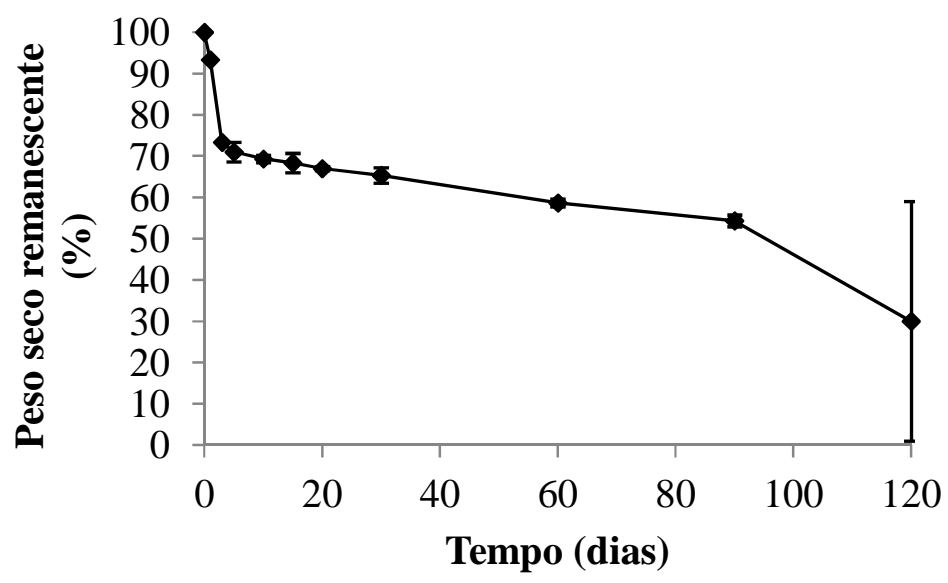

Figura 38: Peso seco remanescente (\%) de Eichhornia azurea no experimento de campo. As barras verticais representam \pm desvio padrão. 
Antagonicamente, Pagioro e Thomaz (1998) avaliaram a decomposição de E. azurea em diferentes áreas da planície de inundação do Alto Paraná e registraram rápida redução da massa (15\%) durante as primeiras 24 horas de incubação. Os autores verificaram que exemplares de E. azurea pertencentes a diferentes ambientes (diferentes lagoas costeiras) decompõem-se em padrões variados. Stripari e Henry (2002) também observaram rápida perda de massa de E. azurea no reservatório Jurumirim (estado de São Paulo), ocorrendo nas primeiras 24 horas do experimento de decomposição.

Verificou-se que a perda das frações lábeis nas primeiras 24 horas do processo de decomposição em laboratório foi mais de duas vezes maior a $25^{\circ} \mathrm{C}$. Carvalho, Thomaz e Bini (2005) relataram a importância da temperatura para o processo de decomposição de macrófitas aquáticas no reservatório de Ituaipu-PR, sugerindo que o incremento de $10^{\circ} \mathrm{C}$ na temperatura, durante a degradação dos detritos, favoreceu o aumento da atividade biológica em até duas ou três vezes. Os autores verificaram que altas temperaturas aumentaram o coeficiente de decaimento de massa, permitindo elevada perda de peso da planta, assim como reportado Thullen et al. (2008) para macrófitas em decomposição na Califórnia. Ainda a respeito do efeito do incremento em $10^{\circ} \mathrm{C}$ na temperatura durante a degradação de detritos, verificou-se, a partir do coeficiente de mineralização da MOR, que o valor de $\mathrm{Q}_{10}$ foi mais elevado ao se comparar o experimento que ocorreu em condições naturais com aquele realizado em laboratório a $25^{\circ} \mathrm{C}(2,21)$. O valor desse coeficiente, obtido para o ensaio in situ e in vitro a $15^{\circ} \mathrm{C}$ foi 1,96 , enquanto que entre os experimentos de laboratório foi 1,13. Esses resultados sugerem que a comunidade que promove a degradação desse recurso é menos sensível a temperaturas mais elevadas. Além disso, é possível inferir que a temperatura foi um dos fatores que influenciou na taxa metabólica dos micorganismos que participam do processo de decomposição de E. azurea.

Em relação aos coeficientes de decaimento, a via de mineralização da MOR indicou que as meias-vidas do detrito de E. azurea foram 266,292 e 136 dias a $15^{\circ} \mathrm{C}, 25^{\circ} \mathrm{C}$ e nos litter bags, respectivamente. Novamente os resultados sugerem que em temperaturas mais elevadas o decaimento da espécie em estudo foi menos intenso, devido, provavelmente, à própria composição química do detrito ou, até mesmo, à comunidade biológica predominante na câmara de decomposição.

Com o intuito de comparar os coeficientes de decaimento obtidos através de modelos matemáticos, Cunha-Santino e Bianchini Jr. (2006) reuniram dados de diferentes espécies de macrófitas aquáticas e mostraram que a fração lábil-solúvel de E. azurea variou entre 8,5 a 25,2\%, sendo que $\mathrm{k}_{\mathrm{T}}$ oscilou de 0,21 a 1,5 d $\mathrm{d}^{-1}$. Em relação à MOR, os valores compilados pelos autores foram de 74,8 a $91,5 \%$, com $\mathrm{k}_{4}$ de 0,0014 a $0,0097 \mathrm{~d}^{-1}$. Em ecossistemas aquáticos tropicais os valores de $k$ reportados para E. azurea foram $0,0175 \mathrm{~d}^{-1}$ durante o período chuvoso e $0,0135 \mathrm{~d}^{-1}$ no período seco, no 
reservatório Jurumirim-SP (STRIPARI e HENRY, 2002). Na planície de inundação do rio Paraná, o valor de $k$ foi $0,018 \mathrm{~d}^{-1}$ (PADIAL e THOMAZ, 2006), enquanto no rio Paraná foi 0,0008 $\mathrm{d}^{-1}$ (PAGIORO e THOMAZ 1998). Cunha-Santino, Bianchini Jr., Okawa (2010), em seu estudo com câmeras de sedimentação, encontraram valor de $k$ de $0,0018 \mathrm{~d}^{-1}$. Dessa maneira, o processo de decomposição de E. azurea no reservatório Itupararanga ocorreu segundo valores mencionados na literatura. $\mathrm{O}$ ajuste dos parâmetros obtidos através do modelo cinético pode ser visualizado nas Figuras 39 e 40.

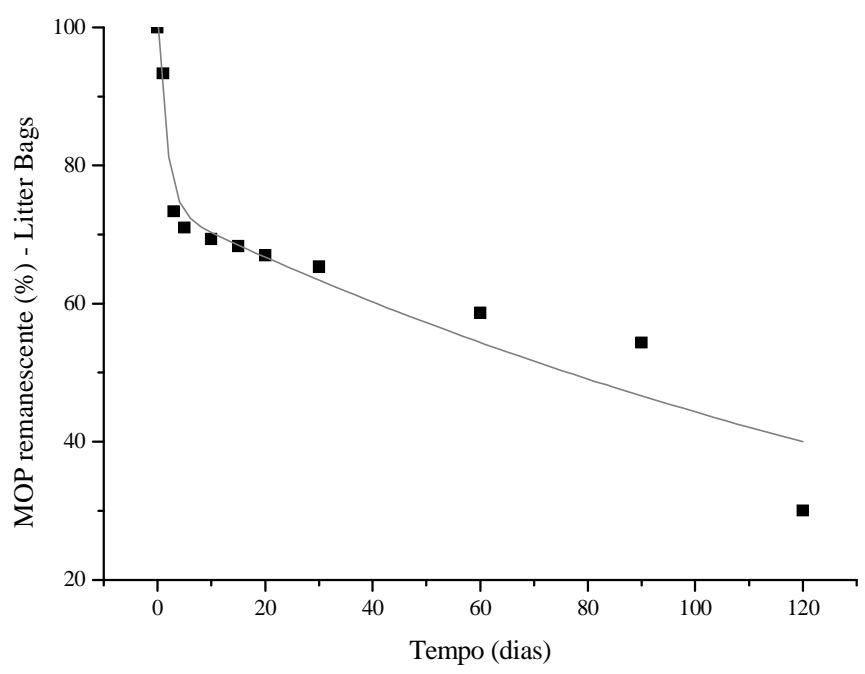

Figura 39: Ajuste dos parâmetros obtidos pelo modelo cinético de decaimento de massa para o experimento com litter bags de $E$. azurea. 

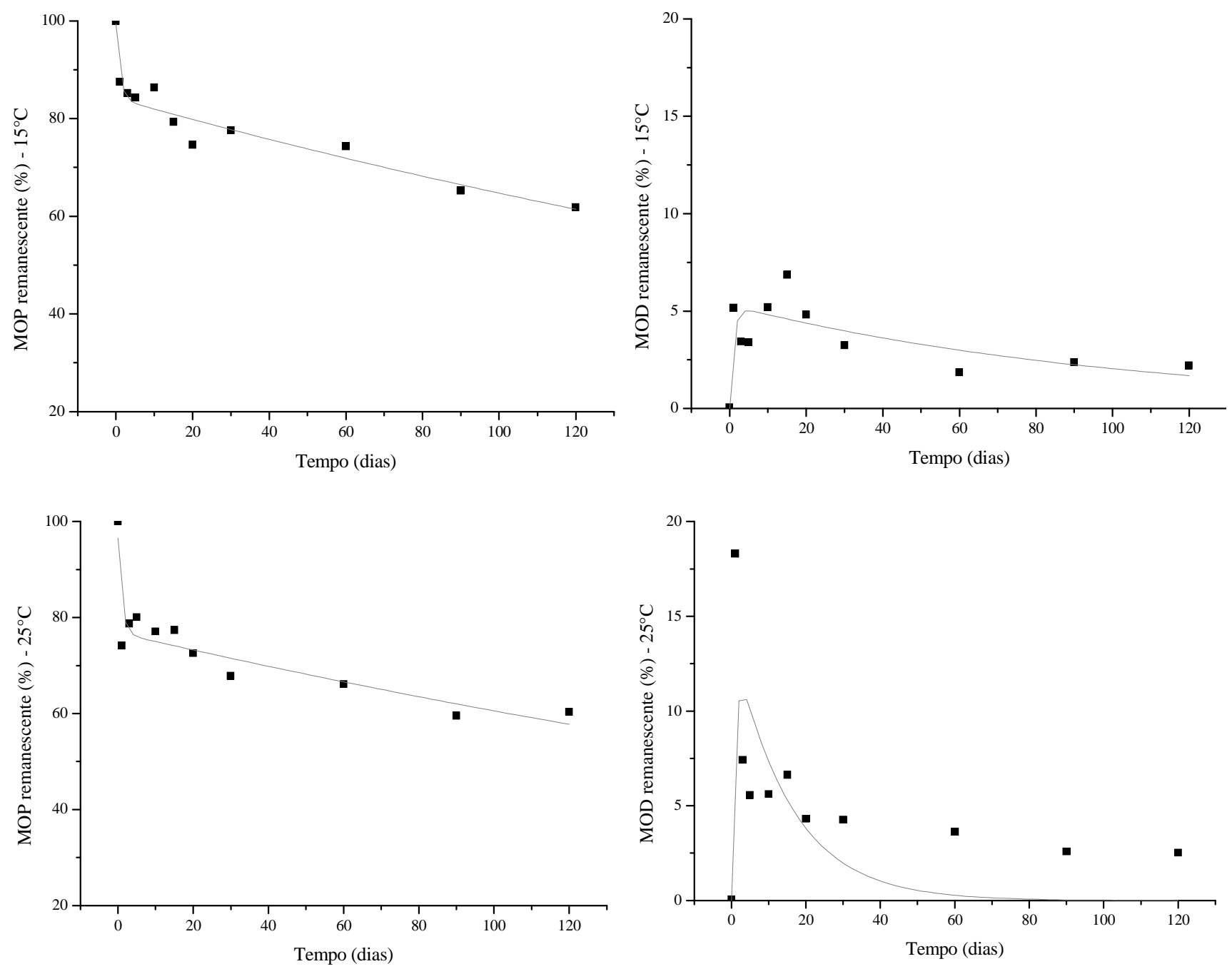

Figura 40: Ajuste dos parâmetros obtidos pelo modelo cinético de decaimento de massa em condições de laboratório (a $15^{\circ} \mathrm{C}$ e a $25^{\circ} \mathrm{C}$ ) para E. azurea.

A variação nas taxas de decomposição das macrófitas pode ser atribuída a interações fisiológicas e ambientais (CHIMNEY e PIETRO 2006). Vários autores (NELSON et al. 2000; HIEBER e GESSNER, 2002; NELSON e THULLEN, 2008) afirmaram que as taxas de decomposição são elevadas quando as concentrações de OD são altas, a temperatura elevada e o pH do meio oscila entre neutro a moderadamente alto. De acordo com os resultados obtidos no reservatório Itupararanga, a temperatura e a precipitação aumentaram durante esse estudo, a concentração de OD estavam elevadas e o pH do meio estava próximo à neutralidade.

Em relação à MOD (Tabela 20), o decaimento dessa fração foi mais rápido em elevadas temperaturas, aproximadamente 7 vezes. A dissolução das frações lábeis da MOP em MOD é de extrema importância, pois esse processo disponibiliza carbono para os microrganismos presentes na 
coluna de água. Cunha-Santino, Bianchini Jr. e Okawa (2010) encontraram 10,6\% de MOD no detrito de E. azurea, com um coeficiente de decaimento equivalente à $0,0896 \mathrm{~d}^{-1}$. A degradação da MOD depende da capacidade enzimática da microbiota e das condições ambientais (Wetzel e Likens, 1991) e por serem mineralizadas rapidamente se mantêm em baixas quantidades nos ecossistemas.

\begin{tabular}{|c|c|c|c|c|c|}
\hline Tratamento & $\begin{array}{c}\text { MOD } \\
(\%)\end{array}$ & $\mathbf{E}$ & $\mathbf{k}_{\mathbf{3}}$ & $\mathbf{E}$ & $\mathbf{r}^{2}$ \\
\hline $15^{\circ} \mathrm{C}$ & 5,25 & 0,7 & 0,009 & 0,004 & 0,6 \\
\hline $25^{\circ} \mathrm{C}$ & 13,26 & 4,1 & 0,065 & 0,04 & 0,5 \\
\hline
\end{tabular}

Tomando-se como base de cálculo a biomassa média (gPS) de E.azurea obtida em campanhas, nas quais essa espécies estava presente $\left(509,7\right.$ gPS.m $\left.{ }^{-2}\right)$, foi possível calcular a contribuição de carbono dessa planta durante o processo de decomposição. A $15^{\circ} \mathrm{C}$ foram obtidos $36 \mathrm{~g}$ de carbono provenientes de fração particulada e $200 \mathrm{~g}$ de carbono refratário. Na incubação realizada a $25^{\circ} \mathrm{C}$, a contribuição referente à MOP foi maior (46 g), entretanto, houve menor contribuição de carbono da MOR (184 g), quando comparada com a temperatura mais baixa. Em relação ao experimento de campo, verificou-se que a fração particulada contribuiu com $66 \mathrm{~g}$ de carbono, enquanto a refratária forneceu $177 \mathrm{~g}$ desse composto. Não foi possível extrapolar esses dados para todo o stand de E. azurea, pois os dados não estavam disponíveis. O cálculo do coeficiente de decaimento da fração refratária foi maior para experimento in situ, indicando que sob condições naturais a mineralização é mais intensa e, portanto, a contribuição de carbono é maior. E. azurea possui, principalmente, compostos refratários em sua composição, podendo acarretar, caso essa planta constitua-se a espécie dominante no reservatório e haja grande mortandade, diminuição das concentrações de oxigênio dissolvido e pH do meio, aumento da concentração de matéria orgânica no sedimento e da DBO, dentre outros.

A evolução da MOPLS, MOD e MI, a $15^{\circ} \mathrm{C}$ e a $25^{\circ} \mathrm{C}$, respectivamente, são apresentadas nas Figuras 41 e 42, as quais indicam que mineralização da MOD foi mais intensa a $25^{\circ} \mathrm{C}$, no primeiro estágio da decomposição. O aumento da MOPLS após a diminuição da MOD pode estar relacionado à incorporação do carbono dissolvido por microrganismos heterotróficos que passaram a constituir a MOP. A MOD, entretanto, continua a ser liberada lentamente através da mineralização das frações refratárias e o conteúdo inorgânico aumentou até o final do experimento, em decorrência da alteração da composição química dos detritos, devido aos processos de fragmentação, lixiviação e catabolismo. Os resultados permitiram pressupor que em elevadas temperaturas E. azurea contribuiu rapidamente 
para a cadeia trófica, enquanto que em temperatura mais baixas a contribuição se dá ao longo do tempo, em baixas quantidades.

A análise estatística (ANOVA) sugeriu diferença significativa entre o decaimento da fração particulada para os tratamentos aplicados $(\mathrm{p}<0,05)$. A Figura 43 confirma que o decaimento da MOP foi diferente entre os experimentos de campo e de laboratório. 


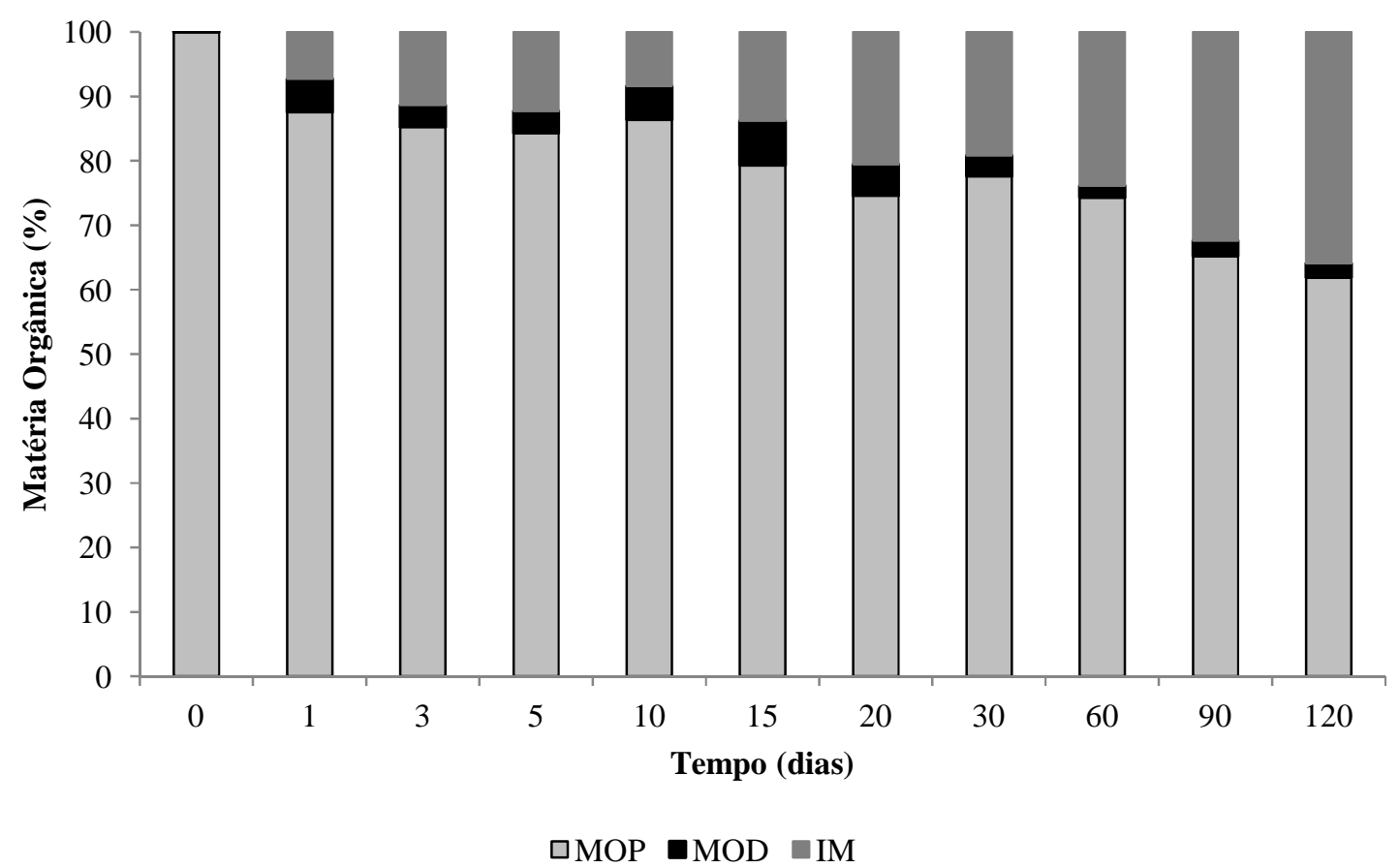

Figura 41: Variação da Matéria Orgânica particulada Lábil Solúvel (MOPLS), Matéria Orgânica Dissolvida (MOD) e Matéria Inorgânica (MI) durante o processo de decomposição de E. azurea à $15^{\circ} \mathrm{C}$ em laboratório.

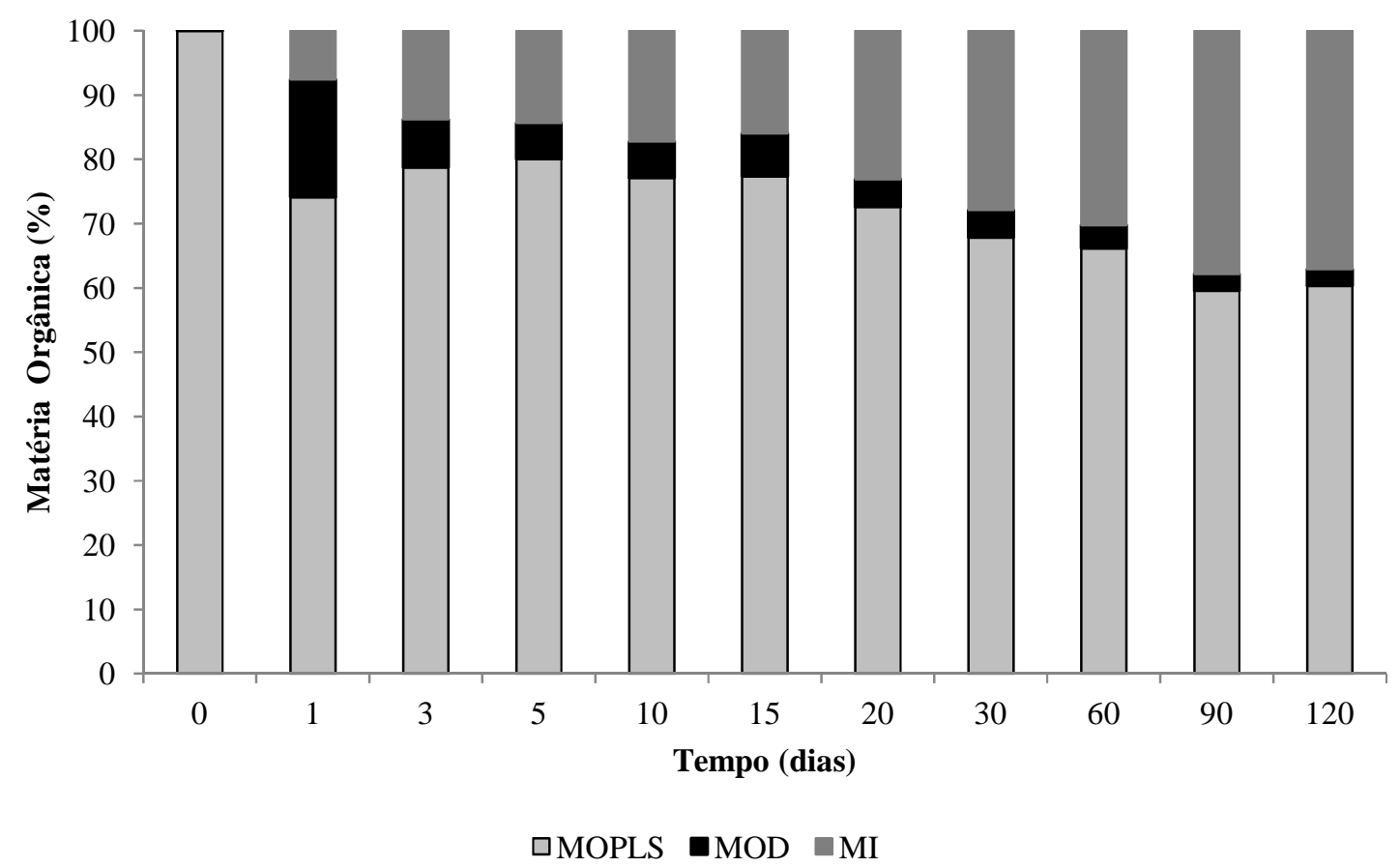

Figura 42: Variação da Matéria Orgânica particulada Lábil Solúvel (MOPLS), Matéria Orgânica Dissolvida (MOD) e Matéria Inorgânica (MI) durante o processo de decomposição de E. azurea à $25^{\circ} \mathrm{C}$ em laboratório. 

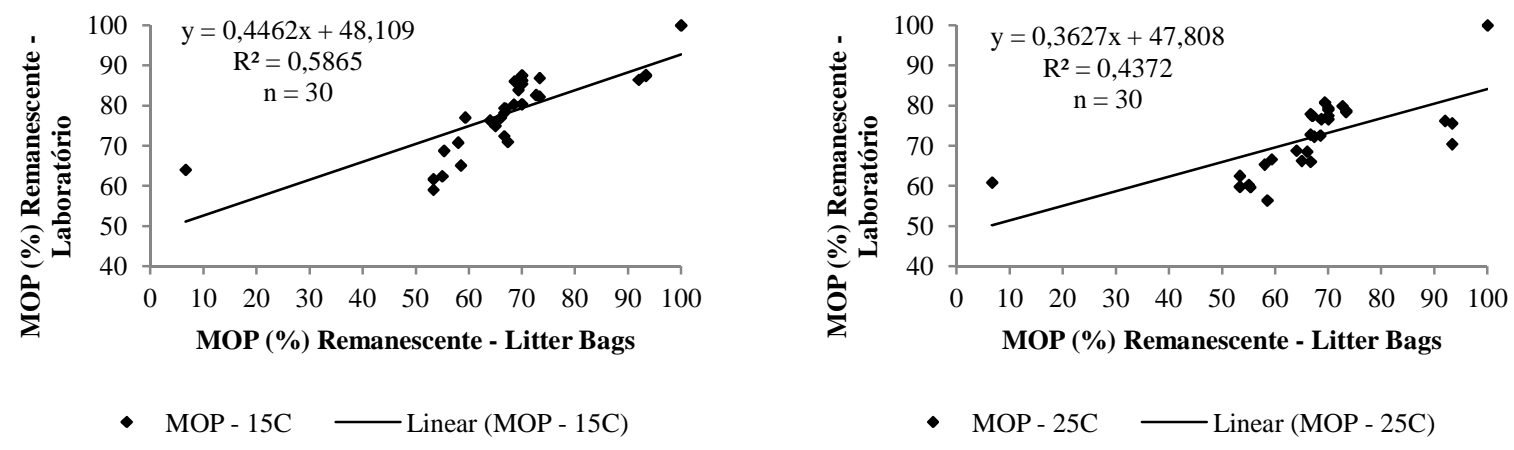

Figura 43: Relação entre a MOP remanescente de E. azurea nos experimentos de campo e laboratório.

Nas Figuras 44 e 45 evidencia-se a condição do meio em que a decomposição realizada em laboratório ocorreu. $\mathrm{O}$ pH aumentou, em ambas as condições de temperatura, ao longo do experimento. Foi verificado aumento dos valores de $\mathrm{pH}$ no $15^{\circ}$ dia de incubação, provavelmente, devido ao consumo de ácidos orgânicos originados com a dissolução da MOPLS no início do experimento. Azevedo et al. (2008) também reportaram comportamento similar do $\mathrm{pH}$, num maior intervalo de tempo, durante o processo de decomposição de E. azurea. De maneira geral, o pH, em ambas as condições de temperatura, estava elevado até os 120 dias de incubação, quando observou-se os maiores valores dessa variável. Segundo Azevedo et al. (2008), o aumento do pH no decorrer do período de estudo pode indicar que o consumo das frações lábeis é mais intenso quando comparado com o consumo na fase de lixiviação.

Em relação à condutividade elétrica, houve um aumento dessa variável, a $15^{\circ} \mathrm{C}$, do início até o $20^{\circ}$ dia de incubação, provavelmente relacionado à liberação da fração dissolvida e, portanto, maior quantidade de íons no meio. A $25^{\circ} \mathrm{C}$ a condutividade aumentou até o $3^{\circ}$ dia do experimento, devido à rápida dissolução da MOP. 


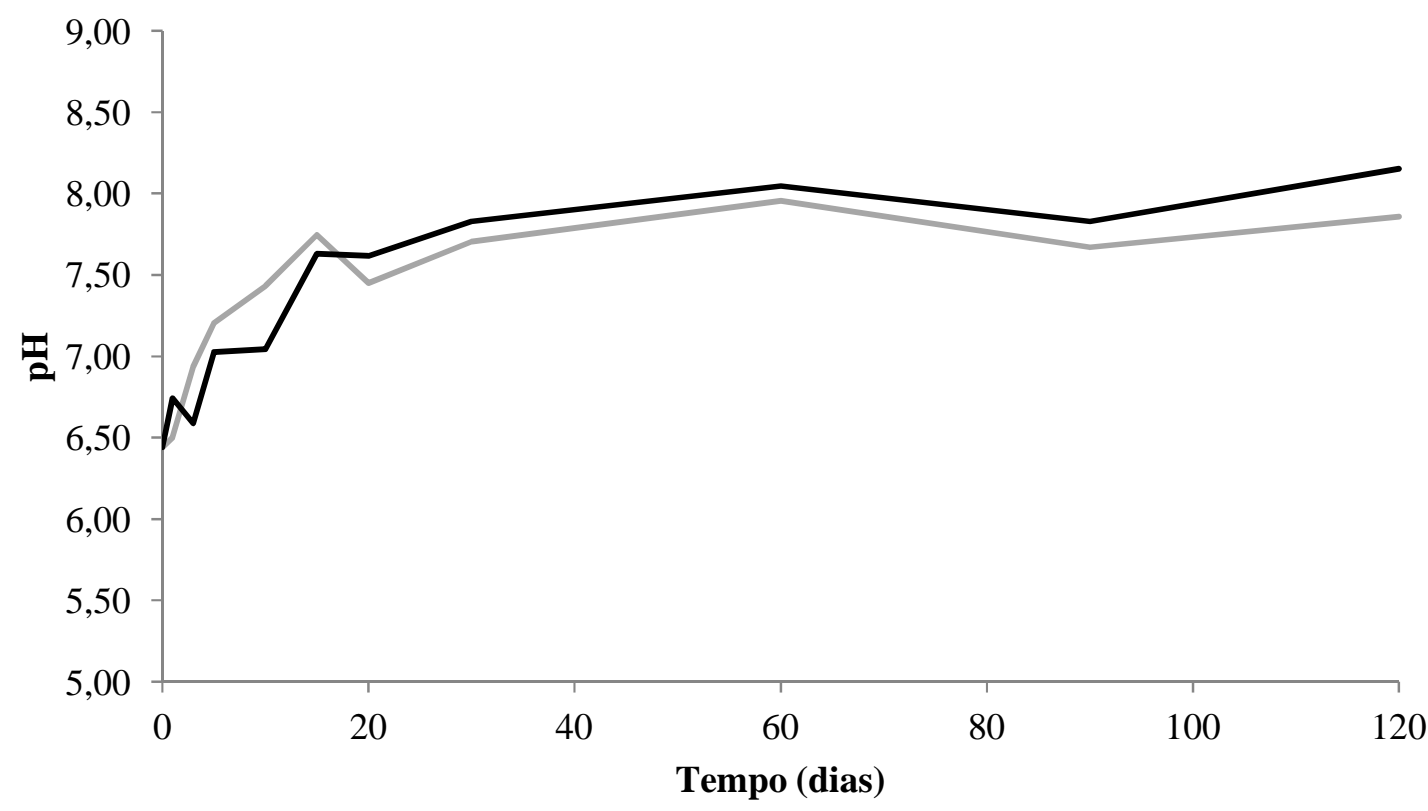

$-15 \mathrm{C}-25 \mathrm{C}$

Figura 44: Variação temporal do $\mathrm{pH}$ durante a decomposição in vitro de E. azurea.

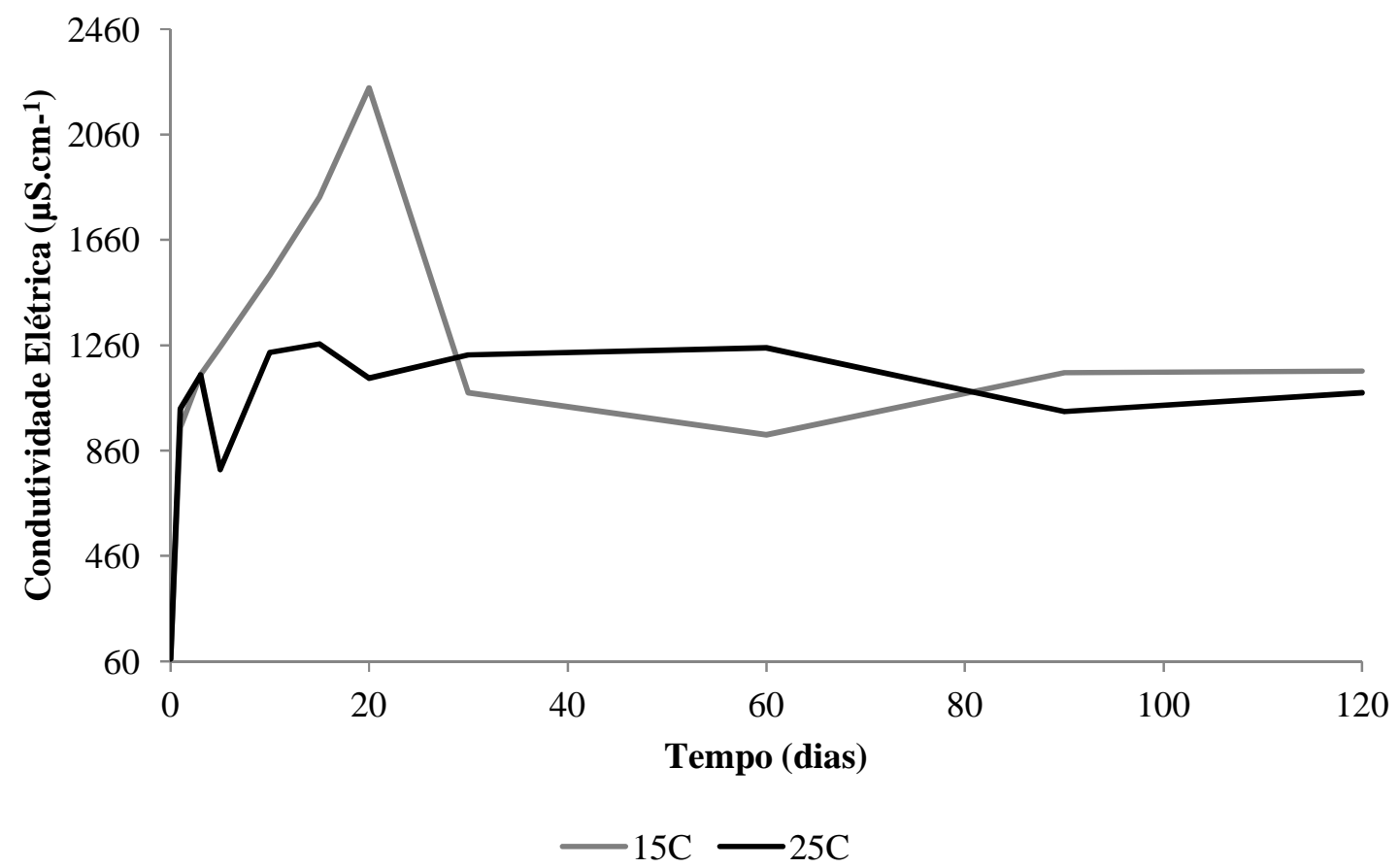

Figura 45: Variação temporal da condutividade elétrica durante a decomposição in vitro de E.azurea. 


\section{CONCLUSÕES}

A partir da análise dos dados obtidos na presente pesquisa pode-se constatar que as variáveis físicas e químicas da água apresentaram heterogeneidade espacial e variabilidade temporal determinadas tanto pela dinâmica fluvial dos tributários e processos autóctones, como pelo ciclo hidrológico.

A caracterização limnológica revelou a ocorrência de micro estratificações térmicas em algumas estações de amostragem, principalmente em períodos de temperatura mais elevada. A estratificação térmica favoreceu a estratificação química do oxigênio dissolvido e do $\mathrm{pH}$, conforme foi constatado nas diferentes estações de amostragem e períodos do ano. Ainda em relação ao oxigênio dissolvido, vale mencionar que as concentrações desse gás foram, de modo geral, elevadas. $\mathrm{O}$ pH diminuiu verticalmente em todas as estações de coleta, e apresentou valores mais elevados no verão, com destaque para $\mathrm{Br}_{3}$. Esse padrão de variação é corroborado pelos resultados de carbono inorgânico, que sugerem a formação de $\mathrm{CO}_{2}$ no fundo da coluna de água, em decorrência dos processos de decomposição.

Houve grande variação vertical da alcalinidade e os valores dessa variável indicaram baixa capacidade tampão do meio. A condutividade elétrica também apresentou intensa oscilação vertical, exceto no outono, período caracterizado por baixa pluviosidade. Entretanto, maior variação foi observada no verão e primavera, quando a precipitação pluviométrica foi elevada, denotando contribuição alóctone via lixiviação da bacia de drenagem. A precipitação pluviométrica registrada na primavera pode ter contribuído ainda, para o aporte de SST aos braços. Nesse período verificou-se maior participação relativa da forma inorgânica dos sólidos, embora a fração orgânica tenha sido predominante no reservatório, principalmente na estação de coleta $\mathrm{Br}_{1}$. Provavelmente a maior quantidade de carga orgânica pode ter influenciado os resultados de COT, que coincidiram com os picos de SSO.

Em relação aos nutrientes, constatou-se que as concentrações de NTK foram baixas no reservatório Itupararanga, assim como as de $\mathrm{NH}_{3}$ (acima do limite de detecção do método apenas no inverno) e as de $\mathrm{NO}_{2}^{-}$. Os resultados indicaram predomínio de $\mathrm{NO}_{3}^{-}$no reservatório, devido, provavelmente, aos altos teores de $\mathrm{OD}$, que favorecem o processo de nitrificação. As concentrações de $\mathrm{NO}_{3}{ }^{-}$estiveram de acordo com os limites propostos pela legislação pertinente para corpos de água classe II.

Verificou-se grande amplitude vertical e sazonal das concentrações de PT e fosfato total dissolvido, as quais foram baixas no outono e elevadas na cabeceira do reservatório, principalmente, no 
período chuvoso. Esses resultados sugerem a contribuição dos tributários para o aporte de fósforo ao reservatório, que apresentou a forma total acima do limite estabelecido pela legislação para corpos de água classe II. Foram registradas baixas concentrações de ortofosfato (abaixo do limite de detecção do método), exceto na estação de coleta $\mathrm{Br}_{1}$ na primavera, provavelmente devido ao aumento da produtividade primária ocasionada pela maior disponibilidade de luz e aumento da temperatura.

No que diz respeito ao compartimento sedimento, observaram-se elevadas concentrações de nitrogênio total quando comparadas com as de fósforo total. Deve-se destacar a estação de coleta $\mathrm{Br}_{2}$ pelas elevadas concentrações de nitrogênio e $\mathrm{Br}_{4}$ por apresentar as menores. Não houve padrão de variação definido para ambas as variáveis. Baixos teores de matéria orgânica foram, novamente, encontrados em $\mathrm{Br}_{4} \mathrm{e}$, apenas na estação de coleta $\mathrm{Br}_{1}$ houve padrão sazonal definido, com decréscimo das porcentagens do inverno para o outono. A análise granulométrica permitiu evidenciar o predomínio da fração silte em todas as estações de amostragem, com maior participação de areia nos períodos mais chuvosos.

Quanto à diversidade de espécies, foram encontrados 9 taxa nos quatro braços do reservatório Itupararanga. Dentre esses, apenas cinco apresentaram-se distribuídos em bancos homogêneos e significativos para a determinação da biomassa. Houve um incremento da parte aérea em períodos de maior intensidade luminosa, o que proporciona altas taxas de crescimento. No entanto, um maior investimento na raiz em períodos específicos (meses com baixas temperaturas e com poucas horas de iluminação diária) pode aumentar a taxa de respiração. É possível supor que os bancos localizados na desembocadura dos tributários, principalmente na cabeceira do reservatório, exerçam um papel importante para a manutenção da qualidade das águas desse manancial, uma vez que podem estar retendo grande quantidade de carga.

Na estação de coleta $\mathrm{Br}_{1}$ verificou-se ausência de $P$. stratiotes quando a biomassa de $E$. crassipes aumentou, denotando assim, um processo competitivo entre essas espécies. Ainda em $\mathrm{Br}_{1}$, supõe-se que o aporte de nutrientes pelos formadores do reservatório, juntamente com as características do entorno, tenham favorecido a ocorrência de ambas as espécies.

Nas estações de coleta $\mathrm{Br}_{2}$ e $\mathrm{Br}_{3}$ foi verificada elevada biomassa de P. lapathifolium nos diferentes períodos estudados. Provavelmente $\mathrm{pH}, \mathrm{OD}$, variáveis do sedimento (nitrogênio e fósforo totais e matéria orgânica) e o tipo de uso e ocupação do solo foram importantes preditores da ocorrência dessa espécie.

Apenas no inverno foi registrada quantidade expressiva de E. azurea na estação de coleta $\mathrm{Br}_{4} . M$. aquaticum esteve presente apenas na primavera. As características da estação de amostragem e o aporte de substâncias inorgânicas pareceram desfavorecer E. azurea em detrimento de M. aquaticum. 
Ambas as espécies utilizadas nos ensaios de decomposição (E. azurea e P. lapathifolium) indicaram que em condições naturais o decaimento de massa é mais efetivo. Comparando-se os ensaios realizados em laboratório, a contribuição de MOP é maior a $25^{\circ} \mathrm{C}$. Em temperaturas mais elevadas, a mineralização da MOD constitui-se em um processo de curto prazo, contribuindo prontamente para o elo microbiano. O pico de condutividade elétrica nas primeiras 24 horas de incubação evidencia que o pool orgânico é maior em um curto período de tempo. O processo de decomposição foi, aproximadamente, 2,0 e 1,2 vezes mais rápido no experimento de campo para E. azurea e $P$. lapathifolium, respectivamente. A temperatura exerceu, segundo o valor de $\mathrm{Q}_{10}$, maior influencia na perda de massa de E. azurea. Embora o decaimento tenha sido significativamente diferente entre os ensaios realizados para uma mesma espécie de macrófita, a contribuição estimada de carbono por espécie de planta foi semelhante para todos os tratamentos. Essas plantas aportam, ao reservatório Itupararanga, maior quantidade de carbono de difícil degradação, pois possuem, principalmente, material refratário em sua composição. De acordo com os valores de $k_{4}$ ambas as espécies contribuem para o acumulo de detrito no reservatório Itupararanga, incrementando o teor de matéria orgânica no sedimento. 


\section{RECOMENDAÇÕES}

As recomendações a seguir poderão servir como subsídio para o conhecimento da ecologia das principais espécies de macrófitas que ocupam o reservatório Itupararanga. Dessa forma, auxiliarão no manejo desses vegetais, caso os mesmos venham a causar prejuízos ao manancial, além de complementar os dados já obtidos pelo presente estudo.

- Estimar a produção primária das macrófitas aquáticas do reservatório Itupararanga a fim de comparar os processos de crescimento e decaimento de massa;

- Estudos que contemplem a produção da biomassa das macrófitas aquáticas e curto período de tempo para que se verifique a influência de diferentes fatores no acúmulo ou perda de massa desses vegetais;

- Avaliar o papel das macrófitas no reservatório Itupararanga, como por exemplo, acumulação/retenção de compostos em sua biomassa. 


\section{REFERÊNCIAS BIBLIOGRÁFICAS}

AGAMI M.; REDDY K. R. Competition for space between Eichhornia crassipes (Mart.) Solms and Pistia stratiotes L. cultured in nutrient-enriched water. Aquatic Botany, n. 38, p.195-208, 1990.

AMARAL, M. C.; BITTICH, V.; FARIA, A. D.; ANDERSON, L. O.; AONA, L. Y. Guia de campo para plantas aquáticas e palustres do estado de São Paulo. Ed. Holos. Campinas. 452p. 2008

AMORIM, M. A.; MOREIRA-TURCQ, P. F.; TURCQ, B. J.; CORDEIRO, R. C. Origem e dinâmica da deposição dos sedimentos superficiais na várzea do lago Grande de Curuai, Pará, Brasil. Acta Amazonica, v.39, n.1, p.165-172, 2009.

ANDERSEN, J. M. An ignition method for determination of total phosphorus in lake sediments. Water Resources, v.10, p. 329-31, 1976.

ANDERSON, J. T.; SMITH, L. M. The effect of flooding regimes on decomposition of Polygonum pensylvanicum in playa wetlands (Southern Great Plains, USA). Aquatic Botany, v.74, n.2, p. 97-108, 2002.

APHA - American Public Health Association, Standard Methods for the examination of water and wastewater. $21^{\text {th }}$ edition Washington, 2005.

ASAEDA T.; TRUNG V. K.; MANATUNGE J. Modeling the effects of macrophyte growth and decomposition on the nutrient budget in shallow lakes. Aquatic Botany, v.68, p.217-237, 2000.

AZEVEDO, J. C. R.; MIZUKAWA, A.; TEIXEIRA, M. C.; PAGIORO, T. A. Contribuiçãoda decomposição de macrófitas aquáticas (Eichhornia azurea) na matéria orgânica dissolvida. Oecologia Brasiliensia, v.12, n.1, p.42-56, 2008.

BEST, E. P. H.; DASSEN, J. H. A.; BOON, J. J.; WEIGERS, G. Studies on decomposition of Ceratophyllum demersum under laboratory and fields conditions: loss and dry mass and nutrients, quantitative changes in organic compounds and consequences for ambient water and sediment. Hydrobiologia, v.194, p.91-114, 1990.

BEU, S. E.; MISATO, M. T.; HAHN, C. M. APA de Itupararanga. In: BEU, S. E.; DOS SANTOS, A. C. A.; CASALI, S. (eds). Biodiversidade na APA Itupararanga. Ed. Grafilar, p. 134-139, 2011. 
BIANCHINI Jr., I. Aspectos dos processos de decomposição nos ecossistemas aquáticos ambientais. In: POMPÊO, M. L. M. (ed). Perspectivas na limnologia do Brasil, p. 21-43, 1999.

BIANCHINI Jr., I. Modelos de crescimento e decomposição de macrófitas aquáticas. In: THOMAZ, S. M.; BINI, L. M. (Org). Ecologia e manejo de macrófitas aquáticas. Eduem, Maringá, p.85-126, 2003.

BIANCHINI Jr., I.; CUNHA-SANTINO, M. B.; PERET, A. M. Oxygen demand during mineralization of aquatic macrophytes from an oxbow lake. Brazilian Journal of Biololy, v.68, p.61-67, 2008.

BIANCHINI Jr I., CUNHA-SANTINO, M. B. Model parameterization for aerobic decomposition of plant resources drowned during man-made lakes formation. Ecological Modelling, v.222, p.12631271, 2011.

BICUDO, D. C.; FORTI, M. C.; CARMO, F. C. D.; BOUROTTE, C.; BICUDO, C. E. M.; MELFI, A.J.; LUCAS, Y.. A atmosfera, as águas superficiais e os reservatórios no PEFI: caracterização química. In: BICUDO, D. C.; FORTI, M. C.; BICUDO, C. E. M. (eds.) Parque Estadual das Fontes do Ipiranga (PEFI): unidade de conservação que resiste à urbanização de São Paulo. Editora da Secretaria do Meio Ambiente do Estado de São Paulo, São Paulo. p.161-200, 2002.

BINI, L. M.; THOMAZ, S. M.; MURPHY, K. J.; CAMARGO, A. F. M. Aquatic macrophyte distribution in relation to water and sediment conditions in the Itaipu Reservoir, Brazil. Hydrobiologia, v.415, p. 147-154, 1999.

BINI, L. M.; OLIVEIRA, L. G.; SOUZA, D. C.; CARVAlHO, P.; PINTO, M. P. Patterns of the aquatic macrophyte cover in Cachoeira Dourada Reservoir (GO-MG). Brazilian Journal of Biology, v. 65, n. $1, \mathrm{p}, 19-24,2005$.

BIUDES, J. F. V.; CAMARGO, A. F. M. Estudos dos fatores limitantes à produção primária no Brasil. Oecologia Brasiliensis, v.12, n.1, p. 7-19, 2008.

BORGES, P. F.; TRAIN, S.; DIAS, J. D.; BONECKER, C. C. Effects of fish farming on plankton structure in a Brazilian tropical reservoir. Hydrobiologia, v.649, n.1, p.279-291, 2010. 
BOtTino F.; PAVÃO, A. C.; BENASSI, R. F.; DOS SANTOS, A. C. A.; CALIJURI, M. C. Macrófitas aquáticas do reservatório Itupararanga. In: BEU, S. E.; DOS SANTOS, A. C. A.; CASALI, S. (eds). Biodiversidade na APA Itupararanga. Ed. Grafilar, p. 134-139, 2011.

BRASIL. Resolução CONAMA 357/2005. Dispõe sobre a classificação dos corpos de água e diretrizes para seu enquadramento, bem como estabelece as condições de lançamento de efluentes e dá outras providências. Diário Oficial da República Federativa do Brasil. Brasília. 2005.

CAFFREY, J. M.; MONAHAN, C.; TIERNEY, D. Factors influencing the distribution of aquatic plants communities in Irish canals. Hydrobiologia, n.570, p. 133-139, 2006.

CALIJURI, M.C.; DEBERDT, G.L.B.; MINOTI, R.T. A produtividade primária pelo fitoplâncton na represa de Salto Grande. In: HENRY, R. (ed.) Ecologia de reservatórios: estrutura, função e aspectos sociais. FUNDIBIO: FAPESP, p.109-148, 1999.

CALIJURI, M.C.; OLIVEIRA, H.T. Manejo da Qualidade de Água: Uma Abordagem Metodológica. In: CASTELlanO, E. G.; CHAUDHRY, F. H. (Org.). Desenvolvimento sustentado: problemas e estratégias. Projeto Reenge. Universidade de São Paulo - Escola de Engenharia de São Carlos, p. 39$58,2000$.

CAMPOS Jr., J. J. F. Contribuição ao estudo da decomposição de macrófitas aquáticas da lagoa do Infernão: Processo anaeróbio, Dissertação de Mestrado. Universidade Federal de São Carlos, 1998, 148p.

CANCIAN, L. F.; CAMARGO, A. F. M.; HENRY-SILVA, G. G. Crescimento de Pistia stratiotes em diferentes condições de temperatura e fotoperíodo. Acta botanica brasilica, v.23, n.2, p. 552-557, 2009.

CAPPS, K. A.; GRAÇA, M. A. S.; ENCALADA, A. C.; FLECKER, A. S. Leaf-litter decomposition across three flooding regimes in a seasonally flooded Amazonian watershed. Journal of Tropical Ecology, v.27, p.205-21, 2011.

CARRILLO, Y.; GUARIN, A.; GUILLOT, G. Biomass distribution, growth and decay of Egeria densa in a tropical high-mountain reservoir (NEUSA, Colombia). Aquatic Botany, v.85, n.1, p.7-15, 2006. 
CARVALHO, F.T.; GALLO, M. L. B. T.; VELINI, E. D. MARTINS, D. Plantas aquáticas e nível de infestação das espécies presentes no reservatório de Barra Bonita, no Rio Tietê. Planta Daninha, v.21, Ed. Especial, p. 15-19, 2003.

CARVALHO, F.T.; VELINI, E. D.; MARTINS, D. Plantas aquáticas e nível de infestação das espécies presentes no reservatório de Barra Bariri, no Rio Tietê, Planta Daninha, v.23, n.2, p. 371-374, 2005.

CARVALHO, P.; THOMAZ, S. M.; BINI, L. M. Effects of temperature on decomposition of a potential nuisance species: the submerged aquatic macrophyte Egeria najas Planchon (Hydrocharitaceae), Brazilian Journal of Biology, v.65, p.51-60, 2005.

CAVENAGHI, A. L.; VELINI, E. D.; GAlO, M. L. B. T.; CARVALHO, F. T; NEGRISOLI, E.; TRINDADE, M. L. B.; SIMIONATO, J. L. A. Caracterização da qualidade da água e sedimento relacionados com a ocorrência de plantas aquáticas em cinco reservatórios da bacia do rio Tietê. Planta daninha, v.21, Ed. Especial, p. 43-52, 2003.

CAVENAGHI, A. L.; VELINI, E. D.; GAlO, M. L. B. T.; CARVAlHO, F. T.; NEGRISOLI, E.; TRINDADE, M. L. B.; SIMIONATO, J. L. A. Caracterização da qualidade da água e sedimento relacionados com a ocorrência de plantas aquáticas em cinco reservatórios da bacia do rio Tietê. Planta daninha, v.21, p. 43-52, 2005.

CETESB Companhia de Tecnologia de Saneamento Ambiental, 2006. Relatório de Qualidade das águas Interiores do Estado de São Paulo. Disponível em: www.cetesb.gov.br/agua/rios/publicacoes.asp. Accesso em: Ago, 2009

CETESB - Companhia de Tecnologia de Saneamento Ambiental, 2008. Relatório de Qualidade das águas Interiores do Estado de São Paulo. Disponível em: www.cetesb.gov.br/agua/rios/publicacoes.asp. Acesso em: Ago, 2009.

CETESB - Companhia de Tecnologia de Saneamento Ambiental, 2010. Relatório de Qualidade das águas Interiores do Estado de São Paulo. Disponível em: www.cetesb.gov.br/agua/rios/publicacoes.asp. Acesso em: Out, 2011.

CHAMBERS, P.A.; LACOUL, P.; MURPHY, K. J.; THOMAZ, S. M. Global diversity of aquatic macrophytes in freshwater. Hydrobiologia, n.595, p. 9-26, 2008. 
CHERUVELIL, K.; SORANNO, P. Relationships between lake macrophyte cover and lake and landscape features. Aquatic Botany, v.88, p.219-227, 2008.

CHIMNEY, M. J.; PIETRO, K. C. Decomposition of macrophyte litter in a subtropical constructed wetland in south Florida (USA). Ecological Engineering, v.27, p.301-321, 2006.

CHRISTENSEN, J. R.; CRUMPTOM, W. G.; VAN der VALK, A. G. Estimating the breakdown and accumulation of emergent macrophyte litter: A mass balance approach. Wetlands, v.29, p.204-214, 2009.

COLE, J. J.; PRAIRIE, Y. T.; CARACO, N. F.; MCDOWELL, W. H.; TRANVIK, L. J.; STRIEGL, R. G.; DUARTE, C. M.; KORTELAINEN, P.; DOWNING, J. A.; MIDDELBURG, J. J.; MELACK, J., Plumbing the Global Carbon Cycle: Integrating Inland Waters into the Terrestrial Carbon Budget. Ecosystems, v. 10, p. 171-184, 2007.

CRONIN, G.; LEWIS, W. M.; SCHIEHESER, M. A. Influence of freshwater macrophytes on the litoral ecosystem structure and function of a young Colorado Reservoir. Aquatic Botany, v.85, p.3743, 2006.

COOK, C. D. K.; GUT, B. J.; RIX, E. M.; SCHNELLER, J.; SEITZ, M. Water plants of the world. Dr. Junk B.V. Pulishers. England. 651 pp, 1974.

CUNHA-SANTINO, M. B.; BIANCHINI, JR., I. Decomposição aeróbia e anaeróbia de Salvinia auriculata Aubl. da Lagoa do Infernão. In: SANTOS J. E.; PIRES, J. S. R. (eds). Estudos Integrados em Ecossistemas, Estação Ecológica de Jataí. Ed. Rima, v.2, São Carlos-SP, 2000.

CUNHA-SANTINO, M. B.; BIANCHINI Jr., I. The aerobic and anaerobic decomposition of Typha domingensis Pers. Acta Limnologia Brasiliensia, v.18, p.321-334, 2006.

CUNHA-SANTINO, M. B.; BIANCHINI Jr., I. Cellulase activities during decomposition of a submerged macrophyte (Utricularia breviscapa): A microcosm assay. Brazilian Journal of Microbiolgy, v.38, p.230-236, 2007.

CUNHA-SANTINO, M. B.; BIANCHINI Jr., I.; OKAWA, M. H. The fate of Eichhornia azurea (Sw,) Kunth detritus within a tropical reservoir. Acta limonologica brasiliensia, v.22, p.109-121, 2010. 
CUNHA-SANTINO, M. B.; BIANCHINI Jr., I. Q(10) of heterotrophic activity during aerobic decomposition of Utricularia breviscapa and its effect on carbon cycling in a tropical lagoon. Brazilian Journal of Biology, v.70, n.2, p.317-24, 2010.

DANIEL, H.; BERNEZ, I.; HAURY, J. Relationships between macrophyte vegetation and physical features of river habitat: The need of morphological approach. Hydrobiologia, v. 570, p. 11-17, 2006.

DOS SANTOS, A.C.A.; CALIJURI, M.C. Temporal variations in phytoplankton primary production in a tropical reservoir (Barra Bonita, SP - Brazil). Hydrobiologia, v.445, p.11-26, 2001.

ELÇI, Ş. Effects of thermal stratification and mixing on reservoir water quality. Limnology, v.9, n.2, p.135-142, 2008.

ESTEVES, F. A.; BARBIERI, R. Dry weight and chemical changes during composition of tropical macrophytes in Lobo Reservoir - Sao Paulo, Brazil. Aquatic Botany, v.16, p.285-295, 1983.

FIGUEIREDO, D. M.; BIANCHINI Jr., I. Limnological patterns of the filling and stabilization phases in the Manso multiple-use reservoir (MT). Acta Limnologica Brasiliensia, v.20, n.4, p.277-290, 2008.

FISHER, J.; ACREMAN, M. C. Wetland nutrient removal: a review of evidence. Hydrology and Earth System Sciences, v.8, n.4, p. 673-685, 2004.

FONSECA, B. M.; BICUDO, C. E. M. Phytoplankton seasonal variation in a shallow stratified eutrophic reservoir (Garças Pond, Brazil). Hydrobiologia, v. 600, p. 267-282, 2008.

FRIESE, K.; SCHMIDT, G.; LENA, J. C.; NALINI Jr., H. A.; ZACHMANN, D. W. Anthropogenic influence on the degradation of an urban lake - The Pampulha reservoir in Belo Horizonte, Minas Gerais, Brazil. Limnologica, v.40, n.2, p.114-125, 2010.

GARCIA J. P. M.; FREITAS N. P., FILHO, N.L.S. Caracterização geo-ambiental da Represa de Itupararanga, 1999. Disponível em: http://ipe.ibrc.unesp.br/cbhsmt/projeto.html. Acesso em Dez, 2009

GENTIL, R. C.; TUCCI, A.; SANT'ANNA, C L. Dinâmica da comunidade fitoplanctônica e aspectos sanitários de um lago urbano eutrófico em São Paulo, SP. Hoehnea, v.35, n.2, p.265-280, 2008.

GESSNER, M. O. Breakdown and nutrient dynamics of submerged Phragmites shoots in the littoral zone of a temperate hardwater lake. Aquatic Botany, v.66, p.9-20, 2000. 
GIKAS, G. D.; TSIHRINTZIS, V.; AKRATOS, C. S.; HARALAMBIDIS, G. Water quality trends in Polyphytos reservoir, Aliakmon River, Greece. Environmental monitoring and assessment, v.149, n.1-4, p.163-81, 2009.

GIMENES, K. Z.; CUNHA-SANTINO, M.; BIANCHINI Jr., I. Decomposição de Matéria Orgânica Alóctone e Autóctone em Ecossistemas Aquáticos. Oecologia Australis, v.14, p.1036-1073, 2010.

GLOSSELINK, J. G.; TURNER, R. E. The role of hydrology in freshwater wetland ecosystems, In: Freshwater Wetlands: Ecological Processes and Management Potential. Academic Press, New York, p.63-78, 1978.

GONZÁLEZ, E. J.; ORTAZ, M.; PEÑAHERRERA, C.; INFANTE, A. Physical and chemical features of a tropical hypertrophic reservoir permanently stratified. Hydrobiologia, v.522, n.1-3, p.301-310, 2004.

GRANADO, D. C.; HENRY, R. The influence of the hydrologic pulse on the water physical and chemical variables of lateral lakes with different connection levels to Paranapanema River in the mouth zone at Jurumirim Reservoir (São Paulo, Brazil). Acta Limnologica Brasiliensia, v.20, n.4, p.265-275, 2008.

HASSAN, S.; SCHMIEDER, K.; BÖCKER, R. Spatial patterns of submerged macrophytes and heavy metals in the hypertrophic, contaminated, shallow reservoir Lake Qattieneh-Syria. Limnologica, v.40, p.54-60, 2010.

HENRY, R. The thermal structure of some lakes and reservoirs in Brazil, In: TUNDISI, J. G.; BICUDO, C. E. (eds). Limnology in Brazil. Brazilian Academy of Sciences and Brazilian Limnological Society, Rio de Janeiro, Brazil, p. 351-65, 1995.

HENRY-SILVA, G. G.; CAMARGO, A. F. M. Interaçãoes ecológicas entre as macrófitas aquáticas flutuantes Eichhornia crassipes e Pistia stratiotes. Hoehnea, v. 32, n.3, p. 445-452, 2005.

HENRY-SILVA, G. G.; CAMARGO, A. F. M.; PEZZATO, M. M. Growth of free-floating aquatic macrophytes in different concentrations of nutrients. Hydrobiologia, v. 610, n.1, p.153-160, 2008.

HIEBER, M.; GESSNER, M, O, Contribution of stream detritivores, fungi and bacteria to leaf breakdown based on biomass estimates, Ecology, v.83, p.1026-1038, 2002. 
HOBSON, P.; FABRIS, R.; DEVELTER, E.; LINDEN, L. G.; BURCH, M. D.; BROOKES, J. D. Reservoir Inflow Monitoring for Improved Management of Treated Water Quality-A South Australian Experience. Water Resources Management, v.24, n.14, p.4161-4174, 2010.

HOWARDS-WILLIMANS, C.; DAVIES, B. R. The rates of dry matter and nutrient loss from decomposing of Potamogeton pectinatus in a brackish south-temperate coastal lake. Freshwater Biology, v.9, p.13-21, 1979.

HU, M.H.; AO, Y. S.; YANG, X. E.; LI, T. Q. Treating eutrophic water for nutrient reduction using a aquatic macrophyte (Ipoema aquatic Forsskal) in a deep flow technique system. Agricultural water management, n.95, p. 607-615, 2008.

IPT - Instituto de Pesquisas Tecnológicas. Relatório Técnico $n^{\circ} 91$ 265-205. Plano de Bacia da Unidade de Gerenciamento de recursos Hídricos do Rio Sorocaba e Médio Tietê (UGRHI 10). Relatório Final, 155p., 2006.

JEFFRIES, M. The spatial and temporal heterogeneity of macrophyte communities in thirty small temporary ponds over a period of ten years. Ecography, v.31, n.6, p.765-775, 2008.

JIN-HO S., YANG K.C., YEON M.H., SHIM J.K. Decomposition and nutrient dynamics of aquatic macrophytes in lake Paldang. Journal of Ecology and Field Biology, v.30, p.231-236, 2007.

Kissmann, K.G., Goth, D. Plantas infestantes e nocivas. BASF: São Paulo, 1997.

KOUKI, S.; M'HIRI, F.; SAIDI, N.; BELAÏD, S.; HASSEN, A. Performances of a constructed wetland treating domestic wastewaters during a macrophytes life cycle. Desalination, v.246, p.452-467, 2009.

LACOUL, P.; FREEDMAN, B. Environmental influences on aquatic plants in freshwater ecosystems. Environmental Reviews, v.136, p.89-136, 2006.

LOPES-FERREIRA, C. Estudo de uma área alagada do Rio Atibaia visando a elaboração de proposta de manejo para a melhoria da qualidade da água no reservatório de Salto Grande (Americana, SP). Tese de Doutorado. Universidade de São Paulo - Escola de Engenharia de São Carlos. 145p, 2000.

MALTCHIK, L.; ROLON, A. S.; SCHOTT, P., Effects of hydrological variation on the aquatic plant community in a floodplain palustrine wetland of southern Brazil. Limnology, v.8, n.1, p. 23-28, 2007. 
MARIANI, C. F.; MOSCHINI-CARLOS, V.; BRANDIMARTE, A. L.; NISHIMURA, P. Y.; TÓFOLI, C. F.; DURAN, D.S.; LOURENÇO, E. M.; BRAIDOTTI, J.C.; ALMEIDA, L. P.; FIDALGO, V. H.; POMPÊO. M. L. M. Biota and water quality in the Riacho Grande Reservoir, Billings Complex (São Paulo, Brazil). Acta Limnologica Brasiliensia, v.18, n.3, p.267-280, 2006.

MARION, L.; PAILLISSON. J. M. A mass balance assessment of the contribution of floating-leaved macrophytes in nutrient stocks in an eutrophic macrophyte-dominated lake. Aquatic Botany, v.75, p.249-260, 2003.

MARTINS, D.; COSTA, N. V.; TERRA, M. A.; MARCHI, S. R. Caracterização da comunidade de plantas aquáticas de dezoito reservatórios pertencentes a cinco bacias hidrográficas do estado de São Paulo, Planta Daninha, v. 26, n.1, p.17-32, 2008.

MATIAS, L.Q.; AMADO, E.R.; NUNES, E.P. Macrófitas aquáticas da lagoa de Jijoca de Jericoacoara, Ceará, Brasil. Acta Botanica Brasilica, v.17, n.4, p. 623-631, 2003.

MERINO-IBARRA, M.; MONROY-RÍOS, E.; VILACLARA, G.; CASTILLO, F. S., GALLEGOS, M. E.; RAMÍREZ-ZIEROLD, J. Physical and chemical limnology of a wind-swept tropical highland reservoir. Aquatic Ecology, v.42, n.3, p.335-345, 2007.

MEYER, M. Avaliação da biomassa de Paspalum Repens Bergius submetida à variação de regimes hidrológicos na represa de Barra Bonita (Zona de Desembocadura do Rio Capivara, SP). Universidade de São Paulo - Escola de Engenharia de São Carlos. 123p, 1996.

MIDDLETON, B. A. Decomposition and litter production in a northern bald cypress swamp., Journal of Vegetation Science, v.5, p.271-274, 1994.

MILNE, J.M.; LANG, P.; MURPHY, K. J. Competitive interactions between Salvinia auriculata Aubl, Limnobium laevigatum (Humb, and Bonpl, ex Willd,) Heine, and other free-floating aquatic macrophytes under varying nutrient availability. Fundamental and Applied Limnology, v.169, p.169176, 2007.

NAHLIK, A. M.; MITSCH, W. J. Tropical treatment wetlands dominated by free-floating macrophytes for water quality improvement in Costa Rica. Ecological Engineering, v.28, p.246-257, 2006. 
NELSON, S. M.; ROLINE, R. A.; THULlEN, J. S.; SARTORIS, J. J.; BOUTWELL, J. E. Invertebrate assemblages and trace element bioaccumulation associated with constructed wetlands. Wetlands, v.20, p.406-415, 2000.

NELSON, S. M.; THULLEN, J. S. Aquatic macroinvertebrates associated with Schoenoplectus litter in a constructed wetland in California (USA). Ecological Engineering, v.33, p.91-101, 2008.

NOGUEIRA, J. B. Análise Granulométrica. In: NOGUEIRA, J. B. (ed) Mecânica dos solos - Ensaios de laboratório. Universidade de São Paulo - Escola de Engenharia de São Carlos, Departamento de Geotecnia, p.93-107, 2005.

PADIAL, A. A.; THOMAZ, S. M. Effects of flooding regime upon the decompositon of Eichhornia azurea (Sw.) Kunth measured on a tropical, flow-regulated floodplain (Parana River, Brazil). River Research and Application, v.22, p.791-801, 2006.

PADOVESI-FONSECA, C.; PHILOMENO, M. G.; ANDREONI-BATISTA, C. Limnological features after a flushing event in Paranoá Reservoir, Central Brazil. Acta Limnologica Brasiliensia, v.21, n.3, p.277-285, 2009.

PAGIORO, T. A.; THOMAZ, S. M. Decomposition of Eichhornia azuera from limnologically different environments of the Upper Paraná River Floodplain. Hydrobiologia, v.411, p.45-51, 1998.

PAVÃO, A.C. Riqueza e distribuição de macrófitas aquáticas no reservatório de Itupararanga, bacia do rio Sorocaba-SP. Dissertação de Mestrado. Universidade Federal de São Carlos, 64 p., 2011.

PEDRALLI, G.; TEIXEIRA, M. C. B. Macrófitas aquáticas como agentes filtradores de materiais particulados, sedimentos e nutrientes. In: Henry, R. (ed). Ecótonos nas interfaces dos ecossistemas aquáticos. Ed. Rima, São Carlos, SP, 2003.

PEDRAZZI, F. J. M. Avaliação da qualidade da água do reservatório Itupararanga, bacia do alto Sorocaba (SP). Dissertação de Mestrado. Universidade Estadual Paulista - Rio Claro, 87 p, 2009.

PETRACCO, P. Efeito das variáveis abióticas na produção primária de Egeria najas e Utricularia breviscapa da Lagoa do Óleo (Estação Ecológica de Jataí - Luiz Antônio - SP). Universidade Federal de São Carlos. 162 p, 2006. 
PEZZATO, M. M. Efeitos da radiação fotossinteticamente ativa, temperatura, pH e carbono inorgânico na produção primária a macrófita aquática Egeria densa Planch. Dissertação de Mestrado. Universidade Estadual Paulista - Faculdade de Ciências Agrárias e Veterinárias de Jaboticabal, 52 p, 2002.

PEZZATO, M. M. Macrófitas aquáticas submersas: crescimento, fotossíntese e variáveis abióticas da água. Tese de Doutorado. Universidade Federal de São Carlos, 95 p, 2007.

PIETERSE, A. H.; MURPHY, K. J. Aquatic weeds: the ecology and management of nuisance aquatic vegetation. Oxford University Press, Oxford, 593p., 1993.

PISTORI, R. E. T. Crescimento da macrófita aquática flutuante Salvinia molesta em viveiros de aqüicultura com distintos estados tróficos. Dissertação de Mestrado. Universidade Estadual Paulista, 35p., 2005.

PITElli, R. L. C. M.; FERRAUdO, A. S.; PITElli, A. M. C. M.; PITElli, R. A.; VElini, E. D. Utilizaçào de análise multivariada e redes neurais artificiais na determinação do comportamento de colonização de populações de macrófitas aquáticas no reservatório de Santana. Planta Daninha, v.27, n.3, p. 429-439, 2009.

POMPÊO, M. L. M. Ecologia de Echinochloa polystachya (H.B.K.) Hitchcock na Represa de Jurumirim (zona de influência do Rio Paranapanema - SP). Tese de Doutorado. Universidade de São Paulo - Escola de Engenharia de São Carlos. 1996.

Pott, V.J., Pott, A. Plantas Aquáticas do Pantanal. Embrapa - Centro de Pesquisa Agropecuária do Pantanal: Corumbá, 2000.

POZO, R.; FERNÁNDEZ-ALÁEZ, C.; FERNÁNDEZ-ALÁEZ, M. The relative importance of natural and anthropogenic effects on community composition of aquatic macrophytes in Mediterranean ponds. Marine and Freshwater Research, v.62, n.2, 2011.

REJMÁNKOVÁ, E.; SIROVÁ, D. Wetland macrophyte decomposition under different nutrient conditions: Relationship between decomposition rate, enzyme activities and microbial biomass. Soil Biology \& Biochemistry, v.39, p. 526-538, 2007. 
RELATÓRIO DE SITUAÇÃO 2011. Unidade de Gerenciamento dos Recursos Hídricos 10 (UGRH 10). Comitê de Bacia Hidrográfica do rio Sorocaba e Médio Tietê. 10p., 2011

ŠAJNA, N.; HALER, M.; ŠKORNIK, S.; KALIGARIÇ, M. Survival and expansion of Pistia stratiotes L, in a thermal stream in Slovenia. Aquatic Botany, v.87, p.75-79, 2007.

SAlleS, M . H. D.; CONCEIÇÃO, F. D.; ANGELUCCI, V. .A.; PEDRAZZI, F. J. M.; CARRA, T. A.; MONTEIRO, G. F.; SARDINHA, D. S.; NAVARRO, G. R. B. Avaliação simplificada de impactos ambientais na bacia do Alto Sorocaba (SP). Revista de Estudos Ambientais, v.10, n.1, p. 6-20, 2008.

SAND-JENSEN, K. Environmental variables and their effect of photosynthesis of aquatic plant communities, Aquatic Botany, v.34, n.1-3, p.5-25, 1989.

SANTOS, A. M. Macrófitas aquáticas da planície de inundação do alto rio Paraná: produtividade primária, decomposição, ciclagem de nutrientes e diversidade. Tese de Doutorado. Universidade Estadual de Maringá, 101 p, 2004.

SANTOS, A. M.; ESTEVES, F. A. Comparison of calculation procedures of primary productivity by aquatic macrophytes in a shallow tropical coastal lagoon. Acta Limnologica Brasiliensia, v.16, n. 3, p. 239-249, 2004.

SANTOS, M. G.; CUNHA-SANTINO, M. B.; BIANCHINI Jr., I. Aerobic decomposition of Myriophyllum aquaticum (Vell.) Verdc. Regulated by chemical composition of detritus and temperature. Acta Limnologica Brasiliensia, v.21, p.269-273, 2009.

SCHNITZER, S. A.; NEELY, R. K. Criticism of the litterbag technique for the study of aquatic plant decay:suppression of epiphytic algal biomass. Archiv fur Hydrobiology, v.148, p.433-440, 2000.

SECCHIN, L. F. Caracterização ambiental e avaliação da produção de cargas difusas da área de drenagem da represa de Itupararanga, SP. Dissertação de Mestrado. Escola de Engenharia de São Carlos - Universidade de São Paulo. Em andamento.

SEMA - Secretaria do meio ambiente. Relatório de qualidade ambiental do Estado de São Paulo 2006, Informações referentes a 2005. Disponível em http://www.sema.sp.gov.br, Acesso em: Dez, 2007.

SILVA, D. S.; CUNHA-SANTINO, M. B.; MARQUES, E. E.; BIANCHINI Jr., I. The decomposition of aquatic macrophytes: bioassays versus in situ experiments. Hydrobiologia, v.665, p.219-227, 2011. 
SOARES, M. C. S.; MARINHO, M. M.; HUSZAR, V. L. M.; BRANCO, C. W. C.; AZEVEDO, S. M. F. O. The effects of water retention time and watershed features on the limnology of two tropical reservoirs in Brazil. Lakes \& Reservoirs: Research \& Management, v.13, n.4, p.257-269, 2008.

SOARES, A.; MOZETO, A. A. Water Quality in the Tietê River Reservoirs (Billings, Barra Bonita, Bariri and Promissão, SP-Brazil) and nutrient fluxes across the Sediment-Water Interface (Barra Bonita). Acta Limnologica Brasiliensia, v.18, n.3, p.247-266, 2006.

SOUSA W. T.; THOMAZ, S. M.; MURPHY, K. J. Response of native Egeria najas Planch and invasive Hydrilla verticillata (L) Royle to altered hydroecological regime in a subtropical river. Aquatic Botany, v.92, p.40-48, 2010.

STANLEY, E. H.; JOHSON, M. D.; WARD, A. K. Evaluating the influence of macrophytes on algal and bacterial production in multiple habitats of a freshwater wetland. Limnology and Oceanography, v. 48, n.3, p.1101-1111, 2003.

STRIPARI, N. L.; HENRY, R. The invertebrate colonization during decomposition of Eichhornia azurea Kunth in a lateral lake in the mouth zone of Paranapanema River into Jurumirim Reservoir (Sao Paulo, Brazil), Brazilian Jouranl of Biology, v.62, p.293-310, 2002.

TAKAMURA, N.; KADONO, Y.; FUKUSHIMA, M.; NAKAGAWA, M.; KIM, B.H.O. Effects of aquatic macrophytes on water quality and phytoplanktonic communities in shallow lakes. Ecological Research, v.18, p.381-395, 2003.

TANAKA, R, H.; CARDOSO, L. R.; MARTINS, D.; MARCONDES, D A. S.; MUSTAFÁ, A. L. Ocorrência de plantas aquáticas nos reservatórios da Companhia Energética de São Paulo. Planta Daninha, v.20, p. 101-111, 2002.

THOMAZ, S.M.; SOUZA, D. C.; KITA, K. K.; CAMARGO, A .F. M. Aquatic macrophytes of Itaipu Reservoir, Brazil: Survey of species and ecological considerations. Brazilian Archives of Biology and Technology, v.42, p. 15-22, 1999.

THOMAZ, S. M.; SOUZA, D. C.; BINI, L. M. Species richness and beta diversity of aquatic macrophytes in a large subtropical reservoir (Itaipu Reservoir, Brazil): the influence of limnology and morphometry. Hydrobiologia, v. 505, p.119-128, 2003. 
THOMAZ, S.M. Fatores que afetam a distribuição e o desenvolvimento de macrófitas aquáticas em reservatórios: uma análise em diferentes escalas. In: NOGUEIRA, M. G.; HENRY, R.; JORCIN, A. (Org). Ecologia de reservatórios: impactos potenciais, ações de manejo e sistemas em cascata. São Carlos, Ed. Rima. p. 165-181, 2005.

THOMAZ, S. M.; PAGIORO, T. A.; BINI, L. M.; MURPHY, K. J. Effect of reservoir darwdown on biomass of three species of aquatic macrophytes in a large sub-tropical reservoir (Itaipu, Brazil). Hydrobiologia, v. 570, p. 53-59, 2006.

THORNTON, W.K. Perspectives on reservoir limnology. In: THORNTON, K.W.; KIMMEL, B. L.; PAYNE, F. E. (eds). Reservoir limnology. Wiley Interscience Publication, New York, p. 1-14, 1990.

THULLEN, J. S.; NELSON, S. M.; CADE, B.S.; SARTORIS, J. J. Macrophyte decomposition in a surface-flow ammonia-dominated constructed wetland: rates associated with environmental and biotic variables. Ecological Engineering, v.32, p.281-290, 2008.

VERHOEVEN, J.T.A.; ARHEIMER, B.; YIN, C.; HEFTING, M. M. Regional and global concerns over wetlands and water quality. Trends in Ecology and Evolution, v.21, n.2, p.96-103, 2006.

VILLAR, C. A.; CABO, L.; VAITHIYANATHAN, P.; BONETTO, C. Litter decomposition of emergent macrophytes in a floodplain marsh of the lower Parana River. Aquatic Botany, v.70, p.105116, 2001.

VIGNATI, D. A. L.; FERRARI, B. J. D.; DOMINIK, J. Laboratory-to-field extrapolation in aquatic sciences. Environmental Science and Technology, v.41, p.1067-73, 2007.

VYMAZAL, J. Long-term performance of constructed wetlands with horizontal sub-surface flow: Ten case studies from the Czech Republic. Ecological Engineering, v.37, p. 54-63, 2011.

WESTLAKE, D. F. Some basic investigation of the productivity of aquatic macrophytes. Memorie dell 'Istituto Italiano di Idrobiologia, v. 18, p. 229-248, 1965.

WETZEL, R. G.; LINKENS, G. E. Limnological analysis, New York: Springer-Verlag, 429 p., 1991.

WILLIS, C.; MITSH, W. J. Effects of hydrology and nutrients on seedling emergence and biomass of aquatic macrophytes from natural and artificial seed banks. Ecological Engineering, v.4, p.65-76, 1995. 
XU, Y.; CAI, Q.; SHAO, M.; HAN, X., CAO, M. Seasonal dynamics of suspended solids in a giant subtropical reservoir (China) in relation to internal processes and hydrological features. Quaternary International, v.208, n.1-2, p.138-144, 2009. 